\title{
II. HOMOSEXUALITÄT ALS SKANDALON
}

Homosexualität gehörte zu den größten Tabus des 19. Jahrhunderts. Insbesondere in Großbritannien galt sie als ein Verbrechen, das in der Medienöffentlichkeit nicht einmal namentlich benennbar war, sondern in gedruckten Formulierungen nur vorsichtig angedeutet wurde. „A crime so loathsome that it had been said that it should not be named amongst Christian men", umschrieben die britischen Zeitungen selbst in den 1880er Jahren noch gleichgeschlechtliche Beziehungen. ${ }^{1}$ Die Angst, bereits die sprachliche Bezeichnung könne Homosexualität akzeptierbar machen und so zu ihr animieren, schlug sich sogar in den gesetzlichen Formulierungen nieder. In Großbritannien gab es zunächst keine eindeutige juristische Benennung des Deliktes, so dass Verurteilungen bis 1885 nur unter Verweis auf den Sammelbegriff „unnatural offences“ erfolgten. ${ }^{2}$ Ähnlich vage Umschreibungen finden sich aber auch in den deutschen Schriften der Zeit, wo pauschale Formulierungen wie „widernatürliche Unzucht“ oder „Sodomie“ dominierten. ${ }^{3}$ Entsprechend zurückhaltend berichteten die Zeitungen über Prozesse, bei denen Homosexuelle verurteilt wurden.

Dies veränderte sich im ausgehenden 19. Jahrhundert. In rascher Abfolge traten zunächst in Großbritannien und dann auch in Deutschland zahlreiche Skandale auf, die die Homosexualität prominenter Bürger enthüllten und so zu einer breiten öffentlichen Auseinandersetzung mit dem Thema führten. Sie zwangen die Zeitungen und die Politiker dazu, sich zur Homosexualität zu positionieren und lösten verstärkt Alltagsgespräche über das Thema aus. Diese oft spektakulären Skandale werfen vor allem zwei Fragen auf, die das folgende Kapitel anhand von Fallanalysen klären soll. Erstens wird ermittelt, auf welche Weise das Tabuthema Homosexualität skandalisiert wurde und so in die Sphäre der öffentlichen Debatte rückte. So ist zu klären, wer die Enthüllungen aus welchen Motiven heraus aufbrachte, wie diese Skandale ihre Dynamik entwickelten und wie die unmittelbar Beteiligten, die Presse und Politiker darauf reagierten. Zweitens geht das Kapitel der Frage nach, welche Zuschreibungen über Homosexualität im Zuge der Skandale entstanden. Denn anzunehmen ist, dass die Skandale im weitaus höheren Maße öffentliche Vorstellungen über Homosexualität prägten als die bereits vielfach untersuchten Schriften der frühen Sexualwissenschaft, die zeitgleich am Beginn der Moderne entstanden. Dabei verhandelten die Homo-

1 So eine typische Formulierung in: Daily Telegraph 3.7.1884, S.4; selbst dies schrieb das Blatt nur mit Verweis auf: UNITED IRELAND 10.4.1884.

2 Erst 1967 trat das Wort "homosexual“ in das englische Recht; vgl. Leslie Moran, The Homosexual(ity) of Law, London und New York 1996, S. 21.

3 Vgl. zur rechtlichen Sprache: RüDIgeR LaUtmann, Das Verbrechen der widernatürlichen Unzucht. Seine Grundlegung in der preußischen Gesetzesrevision des 19. Jahrhunderts, in: DERS. und Angela Taeger (Hrsg.), Männerliebe im alten Deutschland. Sozialgeschichtliche Abhandlungen, Berlin 1992, S. 141-186. 
sexualitätsskandale nicht nur Formen zulässiger Normalität, sondern auch Formen und Grenzen gesellschaftlicher Toleranz.

Die Analyse erfolgt anhand der wichtigsten politischen Homosexualitätsskandale der Jahrzehnte um 1900. Diese wiesen in Deutschland und Großbritannien deutliche Gemeinsamkeiten auf, was den Vergleich erleichtert. In beiden Ländern richteten sich Skandale sowohl gegen hohe Adlige im Umfeld der Monarchen als auch gegen Repräsentanten des Bürgertums. Und in beiden Ländern attackierten oppositionelle Parteien mit derartigen Vorwürfen Repräsentanten des von ihnen bekämpften Systems. Für Großbritannien wird zunächst der „Dublin Castle Skandal“ untersucht, bei dem die irischen Nationalisten die englische Administration mit dem Vorwurf der Homosexualität bekämpften. Eine weitere Fallstudie zur „Cleveland Street Affair“ untersucht einen Skandal, bei dem die Radicals, also der linke Flügel der Liberalen, Adligen vorhielten, ein Homosexuellenbordell mitten in London zu besuchen. Weitere Skandale nach 1890, wie um Oscar Wilde und Hector MacDonald, werden vergleichend herangezogen, um Entwicklungslinien aufzuzeigen. In Deutschland ragen zwei Skandale heraus, die vertieft analysiert werden: Der Krupp-Skandal von 1902, bei dem vornehmlich die Sozialdemokraten dem Unternehmer Homosexualität vorhielten, und der fünf Jahre später ausbrechende Moltke-Eulenburg-Skandal, bei dem der Publizist Maximilian Harden hohen Adligen im Umfeld des Kaisers Homosexualität vorwarf.

$\mathrm{Ob}$ und auf welche Weise im ausgehenden 19.Jahrhundert Homosexualitätsskandale aufkamen, hing von kulturellen, politischen und rechtlichen Vorbedingungen ab. Aus diesem Grunde wird in einem einführenden Kapitel zunächst ein Blick auf die Rahmenbedingungen geworfen. Insbesondere der rechtliche Kontext, die bisherige Form der öffentlichen Auseinandersetzung mit Homosexualität und vorherige Homosexualitätsskandale stehen dabei im Vordergrund.

\section{Homosexualität, Recht und ÖFfentlichkeit IM 19. JAHRHUNDERT}

Das Großbritannien des 19. Jahrhunderts galt und gilt als besonders liberal und fortschrittlich und diente deshalb vielfach als Gegenbild zum deutschen „Obrigkeitsstaat“. Diese Zuschreibung erscheint allerdings weniger passend, wenn man den Umgang mit der Minderheit der Homosexuellen betrachtet. Im 19. Jahrhundert verfügten die Briten über die härtesten Gesetze gegen Homosexuelle in der ganzen westlichen Welt. Bis 1861 galt für Homosexualität noch die Todesstrafe. Sie wurde zwar seit 1836 nicht mehr vollstreckt, aber immerhin in bis zu lebenslängliche Haftstrafen umgewandelt. Die Zeit seit 1800 stand auch nicht für eine zunehmende strafrechtliche Liberalisierung. Vielmehr kam es im ersten Drittel des 19. Jahrhunderts zunehmend zu Verurteilungen und Todesurteilen wegen homosexuellen Verkehrs, danach zu ansteigenden Haftstrafen. In 
das frühe 19. Jahrhundert fiel immerhin die Hälfte der Verurteilungen wegen „sodomy“, die das berühmte Londoner Gericht „Old Bailey“ in den 160 Jahren zwischen 1674 und 1834 fällte, ebenso die Hälfte der Todesurteile. ${ }^{4}$ Diese Hinrichtungen und Verurteilungen hatten jedoch zugleich den Effekt, dass sie das offiziell nicht aussprechbare Vergehen zur Abschreckung öffentlich machten, um es künftig zu verhindern. So begründete ein Richter 1806 die Todesstrafe für fünf homosexuelle Männer damit, „that such a subject should come before the public as it must do, and above all, that the untaught und unsuspecting minds of youth should be liable to be tainted by such horrid faces. "5 Geheimnis und Öffentlichkeit standen damit bei der Homosexualität gerade durch diese zunehmende Bestrafung in einem wachsenden Spannungsverhältnis: Die steigende Zahl an Verurteilungen überführte die Homosexualität immer mehr an die Öffentlichkeit, obgleich die Gerichte sie als ein Tabuthema ansahen. Gerade dieses Spannungsfeld eröffnete Potentiale für Skandale.

Die Gründe für die zunehmenden Verurteilungen wegen Homosexualität im frühen 19. Jahrhundert sind sicherlich vielfältig. Die Verrechtlichung der Gesellschaft, die Ausbildung bürgerlicher Moral- und Geschlechterrollen und die Konstruktion von homosexuellen Identitäten dürfte diese Kriminalisierung mit erklären. ${ }^{6}$ Die Homosexualität erfuhr dabei seit dem 18. Jahrhundert eine Umdeutung von der Sünde zum Verbrechen. Erst 1885 begrenzte der Criminal Law Amendment Act die Bestrafung auf zwei Jahre mit harter Arbeit, wobei das Gesetz das Vergehen erstmals etwas genauer umschrieb („any act of gross indecency with another male person") und auch explizit auf den Verkehr in privaten Räumen bezog. Die Zahl der Verurteilungen blieb in der zweiten Hälfte des 19. Jahrhunderts recht konstant und umfasste Männer aus allen Berufs- und Standesgruppen, wobei Handwerker besonders stark vertreten waren. Zumeist wurden homosexuelle Handlungen in der Öffentlichkeit bestraft, wohingegen der heimliche Verkehr in der privaten Sphäre noch eher toleriert wurde. Bezeichnenderweise erreichte die Zahl der Verurteilungen ihren Höhepunkt jedoch nicht in der viktorianischen Zeit, sondern in den 1950 er Jahren, die in die-

4 Eigene Auswertung der Urteile mithilfe der Datenbank in: http://www.oldbaileyonline.org/ search/crime/ (zuletzt eingesehen Juni 2005). Diese Ergebnisse stützen die Einschätzungen von: A.D. Harvey, Prosecutions for Sodomy in England at the Beginning of the Nineteenth Century, in: Historical Journal 21 (1978), S. 939-948, S.939; ArTHUR GILBERT, Buggery and the British Navy 1700-1861, in: Journal of Social History 10 (1976/77), S.72-98. Als Gesamtüberblicke zur Homosexualitätsgeschichte dieser Zeit vgl. H. Montgomery Hyde, The Other Love. An Historical and Contemporary Survey of Homosexuality in Britain, London 1970, hier bes. S. 92; Jefrerey Weeks, Coming Out: Homosexual Politics in Britain from the Nineteenth Century to the Present, London 1977.

5 Manchester Gazette 23.8.1806, zit. nach: Richard Davenport-Hines, Sex, Death and Punishment. Attitudes to Sex and Sexuality in Britain since the Renaissance, London 1990, S. 102.

6 Vgl. dazu ausführlicher: H.G. Cocks, Nameless Offence, bes. S. 6 u. 18; Harvey, Prosecutions, S. 946. 
ser Hinsicht die eigentlichen „dark ages“ bildeten. ${ }^{7}$ Weibliche Homosexualität war hingegen im 19. Jahrhundert immer noch so tabuisiert, dass sie sich nicht einmal in Gesetzen und Verurteilungen niederschlug und somit straffrei blieb. Als dies etwa 1810 zwei Frauen in London vorgeworfen wurde, gewannen sie ihre Verleumdungsklage mit der Urteilsbegründung, dies sei bei bürgerlichen Frauen nicht denkbar. ${ }^{8}$

Auch Deutschland wies - zumindest im Vergleich mit Frankreich oder Italien - im 19. Jahrhundert eine recht rigide Gesetzgebung gegenüber Homosexuellen auf. Allerdings war die Lage im Deutschen Bund naturgemäß uneinheitlich und das Strafmaß geringer als in Großbritannien. Während das Preußische Allgemeine Landrecht von 1794 für Homosexualität ein- oder mehrjährige Haftstrafen vorsah, hatte die französische Besatzung im Westen die Bestrafung abgeschafft. Auch in der post-napoleonischen Ära verfochten die Rheinprovinzen liberalere Regelungen, so dass im Preußen des 19. Jahrhunderts vielfältige Kompromisse entstanden. ${ }^{9}$ Liberal geprägte Länder wie Bayern, Württemberg oder Baden hoben die Strafen in den Jahrzehnten nach Napoleon weitgehend auf. Bemerkenswerterweise wurden einfache Fälle von Homosexualität oft nicht strafrechtlich verfolgt, weil der damit einhergehenden Publizität schlimmere Folgen zugeschrieben wurden. ${ }^{10}$ Damit prägte bereits die Angst vor Skandalen die rechtliche Praxis. Erst mit der Gründung des Kaiserreiches setzte sich reichsweit die Kriminalisierung nach preußischem Vorbild durch. Der Verweis auf das „Volksbewusstsein“ verdrängte dabei medizinische Argumentationen, die eine Straffreiheit forderten. Ähnlich wie in Großbritannien bezog sich der entsprechende Paragraph 175 nur auf Männer und verband Homosexualität als unnatürlichen Verkehr mit Sodomie. Hier hieß dies konkret: „Die widernatürliche Unzucht, welche zwischen Personen männlichen Geschlechts oder von Menschen mit Tieren begangen wird, ist mit Gefängnis bis zu zwei Jahren zu bestrafen; auch kann auf Verlust der bürgerlichen Ehrenrechte erkannt werden." 11 Die Zahl der Verurteilungen stieg bis 1914 leicht an und lag

7 Zwischen 1850 und 1914 betrug die Verurteilungsrate etwa 0,5 Fälle pro 100000 Einwohner; vgl. Rовв, Strangers, S. 31 u. $272 \mathrm{f}$.

8 Rictor Norton, The Myth of the Modern Homosexual. Queer History and the Search for Cultural Unity, London 1997, S. 150.

9 Vgl. Jürgen Baumann, Paragraph 175, Berlin/Neuwied 1968, S.36f.; Lautmann, Das Verbrechen. Als Überblick zur rechtlichen Entwicklung vgl. bes. Hans-Georg Stümke, Homosexualität in Deutschland. Eine politische Geschichte, München 1989.

10 Jörg Hutter, Die gesellschaftliche Kontrolle des homosexuellen Begehrens. Medizinische Definitionen und juristische Sanktionen im 19. Jahrhundert, Frankfurt a. M. 1992, S. 141.

11 Zur Genese des \$175: KaI Sommer, Die Strafbarkeit der Homosexualität von der Kaiserzeit bis zum Nationalsozialismus, Frankfurt a. M. 1998; Jörg HutTer, Die Entstehung des $\ 175$ im Strafgesetzbuch und die Geburt der deutschen Sexualwissenschaft, in: LAUTMAnN und TAeger (Hrsg.), Männerliebe, S.186-238. Die Bestrafung weiblicher Homosexualität wurde lediglich in Entwürfen in den Jahren vor 1914 diskutiert. Vgl. dazu jetzt: Tracie MatysiK, In the Name of the Law: The "Female Homosexual“ and the Criminal Code in Fin de Siècle Germany, in: Journal of the History of Sexuality 13 (2004), S. 26-48. 
mit einigen hundert jährlich ähnlich hoch wie in Großbritannien, auch wenn exakte Daten fehlen. ${ }^{12}$

In rechtlicher Hinsicht waren somit zumindest im späten 19. Jahrhundert in Deutschland und Großbritannien die Rahmenbedingungen für Homosexuelle relativ ähnlich. In beiden Ländern bildete die Gesetzeslage eine entscheidende Voraussetzung für die Skandalisierung und Veröffentlichung von Homosexualität, die zugleich in der Sphäre des Geheimen bleiben sollte. Ihre Kriminalisierung legitimierte jedoch ihre Aufdeckung durch Polizei und Presse und förderte öffentliche Geständnisse, die Gerichte und die Öffentlichkeit abverlangen konnten. Dementsprechend blieben in Italien und Frankreich auch aufgrund der liberalen Gesetze vergleichbare Skandale um Homosexualität weitgehend aus. ${ }^{13}$

Die rechtlichen Regelungen prägten zwar den öffentlichen Diskurs, dürfen aber mit Blick auf die sozialen Praktiken nicht überbewertet werden. Im Vergleich zu anderen „Verbrechen“ waren die Verurteilungszahlen im 19. Jahrhundert in beiden Länder gering. Dies deutet an, dass in der Alltagspraxis homosexueller Verkehr eine gewisse Tolerierung erfuhr. Ebenso ist hieraus nicht vorschnell eine Homophobie abzuleiten, die jeglichen vertrauten Umgang unter Männern ausschloss. Vielmehr waren im 19. Jahrhundert die Übergänge zwischen homosexuellen Neigungen und intensiven Freundschaften vermutlich fließender als ein Jahrhundert später. Sowohl in Deutschland als auch in Großbritannien entfalteten sich aus romantischen Freundschaftsidealen heraus platonische Beziehungen zwischen bürgerlichen Männern, deren euphorische Briefe aus heutiger Sicht homoerotische Züge trugen. Aus der Sphäre des Privaten traten diese Briefe durch ihre Veröffentlichung oder durch die Beschreibung von männlichen Freundschaften in Romanen. Ritualisiert wurden diese intensiven Männerfreundschaften in Clubs wie den Logen. ${ }^{14}$ Dass zumindest in der entstehenden Metropolenkultur auch ein explizit homosexueller Umgang eine gewisse Tolerierung erfuhr, zeigte sich ebenfalls in beiden Ländern. Sowohl in London als auch in Berlin schuf das Großstadtleben bekannte Orte der Begegnung, die

12 Vgl. die Daten bei Baumann, Paragraph 175, S. 58; bis 1901 liegen in den Statistiken nur Zahlen für Verhaftungen und Verurteilungen vor, die auch den Verkehr mit Tieren einschließen. Pro Einwohner war dieser Anstieg gering; vgl. die Daten bei: HutTer, Die gesellschaftliche Kontrolle, S. 77.

13 Eine generelle Indifferenz und Toleranz gegenüber Liebesaffären betont für Frankreich: BRIAN Jenkins und Peter Morris, Political Scandal in France, in: Modern and Contemporary France (1993), S. 127-137.

14 Vgl. als Überblick zu dieser Entwicklung: Maurice Aymard, Freundschaft und Geselligkeit, in: Philippe Ariès und Roger Chartier (Hrsg.), Geschichte des privaten Lebens, Bd. 3: Von der Renaissance bis zur Aufklärung, Frankfurt a. M. 1991, S. 451-495; Colin Spencer, Homosexuality. A History, London 1995, S.257-262; Stefan-Ludwig Hoffmann, Unter Männern. Freundschaft und Logengeselligkeit im 19. Jahrhundert, in: Manfred HettLing und StefanLudwig Hoffmann (Hrsg.), Der bürgerliche Wertehimmel. Innenansichten des 19. Jahrhunderts, Göttingen 2000, S. 193-216. 
Beziehungen unter Männern in die Öffentlichkeit überführten. ${ }^{15}$ Das Wechselspiel zwischen der Bewahrung des homosexuellen Geheimnisses und seiner Veröffentlichung zeigte sich auch an den zunehmend veröffentlichten autobiographischen Schriften von Homosexuellen, die codiert ihre Neigungen andeuteten. ${ }^{16}$ Alles dies waren tastende Versuche, Grenzen zu erweitern, die im ausgehenden 19. Jahrhundert schließlich verstärkt durch Skandale verhandelt wurden.

Im öffentlichen Umgang mit Homosexualität bestanden jedoch erkennbare Unterschiede zwischen Deutschland und Großbritannien. Das galt vor allem für die Expertendiskurse des 19. Jahrhunderts, die mit zur Konstruktion des Homosexuellen beitrugen. In Deutschland entstand deutlich früher eine medizinische Neudeutung von Homosexualität. Das Verbrechen wurde zu einer Krankheit oder einem angeborenen genetischen Defekt uminterpretiert und Homosexualität so entkriminalisiert. Grundlegend waren hier besonders die seit den 1860er Jahren erscheinenden umfangreichen Schriften Karl Heinrich Ulrichs, der Homosexuelle als „drittes Geschlecht“ mit angeborenen weiblichen Elementen auffasste und als „Urninge“ bezeichnete, die er wiederum in „Mannlinge“ und „Weiblinge“ unterteilte. Nach Ulrichs Zuschreibungen waren Homosexuelle distinkte, erkennbare Menschen, wobei er schätzte, dass einer von 500 Männern dazu gehöre. ${ }^{17}$ Die Wirkungsmacht von Ulrich zeigte sich darin, dass sich bereits 1869 die Gutachter bei einem spektakulären Homosexuellenprozess mit seinen Ideen auseinander setzten, da der Angklagte ein Buch von ihm besaß. ${ }^{18}$ Ebenso gingen seine Begrifflichkeiten zumindest so weit in den Sprachgebrauch ein, dass der Brockhaus von 1898 beim Kurzeintrag „Homosexual“ auf „Urningsliebe“ verwies und entsprechend definierte: „Trieb zum geschlechtlichen Verkehr mit Personen gleichen Geschlechts: Urninge (männliche, weibliche), Personen, die mit derartiger konträrer Sexualempfindung behaftet sind.“ Der Begriff „Homosexualität“ wurde ebenfalls 1868/69 erstmals aufgebracht und dann in Broschüren gegen die preußische Gesetzgebung verwandt. Prominente Mediziner - wie eine Kommission unter Rudolf Virchow lehnten dabei eine juristische Verfolgung ab. Nicht zuletzt durch diese Koinzi-

15 Vgl. für London: Cook, London and the Culture of Homosexuality. Für Berlin: Wolfgang Theis und Andreas Sternweller, Alltag im Kaiserreich und in der Weimarer Republik, in: Michael Bollé (Red.), Eldorado: Homosexuelle Männer in Berlin 1850-1950. Geschichte, Alltag und Kultur, Berlin 1984, S.48-73.

16 Vgl. Klaus Müller, „Aber in meinem Herzen sprach eine Stimme so laut“. Homosexuelle Autobiographien und medizinische Pathologien im 19. Jahrhundert, Berlin 1991, S. 155-268.

17 Vgl. bes. den Nachdruck seiner Schriften: KARL HeINRICH Ulrichs, Forschungen über das Rätsel der mannmännlichen Liebe, Berlin 1994. Als knappe Einführung zu Ulrichs vgl. etwa: Hubert Kennedy, Karl Heinrich Ulrichs, in: Rüdiger Lautmann (Hrsg.): Homosexualität. Handbuch der Theorie- und Forschungsgeschichte, Frankfurt a.M. und New York 1993, S.32-38; Zur Zunahme medizinischer Betrachtungen: HutTER, Die gesellschaftliche Kontrolle, S. 60 .

18 Manfred Herzer, Zastrow - Ulrichs - Kertbeny. Erfundene Identitäten im 19. Jahrhundert, in: Lautmann und Taeger (Hrsg.), Männerliebe, S. 61-80, S. 67. 
denz von neuen Zuschreibungen gelten die späten 1860er Jahre als eine Wasserscheideder Homosexualitätsgeschichte. ${ }^{19}$ Sowohldas Aufkommen entsprechender Begriffe als auch die Etablierung einer derartigen medizinischen Neudeutung der Homosexualität dürfte dabei öffentliche Normenkonflikte gefördert haben, die durch Skandale ausgefochten wurden.

Seit dem späten 19. Jahrhundert trat in Deutschland vor allem der Mediziner Magnus Hirschfeld für eine öffentliche Neubewertung von Homosexualität ein, wobei seine Annahme eines „dritten Geschlechts“ zwischen Mann und Frau vielfach an Ulrichs anknüpfte. Hirschfeld beschränkte sich nicht auf aufklärende medizinische Schriften, wie sie seit den 1890er Jahren insbesondere im Max Spohr Verlag zur Homosexualität erschienen. ${ }^{20}$ Er organisierte seit 1897 mehrere Unterschriftensammlungen und Petitionen an den Reichstag, um die Aufhebung des Paragraphen $175 \mathrm{zu}$ erreichen. Bereits die erste Petition unterschrieben immerhin rund 3000 Ärzte, 750 Direktoren und Lehrer sowie zahlreiche Künstler (wie Rilke, Hauptmann oder Liebermann), was zeigte, wie offen zumindest Teile der deutschen Gesellschaft für Homosexuelle eintraten. ${ }^{21}$ Selbst Hugo von Kupffer, der Chefredakteur des konservativen Massenblatts Berliner Lokal-Anzeiger, unterstützte sie. ${ }^{22}$ Obgleich die Petition ohne Erfolg blieb, erhielt sie mitsamt ihrer Argumentation eine breite Öffentlichkeit, da August Bebel sie im Reichstag einbrachte und zur Diskussion stellte. ${ }^{23}$

Mit der Gründung des Wissenschaftlich-bumanitären Komitees etablierte Hirschfeld 1897 eine Organisation, die das Thema Homosexualität kontinuierlich in die Öffentlichkeit brachte. Da Hirschfeld sich bei Polizei, Gerichten und Personen des öffentlichen Lebens immer wieder als Ansprechpartner anbot, entwickelte er sich in der wilhelminischen Zeit zu einer zentralen Deutungsinstanz. ${ }^{24}$ Die Monatsberichte und Jahrbücher, die das Komitee regelmäßig publizierte, beschrieben auch die Homosexualität von prominenten Personen, um Homosexualität weniger ungewöhnlich erscheinen zu lassen. ${ }^{25}$ Gerade im

19 Norton, The Myth, S.71.

20 Mark Lehmstedt, Bücher für das „dritte Geschlecht“. Der Max Spohr Verlag in Leipzig. Verlagsgeschichte und Bibliographie (1881-1941), Wiesbaden 2002, bes. S. 44-68.

21 Vgl. Sommer, Strafbarkeit, S. 116-126; Rüdiger Lautmann und Angela Taeger, Sittlichkeit und Politik. $\$ 175$ im Deutschen Kaiserreich (1871-1919), in: DIEs. (Hrsg.), Männerliebe, S. 239-268, S. 243.

22 Allerdings betonte der Chefredakteur zugleich, er sehe keinen Weg „gegenüber den herrschenden Vorurteilen die so hoch bedeutsame Angelegenheit in meinem Blatte zu erörtern." Kupffer an das Wissenschaftlich-humanitäre Komitee 30.8.1898, Faks. in: Richard Linsert, Kabale und Liebe. Über Politik und Geschlechtsleben, Berlin o. D. (1930), S.163.

23 Verhandlungen des Reichstages 13.1.1898, Bd.159, 16. Sitz., S. 410.

24 Vgl. generell Manfred Herzer, Magnus Hirschfeld. Leben und Werk eines jüdischen, schwulen und sozialistischen Sexologen, Frankfurt a. M. 1992.

25 Vgl. die Benennung des „Homosexuellen Erzherzogs Ludwig Victor - eines Bruders des Kaisers von Österreichs“ oder die Erwähnung der Erpressung eines Richters und Landgerichtsrat in: Monatsbericht des Wissenschaftlich-humanitären Komitees, Anfang November 1903. 
Vergleich mit Großbritannien fällt auf, wie wohlwollend die Presse mitunter auf die neu erschienenen Jahrbücher des Komitees hinwies, was sich selbst für die eher konservative Boulevardzeitung Berliner Lokal-Anzeiger oder den konservativen Tag bis 1907 belegen lässt. ${ }^{26}$ Bis zum Ausbruch der großen Skandale nach 1900 deutete damit einiges auf eine Liberalisierung des Status von Homosexuellen hin.

Im Unterschied zu Großbritannien initiierten einzelne Mitglieder der deutschen Homosexuellenbewegung bereits populistische Aktionen. So ließ Adolf Brand Flugblätter von der Reichstagstribüne segeln und verletzte den Vorsitzenden des Petitionsausschusses mit einer Hundepeitsche, um vor Gericht ein Forum zu bekommen. ${ }^{27}$ Über die Deutung der Homosexualität und den Umgang mit ihr bestanden jedoch innerhalb dieser frühen Homosexuellenbewegung Differenzen. Obgleich eine gewisse Mehrheit sie als angeboren interpretierte, war ihre Deutung als „Zwischenstufe“ oder als „männliche Kultur“ umstritten. ${ }^{28}$ Die Gegner derartiger Interpretationen lehnten sie aus christlichmoralischen Erwägungen ab oder aus der Angst heraus, diese Deutung würde Geschlechtergrenzen auflösen. ${ }^{29}$

Im Vergleich zu Großbritannien sprachen somit die Experten und die breitere Öffentlichkeit des Kaiserreiches bereits vergleichsweise offen über Homosexualität. Ein Pendant zu Ulrichs gab es auf der britischen Insel nicht, und entsprechende öffentliche Debatten begannen erst sehr zaghaft in den 1890er Jahren. ${ }^{30}$ Die britischen Expertendiskurse zeigen vor allem zwei Auffälligkeiten: Einerseits argumentierten sie weniger medizinisch-biologisch als historisch, indem sie Homosexualität in früheren Kulturen oder bei großen Künstlern und Wissenschaftlern andeuteten und so legitimierten. Andererseits traten hier vor allem Sozialisten für eine tolerante Auseinandersetzung mit der Homosexualität ein. Durch letzteres waren die Ansätze wesentlich stärker in gesamtgesellschaftliche Reformen und Utopien eingebunden, zugleich aber auch noch deutlich marginalisiert. Erinnert sei besonders an Edward Carpenter, der 1895 zunächst eine privat zirkulierende Schrift über Homogenic Love veröffentlichte. ${ }^{31}$ Aus dem

26 Berliner Lokal-Anzeiger Nr.255 29.10.1905; Der TAg 10.2.1907. Vgl. die regelmäßigen Rezensionsauszüge in: Monatsbericht des Wissenschaftlich-Humanitären Komitees.

27 Vgl. Marita Keilson-Lauritz, Die Geschichte der eigenen Geschichte. Literatur und Literaturkritik in den Anfängen der Schwulenbewegung am Beispiel des Jabrbuchs für sexuelle Zwischenstufen und der Zeitschrift Der Eigene, Berlin 1997, S. 85.

28 Vgl. Marita Keilson-Lauritz, Tanten, Kerle und Skandale. Die Geburt des „modernen Homosexuellen“ aus den Flügelkämpfen der Emanzipation, in: zUR Nieden (Hrsg.), Homosexualität, S. 81-99, S. 85.

29 John C. Fout, Sexual Politics in Wilhelmine Germany: The Male Gender Crisis, Moral Purity and Homophobia, in: Journal of the History of Sexuality 2 (1992), S. 388-421, S. 391.

30 Einführend: John Lauritsen und Rainer Guldin, Englische Forschungen im 19. Jahrhundert, in: Lautmann (Hrsg.), Homosexualität, S.70-75.

31 Vgl. Chushichi Tsuzucki, Edward Carpenter 1844-1929. Prophet of Human Fellowship, Cambridge 1980, S.131f.; Weeks dagegen betont, die Schrift sei 1894 in der Manchester Labour Press veröffentlicht worden; DERs., Sex, Politics and Society, S. 172. 
sozialistischen Lager kam auch Havelock Ellis, der als Pionier der britischen Sexualforschung gilt und hier die Annahme verbreitete, Homosexuelle gehörten zu einer anderen „Spezies“ und Homosexuelle und Heterosexuelle seien dichotomisch zu trennen. ${ }^{32}$ Bezeichnender Weise erschien Ellis wichtigstes Werk Sexual Inversion, das Homosexualität als angeboren und damit als nicht strafbar bezeichnete, zunächst 1896 auf deutsch und dann im folgenden Jahr erst als englische Version, deren Verkauf aber verboten wurde. ${ }^{33}$ Diese Schriften trugen dazu bei, auch in Großbritannien Vorstellungen und Sprechweisen über Homosexualität zu erweitern und überführten überhaupt erst diesen Begriff ins Englische. Generell wird man auf dieser ideengeschichtlichen Ebene von einem kulturellen Transfer aus dem deutschsprachigen Raum ausgehen können. Die von Carpenter und Ellis 1914 gegründete British Society for the Study of Sex Psycho$\log y$ lässt sich dabei als verspätetes Pendant zum Berliner Wissenschaftlich-bumanitären Komitee fassen, das diesen Austausch förderte. ${ }^{34}$

Obgleich das Kaiserreich, so lässt sich bilanzieren, oft im Vergleich zu Großbritannien als autoritärer „Obrigkeitsstaat“ gilt, bestanden im Hinblick auf die gleichgeschlechtliche Sexualität damit deutlich mehr Freiheiten in Deutschland - sowohl bei der Thematisierung von Homosexualität als auch in der Auseinandersetzung um ihre Straffreiheit. In beiden Ländern entstand aber im ausgehenden 19. Jahrhundert ein zunehmendes Spannungsverhältnis zwischen ihrer Tabuisierung und der öffentlichen Auseinandersetzung mit Homosexualität, aus dem heraus Skandale entstehen konnten.

\section{VORLÄUFER IM 19. JAHRHUNDERT}

Skandale um Homosexualität traten natürlich in den Jahrzehnten um 1900 nicht erstmalig auf. So lassen sich in den Kampagnen gegen einzelne Monarchen und Adlige bereits vor 1800 Andeutungen über Homosexualität ausmachen. ${ }^{35}$ Ebenso zeigt bereits eine kursorische Auswertung der Zeitungen des frühen 19. Jahrhunderts, dass vor allem in Verbindung mit entsprechenden Gerichtsprozessen Zeitungsartikel hierzu erschienen. Diese schilderten die homosexuellen Normbrüche, ohne sie konkret zu benennen. Stattdessen bedienten sie sich eigener Codes von Umschreibungen, die für die Zeitgenossen zweifelsohne eindeutig waren. Die Sprachregelungen lassen sich nicht allein als eine Selbstzensur auf-

32 Zu Ellis liegen zahlreiche biographische Arbeiten vor; vgl. etwa: Phyllis Grosskurth, Havelock Ellis. A Biography, London 1980; Jeffrey Weeks, Making Sexual History, Cambridge 2000, S. 17-52.

33 Havelock Ellis, Das konträre Geschlechtsgefühl, Leipzig 1896; DERs., Sexual Inversion, London 1897. Zu den Prozessen wegen des Verkaufs: WeEks, Coming Out, S. 60.

34 In den bisherigen Studien zu Ellis' und Carpenters Wirken fand dieser Aspekt bislang wenig Berücksichtigung. Allerdings führte der Ausbruch des Weltkrieges schnell zur Unterbindung eines expliziten Austausches.

35 Vgl. etwa zu den Kampagnen von John Wilkes: Clark, Scandal, S. 30 u. 44. 
fassen, die Unwissenheit stärkte. Sie bildeten vielmehr Ersatzsprachen, die eine öffentliche Kommunikation über Homosexualität erst in gedruckter Form möglich machten und so auch spätere Skandale vorbereiteten. ${ }^{36}$ Und obgleich im Hinblick auf Homosexualität die Grenzen des Sagbaren in Großbritannien wesentlich enger waren, entstand durch die größere Pressefreiheit und die Öffentlichkeit der Prozesse auf dem Inselreich eine weitaus ausführlichere und frühere Berichterstattung über derartige Fälle als in Deutschland. Dass die englischen Gerichte gerade prominente Fälle unter Ausschluss der Öffentlichkeit verhandelten und die offiziellen Aufzeichnungen verkürzten, konnte entsprechende Medienberichte nicht verhindern. ${ }^{37}$ Diese Berichte lebten von einem eigentümlichen Spannungsverhältnis, das die Zeitungen immer wieder selbst thematisierten. Einerseits betonten sie, die Vergehen seien zu „widerwärtig“, als das man über sie berichten könne. Andererseits schrieben sie im gleichen Moment darüber. Sie legitimierten dies damit, dass es zu ihrer Aufgabe gehöre, Prozessinhalte öffentlich zu machen und gegen jede Einschränkung der Öffentlichkeit zu protestieren. Erst die explizite Distanz zum eigenen Artikel rechtfertigte somit den Bericht.

Welche Deutungen und Handlungsmuster solche Presseberichte bereits seit dem frühen 19. Jahrhundert über Homosexualität etablierten, lässt sich exemplarisch an einigen Skandalen zeigen. Ein besonders markanter Fall der 1820er Jahre, der sich für eine vertiefte Analyse anbietet, war etwa der Skandal um Percy Jocelyn, den irischen Bischof von Clogher. Der anglikanische Geistliche, der aus einer alten Adelsfamilie stammte, wurde am 19. Juli 1822 in einer Londoner Kneipe von mehreren Zeugen beim Verkehr mit einem Wachmann überrascht und festgenommen. Nachdem sich seine Identität geklärt hatte, gestatteten die Behörden seine Freilassung gegen Kaution, woraufhin der Bischof sofort nach Frankreich floh und laut Presseberichten 150000 Pfund aus den Ersparnissen der Kirche mitnahm. ${ }^{38}$ Aus diesem bislang wenig beachteten Skandal lassen sich einige systematische Beobachtungen über den öffentlichen Umgang mit prominenten Homosexuellen in der ersten Hälfte des 19. Jahrhunderts ziehen. So zeigte der Fall zunächst, dass die britischen Behörden offensichtlich um die

$36 \mathrm{Zu}$ diesem in Folge der Foucault-Rezeption viel beachteten Paradox zwischen Tabu und Sprechanreiz vgl. hier bes.: Cocks, Nameless Offence, S.2f.

37 Eine verstreute Sammlung von Zeitungsausschnitten zu Fällen von Homosexualität im ersten Drittel des 19. Jahrhunderts findet sich in: British Library (BL) CUP 363 gg 31; sowie: Nachlass Beckford in: Bodleian Library/Oxford University MS, bes. etwa c. 83, fol. 129f., 139; vgl. auch: Rictor Norton, Mother Clap's Molly House. Gay Subculture in England 1700-1830, London 1992, S. 221.

38 Zur öffentlichen Rekonstruktion des Falles vgl. Times 8.10.1822, S. 3 und 11.11.1822, S.3. Eine Sammlung von Karikaturen, Zeitungsausschnitten und Pamphleten hierzu in: BL CUP 363 gg 31. Zum Ereignisablauf bisher, ohne Berücksichtigung der Öffentlichkeit vgl. F. H. Amphlett Micklewright, The Bishop of Clogher's Case, in: Notes and Queries 16 (1969), S.421-430. Einige reißerische journalistische Hinweise, die daran anknüpfen: MATTHEW PARris, The Great Unfrocked. Two Thousand Years of Church Scandal, London 1998, S. 144-157. 
Gefahren eines Prozesses wussten, der ausführliche Details in die Medien gebracht hätte und den Adel und die Kirche insgesamt diskreditieren würde. Jocelyns Freilassung gegen Kaution ist deshalb als eine Fluchtaufforderung zu interpretieren, um das Gerichtsverfahren und die Veröffentlichung zu verhindern. Dies war eine typische Reaktion gegenüber hochrangigen Homosexuellen im 19. Jahrhundert. Nicht die Haft oder die Todesstrafe waren das eigentliche Urteil, sondern das Exil, das zur Bewahrung des Geheimnisses geeigneter erschien als eine offizielle Verurteilung. Schon in den Jahrzehnten zuvor hatten prominente Adlige wie Viscount Courtenay die Flucht wählen müssen, um eine Verfolgung und Veröffentlichung entsprechender Vorwürfe zu verhindern. ${ }^{39}$

Die bürgerlichen Zeitungen schrieben zunächst über den Fall, ohne die Beteiligten namentlich zu nennen, oder sie verzichteten wie die Times zunächst ganz auf Berichte. ${ }^{40}$ Der englische Medienmarkt war jedoch bereits politisch so weit ausdifferenziert, dass der Skandal nicht mehr durch derartige Diskretionen zu verhindern war. Schon das Verschweigen des Kautionsgebers, der Hinweise auf die Identität des Bischofs hätte geben können, führte sofort zu Protesten des radikalen Journalisten William Cobbet, der in dem Sonntagsblatt Constitution die namentliche Nennung einforderte, was wiederum selbst die bürgerliche Times verbreitete. ${ }^{41}$ Radical papers wie The Statesman warfen der sogenannten „respectable press“ eine korrupte Doppelmoral vor und druckten den Namen des Bischofs in voller Länge. ${ }^{42}$

Da die Zeitungen untereinander wie kommunizierende Röhren aufeinander verwiesen, liefen in der Londoner Medienöffentlichkeit schnell unterschiedliche Informationen aus Irland zusammen, etwa von Blättern wie der Dublin Morning Post, dem Patriot Dublin Paper oder dem Dublin Evening Herald. Dadurch entstanden schnell und mosaikartig weitere Neuigkeiten, die die Dynamik des Skandals verstärkten. Wie die Zeitungen durch den vielfältigen Informationseingang herausfanden, war der Bischof 1811 schon einmal von einem Kutscher, dessen Bruder bei dem Bischof arbeitete, der Homosexualität beschuldigt worden. Dies hatte in einem Verleumdungsprozess jedoch nur zur Auspeitschung und zweijährigen Haftstrafe des Kutschers geführt. Gerade diese zusätzlich aufgedeckte Ungerechtigkeit verstärkte die ohnehin breite emotionale Empörung, aufgrund der selbst die Times unzweideutig über den Bischof

39 Frühere Beispiele in: Hyde, The Other Love, S.73f.

40 Vgl. die 1822 publizierte Zusammenstellung der ersten Artikel unter dem Titel: „A correct account of the horrible occurance in the Public-house in St. James Market, in which was discovered that the right Rev. Father in God, the Bishop of Clogher, lately transferred from the Bishopric of Ferns was a principle actor with a Common Soldier!", London 1822, in: BL CUP 363 gg 31.

41 Times 30.7.1822, S.3; ohne Namensnennung, aber äußerst ausführlich: OBserver 21.7.1822. In den umfangreichen Studien zu Cobbett wird dieser Fall nicht erwähnt; vgl. GeORGE SPATER, William Cobbett. The Poor Man’s Friend, Bd.2, Cambridge 1982.

42 The Statesman 22.7.1822. 
urteilte: „He surely deserved to be hanged by the neck.“43 Dagegen wurde der Kutscher, der den Bischof erstmals der Homosexualität beschuldigt hatte, sowohl in der bürgerlichen Presse als auch bei den Radicals als Märtyrer und Held gepriesen. Ähnlich wie beim fast zeitgleichen Queen Caroline Skandal zielten die Vorwürfe so auf eine abgrenzende Identitätsbildung des Bürgertums und der Unterschichten. Die Behörden sahen den Skandal dagegen als eine Bedrohung an, da die Veröffentlichung sexueller Enthüllungen die Gesellschaftsordnung radikal verändern könne. So schrieb ein Mitarbeiter des Home Office an Innenminister Robert Peel: „It will sap the very foundations of society, it will raise up lower orders against higher, and in the present temper of the public mind it will do more to injure the Establishment than all the united efforts of its enemies could have effected in a century." 44

Dass es bei dem Prozess um Homosexualität ging, wurde in der Medienöffentlichkeit in erstaunlich expliziter Sprache berichtet. So sprach die Times von „sodomitical practices“, „abominable turpitude“ und „horrible occurance“. ${ }^{45}$ Auch der Observer beschrieb die Situation und den genauen Ort, wo sie entdeckt wurden. ${ }^{46}$ Sofort erschien eine Broschüre, die die Zeitungsausschnitte gesammelt abdruckte. Schon die ersten Sätze ihrer Einleitung verrieten das neue Selbstbewusstsein der Presse: Ihre Aufgabe sei stets, das Böse aufzudecken, aber besonders, wenn die Machthaber die Laster der oberen Schichten zu verheimlichen versuchten, um Verbrechen ausschließlich den unteren Klassen zuzuschreiben. ${ }^{47}$ Noch deutlicher formulierten dies die Kommentare der populären Kultur, wie sie etwa in überlieferten Spottgedichten überliefert sind. Auf einer Zeitung fand sich etwa der handschriftliche Vers: „The Devil to prove the Church was a farce/Went out to fish for a B[ugge]r/He baited his hook with a Frenchman's arse/and pulled up the Bishop of Clogher. “48 Andere populäre Verse, die über Flugschriften verbreitet wurden, spotteten, dass die Kopulation mit Männern nun zum Seelenheil führe. ${ }^{49}$ Gerade der Spott erleichterte die Kommunikation über das offiziell unbenennbare Verbrechen und förderte sie.

Auch der Ort des homosexuellen Aktes entwickelte sich zu einer Attraktion der Populärkultur. „The people of the public house have made a good deal of money by showing the place“, notierte Charles Greville in sein Tagebuch. ${ }^{50} \mathrm{Ka}$ -

43 Times 8.10.1822, S.3. Da der Fall ist bislang kaum erforscht ist und Archivmaterial kaum aufzufinden war, beruhen meine Ausführungen vor allem auf Medienberichten; einige Hinweise in: Norton, Mother Clap’s, S.216f. Einige Unterlagen in: BL Cup. 363, gg. 31.

47 O.A., A Correct Account, London 1822.

48 Handschriftlich auf Zeitungsausschnitt in: BL CUP 363 gg 31. Eine andere Version spricht direkt vom „soldier's arse“.

49 Gedicht „Lions in Tears“ in: BL CUP $363 \mathrm{gg} 31$.

50 Eintrag 30.7.1822, in: Lytton Strachey und Roger Fulford (Hrsg.), The Greville Memoirs, Bd.1: Jan 1814-July 1830, London 1938, S. 125 f. 
rikaturen, die einzeln verbreitet wurden, zeigten Bischof und Soldaten mit verliebten Blicken, aber auch mit geöffneten Hosen. ${ }^{51}$ Die Folgen der Empörung zeigten sich in Ausschreitungen gegen den Bischof bei der Verhaftung und den folgenden Straßenkrawallen gegen Homosexuelle, die schon bei früheren Verhaftungen aufgetreten waren. Die öffentlichen Berichte scheinen sogar zum Selbstmord des Außenministers Viscount Castlereagh beigetragen zu haben, der verwirrt und offensichtlich erpresst vor seinem Tod dem König anvertraute: „I am accused of the same crime as the Bishop of Clogher. "52 Insgesamt lässt sich der Skandal damit als ein massiver Angriff der Populärkultur gegen die etablierten Machthaber bewerten. Der homosexuelle Verkehr des Bischofs bildete dabei nur einen Anlass für eine breite Empörung.

Diese deutliche Thematisierung von Homosexualität lässt sich auch bei anderen Skandalen in der ersten Hälfte des 19. Jahrhunderts ausmachen. Dabei berichteten die englischen Zeitungen sogar über Anschuldigungen gegen bürgerliche Mitglieder des Unterhauses. So floh der Gelehrte und Unterhaus-Abgeordnete für die Oxford University, Richard Heber, 1826 nach Frankreich, nachdem eine Lokalzeitung ein Verhältnis mit einem deutlichen jüngeren Mann angedeutet hatte und dessen Vater daraufhin mit einer Klage gedroht hatte. In eine breitere Öffentlichkeit kam der Fall aber erst, als daraufhin der Verleger und Herausgeber der Zeitung John Bull, Edward Sheckell, einem weiteren Gelehrten vorwarf, ein Verhältnis mit dem Abgeordneten Heber zu haben. Dieser wies dies erfolgreich mit einem Verleumdungsprozess zurück, der den Fall erst wirklich publik machte. ${ }^{53}$ Die Angst vor der Medienöffentlichkeit und dem Skandal zwang auch hier zur Emigration. Indem die Betroffenen nach Frankreich flohen, konnte Großbritannien zugleich sein Selbstbild als das moralisch überlegene Land rekonstituieren. Die Flucht vor dem Skandal erschien zugleich wie ein Akt der nationalen Reinigung.

Noch detaillierter beschrieben die Zeitungen den Fall von William John Bankes, der Unterhausabgeordneter für die Universität Cambridge war. 1832 hatte ein Wachmann den Ägyptologen verhaftet, als er ihn in der Nähe des Parlaments mit einem Soldaten zusammen in einer öffentlichen Toilette überraschte. ${ }^{54}$ Da Bankes trotz Freilassung nicht floh, kam es zu einem Prozess. Um die Homosexualität eines Politikers als undenkbar zu markieren, stellte sich das Gericht trotz der offensichtlichen Beweise ganz auf die Seite des Abgeordneten. Es gewährte ihm eine „special jury“ und verteidigte seine Ehrenhaftigkeit. Mehrere Abgeordnete und Prominente wie der Duke of Wellington bescheinigten ihm

51 Abgedruckt sind drei Karrikaturen in: PARRIs, Great Unfrocked, S. 147 und 171.

$52 \mathrm{Zu}$ den Ausschreitungen: ObServer 21.7.1822; zu Castlereagh: Harvey, Prosecutions, S. 942.

53 Vgl. Trmes 20.11.1826, S.3 und 28.11.1826, S.3. Bei Hyde eine Erwähnung Hebers, nicht aber des John Bull-Prozesses und der Öffentlichkeit, die der Fall dadurch erhielt; vgl. DERs., The Other Love, S. 93.

54 Vgl. bes. Times 12.6.1833, S. 6, 25.7.1833, S. 5 und 3.12.1833, S. 4f. Knapp erwähnt ist der Fall in: Patricia Usick, Adventures in Egypt and Nubia. The Travels of William John Bankes (1786-1855), London 2002, S. 172. 
einen ehrenwerten Charakter. In seiner Verteidigung wurde zugleich ausgesprochen, welche Bedrohung entstehen könne, falls die Jury ihn schuldig sprechen würde, da dann die Ehre und das Leben eines jeden Mannes gefährdet seien. ${ }^{55}$ Dass dies keine Rehabilitierung bedeutete, sondern nur eine Bewährungsstrafe war, zeigte sich schnell. Trotz des Freispruches beendete der Prozess Bankes politische Karriere. Er wurde nicht wieder gewählt und sozial eher gemieden. Als die Zeitungen 1841 abermals berichteten, er sei in einem Park verhaftet worden („,indecently exposing himself to a soldier“56), kam es wieder zu dem typischen Skandalverlauf: Bankes kam gegen Kaution frei und floh nach Venedig, wo er den Rest seines Leben verbrachte, um so eine öffentliche Debatte über die Vorwürfe zu verhindern. Die erzwungene Emigration sicherte somit erneut die „Selbstreinigung“ der Gesellschaft.

Alle diese Beispiele zeigen folglich, dass auch von staatlicher Seite bei prominenten Fällen nicht die Todesstrafe oder die Haft, sondern die Verbannung als Strafe vorgezogen wurde, um Skandale und die mit ihnen einher gehende öffentliche Auseinandersetzung mit der Homosexualität zu vermeiden. Derartige Fälle dürften dennoch durch ihre mediale Thematisierung in doppelter Hinsicht bürgerliche Selbstgewissheiten unterlaufen haben. Einerseits machten sie deutlich, dass auch Bürger mit Besitz, Bildung und öffentlichen Stellungen homosexuell sein konnten und sich dies nicht allein als Vergehen der Unterschichten und des Adels ausgrenzen ließ. Andererseits zeigten die Fälle, dass weder durch eine wohlwollende Behandlung vor Gericht noch durch die Verbannung ins Ausland eine Thematisierung der Homosexualität zu verhindern war. Vielmehr übten die Zeitungen Umschreibungen ein - wie „crimes of so horrible a nature“, „improper design“ oder „certain misdemeanour“. Im Vergleich zu Zeitungsberichten aus dem frühen 19. Jahrhundert fand sich allerdings kaum noch der Begriff „sodomy“, der anscheinend als zu explizit galt, um ihn in der frühviktorianischen Presse auszusprechen. ${ }^{57}$

In der zweiten Hälfte des 19. Jahrhunderts unterlief insbesondere der viel beachtete Skandal um Ernest Boulton und Frederick William Park bürgerliche Selbstgewissheiten über sexuelle Normen. Deren Prozess verhandelte 1871 erneut, inwieweit es öffentlich denkbar war, dass bürgerliche Männer aus respektablen Familien homosexuell sein könnten. Nachdem die beiden jungen Männer im Jahr zuvor verhaftet worden waren, weil sie öffentlich Frauenkleider trugen, wurden zum Prozess zahlreiche Bürgerliche vorgeladen und wegen der Ausübung von Unmoral angeklagt. ${ }^{58}$ Aus den Prozessberichten erfuhren die Zeitungsleser ausführlich, dass die beiden Männer sich mit Frauennamen anredeten

55 Times 3.12.1833, S. 5.

Times 3.9.1841, S. 7 und Times 25.9.1841, S.7.

Vgl. dagegen etwa die Zeitungsartikel über Hinrichtungen von Homosexuellen um 1800 in: BL CUP 363 gg 31.

58 Wörtlich: „charge of the conspiracy to commit or to incite to the commission of immorality“; vgl. zur Anklage: Times 12.5.1871, S. 11 u. 11.5.1871, S. 11. Vgl. zu dem bekannten Fall etwa: Cocks, Nameless Offence, 2003, S. 106-114, Kaplan, Sodom, S. 19-101. 
und als Frauen geschminkt und verkleidet Männer angesprochen hatten, die das Cross-Dressing nicht erkannten und mit ihnen flirteten. ${ }^{59}$ Dennoch wurden sie freigesprochen, da das Gericht ihr Verhalten und die verlesenen Liebesbriefe mit ihrem jugendlichen Charakter und ihrer Theaterliebe entschuldigte. In die engere Sphäre der Politik wäre der Fall wohl gerückt, wenn der junge Abgeordnete Lord Arthur Clinton, der mit Boulton befreundet war, nicht kurz vor dem Prozess gestorben wäre - vermutlich durch Selbstmord, offiziell an Scharlach.

Für die großen Homosexualitätsskandale des späten 19. Jahrhunderts war auch der Boulton-Park-Prozess prägend. So führte er zu einer maßgeblichen Debatte darüber, wie ein Homosexueller auszumachen sei. Neben der bislang üblichen Charakterprüfung erfuhren die Zeitungsleser nun andeutungsweise von medizinischen Nachweisen von Homosexualität im Prozess, etwa anhand von Anus-Untersuchungen. ${ }^{60}$ Ebenso wurde debattiert, ob Homosexuelle verheiratet sein könnten oder dies eine Altersfrage sei. Der Kronanwalt (Attorney General) nahm dabei die auf dem Kontinent publizierte Literatur über Homosexualität bewusst nicht zur Kenntnis, sondern wies sie mit den Worten zurück, es sei gut, dass es wenig Erkenntnisse oder Wissen über dieses Thema in seinem Land gäbe. ${ }^{61}$ Insgesamt zeigte die Debatte eine große Verunsicherung, die gerade daraus resultierte, dass Homosexualität quasi überall sein könne, aber nicht klar nachweisbar sei.

Darüber hinaus lassen sich derartige Skandale als eine Bedrohung für das männliche Rollenverständnis interpretieren. Ihre Frauenkleider prägten nachhaltig die Vorstellung vom weiblich wirkenden Homosexuellen, der nach außen markierte Geschlechterrollen durchbrach. Dies erschien zugleich als eine Gefahr für heterosexuelle Männer, die dies im Flirt mit solchen vermeintlichen Frauen nicht durchschauten. Dass die angeklagten homosexuellen Transvestiten keiner geregelten Erwerbsarbeit nachgingen, sondern nur gelegentlich Theater spielten, brach ebenfalls mit männlichen Rollenvorstellungen. ${ }^{62}$ Der Fall entwickelte sich darüber hinaus zu einer grundsätzlichen öffentlichen Selbstvergewisserung über die Sittlichkeit des Landes. Da auch ausländische Medien den Prozess verfolgten, sah die Times ihn für das In- und Ausland als eine „reflection on our national morals“. ${ }^{63}$ Dies wurde mit der Warnung verbunden, dass der Niedergang der französischen Moral für die Kriegsniederlage gegen Deutschland verantwortlich sei, weshalb nun das Vordringen der Pariser Sitten nach England verhindert werden müsse. Damit war die Homosexualität nicht nur eine Frage der nationalen Ehre und abgrenzenden Identifikation, sondern auch der nationalen Wehrhaftigkeit. Dementsprechend wies auch der Richter in

59 Vgl. etwa: Reynolds’s Newspaper 29.5.1871; Pall Mall Gazette 20.5.1870.

60 Zur Definitionsmacht der Gerichtsmedizin, die solche Untersuchungen schon in der Frühen Neuzeit vornahm, vgl. mit Blick auf Deutschland: Müller, „Aber in meinem Herzen“, S. 91110.

61 Zit. nach: Weeks, Sex, S. 101.

62 Cocks, Nameless Offence, S. 111.

63 Times 16.5.1871, S. 9. 
seinem entlastenden Plädoyer darauf hin, dass die Unmoral von Boulton und Park nicht die Moral des „national character“ befleckt habe. ${ }^{64}$

Vergleichbare explizite Thematisierungen oder Skandale lassen sich für Deutschland in den ersten zwei Dritteln des 19.Jahrhunderts kaum ausmachen. ${ }^{65}$ Auch wenn die wesentlich schlechtere Forschungslage keine abschließenden Befunde über die öffentliche Auseinandersetzung mit Homosexualitätsprozessen in dieser Zeit zulässt, kann man insgesamt feststellen, dass nicht zuletzt die harte Zensur im Deutschen Bund eine ähnliche mediale Thematisierung derartiger Fälle verhinderte. So sorgte das preußische Justizministerium bei einem Homosexualitätsprozess von 1835, bei dem auch hohe Adlige beteiligt waren, für eine sofortige Einziehung der Akten, um jede öffentliche Thematisierung zu unterbinden. Als bedrohlich erschien dabei, wie Bismarcks spätere Erinnerung an diesen Fall illustriert, auch „die gleichmachende Wirkung des gemeinschaftlichen Betreibens des Verbotenen durch alle Stände hindurch."66 Dass derartige Prozesse in alltäglichen Gesprächen für Diskussionen sorgten, ließ sich anscheinend nicht verhindern. Auch der Prozess um Reichsfreiherr von Malzan 1849/50, dessen Tagebücher seinen regelmäßigen homosexuellen Verkehr der letzten 26 Jahre dokumentierten, drang trotz aller Restriktionen in die Berliner Alltagsgespräche. ${ }^{67}$ Bei diesem Fall galt ebenfalls der sexuelle Verkehr zwischen Adligen und Soldaten als spektakulär. Wie bei späteren Skandalen erschien Homosexualität in Deutschland damit nicht nur als Angriff auf die moralische Ordnung, sondern auch auf die der Klassen.

Selbst im frühen Kaiserreich blieben die Grenzen des Sagbaren enger, gerade wenn es sich um prominente Repräsentanten der Gesellschaft handelte. Die homosexuellen Neigungen des Königs Ludwig II. von Bayern etwa, die heute als paradigmatisch für die hochadlige Homosexualität im 19. Jahrhundert gelten, waren damals zweifelsohne innerhalb des Adels und der regionalen mündlichen Öffentlichkeit bekannt und sorgten für nur leicht verdeckte Spekulationen. ${ }^{68}$ Die breitere Presseöffentlichkeit thematisierte dies jedoch nicht. Zumindest zeigt ein Blick in die großen liberalen Zeitungen, dass nur wenige vorsichtige

64 Ebd., S. 11.

65 Zur Forschungslage vgl. Bernd-Ulrich Hergemöller, Einführung in die Historiographie der Homosexualitäten. Tübingen 1999; vgl. zudem die zahlreichen Biographien in: DERs., Mann für Mann. Biographisches Lexikon zur Geschichte von Freundesliebe und mannmännlicher Sexualität im deutschen Sprachraum, Hamburg 1998.

66 Zit. nach: Linsert, Kabale, S.173. Hier Andeutungen zu dem Fall.

67 Die öffentliche Rezeption des Fall „Cajus“ (so der Decknahme) dokumentierten Johann Ludwig Caspers gerichtsmedizinische Schriften von 1858; vgl. Müller, „Aber in meinem Herzen", S. $182 \mathrm{f}$.

68 Vgl. hierzu RaIner Herrn, Ein historischer Urning. Ludwig II. von Bayern im psychiatrischsexualwissenschaftlichen Diskurs und in der Homosexuellenbewegung des frühen 20. Jahrhunderts, in: Katharina Sykora (Hrsg.), „Ein Bild von einem Mann“. Ludwig II. von Bayern. Konstruktion und Mythos, Frankfurt a. M. 2004, S. 48-89. Andeutungen nur in: LudwiG HütTl, Ludwig II., München 1986, bes. S. 369f. u. 388; Franz Herre, Ludwig II. von Bayern. Sein Land - sein Leben - seine Zeit, Stuttgart 1986, S. 146, 332-338 u. 361. 
Andeutungen über dieses Gerücht in die Presse gingen („Seine anerkannte Sittenreinheit ward zur Weiberfeindschaft"), sie ansonsten aber lediglich seine Geisteskrankheit diskutierten. ${ }^{69}$ Die Befragungen bei seiner Entmündigung bezogen sich ebenfalls bewusst nicht hierauf.

Auch innerhalb der frühen Arbeiterbewegung war umstritten, wie mit Homosexuellen innerhalb der eigenen Führung umzugehen sei. Dies zeigte sich bei Johann Baptist von Schweitzer, der 1867 Reichstagsabgeordneter und 1868 Präsident des Allgemeinen Deutschen Arbeitervereins wurde, jedoch wegen eines homosexuellen Vergehens verurteilt war. Während Lassalle ihn etwa verteidigte, sprachen sich andere Sozialdemokraten sowie Marx und Engels wegen seiner Geschlechtsorientierung gegen ihn aus. Auch Karl Marx’ Bewertungen über Ulrichs Schriften belegen, welche starken Vorurteile und Ängste vor Homosexualität innerhalb der sozialistischen Bewegung herrschten. ${ }^{70}$

Trotz der weitgehenden Ausschaltung der Öffentlichkeit kam es auch in Deutschland zu Prozessen, die Vorstellungen von Homosexualität durch ihre breite öffentliche Aufmerksamkeit prägten. Im Unterschied zu Großbritannien war hierfür aber eine Verbindung mit anderen Verbrechen nötig. Eine herausragende Bedeutung hatte dabei der Berliner Prozess gegen den Leutnant a. D. Carl von Zastrow, der im Januar 1869 trotz dürftiger Beweise zu 15 Jahren Haft verurteilt wurde, weil er einen Fünfjährigen vergewaltigt und schwer verletzt habe und zwar nicht die Tat, wohl aber seine homosexuelle Anlage vor Gericht gestand. ${ }^{71} \mathrm{Da}$ die Zeitungen die Suche nach dem Täter begleiteten, nahm die Bevölkerung breiten Anteil, auch wenn die Öffentlichkeit im Unterschied zu den englischen Prozessen ganz ausgeschlossen war. Die große Wirkung des Falles zeigte sich nicht zuletzt darin, dass der Name Zastrow sich im frühen Kaiserreich anscheinend zu einem Synonym und Codewort für Homosexualität entwickelte. Zumindest berichtete Karl Heinrich Ulrichs in seiner frühen Schrift Argonauticus, die zeitgleich zum Prozess entstand: „In Kaffeehäusern und Concertsälen genügt es, dem Nachbarn in's Ohr zu raunen: ,Jener Herr dort ist ein Zastrow', um innerhalb weniger Minuten einen Skandal hervorzurufen, gegen den es für den Bezeichneten, sei wirklich auch ein Dioning, Rettung nicht

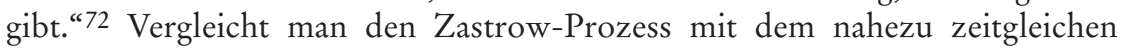
Boulton/Park-Skandal in Großbritannien, so lassen sich einige deutsche Spezifika erkennen. Der deutsche Prozess verbreitete bereits kurz vor der Gründung des Kaiserreiches die medizinische Neudeutung der Homosexualität. Zastrow

69 Zit. Vossische Zeitung 8.6.1886. Deutlich zudem ebd., 22.6.1886. Ausgewertet wurden als Stichprobe die Frankfurter Zeitung und die Vossische Zeitung zwischen Entmündigung und Tod, vom 5.6.1886 bis 23.6.1886.

70 Vgl. Hubert Kennedy, Johann Baptist von Schweitzer: The Queer Marx Loved to Hate, in: Journal of Homosexuality 29 (1995), S.69-96, S. 71; August Bebel, Aus meinem Leben, Bd.2, Berlin 1911, S.9f. Bebel rechnet hier generell mit Schweitzer ab, deutet dabei aber immer wieder „Untugenden“ an.

71 Hinweise in: Herzer, Zastrow, S. 67.

72 K.H. Ulrichs, Argonauticus, Leipzig 1869, S. 124. 
selbst bekannte sich freimütig, zum dritten Geschlecht im Sinne Ulrichs zu gehören, und auch die Gutachter setzten sich mit Ulrichs Ideen auseinander. ${ }^{73}$ Während in den britischen Skandalen Homosexualität vor allem als eine Form bürgerlicher oder adliger Dekadenz erschien, konstruierte der Zastrow-Prozess eher das kriminalistische Bild des pathologischen, triebgesteuerten und hemmungslosen Homosexuellen, der selbst Kinder missbrauche, was entsprechend die Angst vor Homosexuellen förderte.

Obgleich in Großbritannien bis zum letzten Drittel des 19.Jahrhunderts schärfere Strafen drohten und das Sprechen über Homosexualität stärker tabuisiert war, lässt sich somit im Kontext von Skandalen frühzeitiger eine intensivere Auseinandersetzung mit ihr ausmachen. Während die Bücher der Experten verboten blieben, entstand dank der stärkeren Pressefreiheit und Öffentlichkeit der Prozesse eine populäre Debatte und Empörung. Die skizzierten Skandale waren Auseinandersetzung zwischen Schichten und sozialen Gruppen, weniger jedoch politische Kampagnen im engeren Sinne. In beiden Ländern leiteten die Artikel über entsprechende Prozesse aber zweifelsohne sprachliche Verschiebungen, neue Vorstellungen und veränderte Tabugrenzen ein, an die im späten 19. Jahrhundert politische Kampagnen anknüpfen konnten, die Homosexualität enthüllten.

\section{Homosexualität und IRISH Home RULE}

Im späten 19. Jahrhundert veränderte sich der Charakter der öffentlichen Enthüllung von Homosexualität. Ähnlich wie in den Jahrzehnten zuvor wurde sie zumeist weiter mit versteckten Andeutungen und im Kontext von Prozessen verhandelt. Aber nun erhielten diese Anschuldigungen stärker das Antlitz von gezielten politischen Kampagnen, die grundsätzliche politische Konflikte austrugen. Die Aufdeckung von Homosexualität diente jetzt vor allem der moralischen Diskreditierung des politischen Gegners.

Ein Meilenstein in dieser Entwicklung waren in Großbritannien die Enthüllungen, die 1883/84 irische Nationalisten gegen die englische Verwaltung in Dublin richteten. Die Journalisten und Politiker William O'Brien und Tim Healy hielten dabei in Zeitungen und in Unterhausreden verschiedenen höheren Beamten der englisch geprägten Dubliner Verwaltung vor, homosexuell zu verkehren. ${ }^{74}$ Die folgenden Beleidigungsprozesse leiteten daraufhin einen politischen Homosexualitätsskandal ein, der über ein Jahr die Öffentlichkeit beschäftigte. Wieso kam es gerade von irischer Seite und ausgerechnet Anfang der 1880er

73 Vgl. die Gerichtsberichte in den Zeitungen wie: Norddeutsche Allgemeine Zeitung 6.7.1869.

74 Dieser Fall ist in der Literatur bisher nur am Rande erwähnt worden. Vgl. die Andeutungen in: Hyde, The Other Love, S.128-133; Frank Callanan, T. M. Healy, Cork 1996, S. 89-91; Cocks, Nameless Offence, S. 140-144. 
Jahre zu dieser markanten Verschiebung der Sagbarkeitsgrenzen, die die politische Kommunikation insgesamt nachhaltig veränderte? Generell war in den 1880er Jahren die Auseinandersetzung über die Unabhängigkeit Irlands eines der wichtigsten und besonders umkämpften politischen Themen in Großbritannien. Premierminister William Gladstone hatte seit 1869 einige bedeutende, aber in England umstrittene Reformgesetze für Irland eingeleitet, die den Landbesitz und die Pachtmöglichkeiten der Iren gerechter gestalten sollten, jedoch die Proteste der irischen Land League nicht beruhigen konnten. ${ }^{75}$ Am umstrittensten war die Frage der irischen Selbstverwaltung, der Home Rule, die Gladstone deshalb erst Mitte der 1880er Jahren aufgriff. Welche Bedeutung und Sprengkraft die Home Rule hatte, die zugleich das Selbstverständnis des Empires verhandelte, zeigte sich nicht zuletzt darin, dass sie 1886 zur Spaltung der Liberalen Partei und damit zum Machtverlust von Gladstone führte. ${ }^{76}$ Ebenso sorgte sie für eine politische (Neu-)Formierung der irischen Nationalisten seit den späten 1870er Jahren unter der Führung von Charles Stewart Parnell, die mit äußerst großer Aktivität im Unterhaus auf ihre Forderungen aufmerksam machten und sich einer provokativen Obstruktionspolitik bedienten. ${ }^{77}$

Dass sich dieser Schlüsselkonflikt ausgerechnet $1883 \mathrm{zu}$ einem Skandal mit Homosexualitätsvorwürfen zuspitzen konnte, hing mit dieser Radikalisierung des Konfliktes im Jahr zuvor zusammen, als irische Extremisten im Phoenix Park den neuen Chief Secretary für Irland, Lord Frederick Cavendish, und Untersekretär Burke ermordeten. ${ }^{78}$ Das Attentat führte zur Verhaftung und moralischen Diskreditierung zahlreicher irischer Politiker, obgleich sie sich sofort von der Gewalttat distanzierten. Die Verfolgungen hatten ein doppeltes Resultat: Sie verstärkten die Verbitterung über die englischen Herrscher und sie vergrößerten die Bedeutung von einzelnen irischen Presseorganen wie dem United Ireland oder dem Freeman's Journal, da sie während der Verhaftungen als Sprachrohr der irischen Bewegung agierten. Insbesondere die 1881 gegründete Zeitung United Ireland und ihr Herausgeber William O’Brien versuchten im Zuge dieser Polarisierung, durch skandalisierende Vorwürfe die Engländer moralisch und politisch zu treffen. So warf er der englischen Administration in Dublin 1882 in einer Artikelreihe Korruption und Misswirtschaft vor und bekämpfte im Jahr darauf den irischen Crown Solicitor als „swindler“, „blackguard“ und „adulterer“, der sich zudem an dem Vermögen seiner betrogenen

75 Vgl. George Boyce, Gladstone and Ireland, in: Peter J. Jagger (Hrsg.), Gladstone, London 1998, S.105-122; von den zahlreichen Biographien über Gladstone vgl. bes.: H.C.G. MATTHEw, Gladstone 1809-1898, Oxford 1997. Der hier untersuchte Skandal wird in keiner dieser Darstellungen berücksichtigt.

76 Vgl. ereignisbezogen zu dieser Spaltung: Cook und Vincent, The Governing Passion.

77 Grundlegend zu seiner Biographie: Francis Steward Lyons, Charles Stewart Parnell, London 1977. Zur Home Rule vgl. einführend: Alan O’Day, Irish Home Rule, 1867-1921, Manchester 1998 .

78 Zur Bedeutung der Phoenix Park Murders und deren Nachwirkungen vgl. auch Kapitel V.2. 
Ehefrau bereichert habe. ${ }^{79}$ Nicht minder drastisch fielen die Vorwürfe des irischen Abgeordneten Tim Healy aus, die er sowohl im United Ireland als auch im Unterhaus gegen die Engländer richtete. So beschuldigte Healy den Unterinspektor des Royal Irish Constabulary, der die Niederschlagung des irischen Aufstandes in Wexford geleitet hatte, er habe vor der Heirat mit seiner Frau zusammengelebt und erkundigte sich nach dem Stand des Bankrottprozesses des Lord Lieutenant George Bolton. ${ }^{80}$ Die Iren überführten damit in ihrem Kampf gegen die englische Herrschaft gezielt Normbrüche in der privaten Sphäre in die politische Öffentlichkeit.

Derartige Vorwürfe fanden schnell eine entsprechende Aufmerksamkeit. Die Times, die vehement gegen eine Ausweitung der irischen Rechte eintrat, sah bereits in Healys ersten Andeutungen im August 1883 einen Bruch des „unwritten code of good breeding and good feeling“, den bislang alle befolgten hätten, weshalb jeder Ire mit „any sense of decency“ beschämt sein sollte. ${ }^{81}$ Der Kampagnenstil war auch bei den irischen Nationalisten nicht unumstritten. So kritisierte die irische Tageszeitung Freeman's Journal die ,improper language and personal attacks “ in den Parlamentsreden. ${ }^{82}$ Im Unterhaus verweigerte der Irlandminister George Trevelyan gegenüber Healy jede weitere Antwort zu seinen Anfragen über den Unterinspektor der irischen Polizeieinheit, bis er sich wegen seiner Angriffe gegen die Frau des Unter-Inspektors entschuldigt habe. ${ }^{83}$

Diese Begrenzungsversuche spornten die irischen Abgeordneten jedoch eher zu einer Ausweitung der Skandalisierung an. So verteidigte Healy in irischen Zeitungen die Veröffentlichungen über den „private character“ der englisch dominierten Bürokratie, da diese deren politische Stellung betreffen würde. ${ }^{84} \mathrm{Zu}$ gleich drohte er im United Ireland direkt:

If the House of Commons wants to make rules to stop such questions as Mr. Healy's, it is open to do it to devote its valuable time to the attempt, but it will not do so until the life

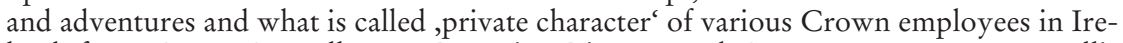
land, from Corry Connellan, to Detective Director and County Inspector James Ellis French are fully laid bare to the universe. ${ }^{85}$

79 United Ireland 3.11.1883, 14.6.1884. Vgl. rückblickend Times 2.8.1884, S.7; vgl. auch zu O'Briens Kampagne: Sally Warwick-Haller, William O’Brien and the Irish Land War, Dublin 1990, S.71-73. Unerwähnt bleibt sie in: Joseph O'Brien, William O'Brien and the Course of Irish Politics 1881-1918, London 1976.

80 Vgl. Hansard's Parliamentary Debates 7.7.1884 u. 14.7.1884, Bd.290, Sp. 213 und 908; Times 18.8.1883, S. 8 und 20.8.1883, S.7.

81 Vgl. die ausführlichen, mehrfachen Hinweise darauf in Times 18. 8.1883, S. 6-9.

82 Freeman's Journal 20.8.1883, S. 4.

83 Times 18.8.1883, S.8.

84 United IRLAND 25.8.1883, S. 5.

85 Ebd., auch in: Times 5.11.1883, S.10. Der Herausgeber des United Ireland, William O'Brien, schrieb in seinen Memoiren rechtfertigend, Healy habe diesen Artikel geschrieben und er selbst habe ihn bei der Redaktionsarbeit übersehen; WILliam O’Brien, Evening Memoirs, Dublin und London 1920, S. 17. 
Auch wenn dies nur als Anspielung formuliert war, bestand dank der eingeübten codierten Sprache über Homosexualität kein Zweifel, was diese Andeutungen über den „private character“ meinten. In den folgenden Monaten wiederholte er seine Drohungen und konkretisierte sie im United Ireland: Die Bewohner Sodoms seien eine respektable Gesellschaft im Vergleich zu einigen Halunken, die für Ihre Majestät im Dublin Castle Irland regierten. Der offizielle Leiter der Irlandpolitik, der Lord Lieutenant Earl Spencer, stehe auf Seite der Beschuldigten, weil er die Ermittlungen behindere, obwohl er Beweise für die "abomination" habe. ${ }^{86}$

Der Unterschied $\mathrm{zu}$ früheren Homosexualitätsskandalen ist somit unverkennbar. Hier brachten Parlamentarier, die zugleich als Journalisten arbeiteten, den Vorwurf der Homosexualität gezielt in die Öffentlichkeit, um auf diese Weise davon völlig unabhängige politische Ziele zu erreichen. Ihre Zeitungsartikel und Parlamentsreden bezogen sich dabei wechselseitig aufeinander, um die öffentliche Wirkung zu verstärken. Sie zitierten im Parlament aus den Artikeln im Freeman's Journal oder United Ireland mit der Frage, ob diese Vorwürfe zuträfen, und zitierten dann die Reden und Antworten im Parlament in der Presse. Durch dieses Wechselspiel gelang es ihnen, die Aufmerksamkeit der breiten nicht-irischen Medienöffentlichkeit zu erreichen. ${ }^{87}$ Gerade diese Verschränkung von Medien- und Parlamentskommunikation gab dem Skandal erst seine Dynamik.

Mit ihren Angriffen gegen die englische Verwaltung konstruierten Healy und O’Brien das Bild des moralisch überlegenen Irlands, das von sexuell unmoralischen Besatzern beherrscht würde. In gewisser Weise stand dieses Bild in Verbindungen mit den aufkommenden kritischen Kolonialdiskursen, die ebenfalls die sexuelle Doppelmoral der von außen kommenden englischen Verwaltung attackierten. ${ }^{88}$ Dieses Narrativ versprach in Irland insbesondere durch die religiöse Aufladung des Konfliktes mit England Erfolg, weil sich die katholischen Iren gegenüber den anglikanischen Engländern als moralisch überlegen fühlten, da sie strengere moralische Maßstäbe anlegten. In der Rhetorik der irischen Nationalisten wurde dieses Bild der moralisch verkommenen englischen Besatzer auch nach dem Abflauen des Skandals immer wieder auf diesen Fall bezogen. „The Law the Irish people got was the law of George Bolton“, hieß es etwa in den Reden Healys. ${ }^{89}$

Die Iren durchbrachen mit diesen Anschuldigungen unverkennbar die bisherigen sprachlichen Konventionen, wie sie vor allem im Unterhaus, aber auch in der politischen Medienöffentlichkeit galten. Die Außenseiterstellung der Iren und ihrer Zeitungen erleichterte diese Grenzüberschreitung in der britischen

\footnotetext{
United Ireland 20.10.1883, 1.3.1884, 7.3.1884, 10.5.1884 und 24.5.1884.

Vgl. für diesen Fall etwa: 28.7.1884, Hansard’s Parliamentary Debates Bd.291, Sp.659.

88 Hierzu ausführlich Kap. IV. Im Kontext von Kolonialismus und Homosexualität erwähnt den Fall knapp: Robert Aldrich, Colonialism and Homosexuality, London 2003, S. 185.

89 Times 4.9.1884, S.7.
} 
Öffentlichkeit. Biographisch kann man diese Verschiebung durch ihre Verbitterung über die Engländer nach den Verhaftungen erklären. Immerhin war selbst der führende irische Abgeordnete Healy wegen seiner politischen Schriften 1882 just zuvor vier Monate im Gefängnis gewesen. Nicht zuletzt deshalb richteten sich die irischen Vorwürfe vor allem gegen leitende Personen in Polizei und Justiz. So beschuldigten sie besonders den Dubliner Leiter der Kriminalpolizei, James Ellis French, und den königlichen Staatsanwalt, George Bolton, der bei dem Phoenix Park-Attentat die Ermittlungen führte. Ein mindestens ebenso entscheidender Grund, warum ausgerechnet die irischen Nationalisten die Sagbarkeitsgrenzen überschritten, war vermutlich, dass sie im Unterschied zu den meisten englischen Abgeordneten und Journalisten nicht über das elitäre englische Privatschul- und Universitätssystem sozialisiert worden waren, das selbst in politisch umkämpften Fragen bestimmte konsensuale Umgangsformen prädisponierte. ${ }^{90}$ Ähnlich wie die deutschen Sozialdemokraten hatten Politiker wie Healy vielmehr zuvor als Journalisten gearbeitet und übertrugen nun die dort eingeübte Kommunikationsform auf die parlamentarische Auseinandersetzung.

Die breitere britische Medienöffentlichkeit griff die Anschuldigungen der Iren zunächst nicht auf, bis es zu offiziellen Reaktionen aus der Verwaltung kam. So deutete die Times erst Anfang November die Vorwürfe an, als der beschuldigte Polizei-Inspektor James Ellis French nach Paris geflohen war und seine Entlassung gemeldet wurde „under circumstances that are likely to create a profound sensation when they are revealed“. ${ }^{91}$ Deshalb prophezeite sie bereits heikle Fragen an die Regierung, wenn das Parlament wieder zusammen träte.

Die Iren sorgten auch im folgenden Jahr auf unterschiedlichen Bühnen für die weitere Verbreitung ihrer Beschuldigungen, die gegenseitig die öffentliche Aufmerksamkeit verstärkten und dem Skandal seine Wirkungsmacht gaben: im Gerichtssaal, im Unterhaus und in der Presse. Der Gerichtssaal hatte sicherlich die wichtigste Verstärkerfunktion. Im Herbst hatte O’Brien seine Andeutungen über die Homosexualität des Polizei-Inspektors French im United Ireland solange wiederholt, bis dieser notgedrungen wegen Verleumdung klagte, diesen Prozess aber durch seine zeitweilige Flucht und nervliche Zerrüttung hinaus zögerte. Die verschiedenen Verleumdungs- und Strafprozesse, zu denen es 1884 kam, sorgten mehrfach für eine wochenlange Berichterstattung, die ähnlich wie bei früheren Homosexualitätsskandalen erst genauere Details beschreibbar machten. Wie bereits die Schlagzeilen zeigten, bezeichneten nun fast alle Zeitungen den Fall explizit als „Skandal“: Der Daily Telegraph überschrieb seine Artikel regelmäßig mit „The Dublin Scandal Trial“, Reynolds's Newspaper mit „The Horrible Dublin Scandal“, die Daily News und die Pall Mall Gazette mit

90 Bezeichnender Weise erwies sich Parnell, der in Cambridge studiert hatte, im Umgang mit den Engländern als besonders kompromissbereit. Zur Sozialisation der führenden englischen Journalisten in Oxbridge vgl.: Brown, Victorian News, S. 76, $210 \mathrm{f}$.

91 Times 5.11.1883, S. 10. 
„The Dublin Scandals“.92 Der Ortsbezug verwies auf den Irlandkonflikt, verdeckte aber zugleich den eigentlichen Vorwurf. Auf diese Weise wurde jedoch das Dublin Castle, also der englisch dominierte Regierungs- und Verwaltungssitz, zu einem Synonym für Homosexualität.

Das Vergehen selbst beschrieben die Zeitungen mit den eingeübten Umschreibungen, die auf die unglaubliche Schwere des „Verbrechens“ hinwiesen, ohne es zu direkt zu nennen. Sie sprachen, wie auch im Gerichtsraum üblich, über „the most abominable crime that could be attributed to a man“, „horrible offences“, „felonious practices“ oder „unnatural crimes“. 93 Sprachlich gab es somit kaum eine größere Offenheit als im frühen 19.Jahrhundert. Auch die Assoziationen, mit denen die Vorwürfe spielten, erinnerten an ältere Semantiken. Die Verweise auf das Schloss, in dem die unmoralischen Vertreter der Krone in Dublin regieren würden, knüpften an Imaginationsräume aus Schauerromanen an, die eng mit der klassischen Lichtmetaphorik von Öffentlichkeit und Geheimnis verbunden waren. So sprach O'Brien im Unterhaus von einem „system under the walls of Dublin Castle“, das er an das Licht der Öffentlichkeit holen wolle. ${ }^{94}$ Indem die Kampagne dem Schloss sein Geheimnis zu nehmen vorgab, machte sie es jedoch erst geheimnisvoll.

Nicht die neuen Massen- und Boulevardblätter, sondern Parlamentarier und ihre kleinen politischen Zeitungen hatten somit diesen „Sex-Skandal“ angestoßen. Selbst ein „Sensationsblatt“ wie die Pall Mall Gazette berichtete zwar regelmäßig, aber nur äußerst zurückhaltend und vage über die Enthüllungen. Der zu dieser Zeit gerade entstehende und oft hervorgehobene „New Journalism“ des Pall Mall Gazette Herausgebers W. T. Stead stieß hier offensichtlich durch seine puritanische Prägung auf eine Grenze des Schreibbaren. Sogar beim Urteil gegen den leitenden Beamten Cornell deutete die Pall Mall Gazette nicht einmal den Grund des Verleumdungsprozesses an und sprach in der Woche darauf nur von „charged with crime“.95 Vergleichbar knapp, wenn auch regelmäßiger, waren auch die Artikel der Reynolds's Newspaper, die ebenfalls stets als Skandalblatt abgewertet wird. ${ }^{96}$ Besonders ausführlich berichteten dagegen die sogenannten Qualitätszeitungen, wie der Daily Telegraph und die Times. Ihre Berichte erfüllten bezeichnender Weise genau die Kriterien, die von der Mediengeschichtsschreibung oft für die frühen „Sensations“- und Boulevardblätter angenommen werden. So kündigte die Times ihren Lesern den ersten Prozess schon vorab als eine noch nie dagewesene Sensation an: „The case is the first of a series of sensational proceedings of an unprecedented character, and it has excited in-

92 Vgl. etwa: Daily Telegraph 3.7. bis 8.7.1884; Reynolds's Newspaper 20.7.1884, S.2; Pall Mall GazetTe 15.7.1884, S. 10; Daily News 31.7.1884, S.3.

93 Vgl. etwa Pall Mall Gazette 31.7.1884, S. 8; Daily News 31.7.1884, S.3.

94 17.6.1884 Hansard's Parliamentary Debates 3rd Series, Bd.291, Sp. 690.

95 Pall Mall Gazette 8.7.1884, S.7 und 15.7.1884, S.10; vgl. auch die täglichen Berichte in: Pall Mall Gazette i. bis 7.7.1884, S.2.

96 Reynolds's Newspaper 6.7.1884, S. 8; 13.7.1884, S. 5; 20.7.1884, S. 2; 27.7.1884, S. 1; 3.8.1884, S.3. Zur Charakterisierung von Reynolds's vgl. Berridge, Popular Sunday Papers. 
tense interest, chiefly on account of the position of the parties and the enormity of the charges imputed to an official of the Government by an avowed and uncompromising foe." 97 Damit wird deutlich, dass wie bei den späteren Skandalen die Grenzen zwischen der Popular Press und Quality Press nur bedingt an der Berichterstattung über sogenannte Sensationsfälle auszumachen sind. Moralische, kommerzielle und politische Interessen sorgten vielmehr für vielfältige Überschneidungen. Besonders ausführlich waren erwartungsgemäß die Artikel der irischen Zeitungen. Auch sie betonten, dass sie nur ungern und gezwungener Maßen im Dienste der Wahrheit über dieses Thema berichten würden und alle Aussagen ausgespart hätten „which might be even of a character too vile to be printed." 98 Dies war nicht nur eine rituelle Selbstlegitimierung. Sie verwiesen auch auf auszufüllende Leerstellen im Text, die Imaginationsräume über noch sensationellere Enthüllungen über die Schuld eröffneten und mündlich über Prozesszuschauer eingeholt werden konnten.

Die Prozesse zeigten, woher die Enthüllungsjournalisten ihre Informationen hatten. Sie beruhten charakteristischerweise zunächst nur auf zugetragenen Gerüchten aus Polizeikreisen. Erst als sich Verleumdungsklagen abzeichneten, beauftragte O'Brien einen Detektiv, der tatsächlich erfolgreich Zeugen ausfindig machte, die eine öffentliche Erhärtung seiner Anschuldigungen erlaubten. ${ }^{99}$ Durch diese Zeugenaussagen kamen bei den Prozessen weitere private Normbrüche an die Öffentlichkeit, die die britische Verwaltung zusätzlich diskreditierten. So beschuldigten mehrere Zeugen Gustavus Charles Cornwall, den Secretary of the General Post Office in Dublin Castle, sowohl bei seinen Kutschenfahrten durch den botanischen Garten als auch in seiner Wohnung homosexuell verkehrt zu haben. Andere wichtige Zeugen, die nach Frankreich flohen, bestätigten gerade durch ihre Abwesenheit den Verdacht. Und der beschuldigte Staatsanwalt Bolton musste im Verleumdungsprozess zumindest zugeben, dass er ein außereheliches Kind hatte und das Vermögen seiner Frau durch einen extravaganten Lebensstil verschleudert hatte. Obgleich die Gerichte dem irischen „Politiker-Journalisten“ O’Brien kritisch gegenüber standen und ihm vorhielten, bewusst falsche Beweise ermittelt zu haben, gewann er den Prozess gegen French und Cornwall und ging aus dem Prozess gegen Bolton trotz einer Strafe von 3000 Pfund als moralischer Sieger heraus. Damit trug der Gerichtsprozess entscheidend dazu bei, eine wirkungsmächtige „Wahrheit“ über die englische Homosexualität zu ermitteln.

Die große Wirkung der Prozesse zeigte sich nicht nur im Medienecho, sondern auch in der direkten Interaktion mit der „Encounter-Öffentlichkeit“ der alläglichen Begegnungen. Nach den Urteilsverkündigungen wurde O’Brien in

97 Times 3.7.1884, S.6.

98 Freeman's Journal 8.7.1884, S. 4.

99 Nach O'Briens Erinnerungen erhielt O'Healy den Hinweis von einem District Inspector of Constabulary in Charleville, während der Detektiv dann die genauen Hinweise ausmachte; DERs., Evening Memoirs, S. 18 u. 22. 
Dublin gefeiert und unter Musik und Jubel durch die Straßen begleitet. Eine Spendensammlung für ihn erbrachte 7610 Pfund und ersetzte seine Unkosten. Noch in seinen Memoiren ein halbes Jahrhundert später betonte Healy die außergewöhnlichen emotionalen Ausbrüche, die der Prozess in der irischen Bevölkerung ausgelöst habe. ${ }^{100}$ Insbesondere nationalistische irische Organisationen wie die National League priesen William O'Brien „for unearthing a terrible scandal."101 Charakteristisch war zudem der Kommentar des Dubliner Freeman's Journal, der aus dem Fall den generellen Schluss zog, dass die Herrschaft von autokratischen Systemen vor ihrem Niedergang zumeist „all forms of unnatural vice“ aufwies, wobei das antike Rom die implizite Vorlage für dieses Verfallsnarrativ gab. ${ }^{102}$ Aus der beschriebenen „Fäulnis“ der Herrscher wurde damit die Utopie einer zuküntigen moralisch integereren Freiheit abgeleitet.

Neben dieser Agitation vor Gericht hielten die irischen Abgeordneten die Vorwürfe mit zahlreichen Anfragen im Unterhaus weiter in der Öffentlichkeit. Dabei lassen sich verschiedene Strategien der Skandalisierung ausmachen. Die Iren betonten eher defensiv, nur notgedrungen das Thema aufzubringen, da auf ihre Andeutungen hin keine Untersuchungen erfolgt wären. Dies ergab sich aus der berechtigten Angst vor dem Vorwurf, der Tabubruch könne auf sie selbst zurückfallen. Healy und O’Brien richteten ihre parlamentarischen Anklagen nicht nur gegen die Homosexualität der Dubliner Beamten, sondern vor allem gegen die britische Regierung und die Dubliner Verwaltungsspitze, die den Fall vertuscht hätten und somit in Verbindung mit den Homosexuellen stünden: „[...] the Government practically invited those witnesses to fly from the country and escape the unpleasant duties which were attached to them. " 103 Dadurch verlagerte sich der öffentliche Fokus von der illegitimen Sexualität hin zur Anprangerung einer ungerechten Justiz und korrupten Regierung. Indem die Iren die scharfen Verfolgungen nach den Phoenix Park-Morden mit der ausbleibenden Bestrafung der Beamten verglichen, setzten sie die Homosexuellen quasi mit Mördern gleich und stilisierten sie zu Kapitalverbrechern. Die Einzelfälle verallgemeinerten sie durch Ausdrücke wie „system“ auf die gesamte irische Administration, wogegen sich Premierminister Gladstone besonders nachdrücklich wandte („a more frightful charge never was launched by one man against a whole body of men“). ${ }^{104}$ Erwartungsgemäß scheiterte schließlich der Versuch

100 „The trial exited feelings higher than anything since the ,Yelverton“ marriage case in the ,sixties““; T.M. Healy, Letters and Leaders of My Day, London o. D. (1928), S. 195. Zur Reaktion in den Straßen vgl. etwa: Reynolds's Newspaper 13.7.1884, S.5; Times 10.7.1884, S. 9.

101 Times 24.7.1886, S. 10.

102 Freeman's Journal 8.7.1884, S. 4.

103 So O’Briens Anklage im Unterhaus, die auch in die unionistischen Medien ging; vgl. Times 22.7.1884, S.6; vgl. die ausführliche Debatte dazu im Unterhaus: 21.7.1884 Hansard's Parliamentary Debates 3rd Series, Bd.291, Sp. 1802-1878.

104 21.7.1884 Hansard's Parliamentary Debates 3th Series, Bd.290, Sp.1859; vgl. hierzu auch Gladstones Tagebucheintrag 23.7.1884: Henry Colin MatThew (Hrsg.), The Gladstone Diaries with Cabinet Minutes and Prime-Ministerial Correspondence, Bd.11: July 1883-December 1886, Oxford 1990, S. 177. 
der Irish Nationalist Party, einen Untersuchungsausschuss zu dem Fall einzusetzen. Durch ein Select Committee mit entsprechenden Befragungen und Berichten hätten die Iren das Thema sicherlich gut ein Jahr länger in den Medien halten können, was die Liberalen und Konservativen nicht zuletzt deshalb gemeinsam ablehnten. ${ }^{105}$

Auch die katholische Kirche griff als maßgebliche öffentliche Deutungsinstanz Irlands den Fall auf. Ein Hirtenbrief, der in allen katholischen Kirchen verlesen wurde, erinnerte mahnend an die Gefahren, die der Fall gezeigt habe. Er benannte die Homosexualität zwar nicht explizit, wohl aber metaphorisch als tödliche Seuche, die schlimmer sei als die grassierende Cholera. ${ }^{106}$ Zugleich wandte sich der Hirtenbrief nachdrücklich gegen jede Veröffentlichung derartiger Enthüllungen und Prozessberichte und forderte ein Bündnis zum Boykott von Zeitungen mit derartig „schmutzigen“ Artikeln. Anderenfalls würde der Kardinal die Familien auffordern, Zeitungen mit derartigen Berichten nicht mehr zu kaufen. Da die irischen Nationalisten von ihrem Selbstverständnis her in enger Verbindung mit den Kirchen agierten, dürfte dies derartige Kampagnen seit Herbst 1884 mit eingedämmt haben.

Der Skandal hatte vielfältige Folgen. Innerhalb der englischen Regierung und der Dubliner Verwaltungsspitze führte er zu einer massiven Verunsicherung und zu Rücktrittsangeboten. Wie der Repräsentant der Krone in Irland, der Lord Lieutenant of Ireland Earl Spencer, Premierminister Gladstone brieflich mitteilte, fühlte sich die Verwaltungsspitze nervlich zerrüttet, da jeder Engländer in Dublin bedroht sei, „[...] as recent events prove, by a terrible and ever-present risk to his character and reputation. "107 Der Versuch des IrlandMinisters, den formal rehabilitierten Staatsanwalt George Bolton wieder in sein Amt zu setzen, führte zu weiteren Vorwürfen der Iren und zu einer breiteren Empörung bei den Parlamentariern, weil der Skandal zumindest Boltons Verschuldung auf Kosten des Vermögens seiner Frau öffentlich gemacht hatte. ${ }^{108}$

Da sich die Aufmerksamkeit der Polizei und der Öffentlichkeit nun auf Homosexuelle konzentrierte, kam es zu zahlreichen weiteren Verfolgungen und Anklagen. Gerüchte kamen auf, dass auch Geistliche und Soldaten betroffen seien. ${ }^{109}$ Ebenso scheint es in der folgenden Zeit verstärkt zu Erpressungsversu-

105 Dies scheiterte klar mit 24 zu 143 Stimmen. 21.7.1884 Hansard's Parliamentary Debates 3rd Series, Bd.290, Sp. 1857.

106 „Permit me to warn you of the moral pestilence with which we are threatened and which, if not averted, will work in the souls of the young a death more terrible than cholera, in its worst form, could work in our moral bodies." Times 4. 8.1884, S. 10.

107 Spencer an Gladstone 7.3.1884 u. 26.8.1884, in: BL Gladstone Mss. Add., 44331: 77-81, 17986. Vgl. auch Trevelyan an Gladstone 26.7.1884, in ebd. 44335: $168 \mathrm{f}$.

108 Vgl. die regelmäßigen Briefe Campbell-Bannermanns an Earl Spencer hierzu, bes.: 30. 10.1884, 3.11.1884, 4.11.1884, 5.11.1884, 7.1.1884 in: BL Althorp Papers Add. Mss. 76867, sowie in: BL Campbell-Bannerman Papers Add. Mss. 41228.

109 Reynolds's Newspaper 3.8.1884, S. 3 und 27.7.1884, S. 1. 
chen gekommen zu sein. ${ }^{110}$ Dagegen interessierte sich die Medienöffentlichkeit kaum noch für die Verurteilung der im Dublin Castle-Skandal Involvierten, da dies Ende 1884 durch die lange Dauer des Skandals ihren Neuigkeitswert verloren hatte. ${ }^{111}$ Das ermüdende Interesse machte deutlich, dass eben nicht das Schicksal einzelner Homosexueller im Vordergrund stand, sondern die englische Reputation.

Der Skandal verfestigte dennoch moralische Normen und trug mit zu einer Neuformulierung der Homosexualitätsgesetze bei. Allerdings waren es weniger die irischen Politiker, die sich für Änderungen einsetzten. Dies unterstrich erneut, dass es ihnen eben nicht um die Homosexualitätsfrage, sondern um ihre Unabhängigkeit ging. Die entsprechende Gesetzesreform forcierte vielmehr der Journalist W.T. Stead von der Pall Mall Gazette, der unmittelbar nach dem Skandal Unterlagen über verschiedene Homosexualitätsfälle sammelte und als potentielles Druckmittel archivierte, wenn auch nicht veröffentlichte. Jedoch übergab er sie dem Journalisten und radikalen Abgeordneten Henry Labouchere als Argumentationshilfe für eine Gesetzesnovelle, die dieser tatsächlich erfolgreich einbrachte. ${ }^{112}$ Begründet wurde die Notwendigkeit dieses Gesetzes mit der nicht zuletzt durch den Dubliner Skandal etablierten Vorstellung, dass die Verbreitung der Homosexualität zunähme. Der Paragraph minderte zwar das Strafmaß auf bis zu zwei Jahre Haft mit harter Arbeit, spezifizierte aber die Ausdehnung des Gesetzes auf „any act of gross indecency with another male Person“ (\$11). ${ }^{113}$ Bemerkenswert war vor allem, dass nach dem Skandal Homosexualität in Großbritannien öffentlich so präsent war, dass sie nun selbst in einem Gesetzestext recht explizit umschrieben werden konnte.

Der Dublin Castle-Skandal hatte so von der Peripherie aus dazu beigetragen, das moralische Selbstverständnis Großbritanniens zu erschüttern. Gerade weil sich die neu formierenden Irischen Nationalisten nicht an die Regeln der britischen Öffentlichkeit hielten, konnte ihnen dies gelingen. Auf diese Weise machte der Skandal Verhaltensweisen öffentlich, welche die bürgerliche Identität bedrohten, die sich im hohen Maße aus ihrem moralischen Selbstverständnis speiste. Denn er zeigte nicht nur eine Doppelmoral englischer Eliten, sondern auch intime Beziehungen jenseits der Klassengrenzen, da wohlhabende Angehörige der Administration mit ärmeren Iren verkehrt hatten. Gerade die daraus entstehende Frage, ob Homosexuelle vornehmlich der britischen Oberschicht angehören würden und Unterschichten mit ihrem Vermögen sexuell korrumpierten, prägte auch die folgenden Homosexualitätsskandale, die sich rasch anschlossen.

110 So zumindest: Cocks, Nameless Offence, 2003, S. 142.

111 Vgl. Times 9. 8.1884, 30.10.1884 und 22.12.1884, S.6.

112 So zumindest rückblickend Laboucheres Darstellung in: Hansard's Parliamentary Debates 28.2.1890, Sp.1534f.

113 Cocks, Nameless Offence, S. 17. 


\section{WEST END SCANDALS}

Der Dublin Castle-Skandal war nur der Auftakt zu einer Reihe von britischen Skandalen, die über die Thematisierung von Homosexualität grundsätzliche Konflikte austrugen. Damit zeigte sich eine typische Dynamik: Nachdem ein politischer Skandal die Sagbarkeitsgrenzen in einem Feld verschoben hatte, folgten weitere zum gleichen Thema. Der größte Skandal kam bereits 1889/90 auf, als sich bekannte Adlige des Vorwurfes erwehren mussten, regelmäßig Besucher eines Londoner Homosexuellenbordells gewesen zu sein. Zu einem politischen Skandal entwickelte sich dieser Normbruch nicht nur durch die öffentlichen Deutungen des Falles, sondern auch, weil die Regierung mehrfach versuchte, die Veröffentlichung der Vorwürfe und gerichtlichen Ermittlungen zu unterbinden. Der Skandal sollte als „Cleveland-Street-Affair“ in die Geschichte eingehen, auch wenn ihn die zeitgenössischen Zeitungen, besonders die linksliberalen, als „West End Scandals“ bezeichneten. Wie beim Dublin Castle-Skandal entlehnte er somit seinen Namen aus einer Ortsbezeichnung, da der Normbruch an sich nicht plakativ benennbar war.

Ähnlich wie bei den irischen Skandalen erklärt sich das Aufkommen dieser Vorwürfe zunächst aus einer grundsätzlichen Verschiebung der politischen Konfliktstrukturen. Die Auseinandersetzung um die Home Rule hatte 1886 das Ende einer langen liberalen Ära in Großbritannien eingeleitet. Auch wenn die Liberalen 1892 noch einmal kurz in die Downing Street einzogen, regierten nun fast zwei Jahrzehnte die Konservativen. Sowohl die Abspaltung der Unionisten von den Liberalen als auch die Ausdehnung des Wahlrechts führten dabei in der zweiten Hälfte der 1880er Jahre zu einer zunehmenden Politisierung, Polarisierung und entsprechend harten Debatten. Bei den Liberalen profilierte sich besonders ihr linker Flügel, die Radicals, zunehmend durch ihre gesellschaftskritische Agitation in Politik und Öffentlichkeit, die nicht zuletzt die Etablierung einer Arbeiterpartei auffangen sollte.

Vor allem der vielleicht aktivste Radikalliberale des späten 19. Jahrhunderts, der Abgeordnete und Journalist Henry Labouchere, trug bei diesem Homosexualitätsskandal maßgeblich dazu bei, die konservative Regierung moralisch zu diskreditieren. In gewisser Weise bedienten sich Labouchere und andere radikale Journalisten eines ähnlichen Kampagnenstils wie die Iren und knüpften an deren Agitation an. Auch den radikalliberalen Engländern ging es weniger um die Homosexualität einiger Adliger als vielmehr um die Aufdeckung sozialer und gesetzlicher Ungerechtigkeiten sowie um die Bloßstellung der Aristokratie und der konservativen Regierung. Insbesondere dem konservativen Premierminister Lord Salisbury, der selbst aus einer alten Adelsfamilie kam, hielten diese Radicals den Schutz seiner Standesgenossen vor.

Im Cleveland Street-Skandal erfuhr die Öffentlichkeit, dass es mitten in London Bordelle für Homosexuelle gab, die selbst hohe Adlige aus dem Umfeld des Königshauses regelmäßig besuchten. Die Polizei deckte dies durch einen Zufall auf. Ein Postjunge, bei dem die Polizei Anfang Juli 1889 eine größere Geldsum- 
me fand, sagte aus, sie stamme nicht aus Diebstählen, sondern aus „payment for going to bed with gentlemen. " 114 Als die Polizei das von ihm angegebene Bordell in der Londoner Cleveland Street aufsuchte, bei dem sich noch andere Jungen von der nahe gelegenen Post prostituierten, war es dank einer Vorwarnung bereits leer geräumt. Die polizeilichen Observationen an dem Haus ergaben jedoch, dass gut gekleidete Männer, aber auch Soldaten, alleine oder in Begleitung von Jungen dort anklopften. ${ }^{115}$ Unter anderem beobachteten sie, wie Lord Arthur Somerset vergeblich auf Einlass wartete, den auch die verhafteten Jungen als regelmäßigen Besucher identifizierten. Der 38-jährige Somerset diente am Königshof als Superintendent of the Stables and Extra Equerry des Prince of Wales. Darüber hinaus war er seit Kindheit eng mit der Königsfamilie verbunden und ein enger Freund des Prince of Wales. Ebenso war Somerset mit dem Sohn des Prinzen, Prince Eddy, befreundet, dessen Junggesellenleben seit längerem für Gerüchte sorgte, bis hin zu der bis heute kursierenden Annahme, er sei für die Jack the Ripper-Morde verantwortlich. ${ }^{116}$ Mit Somerset drohte somit das Königshaus in den Skandal um das Homosexuellenbordell verwickelt zu werden. Die Fallhöhe und die mediale Aufmerksamkeit für einen großen Skandal waren damit gesetzt.

Wie reagierten die Behörden und die Regierung auf den drohenden Skandal? Bemerkenswerterweise setzte sofort ein riskanter Aktionismus ein, um ihn zu verhindern. Noch am gleichen Tag, als Somerset identifiziert wurde, nahm der Innenminister die Ermittlungen der Polizei aus der Hand und übertrug sie dem ihm direkt unterstellten Director of Public Prosecutions, Augustus Stephenson. ${ }^{117}$ Zwischen dem Innenministerium, den Ermittlungsbehörden und der Polizei setzte nun ein immenser Briefwechsel über die Frage ein, wie man die Publizität des Falles verhindern könne. Ihre Furcht vor Indiskretionen war so groß, dass Lord Somerset selbst in der internen Korrespondenz der politischen Führung nicht namentlich erwähnt wurde, sondern nur mit Decknamen oder Kürzeln. Mal sprachen die Briefe von „certain persons“, machten eine Leerstelle mit Strich („_“), kürzten ihn „L.A.S.“ ab oder schrieben über Mr. Brown, wie

114 Bericht Metropolitan Police 18.7.1889, in: TNA, HO 144/477/X24427. Als Überblick zum Ereignisablauf vgl.: Chronological Summary, in: TNA, DPP 1/95/5. Während der grundsätzliche Ereignisablauf des Cleveland-Street-Falles durch zwei ältere Darstellungen gut bekannt ist und hier nur um einzelne Punkte ergänzt wird, fand bislang die Interaktion zwischen den Medienberichten und Ermittlungen wenig Beachtung, die hier deshalb ganz im Vordergrund steht; vgl. H. Montgomery Hyde, The Cleveland Street Scandal, London 1976; Lewis Chester et al., The Cleveland Street Affair, London 1976; ähnlich erzählerisch, mit einigen Ergänzungen: Kaplan, Sodom, S.186-223, sowie Ders., Did „My Lord Gomorrah“ Smile? Homosexuality, Class and Prostitution in the Cleveland Street Affair, in: Nancy Erber und George Robb (Hrsg.), Disorder in the Court. Trials and Sexual Conflicts at the Turn of the Century, New York 1999, S. 78-99.

115 Bericht Metropolitan Police 18.7.1889, in: TNA, HO 144/477/X24427.

116 Vgl. zu letzterem, auch mit Blick auf den Cleveland Street Fall: Theo Aronson, Prince Eddy and the Homosexual Underworld, London 1994.

117 Home Office an DPP 24.7.1889, in: TNA, DPP 1/95/1:13. 
Somerset sich gegenüber den Prostituierten genannt hatte. ${ }^{118}$ Damit Somersets Name beim Prozess gegen die Jungen im September 1889 nicht fiel, wies der Kronanwalt (der Attorney General) vorher das Gericht an, die Nennung von Namen zu verhindern. Allenfalls nach den von den Jungen benutzten Decknamen und andere Identifikationsmerkmalen sei zu fragen. Tatsächlich konnte gleich nach dem Prozess intern vermeldet werden: „no name disclosed“.119 Ebenso unsagbar wie das Vergehen selbst blieb die mutmaßliche Benennung der adligen Verdächtigen.

Diese Verschleierungstaktik von Regierung und Justiz konnte jedoch nicht verhindern, dass vor allem die linksliberale Presse den Fall aufgriff. Sie nannten zwar nicht explizit die Namen von Lord Somerset und anderen Adligen, spielten aber mit unverkennbar drohenden Andeutungen. Die Pall Mall Gazette fragte, warum die beschuldigten „two noble lords and other notable persons in society " nicht bestraft würden. ${ }^{120}$ Die Zeitschrift Men of the World druckte direkt neben einem Bericht über einen „gross scandal, the like of which has not been heard in England for many years“, bei dem bekannte Männer aus höchsten Kreisen involviert seien, die Meldung, Lord Somerset habe auf unbestimmte Zeit England verlassen. ${ }^{121}$ Das Blatt konnte so spielerisch einen Zusammenhang andeuten, ohne sich der Gefahr einer Verleumdungsklage auszusetzen.

Die radikalliberalen Printmedien entfalteten aus den Andeutungen eine politische Kampagne, die Moralismus und weltanschauliche Auseinandersetzung verband. Das kleine Blatt North London Press berichtete unter der Überschrift „Our old Nobility / Charges of infamous conduct against Peers“ zunächst über den Schwiegerbruder des Premierministers Lord Salisbury, der ein 10-jähriges Mädchen unsittlich berührt hätte, aber dank seiner Verwandtschaft und der Klassenjustiz nicht verfolgt worden sei, bis die Zeitung Scottish Leader darüber berichtete. Als Beleg für die generelle Verkommenheit des Adels und der politischen Führung schloss ein Bericht über den Cleveland Street-Prozess an. Um seine Macht zu demonstrieren, aber wohl auch um Prozesse zu vermeiden, spielte das Blatt zunächst nur drohend auf die Beschuldigten an: „The heir of a duke, the younger son of another duke and an officer holding command in a southern district“ seien unter den Angeklagten. „The names of these men are in our possession and we are prepared to produce them if necessary. " 122 Der Artikel beschuldigte dabei Polizei und Behören, den Fall bewusst vertuscht zu haben und neben den Adligen auch dem Bordellbesitzer die Flucht ermöglicht zu haben, während einfache Leute dafür lebenslänglich im Gefängnis säßen. Unter der Überschrift „Horrible Charges against peers“ zirkulierte der Artikel fast

118 Vgl. bes. die Briefe in TNA, DPP 1/95/1:50, 78, 218 u. DPP 1/95/3:13.

119 Richard Webster/Attorney General an Stephenson/DDP 29.8.1889 und 31.8.1889, in: TNA, DPP 1/95/1:63 und 78; an Webster/AG in: TNA, DPP 1/95/1:100.

120 Pall Mall Gazette 12.9.1889, S.2.

121 Men of the World 14. 9.1889.

122 North London Press 28. 9.1889. 
identisch am nächsten Tag in dem radikalen Wochenblatt Reynolds's Newspaper, das seit den 1860er Jahren immerhin eine Auflage von angeblich rund 300000 hatte und im höheren Maße auch Unterschichten ansprach. ${ }^{123}$ Die Erstnennung in einem kleinen Blatt legitimierte quasi als Eisbrecher den massenwirksamen Bericht. Die schnelle Übernahme spricht dabei für eine koordinierte Aktion zwischen den Zeitungen.

Diese Presseberichte führten zu unterschiedlichen Reaktionen in den Behörden. Die mittlere Ebene von Justiz und Polizei strebte daraufhin eine öffentliche Untersuchung an. Schon die ersten Andeutungen in der Pall Mall Gazette sorgten intern für Aufregung. ${ }^{124}$ Auf die Artikel in der Reynolds's Newpaper, die die Inaktivität der Polizei anprangerten, reagierte die Polizeiführung mit Rechtfertigungen gegenüber dem Staatsanwalt, dass die Untätigkeit nicht an ihnen liege. Da die Zeitungsartikel offensichtlich das Ehrgefühl der Polizei verletzten, verlangten sie eine genauere Klärung der Verantwortung und Zuständigkeit. ${ }^{125}$ Ebenso drängte der Oberstaatsanwalt direkt nach dem Artikel in der Pall Mall Gazette darauf, gegen Somerset vorzugehen, da er sich nicht Untätigkeit und Klassenjustiz vorwerfen lassen wollte. Er leitete die Beschwerden der Polizei an den Innenminister weiter und betonte auch gegenüber dem Attorney General die erdrückenden strafrechtlichen Beweise gegen Somerset: Es gäbe keine Zweifel „that LAS was a frequent visitor at 19 Cleveland Street for immoral purpose“ (H.i.O.). Allerdings könne er wegen der Weisungen des Innenministers nicht handeln. Dabei stellte er sich auf die Seite der jungen Prostituierten. Es sei Pflicht des Gesetzes, die „unfortunate boys“ gegen die „unnatural lust of fullgrown men“ zu schützen. ${ }^{126}$ Somit schloss er sich dem Perspektivwechsel der liberalen Zeitungen an, welche die jungen Prostituierten als Opfer reicher Freier umdeuteten, und nicht als moralisch verdorbene Verführer. Diese Umdeutung junger Prostituierter war bereits in den 1880er Jahren durch die Kampagnen von Steads Pall Mall Gazette eingeleitet worden, der die Verbreitung von Kinderprostitution in London mit emotionalisierenden Beispielen spektakulär in die Zeitungen brachte. ${ }^{127}$ Bemerkenswerterweise übertrug dies nun selbst die Justiz auf die homosexuell anschaffenden Jungen.

Es ist bezeichnend für die britische Regierung, dass sie weiter die als homosexuell Beschuldigten Bordellbesucher deckte. Sowohl Premierminister Salisbury

123 Reynolds's Newspaper 29.9.1889. Vgl. zu dem Blatt selbst: Anne Humpherys, G.W.M. Reynolds: Popular Literature and Popular Politics, in: Wiener (Hrsg.), Innovators, S.3-21; Berridge, Popular Sunday Papers, S. 208.

124 An Stephenson 13.9.1889, in: TNA, DPP 1/95/1: 133.

125 Monro an DPP 1.10.1889 u. an Attorney General, in: TNA, DPP 1/95/1: 218 u. 221; Monro an Solicitor to the Treasury 5.10.1889, in: TNA, DPP 1/95/1: 225; an DPP 21.10.1889, in: TNA, DPP 1/95/1: 296.

126 Stephenson an AG 15.9.1889, in: TNA, DPP 1/95/1: 146-152; vgl. auch seine Beschwerde: DPP an Lushington/Home Office 17.10.1889, in: TNA, DPP 1/95/5: 157.

127 Hierzu ausführlich Kap. III.1. Vgl. zur Etablierung des Narrativs bereits: Walkowitz, City, S. 81-120. 
als auch Innenminister Matthews bemühten sich weiterhin mit allen Mitteln, einen Skandal zu verhindern und unterbanden konsequent die Ermittlungen von Justiz und Polizei. Schon bei den ersten Polizeimeldungen wiesen sie den Oberstaatsanwalt an, bis zu ihrer Absprache abzuwarten. Auch auf die Mahnung des Kronanwaltes, an Somersets Schuld bestehe kein Zweifel, legte Premierminister Salisbury ihm Zurückhaltung auf. ${ }^{128}$ Dann einigten sich Premierminister und Innenminister, zunächst nur gegen den Bordellbesitzer Hammond vorzugehen. ${ }^{129} \mathrm{Da}$ dieser aber bereits nach Frankreich geflohen war, beschloss Salisbury bereits im Juli und August 1889 zwei Mal, von der französischen Regierung keine Auslieferung zu beantragen. ${ }^{130} \mathrm{Da}$ Hammond zugleich der wichtigste Zeuge und Angeklagte war, erschien diese Entscheidung wie eine Tolerierung der Flucht durch die Regierung, um Aussagen über seine Kunden zu verhindern. Zudem vermied die Regierung so gegenüber den französischen Behörden das Eingeständnis, dass es auch in Großbritannien Homosexualität gab. Stattdessen schickte sie einen Inspektor von Scotland Yard zur Überwachung nach Paris. Aber auch hier erfolgte die Anweisung des Innenministeriums an den Oberstaatsanwalt, von dessen vertraulichen Berichten möglichst keinen Gebrauch zu machen. ${ }^{131}$ Ebenso ließen sie Somerset fliehen, der nach Deutschland reiste und hier völlig resignierte, als er über seinen Fall in der Pall Mall Gazette las. ${ }^{132}$ Dass diese Flucht durchaus dauerhaft sein konnte und sollte, deutete auch der Kronanwalt dem Premierminister an. ${ }^{133}$ Als Polizei und Justiz der Regierung berichteten, Somerset sei wegen eines Todesfalles wieder nach England zurückgekommen und könne nun verhaftet werden, lehnte der Innenminister dies mit dem Argument ab, es lägen nicht genügend Beweise vor. ${ }^{134}$ Die somit blockierte Polizei beschwerte sich intern frühzeitig, dies sei eine „conspiracy on the amount of certain persons to defeat the end of justice“135. Dagegen sah der für die Justiz zuständige Lord Chancellor eine weitere Verfolgung als „injury for public morals“, weshalb er davon absehen ließ. ${ }^{136}$ Gerechtigkeit vor

128 Dies wird deutlich aus: Webster an Salisbury 18. 9. 1889, in: NL Salisbury Hatfield House.

129 Lister/Foreign Office an Matthews 24.7.1889, in: TNA, DPP 1/95/1:13; Home Office an DPP 10. 8. u. 12.8.1889, in: ebd. 1:20 u. 22.

130, „...] Salisbury having decided that it is impossible to move the French Government in the question of the suggested surrender or expulsion of Hammond from France." Lushington/ Home Office an DDP 10.8.1889, in: TNA, DPP 1/95/1:40. Ebenso: [...] his lordship does not consider this to be a case in which any official application could justifiably be made to the French Government for assistance in surrendering the fugitive to this country." Lister/Foreign Office an Matthews/Home Office 24.7.1889, in: TNA, DPP 1/95/1.

131 Home Secretary an Stephenson/DPP 12.8.1889, in: TNA DPP 1/95/1.

132 „No one can describe my horror, read the [...] Pall Mall last night in the train." Somerset an Brett 14.9.1889, in: Churchill Archives Centre/Cambridge (CAC) ESHR Papers 12-3. Somerset schrieb Brett während seiner Flucht nahezu täglich.

133 „I do not think the person in question will face the enquiry." Webster an Salisbury 18. 9.1889, in: NL Salisbury, Salisbury Hatfield House.

134 Vgl. die zahlreichen Anfragen von 5. bis 14.10.1889, in: TNA, DPP 1/95/1: 245-270.

135 an DPP 21.10.1889, in: TNA, DPP 1/95/1: 296.

136 Lord Halsbury o.D.in: TNA, DPP 1/95/3: 23. 
Gericht und die Bewahrung adliger Reputation standen damit gegeneinander. Insgesamt ging die konservative Regierung somit bereits in dieser Phase ein bemerkenswertes Risiko ein, um durch die Blockade von Polizei und Justiz einen Skandal zu verhindern.

Zudem starteten vielfältige Bemühungen, die Königsfamilie direkt zu schützen. Damit weder der Prince of Wales noch sein Sohn und potentieller Nachfolger Prinz Albert Victor („Prinz Eddy“) in die folgenden Prozesse eingezogen werden konnten, blieben beide acht Monate im Ausland bei einer ausführlichen Indien-Tour. Dennoch machten sich Somersets Vertrauter Reginald Brett und Somersets Anwalt Newton vor dem Prozess Gedanken, wie man die Unschuld von Prinz Eddy („the person in India“) im Zweifelsfall vor Gericht beweisen könne. ${ }^{137}$ Denn innerhalb des Adels kam rasch das Gerücht auf, Lord Somerset habe verbreitet, dass er unschuldig sei und nur zum Schutz von Prinz Eddy geflohen sei, was Vertraute des Königs mit Zurückweisungen verfolgten. ${ }^{138}$ Zwei Vertraute des Königshauses fragten zudem frühzeitig bei der Polizei nach dem Ermittlungsstand und setzten sich bei ihr zunächst für Somerset ein. ${ }^{139}$ Ebenso trafen sie sich mit Premierminister Salisbury, um genaueres über die Verfolgung von Somerset zu erfahren, woraufhin Somerset die Flucht ergriff. ${ }^{140}$ Der Haftbefehl gegen Somerset wurde dann erst nach seiner Flucht und seiner ehrenhaften Entlassung aus der Armee ausgestellt, was eine klare Aufforderung an ihn war, für den Verzicht auf den Prozess dauerhaft im Ausland zu bleiben. Abermals war das Exil somit die eigentliche Strafe, die einen Skandal vermeiden sollte. An der Verhinderung eines Prozesses arbeitete auch Somersets Anwalt Newton, der den jungen Prostituierten und dem Bordellbesitzer Geld für ihre Flucht gab. Entsprechende Finanztransfers und Anweisungen wurden dabei über den Vertrauten Somersets und des Königshauses, Reginald Brett (der spätere Viscount Esher) abgewickelt. ${ }^{141}$ Trotz des rechtsstaatlichen englischen Regierungssystems wurden somit alle möglichen rechtlichen Schritte gezielt verhindert, um einen Skandal zu vermeiden. Der Leiter der Ermittlungen wehrte sich dagegen frühzeitig mit dem Argument, dass es zwar wichtig sei, den Skandal zu verhindern, es aber einen nur viel größeren Skandal geben würde, wenn die Vertuschung herauskomme. ${ }^{142}$ Dennoch fügte er sich unter Protest den politischen Weisungen der Regierungsspitze.

137 Newton an Brett 13.12.1889, in: CAC ESHR Papers 12-3.

138 Vgl. die zwei anonymen Schreiben an Brett, o.D., in: Churchill Archives/ Cambridge ESHR Papers 12-3; Probyn an Waterford 29.12.1889, in: ebd.

139 Cuffe an Lord Chancellor 16.10.1889 u. 18.10.1889, in: TNA, DPP 1/95/1: 283ff.

140 Somerset an Brett 17.10.1889 (5 pm); vgl. auch 16.10. und 17.10.1889 (morgens), in: CAC ESHR Papers 12-3.

141 Vgl. die Korrespondenz bes. ab 9.9.1889 in: CAC ESHR Papers 12-3. Obgleich eine umfangreiche Korrespondenz zwischen Brett und Somerset vorliegt, ging kein einziger dieser Briefe in die Briefedition von Brett (später Viscount Esher) ein, in: MAURICE V. BRETT (Hrsg.), Journal and Letters of Reginald Viscount Esher, Bd.1: 1870-1903, London 1934.

142 Stephenson an Home Secretary 31.8.1889 in: TNA, DPP 1/95/1:86. 
Tatsächlich entwickelte sich gerade aus diesen Vertuschungsversuchen der Regierung ein weiterer „sekundärer Skandal“, der sich um das unaufrichtige Verhalten der politischen Führung im eigentlichen Skandalfall drehte. In den Londoner Clubs war Somersets Flucht schnell bekannt. Nachdem die Journalisten dies zunächst nur mit Andeutungen aufgegriffen hatten, gab der radikale Abgeordnete Henry Labouchere in seiner Wochenzeitung The Truth den entscheidenden Anstoß. Laboucheres Blatt, das er seit 1877 betrieb, hatte zwar nur eine mittelgroße Auflage von rund 30000 Exemplaren, zog aber seine Bedeutung vor allem aus den gut informierten kritischen Enthüllungen, die es regelmäßig im Stile des New Journalism publizierte. ${ }^{143}$ In gewisser Weise entsprach es dem United Ireland, das im vorherigen Dublin Castle-Skandal ebenfalls aus seiner politischen Außenseiterrolle Sagbarkeitsgrenzen durchbrochen hatte. Labouchere veröffentlichte in seiner Zeitschrift den Vorwurf, der Innenminister blockiere die Ermittlungen in dem Skandal, toleriere die Flucht von Beteiligten und habe sie durch Warnungen sogar gefördert. Der Regierung warf er deshalb vor, ein „Government of the classes“ zu sein. Ohne die Namen von Somerset oder anderen zu nennen, drohte er dem Innenminister: „I warn Mr. Matthews that if he does not take action in this matter there will be a heavy reckoning when Parliament meets. " ${ }^{44}$ In den folgenden Ausgaben konkretisierte er seine Drohung: Er habe mit verschiedenen Abgeordneten gesprochen und werde auf eine Untersuchung bestehen, wenn die Regierung nicht ihr Handeln offen lege. ${ }^{145}$ Wie beim Dublin Castle-Skandal brachte somit eben nicht ein politisch unabhängiges Boulevardblatt die entscheidenden Vorwürfe auf, sondern journalitisch ambitionierte Politiker, die für kleine politische Blätter schrieben, die ihren Kurs vertraten. Die parlamentarische Kritik und Untersuchung wies damit erneut ein symbiotisches Verhältnis zur medialen Agitation auf. Und abermals begann der Skandal nicht mit einer expliziten Aufdeckung eines Normbruches, etwa in einer großen Schlagzeile, sondern mit einer erpresserischen Andeutung.

Laboucheres Anklagen förderten weitere kritische Berichte in der liberalen Presse. Die Pall Mall Gazette schloss sich direkt Laboucheres Warnung an den Innenminister an und mahnte, die Namen der Beteiligten seien „common talk“ in jedem Club. ${ }^{146}$ Dennoch nannte auch das vermeintliche Sensationsblatt Somersets Namen nicht. Erst die kleine radikale North London Press druckte sie am Tage darauf unter der Überschrift „The West-End Scandal: Names of some of the Distinguished Criminals who escaped“. ${ }^{147}$ Auch in den nächsten Tagen schrieb ihr Herausgeber Ernest Parke weitere Artikel zu dem Fall, die sein

143 Truth 14.11.1889. Eine plausible Charakterisierung des Blattes als Vorläufer des New Journalism gibt: Gary Weber, Henry Labouchere, Truth and the New Journalism of Late Victorian Britain, in: Victorian Periodicals Review, 26 (1993), S. 36-43; vgl. auch R. J. Hind, Henry Labouchere and the Empire 1880-1905, London 1972, S.3.

144 TRUTH 14.11.1889.

145 Truth 28.11.1889 und 12.12.1889.

146 Pall Mall Gazette 15.11.1889 und 20.11.1889.

147 North London Press 16.11.1889. 
Wissen offensichtlich aus Polizeiquellen und Regierungskreisen speiste. Anscheinend hatte die Polizei, gerade weil sie nicht weiter ermitteln durfte, dem Journalisten vertrauliche Hinweise gegeben. Parkes Artikel nahmen dementsprechend die Polizei in Schutz, da sie von oben blockiert worden sei, und verlangten eine parlamentarische Befragung des Innen- und Premierministers. ${ }^{148}$ Anscheinend konnte der Herausgeber Ernest Parke, der nebenbei auch für den Star schrieb, derartige Meldungen nicht in dem großen Massenblatt unterbringen. Obwohl der Star ebenfalls als „Sensationszeitung“ des New Journalism galt, hielt er sich zurück. ${ }^{149}$ Damit zeigte sich erneut, dass die Grenzen des $\mathrm{Pu}$ blizierbaren für die Massenpresse gerade beim Thema Homosexualität äußerst eng waren, obgleich offene Enthüllungen in solch einem Skandal sicherlich hohe Auflagen und Gewinne garantiert hätten.

Erneut erhielt der Skandal eine starke Dynamik durch einen Verleumdungsprozess. Da die North London Press noch einem anderen Adligen, Lord Euston, Bordellbesuche und eine anschließende Flucht ins Ausland vorgeworfen hatte, obwohl dieser in London geblieben war, klagte Euston gegen den Journalisten Parke wegen Verleumdung. Wie beim Dublin Castle-Skandal war diese riskante Reaktion die einzige Alternative zu seiner Flucht, da Stillschweigen öffentlich als Schuldeingeständnis gewertet worden wäre. Dieser Schritt förderte jedoch die ausführliche Veröffentlichung der Vorwürfe. Die Klage spornte zu zahlreichen weiteren Medienberichten an, der Prozess gab dem Journalisten eine öffentliche Bühne, und die Zeugenaussagen förderten eine öffentliche Wissensbildung, da der Prozess selbst in der regierungsnahen Presse explizite Berichte legitimierte. Nun schrieb sogar die Times unter Nennung von Somersets Namen über dessen Flucht und die Versuche, Zeugen mit Geld zur Flucht zu animieren. ${ }^{150}$ Die Verfolgung von Parke und sein Kampf mit der Regierung und Justiz machte den Journalisten außerdem prominent, was er zur Werbung für sein Blatt benutzte. ${ }^{151}$

Der plötzliche Ruhm des Journalisten beruhte jedoch nicht auf seiner Recherche. Vielmehr ließ der Fall ähnliche journalistische Arbeitsweisen erkennen wie der Dublin Castle-Skandal. Während die Artikel zunächst nur auf Gerüchten und einzelnen Hinweisen aus der Polizei aufbauten, recherchierte der Journalist zur Vorbereitung der Gerichtsverhandlung - wie im Dublin Castle-Prozess nicht selbst, sondern beschäftigte einen Privatdetektiv. Dieser machte zahlreiche Zeugen ausfindig, die Euston beim Besuch des Bordells gesehen hatten. Die

\footnotetext{
148 TRUTH 23.11.1889, S.5.

149 Die Grenzen der Berichterstattung des Stars betonte auch: LAUREL Brake, Government by Journalism and the Silence of the Star: Victorian Encounters 1885-90, in: Laurence Brake und Julie F. Codell (Hrsg.): Encounters in the Victorian Press. Editors, Authors, Readers, Basingstoke und New York 2005, S.213-235. Zum Star vgl.: John Goodbody, The Star: Its Role in the Rise of New Journalism, in: Wiener (Hrsg.), Papers, S.143-163, S. 148.

150 Times 24.12.1889, S. 10.

151 STAR 25.11.1889, S.4: „Buy it today. [...] West End Scandals Prosecution of the Editor for Libel of Earl of Euston."
} 
Prozesse förderten somit die investigative Recherche der Journalisten, die diese aber nicht unbedingt selbst übernahmen.

Der Prozess ermöglichte ein offeneres Sprechen über die homosexuelle Prostitution. Zahlreiche männliche Prostituierte und Anwohner sagten freimütig aus, so dass die gesamte Öffentlichkeit Details über das Bordellleben und die Homosexualität im Allgemeinen erfuhr. Abermals betonten verschiedene Zeitungen, vieles könne unmöglich wiedergegeben werden, und tatsächlich fanden sich viele explizite Gerichtsaussagen nicht in den Blättern. Dennoch lässt sich kaum die Annahme von Laurel Brake teilen, die Leser hätten, weil die Homosexualität nicht explizit genannt wurde, die Artikel kaum verstehen können und für Berichte über heterosexuelle Bordelle halten können. ${ }^{152}$ Vielmehr benutzten die Artikel seit langem eingeübte Codewörter, die durchaus eine Verständigung über Homosexualität ermöglichten. Hierzu zählten weiterhin Umschreibungen wie "abominable crimes“, „a felony of the most grave and attracious character" oder "heinous crimes revolting to one's notions of all that was decent in human nature“. Auch Laboucheres spätere Anklage gegen die Regierung sprach nur von „a certain offence - I will not give it a name. "153 Direkte Beschreibungen des sexuellen Aktes (wie "going to bed with gentlemen“154) fanden sich hingegen weiterhin selten. Das galt auch für visuelle Darstellungen. ${ }^{155}$

Ähnlich wie Steads berühmte Maiden-Tribute-Kampagne konstruierten die Skandalberichte zudem ein Wissen über den Alltag der in diesem Fall männlichen Prostituierten. Sie beschrieben etwa, wie sie Männer auf der Straße ansprachen und mit Stammkunden engere Beziehungen eingingen. Zudem erfuhren die Leser, dass anscheinend die Nachbarn des Hauses mit dessen Ruf vertraut waren und käufliche Homosexualität mitten in London tolerierbar erschien. Ein Prostituierter sagte sogar aus, die lokale Polizei habe keine Probleme gemacht. ${ }^{156}$ Käufliche Homosexualität erschien damit wie ein Alltagsphänomen der Metropole.

Für die öffentliche Konstruktion des Homosexuellen war bedeutsam, dass die Zeugen die Bordellbesucher als „Gentlemen“ bezeichneten, die mitunter mit der eigenen Kutsche vorgefahren seien. Obgleich die Freier, die in den Polizeiakten zu finden sind, kaum namentlich genannt wurden, verfestigte sich damit das Bild des reichen Homosexuellen, der gegen Geld arme Jungen missbrauchte. Laboucheres Reden im Unterhaus forderte ebenfalls Mitleid mit den ausgenutzten Jungen. „These poor and wretched creatures live to minister to the vices of those in a superior station“, klagte er und integrierte damit Prostitution und Homosexualität in sozialistische Gesellschaftsanklagen. ${ }^{157}$ Die liberale Presse benutzte in ihren Prozessberichten ebenfalls dieses Bild in einer geradezu klas-

152 BRAKe, Government, S. 220 u. 224.

153 28.2.1890, Hansard's Parliamentary Debates, 3rd Series, Bd.341, Sp. 1534.

154 Zit. in: Times 24.12.1889, S. 10.

155 Vgl. Illustrated Police News 18.1.1890, S. 1. u. 25.1.1890, S.1.

156 Vgl. bes. die Zeitungsberichte 15.1. u. 16.1.1890.

157 28. 2. 1890, Hansard's Parliamentary Debates, 3rd Series, Bd.341, Sp. 1548. 


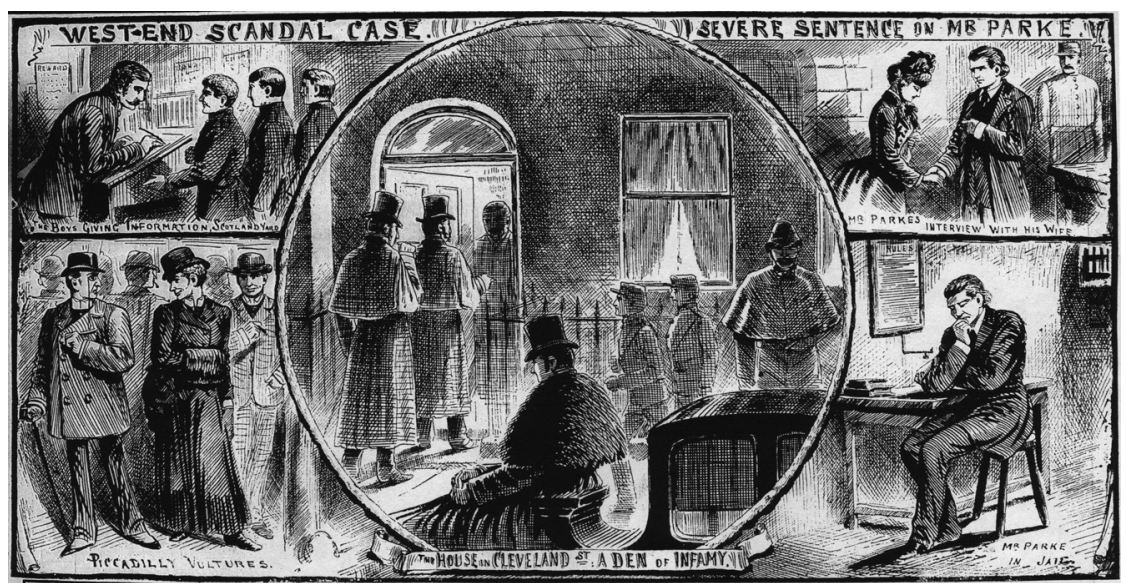

Abb. 1: Der "West-End Scandal" etablierte auch visuell das Bild des reichen Homosexuellen, der durch sein Geld arme Jungen korrumpiert und nicht bestraft wird (Mitte und links). Der Journalist Parke (rechts) muss dagegen für seinen Kampf in Haft und erbält so eine Märtyrerrolle; aus: ILLUSTRATED POLICE NEWS 25.1.1890, S.1.

senkämpferischen Abgrenzung gegenüber dem Adel und der Upper Class. Auch visuell wurde diese Deutung in der Illustrated Police News verfestigt, die reiche Besucher homosexueller Bordelle skizzierte. Entgegen ihrer sonstigen Verbrechensberichte wurden dagegen die männlichen Prostituierten als kultivierte Zeugen gezeichnet (vgl. Abb. 1). ${ }^{158}$ Die von vielen liberalen Zeitungen regelmäßig benutzte Überschrift „Westend Scandal“ verwies bereits geographisch auf die wohlhabenden Kreise Londons. ${ }^{159}$ Diese Formulierung etablierte sich soweit, dass selbst die offiziellen Parlamentsberichte sie als Überschrift wählten. ${ }^{160}$ Ebenso pauschalisierten Überschriften radikalliberaler Zeitungen die Anschuldigungen gegen die gesamte Aristokratie („Horrible Revelations about the Aristocracy“). ${ }^{161}$ Dass Somersets Anwalt dem Bordellbesitzer mit Geld die Flucht in die USA ermöglicht hatte und zumindest versuchte, die Prostituierten durch Erstattung von Transfers und Startkapital ebenfalls zur Ausreise zu bewegen, fügte sich in diese Korruptionsvorwürfe ein. Somit ging es nicht mehr um die Bestrafung von Homosexuellen, sondern um Gleichheit vor dem Gesetz.

Nicht thematisierbar war dagegen in der britischen Presse die Frage, welche Beziehung der Fall zum Königshaus habe. Selbst monarchiekritischen Blättern wie Reynolds's Nerespaper erschien dies offensichtlich beim Thema Homosexu-

158 Vgl. Illustrated Police News 18.1.1890, S.1. u. 25.1.1890, S.1.

159 DaIly News 7.1.1890, S.3; allgemein zum Zusammenhang zwischen Metropolenkultur und Homosexualität vgl. Cook, London.

160 Hansard's Parliamentary Debates, 3.3.1890, Bd.341, Sp. 1618.

161 Reynolds's Newspaper 12.1.1890, S. 5. 
alität zu heikel. Entsprechende Londoner Gerüchte über die Involvierung von Prince Eddy kursierten in gedruckter Form jedoch in der amerikanischen Presse. So fragte die New York Times, warum Prinz Eddy so lange in Indien bleibe und druckte das Gerücht, der Prinz solle in Indien bei der Jagd sterben, um seine spätere Thronbesteigung zu verhindern. Damit die englischen Zeitungen dies nicht aufgriffen, erfolgte im gleichen Blatt aber das anonyme Dementi, der Prinz habe nichts mit „,ertain abominable scandals“ zu tun. ${ }^{162}$

Auch das Londoner Gericht erwies sich kaum als eine unabhängige Instanz und deckte mit äußerstem Wohlwollen das Verhalten des Adligen. Trotz der zahlreichen Zeugenaussagen verurteilte es den Journalisten Parke zu zwölf Monaten Gefängnis wegen Verleumdung. Während es die Aussagen der Prostituierten und Nachbarn durchweg als unglaubwürdig abqualifizierte, vertraute das Gericht der Aussage Lord Eustons, das Haus nur einmal zufällig betreten zu haben, weil ihm eine Werbekarte dort „poses plastique“ versprochen habe, eine Vorform des Striptease. Der Richter begründete diese hohe Bestrafung des Journalisten mit dem exzeptionellen Charakter des Artikels: „I think that a more atrocious libel than that of which you have been guilty has never been published by any man in circumstances less justifiable than those in which you have published the libel."163 Einen Mann als homosexuell zu beschuldigen galt demnach als die schwerste Ehrverletzung überhaupt. Das Gericht begründete das Urteil zudem damit, dass es andere Publizisten von leichtfertigen Verleumdungen abschrecken sollte. Die liberale Presse protestierte entsprechend gegen das Urteil, die konservativen Zeitungen lobten es. Letztere sahen es ebenfalls als Warnung an alle Journalisten, die sich zum Richter aufschwängen und Verdächtigungen und Misstrauen ins öffentliche Leben tragen würden. ${ }^{164}$ Nach einer kurzeitigen breiten Empörung über die politischen Lager hinweg verfestigten sich damit wieder die politischen Grenzen.

Dieses unverkennbar parteiliche Urteil gegen den Journalisten förderte die letzte und politisch schwerwiegendste Eskalationsstufe des Skandals. Der radikalliberale Abgeordneten Henry Labouchere wandte sich nun über das Parlament an die Öffentlichkeit, um der Regierung die bewusste Vertuschung und Rechtsbeugung vorzuwerfen. Seine Enthüllungen im Unterhaus waren nicht spontan, sondern auf allen Ebenen vorher angekündigt, was die Aufmerksamkeit erhöhte. In seiner Zeitschrift The Truth hatte er seit November 1889 regelmäßig und zunehmend direkt Premierminister Salisbury und Innenminister Matthews vorgeworfen, die Ermittlung unterbunden zu haben: „The escape was immediately due to Lord Salisbury“, hieß es hier, und er verwies drohend auf die nächsten Unterhaussitzungen. ${ }^{165}$ Auch intern kündigte er etwa gegenüber

162 New York Times 10.11.1889, zit. in: Arolson, Prince Eddy, S.146; Hyde, Cleveland Street, S. $128 \mathrm{f}$.

163 Urteilsbegründung nach: DAILY NEws 16.1.1890, S.3.

164 Daily Telegraph 17.1.1890, S. 5.

165 Zit.Truth 6.2.1890; vgl. bes. auch Truth 2.1.1890, 30.1.1890. 
Reginald Brett, einem engen Vertrauen Somersets und des Königshauses, seine Enthüllungen genau an. Brett versuchte daraufhin vergeblich, Labouchere zu besänftigen, weniger unter Verweis auf Somersets Unschuld denn im Hinblick auf das Königshaus und Somersets Eltern. ${ }^{166}$ In dieser Phase löste sich der Skandal nahezu vollständig von den sexuellen Normkonflikten ab. Labouchere sprach in seiner langen Parlamentsrede am 28. Februar 1890, die den Fall minutiös rekonstruierte, fast überhaupt nicht mehr über die Homosexualität und ihre moralische Verwerflichkeit. Ihm ging es ausschließlich darum zu belegen, dass der konservative Premierminister Salisbury gezielt laufende Ermittlung verhindert habe, um vor allem die Flucht von Somerset zu ermöglichen. So sprach er direkt von einer „criminal conspiracy, by the very guardians of public morality and law, with the Prime Minister at their head, to defeat the ends of justice."167 Vor allem deckte er auf, dass Salisbury sich mit Somersets Freund Dighton Probyn über den bevorstehenden Haftbefehl ausgetauscht habe und so dessen Flucht und vorherige ehrenhafte Entlassung aus der Armee ermöglicht habe. Die Prostituierten hätten wegen eines „corrupt bargain“ geringe Strafen erhalten, damit sie schwiegen. Aus diesem Grunde verlangte er die Einsetzung eines Untersuchungsausschusses.

Auch diese Parlamentsrede stand für eine Veränderung der politischen Kommunikation. Mit den Vorwürfen, die den Premierminister der Lüge bezichtigten, durchbrach Labouchere eindeutig die ungeschriebenen Regeln des Unterhauses, die sich im Unterschied zu Deutschland durch rhetorische Höflichkeit und Akzeptanz des Ehrenwortes auszeichneten. Bereits der Kronanwalt entgegnete in seiner Antwort im Parlament, „more infamous conduct was never charged against persons in authority. "168 Beide Seiten verweigerten die Kommunikation: Während Labouchere im Unterhaus erst die Nennung seines Hauptinformanten ablehnte, waren die Konservativen nicht bereit, die von ihm angebotene schriftliche Nennung zu verlesen. Als Labouchere auch auf Nachfrage nicht Salisburys Unschuldsbeteuerung glaubte, wurde er für einige Wochen des Parlaments verwiesen. Die Medienöffentlichkeit blieb über sein Verhalten gespalten: Die konservative Presse bezeichnete seine Zweifel am Wort des Premierminister als „gravest charges“ und „worse than murder“, während liberale Blätter wie der Star Laboucheres Indizien überzeugend fanden, gegen seinen Ausschluss protestierten und ihm durch Interviews ein Forum gaben. ${ }^{169}$

Der Skandal brach damit nicht nur die Sagbarkeitsregeln der Medien auf, sondern auch die des Parlaments. Die sich anschließende Debatte drehte sich

166 Labouchere an Brett 1.2.1890 und 21.2.1890, Brett an Labouchere 6.2.1890 in: CAC ESHR Papers 12-3.

167 Vgl. die Debatte in: 28.2.1890, Hansard's Parliamentary Debates, 3rd Series, Bd. 341, Sp. 15341611, zit. Sp. 1546.

168 So der Attorney General Webster in: Hansard's Parliamentary Debates, ebd., Sp. 1552.

169 Vgl. Daily Telegraph 1.3.1890, S.4; Times 1.3.1890, S.8; The Star 1.3.1890, S.1; Pall Mall Gazette 1.3. bis 3.3.1890, S. 1. Zum Ausschluss: Hansard's Parliamentary Debates, 3rd Series, Bd.341, Sp. 1570. 
ebenfalls fast ausschließlich um die Frage, ob der Premierminister tatsächlich die Wahrheit sage und ob es zulässig sei, sie anzuzweifeln. Salisbury gab klugerweise seine Replik erst einige Tage später im Oberhaus, wo inmitten der Adligen mehr Rückendeckung zu erwarten war. Auf Somerset spielte er nur vorsichtig an, ohne dessen Namen zu nennen. ${ }^{170}$ Der Premierminister gab aber zu, bei dem Treffen mit dem Vertrauten Somersets über die Verhaftung gesprochen zu haben, aber nur über Gerüchte über neue Beweise. Sowohl die Zeitgenossen als auch die Historiker haben vielfach gemutmaßt, ob der Premierminister in dieser Krise tatsächlich Parlament und Öffentlichkeit belogen hat. ${ }^{171}$ Die Archivquellen belegen, dass Salisbury sich in der Tat im hohen Maße am Schutz von Somerset beteiligte. Wie die regelmäßigen Briefwechsel zwischen Somerset und Brett zeigen, wusste Somerset sogar vorher von dem vermittelnden Treffen zwischen seinem Freund und Salisbury, dem er ängstlich entgegenfieberte. ${ }^{172}$ Salisbury ließ in dem Gespräch, das Somerset das Exil nahelegte, jedoch offen, ob ein Haftbefehl folgen würde. So schrieb Somerset kurz nach seiner Flucht aus Frankreich: „You say Salisbury will see about the warrant - has he been approached on the subject? I am awfully grateful to my friends." 173 Deshalb bot Somerset aus Frankreich an, im Falle seiner Rückkehr ein zurückgezogenes Leben als Pferdezüchter auf dem Land zu führen. ${ }^{174}$ Mit dieser Protektion und dem falschen Ehrenwort war der Premierminister ein großes Risiko eingegangen, das ihm aber anscheinend nötig erschien, um den Ruf von Monarchie und Adel zu schützen. In gewisser Weise wurde Lord Somerset, der den Rest seines Lebens im Exil verbringen musste, dafür geopfert, damit die Empörung über die Homosexualität des hohen Adels abebbte und vor allem nicht das Königshaus erreichte. Ein weiteres Motiv für Salisburys Protektion war vermutlich, dass der Vater von Somerset, der Duke von Beaufort, ein wichtiger Tory und politischer Unterstützer von Salisbury war. ${ }^{175}$

Innerhalb der Regierung und der Bürokratie löste bereits die Frage Panik aus, wie ein oppositioneller radikaler Politiker und Journalist an Informationen über die vertraulichen Gespräche und Briefe des Premierministers kommen konnte. Da Justiz und Polizei sofort bemerkten, dass Laboucheres Anklagen auf internen Informationsquellen beruhten, prüften sie seine Aussagen Satz für Satz auf

170 Hansard's Parliamentary Debates Bd.341, Sp.1618. In seiner Rede, die die Presse ausführlich verbreitete, sprach er nur von einer Person „whose name it was unnessecary to mention“; Pall Mall Gazette 3.3.1890, S. 7.

171 Dass Salisbury Somerset so indirekt zur Flucht verhalf, vermutet die grundlegende Biographie mit einer knappen Andeutung: Andrew Roberts, Salisbury. Victorian Titan, London 1999, S. 546; das Gegenteil nimmt an: Hyde, Cleveland Street, S. 220. Keine Erwähnung findet der gesamte Fall, obgleich er für Salisburys Karriere äußerst kritisch war, in: DAvid STEELE, Lord Salisbury. A Political Biography, London 1999.

172 Somerset an Brett 17.10.1889 (5 pm) in: Churchill Archives/Cambridge ESHR Papers 12-3.; vgl. auch die Briefe 16.10. und 17.10.1889 (morgens), in: ebd.

173 Somerset an Brett 24.10.1889, in: CAC ESHR Papers 12-3.

174 Somerset an Brett 21.10.1889, in: ebd.

175 Roberts, Salisbury, 1999, S. 546. 
ihre Herkunft. Das umfangreiche Dossier, das sie aus seiner Rede erstellten, verwies auf einzelne interne Briefwechsel, die Labouchere offensichtlich kannte. ${ }^{176}$ Hinter dieser aufwendigen Arbeit stand offensichtlich die Angst, radikale Journalisten und Politiker könnten durch „Lecks“ interne Geheimnisgrenzen aufbrechen und so weitere Skandale auslösen. Zu einer offiziellen Untersuchung der Vorwürfe kam es dagegen nicht: Im Unterhaus wies der Kronanwalt Laboucheres Vorwürfe zurück und die konservative Mehrheit verhinderte die Einsetzung eines Untersuchungsausschusses.

In der Öffentlichkeit berichteten alle Zeitungen über Laboucheres Vorwürfe. In dieser letzten Stufe des Skandals verhandelte die Öffentlichkeit jedoch kaum noch das ursprüngliche Thema Homosexualität. Vielmehr ging es nun nahezu ausschließlich um die Integrität von Regierung und Justiz, um den Stil der parlamentarischen Beschuldigungen sowie um die Frage, wer Labouchere die Informationen dafür gegeben habe. Alle diese Punkte debattierten Vorstellungen über das britische Regierungssystem und zeigten damit, wie sehr sich der ursprünglich recht unpolitische Homosexuellenprozess $\mathrm{zu}$ einem politischen Skandal entwickelt hatte. Klassenspezifische Strafen, die Beeinflussung der Justiz durch die Exekutive und die Stellung des Premierministers, der vermutlich Parlament und Öffentlichkeit belogen hatte, waren dabei die zentralen Normkonflikte. Die öffentlichen Kommentare verwiesen vielfach auf andere Skandale, die nicht Homosexualität thematisierten. Am häufigsten war dabei der Verweis auf den Parnellism and Crime-Skandal, bei dem die Times Parnell mit gefälschten Briefen eine Verbindung zu Terroristen vorgeworfen hatte, weshalb eine Royal Commission eingesetzt worden war. So argumentierte auch Labouchere im Parlament, dass für konservative und irische Spitzenpolitiker ein unterschiedliches Recht gälte. ${ }^{177}$ Auch die Iren erneuerten die Anklagen unter Verweis auf Lord Salisburys Verhalten in diesem Skandal einige Jahre zuvor. ${ }^{178}$ Nachdem Labouchere des Parlamentes verwiesen worden war, nahmen sie sich verstärkt des neuen Skandals an und verglichen die tolerierte Flucht mit der scharfen Verfolgung der irischen Nationalisten. ${ }^{179}$ Auf diese Weise überführten die Iren die Klage gegen die soziale Klassenjustiz in eine Kritik an einer imperialen Klassenjustiz.

Der Skandal erweiterte die Sagbarkeitgrenzen über Homosexualität, verfestigte das Bild des reichen Homosexuellen und etablierte das Mitleid mit jungen männlichen Prostituierten. Dennoch trug er nicht zur Liberalisierung der Homosexualität bei. Kritik an einer Bestrafung von Homosexuellen erhob sich kaum. Eine gewisse Ausnahme bildete der Schriftsteller Bernhard Shaw, der mit einem Leser-

\footnotetext{
176 Vgl. die handschriftlichen Kommentare (wie „who told him?“) an den Zeitungsartikeln in: TNA, DPP 1/95/2: 110; die Zusammenstellung in: Cuffe an Smith März 1890, in: TNA, DPP 1/95/6: 2-48.

177 Zum Parnellism and Crime-Skandal vgl. ausführlich Kap. V.1.

178 So MacNeil im Unterhaus: Times 6.3.1890, S.7.

179 Vgl. Hansard's Parliamentary Debates, 3rd Series, Bd.341, Sp.1573-1611.
} 
brief an Laboucheres Zeitschrift Truth gegen Gesetze protestierte, die zwei erwachsene Menschen wegen eines „private act“ verurteilten, der nur sie etwas angehe und in Geschichte und Gegenwart stets bei einer Minderheit üblich gewesen sei. ${ }^{180}$ Laboucheres Blatt druckte selbst diesen Brief nicht ab. Denn schließlich war der radikale Politiker mit dafür verantwortlich gewesen, dass 1885 das Gesetz zur Bestrafung von Homosexualität präzisiert worden war.

Die personellen Konsequenzen des Skandals lassen sich nicht ganz eindeutig bewerten. Premierminister Salisbury konnte zwar seinen Posten vorerst behalten, war aber durch die Beschuldigungen angeschlagen. Salisburys Verwicklung in diesen und andere Skandale dürfte zumindest mit dazu beigetragen haben, dass die Tories die Wahl im folgenden Jahr verloren. Allerdings konnte Salisbury 1895 wieder für sieben Jahre in die Downing Street zurückkehren. Die Mythenbildung um die homosexuelle Orientierung des potentiellen Thronfolgers Prince Eddy, der zwei Monate nach Abklang der Debatte wieder aus Indien zurückkam, konnte Salisbury ebenfalls nicht verhindern. Das Königshaus bemühte sich umgehend um die Verheiratung des 27-jährigen Prinzen, um die moralische Ordnung herzustellen. Nur ein Jahr später verstarb er jedoch plötzlich an einer Grippe, was wiederum das Gerücht beförderte, er sei vergiftet worden, um einen Thronfolger mit einem derartig ausschweifenden Sexualleben zu verhindern. Da sein Vater sofort die Vernichtung seiner Korrespondenz anordnete, lässt sich die Frage, ob der Prinz ebenfalls mit Jungen aus dem Bordell verkehrte, weiterhin nur spekulativ beantworten. ${ }^{181}$

Die beteiligten Journalisten gingen langfristig gestärkt aus dem Skandal, auch wenn er ihnen kurzzeitig schwere Belastungsproben auferlegte. Die North London Press wurde mit Parkes Verurteilung und Haft eingestellt. Langfristig war Parkes offensives Auftreten und seine Berühmtheit, die er durch den Skandal erlangte, für seine journalistische Karriere jedoch von Vorteil: Parke stieg nach seiner Freilassung sogleich zum Editor des Star auf und wurde dann Gründer und Herausgeber des Morning Leader. Henry Labouchere durchlitt zunächst die versteckte Rache seiner nunmehr zahllosen Gegner, die ihn nach heutigem Sprachgebrauch hinterhältig „mobbten“: Sie bestellten Leichenwagen und Einäscherungen für ihn, Luxusgüter an seine Adresse und angebliche Einladungen und Geschenke in seinem Namen. ${ }^{182}$ Besonders schwer traf ihn, dass er 1892 nicht im Kabinett Gladstone berücksichtigt wurde, obwohl er zu den profiliertesten und bekanntesten liberalen Abgeordneten zählte. Offensichtlich hatte Premierminister Gladstone Angst, Labouchere würde nach seinen Beschuldigungen zu sehr polarisieren. Auch die Zustimmung der Queen erschien nach dem Skandal unsicher. Im Parlament blieb Labouchere jedoch bis zum Anfang

180 Shaw an Truth 26.11.1889, abgedr. in: Dan Laurence (Hrsg,), Bernhard Shaw. Collected Letters, Bd.1: 1874-1897, London 1965, S.230f.

$181 \mathrm{Vgl}$. auch die abgewogenen Vermutungen in der bislang ausführlichsten Darstellung: Aronson, Prince Eddy, S. 185-216.

182 Algar Labouchere Thorold, The Life of Henry Labouchere, London 1913, S. 368. 
des neuen Jahrhunderts äußerst aktiv und profilierte sich als einer der wichtigsten Sprecher.

Auch für die „Skandalopfer“ waren die Folgen ambivalent. Während Lord Somerset bis an sein Lebensende im Ausland bleiben musste, konnte Lord Euston anscheinend wieder gesellschaftliche Akzeptanz gewinnen, obwohl er zumindest zugegeben hatte, das Bordell wegen der vermuteten „Poses Plastique“ aufgesucht zu haben. ${ }^{183}$ Dies zeigte, dass ein Freispruch mit Rückendeckung in den konservativen Medien selbst bei vermuteter Homosexualität zur Wiederherstellung der männlichen Ehre dienen konnte. Für Somersets Anwalt, der sich durch seine Fluchthilfe klar der Rechtsbeugung schuldig gemacht hatte, setzten sich zahlreiche Londoner Anwälte mit einer Unterschriftenpetition ein, und tatsächlich kam er mit einem milden Urteil davon. ${ }^{184}$ Er machte eine Karriere als Staranwalt für prominente Fälle. Eine gewisse Bedrohung blieb der Bordellbesitzer Hammond, der sich zehn Tage nach Laboucheres Rede über ein Interview im New York Herald meldete und sensationelle Enthüllungen ankündigte, vermutlich um Geld zu erpressen. ${ }^{185}$ Gerade hier zeigte sich die Transnationalisierung der Medienlandschaft: Selbst ein in die USA geflüchteter Zuhälter konnte indirekt über die amerikanische Presse mit den britischen Politikern kommunizieren und diese vor massive Probleme stellen.

In gewisser Weise stand der Skandal schließlich für eine Verkehrung der kulturellen Topographie Londons. In den 1880er Jahren hatten die Flaneure und „Social Explorer“ das Londoner East End wie eine fremde Welt entdeckt und mit voyeuristischer Neugier dessen Sexualität öffentlich thematisiert. Das East End erschien hier als ein exotisches Gebiet, in der die bürgerlichen Regeln keine Gültigkeit hatten. ${ }^{186}$ Mit dem Cleveland Street-Skandal drehte sich diese Perspektive um. Er machte öffentlich, dass mitten in London, reiche Bewohner des Westens moralische Normbrüche begingen, die vielleicht noch spektakulärer erschienen als Steads berühmte Artikel über die Kinderprostitution im East End. Nicht die armen Prostituierten erschienen allerdings im Zuge des Skandals als Bedrohung, sondern adlige und wohlhabende Homosexuelle, die mittellose Jungen durch ihr Geld verführten und dabei noch durch die Regierung gedeckt wurden. Homosexualität war damit wie beim irischen Skandal vor allem ein Thema, um über die Medien moralisch politische Machtkonstellationen zu attackieren. Die Skandale machten Homosexualität thematisierbarer, führten aber gerade nicht zu mehr Toleranz. Vielmehr nahm zumindest in London die Zahl der Verurteilungen wegen Homosexualität nach 1891 überproportional zu. ${ }^{187}$

183 So die Einschätzung von: Chester et al., The Cleveland Street, S. 220; Hyde, Cleveland Street, S. 245 .

184 Vgl. zu Newton von rechtshistorischer Seite: Martin Dockray, The Cleveland Street Scandal 1889-1890. The Conduct of the Defence, in: Journal of Legal history 17 (1996), S.1-16.

185 Reynolds's Newspaper 9.3.1890, S. 4.

186 Vgl. Walkowitz, City, S. $10 \mathrm{f}$.

187 Vgl. die Statistik in Cook, London, S.151. Die eingangs genannte Kontinuität pro Einwohner bezog sich dagegen auf landesweite Berechungen. 


\section{GRENZZIEHUNGEN UM 1900}

Durch die beiden großen Skandale der 1880er Jahre etablierten sich Konfliktmuster für weitere Homosexualitätsskandale. Alle entsprechenden Enthüllungen nach 1890 waren sich dieser Präzedenzfälle bewusst. In der Tradition des Dublin Castle-Skandals standen bereits, nur ein Jahr nach dem Cleveland StreetSkandal, die Vorwürfe gegen den Abgeordneten Edward Samuel Wesley de Cobain, welche die Iren und die Radikalliberalen nun zusammen erhoben. Dabei verknüpften sie abermals das Bild des homosexuellen Besatzers und des unmoralischen Konservativen, der von der Regierung geschützt würde. Die Interaktion zwischen der Presse und den beteiligten Politikern erinnerte an frühere Skandale und war ein erneuter Versuch, die irische Unabhängigkeit durch eine moralische Diskreditierung zu erreichen, da dies eine größere öffentliche Aufmerksamkeit versprach als konkrete Vorschläge zur „Home Rule“.

Der Fall Cobain machte wie bislang kein Skandal deutlich, dass auch aktive Politiker homosexuell sein konnten. In diesem Fall erfuhr der Methodist Cobain, der für die Konservativen den Wahlkreis East Belfast vertrat, im April 1891 von einem Bericht in einer irischen Lokalzeitung, der einen bevorstehenden Haftbefehl wegen Homosexualität andeutete. Wie die früheren Skandalopfer floh auch Cobain sofort nach Frankreich und Italien, bevor anschließend der Haftbefehl erfolgte. ${ }^{188}$ Erneut ergriffen der radikale Politiker und Journalist Henry Labouchere und der irische Politiker und Journalist Tim Healy die öffentliche Initiative und machten den Fall zu einem Politikum, das sich gegen die Konservativen richtete. Damit wurde deutlich, dass sich im Unterhaus Experten für derartige Enthüllungen etabliert hatten. Sowohl der Irlandkonflikt als auch die Gleichheit vor dem Gesetz bildeten wieder die Hauptargumentationslinien. Und abermals drehte sich die Skandalisierung zunächst darum, das tabuisierte Vergehen möglichst explizit in eine breite Öffentlichkeit zu bringen. Healy forderte die Einsetzung einer Special Commission, was die konservative Mehrheit verhinderte. Um das Thema publik zu machen, fragte Healy zudem die Regierung dezidiert, weshalb genau der Haftbefehl ausgestellt worden sei und wer noch verwickelt wäre. Damit zwang Healy die Regierung, die dann in allen Zeitungen abgedruckte Aussage zu machen, einer ihrer Abgeordneten würde „for the offence of inciting to the commission of the felony" steckbrieflich gesucht. 189 Indem er Cobain als „Grand Master of the Orange Lodge“ bezeichnete, markierte er ihn als wichtigen Irengegner.

188 Pall Mall Gazette 17.6.1891, S. 5; Times 2.5.1891, S. 9, 10.6.1891, S. 6 und 15.6.1890, S. 10. $\mathrm{Da}$ zu diesem Fall keine Akten ausfindig gemacht werden konnten, erfolgt seine Rekonstruktion über die Medien- und Parlamentsberichte zwischen April und Juli 1891 und Februar 1892.

189 Hansard's Parliamentary Debates 20.4.1891 u. 21.4.1891, Bd.352, Sp. 926 u. 1026; ebd. 8.5.1891, Sp. 365. Auch der irische Unionist Colonel Saunderson fragte dabei nach dem Haftbefehl. Vgl. zur öffentlichen Rezeption von Healys Agitation auch Times 21.4.1891, S.6, Times 22.4.1891 und 9.5.1891, S. 8 . 
Spezifisch an dem Fall war zweierlei. Zum einen kommunizierte der beschuldigte Politiker nach seiner Flucht über die Medien mit der Öffentlichkeit und den Politikern im Parlament. Mehrfach schickte er rechtfertigende Briefe an vertraute Politiker, die diese dann den Zeitungen überreichten. Cobain selbst sah sich in diesen öffentlichen Briefen aus dem Exil als Opfer lokaler Belfaster Intrigen. Wegen seiner Aussagen zum Polizeieinsatz bei den Belfaster Aufständen 1886 hätte er sich unbeliebt gemacht, weshalb sie jetzt seinen Erpressern glaubten. ${ }^{190} \mathrm{Da}$ er nervlich zerrüttet sei, müsse er sich aus gesundheitlichen Gründen im Ausland aufhalten und sei nicht reisefähig. Öffentlich unterstützt wurde Cobain dabei durch Resolutionen der Belfaster Independent Conservative Association, die ihren festen Glauben an seine Unschuld den Medien versicherte. ${ }^{191}$ Die öffentliche Aufmerksamkeit, die Cobain und seine Anhänger durch diese mediale Rechtfertigung auf sich zogen, hatte jedoch einen gegenteiligen Effekt. Sie verhinderte gerade eine Beilegung des Falles.

Zum anderen war die gerichtliche Verfolgung eines geflohenen Abgeordneten ein Novum. Im Unterschied zu anderen Fällen verhinderte sie die sonst übliche stille Tolerierung der Flucht und machte eine Debatte über seine weitere Mitgliedschaft im Unterhaus erforderlich, wodurch die Liberalen und Iren den Skandal in der Öffentlichkeit hielten. Nachdem Cobain eine vom Parlament gesetzte Frist bis zu seiner Rückkehr verstreichen ließ, stimmte die konservative Regierungsmehrheit ein halbes Jahr später Cobains Ausschluss zu. Wie Arthur Balfour in seiner Rede betonte, sahen die Konservativen hierin keine Entscheidung über seine Schuld, sondern beschlossen dies offiziell nur, weil Cobain wissentlich trotz des Strafbefehls wegen "gross and criminal acts of indecency" weder in sein Land noch in das Parlament zurückkehre. ${ }^{192}$ Da dies erst der zweite Ausschluss in der Geschichte des Unterhauses war, führte der Fall zu einer grundsätzlichen Debatte, wie hierbei zu verfahren sei. Im Vergleich zu den vorherigen Skandalen erreichte der Fall Cobains insgesamt jedoch trotz dieser Diskussionen keine derartige öffentliche Bedeutung, da es durch seine Flucht zunächst zu keinem Prozess kam, der entsprechende Details hätte ausbreiten können. Erst zwei Jahre später wurde Cobain verhaftet und zu einem Jahr Gefängnis verurteilt. Allerdings hatte der Fall nun keine politische Prominenz mehr. ${ }^{193}$ In gewisser Weise lässt sich von einem verschleppten Skandal sprechen, dem ein Kulminationspunkt mit umfassenden Enthüllungen fehlte.

Der Skandal um den Abgeordneten verstärkte erneut die Vorstellung, Homosexualität würde sich besonders in den Oberschichten zunehmend verbreiten, weshalb verstärkt gegen sie vorzugehen sei. Nur vor dem Hintergrund der dargestellten Skandale ist auch der berühmte Fall von Oscar Wilde zu verstehen, dem heute wohl bekanntesten Skandal der viktorianischen Ära. Da er bereits

\footnotetext{
190 Pall Mall Gazette 17.6.1891, S. 5.

191 Times 15.5.1891, S.7.

192 Hansard's Parliamentary Debates 26.2.1892, Bd.1, Sp. $1401 \mathrm{f}$.

193 Dennoch finden sich Prozessberichte; vgl. Times 21.3.1893 und 22.3.1893, S. 10.
} 
vielfältig untersucht wurde, ist eine ausführliche Darstellung verzichtbar. ${ }^{194} \mathrm{Zu}$ dem war er nicht im engeren Sinne politischer Natur. Sein Verlauf lässt sich dennoch als Ergebnis der Deutungen und politischen Implikationen der vorherigen Skandale erklären. So war seine öffentliche Wahrnehmung maßgeblich durch den Cleveland Street-Skandal und die hier etablierten Narrative geprägt. Bereits Wildes Schlüsselroman „The Picture of Dorian Gray“ verstanden die Zeitgenossen in diesem Kontext. So hieß es in einer der vernichtenden Kritiken, Wilde schreibe für "outlawed noblemen and perverted telegraph boys. "195 Ähnlich wie bei den vorherigen Skandalen konstruierten seine insgesamt drei Prozesse von 1895 erneut das Bild des reichen Homosexuellen, der aus seinem Müßiggang heraus arme Jungen verführt und prostituiert.

Dieses Narrativ wurde in der populären radikalen Presse entsprechend politisiert. Das Massenblatt Reynolds's Newspaper bezeichnete im Zuge des WildeSkandals Homosexualität als „a common practice of our leisured and cultured class" und belegte dies mit einer knappen Erinnerung an die dargestellten Skandale der letzten Jahrzehnte. ${ }^{196}$ Direkt neben den Wilde-Artikeln druckte es zudem Berichte über andere gleichzeitige Homosexualitätsfälle und bediente sich einer weitaus expliziteren Sprache, die direkt von „male prostitution“ oder „sex“ sprach. ${ }^{197}$ In der radikalen Sonntagszeitung erschien London nun als Ort der zunehmenden homosexuellen Überwältigung und die Gegenwart insgesamt als „immoral revolution“, was die Polizei aber wegen des Reichtums der Homosexuellen toleriere. Der Schutz der Jugend gegen die homosexuellen „Corrupter of the Youth" stand dementsprechend auch im Vordergrund der öffentlichen Debatte. ${ }^{198}$

Dabei kam es zumindest in der linksliberalen Presse zu einer weiteren Umdeutung der Ursachen für Unmoral. Während die bürgerlichen Sozialreformer der 1880er Jahre Armut und schlechte Bildung als Grund für mangelnde Moral angesehen hatten, wurden im Kontext des Wilde-Skandals die teuren und männerbündischen Privatschulen und Universitäten als Quelle der Homosexualität gesehen. So kommentierte Reynolds's Newspaper: „Innocent lads, with the purity and refinement of home life in their hearts, become tainted with the traditional vices of these [public] schools and colleges before they have been many months within their walls. "199 Zahlreiche Leserbriefe bestätigten dies in den

194 Aus der umfangreichen Literatur vgl. etwa: NeIL McKenna, The Secret Life of Oscar Wilde, London 2003; Michael S. Foldy, The Trials of Oscar Wilde. Deviance, Morality, and LateVictorian Society, New Haven und London 1997. Als Quelle jetzt sogar übersetzt: MERLIN Holland, Oscar Wilde im Kreuzverhör. Die erste vollständige Niederschrift des Queensberry-Prozesses, München 2003.

195 Zit. nach Hyde, Cleveland Street, S. 240. In Verbindung mit dem Cleveland Street-Skandal sieht auch die neuere Literatur den Fall Wilde; vgl. Kaplan, Sodom, S. 224-251.

196 Vgl. bes. Reynolds's NewsPaper 26.5.1895, S. 1.

197 Reynolds's Newspaper 14.4. und 28.4.1895, S. 1; 5. 5.1895, S. 8.

198 Vgl. auch Weeks, Sex, Politics and Society, S. 107.

199 Reynolds's Newspaper 14.4.1895, S. 1. 
Ausgaben der folgenden Wochen. Hier berichteten ehemalige Schüler erstaunlich offen über das Masturbieren in Privatschulen, bezeichneten sie als „hot-bed of vice" und warnten aus ihren eigenen homosexuellen Erfahrungen heraus vor Privatschulen. ${ }^{200}$ Leserbriefe über den homosexuellen Verkehr an Oxforder Colleges ergänzten dies. Selbst wenn diese Zuschriften erfunden waren, überführte das Blatt so die Empörung über Oscar Wildes Homosexualität in eine grundsätzliche politische Debatte über das plutokratische und geschlechtergetrennte Bildungssystem. Zugleich erklärte Reynolds's Newspaper Homosexualität wie im Cleveland Street-Skandal aus der Dekadenz der Oberschicht heraus, die wie in Griechenland, Rom oder Frankreich stets den Niedergang einer Führungsschicht angezeigt habe. 201

Von seinem Verlauf her unterschied sich der Fall Wilde von den meisten Homosexualitätsskandalen im 19. Jahrhundert. Denn im Unterschied zu allen skizzierten Fällen wurde Wilde zunächst weder von der Presse noch von der Justiz der Homosexualität beschuldigt. Lediglich eine Karte des Marquis of Queensberry, dem Vater von Wildes Liebhaber Lord Alfred Douglas, bezeichnete Wilde als „sodomite“. Wilde wählte jedoch im Unterschied zu den meisten vorherigen Skandalen nicht die Flucht auf den Kontinent, die problemlos möglich gewesen wäre, sondern klagte gegen Queensberry wegen Verleumdung. Vielleicht machte die erfolgreiche Verleumdungsklage, die Lord Euston im Cleveland Street-Skandal gelungen war, auch Wilde Hoffnung auf eine ähnliche Protektion vor Gericht. ${ }^{202}$ Erst der von Wilde initiierte Prozess überführte den Vorwurf in die breite Medienöffentlichkeit und produzierte wieder jene detaillierten Aussagen von Zeugen, die erneut privat eingestellte Detektive ausfindig machten. Queensberrys Detektive spürten dabei gut ein Dutzend männliche Prostituierte auf, mit denen Wilde und seine mit angeklagten Freunde verkehrt haben sollten. Damit knüpfte der Fall nahtlos an den Cleveland Street-Skandal an und schien ihn zu wiederholen. Die erneut aufgezeigte intime Verbindung zwischen armen und reichen Männern verunsicherte die bürgerlichen Zeitungen ebenso wie der Umstand, dass gerade hochgebildete und verheiratete Männer der Oberschicht homosexuell seien. Dass der Richter diesmal für Wilde und den mit angeklagten Alfred Taylor die Höchststrafe von zwei Jahren Haft mit harter Arbeit verhängte, ist nicht zuletzt ebenfalls als ein Ergebnis der vorhergehenden Skandale zu bewerten. Das Urteil sollte nach der Flucht von Somerset und Cobain den Ruf der Polizei und der Justiz wiederherstellen, öffentlich abschrecken und die Grenzen des Tolerierbaren nach den politisch bedingten milden Urteilen neu abstecken.

200 Vgl. Reynolds's Newspaper 21.4. bis 2.6.1895, vgl. bes. 21.4.1895, S.5; 25.5.1895, S.3; 2.6.1895, S. 3 .

201 Reynolds's Newspaper 21.4.1895, S. 1.

202 Auch einige Zeitgenossen gingen von einem Sieg Wildes gegen den exzentrischen Lord aus und sahen dessen Sieg als Überraschung; vgl. Tagebuch Hamilton 4. und 5.4.1895, in: DAvid Broокs (Hrsg.), The Destruction of Lord Rosebery. From the Diary of Sir Edward Hamilton 1894-1895, London 1986, S. 236. 
Obwohl sich im Prozess viele Vorwürfe aus dem Cleveland Street-Skandal wiederholten, wurden sie, der medialen Logik folgend, als noch nie gehörte Neuigkeit stilisiert. Alle größeren Zeitungen verurteilten Wilde. ${ }^{203} \mathrm{Da}$ der Prozess zugleich Wildes Kunstauffassung verhandelte, sah gerade die konservative Presse das Urteil als einen wichtigen Schritt gegen das Vordringen französischer Kultur. ${ }^{204}$ Oscar Wilde wurde dabei als „loathsome importer of exotic vice“ gesehen, der ein unenglisches Laster ins Land bringe. ${ }^{205}$ Die weiterhin bestehenden Grenzen des Darstellbaren belegten die zahlreichen Illustrationen der Illustrated Police News: Wilde wurde immer wieder im Zeugenstand oder in Haft gezeichnet, nicht aber andeutungsweise sein Vergehen selbst. ${ }^{206}$

Immerhin fanden sich zumindest in der linksliberalen Presse einzelne Stimmen, die sich gegen die Verurteilung Homosexueller wandten. Dies geschah weniger durch Artikel von Journalisten als durch Leserbriefe. So wandte sich ein Leser in der Reynolds's Newspaper gegen die Zuschreibung „unnatural“, da Homosexualität auch im Tierreich vorkomme. Ebenso trat er gegen die Verfallsthesen ein, da große Männer homosexuell gewesen seien, und gegen die Bestrafung, weil durch den privaten Verkehr niemand öffentlich gestört würde. ${ }^{207}$ Auch der linksliberale Star veröffentlichte neben der üblichen Kritik zumindest einzelne verständnisvolle Zuschriften. ${ }^{208}$ Die vergleichsweise offene Aussprache über Homosexualität, die sich aus den Skandalen entwickelt hatte, machte nun also vereinzelte tolerante Deutungsangebote sagbar.

Unter den Journalisten war es ausgerechnet der moralistische Sensationsjournalist W. T. Stead, der Wilde quasi als einziger in gewisser Weise verteidigte, obgleich er Homosexualität generell ablehnte. In seiner Review of Reviews klagte Stead, wenn Wilde wegen der Verführung von jungen Männern verurteilt würde, deren Leben er vernichtet habe, dann müsse das gleiche Urteil auch für Männer gelten, die das Leben von jungen Frauen durch Verführung zerstörten. Ebenso unterstrich Stead die weite Verbreitung von Homosexualität innerhalb der Oberschicht: „If all persons guilty of Oscar Wilde's offences were to be clapped into goal, there would be a very surprising exodus from Eton and Harrow, Rugby and Winchester, to Pentonville and Holloway“.209 Mit diesen Äußerungen knüpfte

203 McKenna, Oscar Wilde, S. 515. Dagegen sieht Graham Robb einen „widespread support for Wilde“, wobei er außer Stead jedoch nur einzelne Künstler und Adlige aus Wildes Umfeld als Beleg anführen kann; Rовв, Strangers, S. $37 \mathrm{f}$.

204 Daily Telegraph 6.4.1895. Zeitungsartikel zum Prozess gedruckt in: Jonathan Goodman (Hrsg.), The Oscar Wilde File, London 1988.

205 News OF THE WORLd 26.5.1895.

206 Vgl. Illustrated Police News 13.4.1895, 4.5.1895, 18.5.1895, 1.6.1895.

207 Reynolds's Newspaper 26.5.1895, S.1. Allerdings druckte Reynolds nicht die angebotene Verteidigungsschrift von James Wilson; vgl. Joнn Sтокеs, Oscar Wilde: Myths, Miracles, and Imitations, Cambridge 1996, S.53-62.

208 Eine Analyse der Berichterstattung und vor allem des Star in: Foldy, The Trials, S. 61-65.

209 Die Orte spielen auf die englischen Eliteschulen und die Orte der Gefängnisse an; Review of Reviews Mai 1895, S. 492. Ebenso druckte er einen Artikel von Artur Newman aus der Free Review ab, der Wilde als Künstler verteidigte; Review of Reviews Juni 1885, S. 539. 
Stead an den bereits im Cleveland Street-Skandal erkennbaren Trend an, Homosexualität im Kontext von Prostitution zu sehen. Zudem lässt sich Steads Unterstützung vielleicht auch damit erklären, dass Oscar Wilde in seiner Pall Mall Gazette seit 1886 Kritiken geschrieben hatte und er ihn daher kannte und schätzte.

Der Wilde-Skandal war freilich nicht nur über diese öffentlichen Diskurse mit der politischen Sphäre verbunden. Vielmehr kam schnell das Gerücht auf, dass der liberale Premierminister Lord Rosebery in Wildes Prozesse involviert sei. Rosebery habe demnach eine Affäre mit dem ältesten Sohn von Queensberry gehabt, den er als Privatsekretär beschäftigte, bis sich dieser erschoss. Der Premierminister war sich offensichtlich sofort bewusst, dass aus Wildes Prozess ein Skandal von wesentlich größerem Umfang entstehen könnte. Am gleichen Tag, als Queensberry Wilde mit seinem Brief zu einem Prozess herausforderte, kündigte Rosebery zumindest seinen Rücktritt an und fiel in eine nervliche Zerrüttung, die ihn arbeitsunfähig machte. ${ }^{210}$ Durch eine Indiskretion aus der Jury erfuhr die französische Presse von seiner möglichen Verwicklung, so dass hier Andeutungen über die Involvierung führender Liberaler erschienen, die wiederum in die Gespräche der Londoner Clubs einflossen. ${ }^{211}$

Bezeichnend ist jedoch, dass die britischen Zeitungen hierüber nicht berichteten. Dem Premierminister auf Verdacht öffentlich Homosexualität vorzuwerfen, war offensichtlich eine Grenze, die trotz der bevorstehenden Wahl nicht überschreitbar war. Auch wenn Rosebery den Rücktritt zurückzog und sich stattdessen im folgenden Monat abwählen ließ, hatte die vermutete Involvierung des Premierministers beträchtliche Konsequenzen für den Prozess. Zumindest einige Zeitgenossen nahmen bereits an, Queensberry habe intern ein Ultimatum gestellt, er würde Belege für die Homosexualität des Premierministers und anderer liberaler Politiker an den Skandalisierer Henry Labouchere übergeben, wenn Wilde nicht die Höchststrafe bekäme. Ob Wildes Urteil dem Premierminister eine derartige Anklage ersparte, ist durch keine überlieferte Quelle klar belegt. ${ }^{212}$ Aber immerhin, und das ist bereits ein wichtiger Befund, erschien der „Encounter“-Öffentlichkeit der Clubs nach den zahlreichen Skandalen denkbar, dass selbst die ranghöchsten Politiker homosexuell sein könnten und ihre Stellung deshalb von der Diskretion der Journalisten abhing. Allerdings war diese Annahme selbst in Tagebüchern nur andeutungsweise formulierbar. Das Urteil sei „in order to shield others of a higher status in life“, formulierte etwa Edward Hamilton in seinen privaten Aufzeichnungen. ${ }^{213}$ Und nur auf Wildes

210 McKenna, The Secret, S.466, 472 und 514. Queensberrys Detektiv hatte ihm 1894 Zeugenaussagen von Zimmermädchen über das Verhältnis zum Premierminister übermittelt.

211 Revue Blanche 1.6.1896; Hyde, The Other Love, S. 148; Ders., Oscar Wilde. A Biography, London 2001 (Erstausgabe 1976), S.205.

212 Als Indiz gilt u.a., dass Roseberys Gesundheit seit Queensberrys Vorwürfen völlig zusammenbrach und er erst nach Wildes Verurteilung wieder konzentriert arbeitsfähig war; vgl. McKenna, The Secret, S. 425, 506f. u. 540f.; Foldy, Trials, S. 24-29.

213 Eintrag Tagebuch Hamilton 20.5.1895, in: Brooks (Hrsg.), Diary of Sir Edwald Hamilton, S. 250. 
Bitte hin verzichtete Alfred Douglas auf die Veröffentlichung eines Artikel in einer französischen Zeitung, der anklagte, Wilde sei nur zum Schutz führender Liberaler verurteilt worden, da die Polizei Listen mit Tausenden von Homosexuellen habe, gegen die sich nicht vorgehen würde. ${ }^{214}$

Die gesellschaftlichen Folgen des Wilde-Skandals wurden in der Forschung bereits vielfach diskutiert. Viele Autoren schlossen sich zeitgenössischen Berichten an, die von einer panikartigen Flucht von Homosexuellen auf den Kontinent berichteten, was neuerdings wieder bezweifelt wird. ${ }^{215}$ Viele Zeitgenossen und spätere Historiker gingen zudem von einer Zunahme der strafrechtlichen Verfolgungen aus. Dies bestätigen die Statistiken nicht. Lediglich die Verurteilungen wegen Aufforderungen zu homosexuellen Handlungen stiegen an. ${ }^{216}$ Ebenso wurde argumentiert, dass in England durch den Wilde-Skandal keine vergleichsweise offene Diskussion über Homosexualität wie in Deutschland eingesetzt habe. ${ }^{217}$ Allerdings ließe sich dagegen anführen, dass im Zuge des Cleveland Street- und Wilde-Skandals überhaupt erst ab 1896 entsprechende Schriften in England aufkamen und die Skandale immerhin ein freieres Sprechen über Homosexualität ermöglichten.

Auffällig ist schließlich, dass es in den folgenden Jahren vorerst zu keinen vergleichbaren Skandalen um Homosexualität mehr kam. Die bisherigen Skandale waren vermutlich selbst für die Medien eine solche Schockerfahrung, dass sie stärker versuchten, derartige Veröffentlichungen zu verhindern. Denn selbst wenn man davon ausgeht, dass sich die britischen Homosexuellen nach den Skandalen um äußerste Diskretion bemühten, erklärt dies nicht allein, warum die Skandalwelle abebbte. Vielmehr lässt sich die These erwägen, dass die Skandale nicht nur eine Repression homosexueller Praktiken schufen, sondern auch eine gewisse Toleranz, die sich in der kollektiven Vermeidung von derartigen Skandalen niederschlug.

Um den Umgang mit prominenten Homosexualitätsvorwürfen nach diesen großen Skandalen der 1890er Jahre zu untersuchen, lohnt ein abschließender Blick auf den „blockierten“ Skandal um den schottischen Kolonialhelden Hector MacDonald. Dem Generalmajor wurde 1903 vorgeworfen, mit mehreren singalesischen Jungen in einem Bahnwagon in Ceylon masturbiert zu haben. Dieser Fall wies damit prinzipiell alle Vorraussetzungen auf, um eine ähnlich große öffentliche Wirkungsmacht wie die spätviktorianischen Homosexualitätsskandale zu entwickeln. Das lag zunächst am Protagonisten. MacDonald war spätestens seit dem Burenkrieg berühmt, und die Medien berichteten häufiger über ihn. ${ }^{218}$ Aus

214 Auszüge aus diesem Manuskript in: Regenia Gagnier, Idylls of the Marketplace. Oscar Wilde and the Victorian Public, Aldershot 1987, S. 205f. Gagnier konzentriert sich ansonsten jedoch auf die Rezeption von Wildes Werk.

215 Vgl. Roвb, Strangers, S. 36.

216 Ebd., S.272f.

217 Lauritsen und Guldin, Englische Forschungen, S. 70.

218 Noch kurz vor Beginn des Skandals gab es am 21.2.1903 sogar im Unterhaus eine Anfrage nach MacDonalds Gesundheitszustand; Times 22.2.1903, S. 4. 
einfachen Verhältnissen stammend, hatte MacDonald nach Kämpfen in diversen Kolonien im Burenkrieg als Regimentskommandeur gedient, anschließend in Indien und Ceylon. ${ }^{219}$ Da MacDonald den Vorwürfen zufolge mit armen Jungen verkehrte, knüpfte der Fall an das bislang etablierte Narrativ der homosexuellen "Corruption of the Youth“ und der Ausnutzung sozialer Unterschiede an. Zugleich verlagerte dies den Diskurs in einen kolonialen Kontext. Durch die Kritik, die im Burenkrieg an den militärischen Praktiken des Kolonialismus aufkam, stand MacDonald inmitten weiterer politischer Konfliktlinien. Denn zumindest moralisierende Journalisten wie W.T. Stead und C.P. Scott hatten sich im Burenkrieg scharf gegen die koloniale Kriegsführung gewandt und dabei besonders in der Debatte über die „Concentration Camps“ Unterstützung von prominenten Liberalen erhalten. ${ }^{220}$ Eine entsprechende Enthüllung versprach zudem eine breite Medienaufmerksamkeit, da gerade Homosexualität im Militär ein besonders sensibler Tabubereich war.

Dennoch verlief der drohende Skandal anders als seine Vorläufer im Jahrzehnt zuvor. Sein Beginn wies noch gewisse Ähnlichkeiten zu den vorherigen Fällen auf. Als Ceylons Gouverneur Joseph West-Ridgeway Mitte Februar 1903 von den Beschuldigungen erfuhr, schlug er, aus Angst vor der Medienöffentlichkeit, statt einer Untersuchung die sofortige Ausreise MacDonalds und anschließende Versetzung vor, obgleich homosexueller Verkehr in Ceylon nicht strafbar war. Dem Londoner Kolonialministerium deutete er dies nur telegraphisch an: „His immediate departure is essential to save grave public scandal which I cannot explain by telegraph. "221 Dementsprechend meldete auch die britische Presse zunächst lediglich seine Rückkehr. ${ }^{22}$ Da MacDonald in Gesprächen im Kriegsund Kolonialministerium seine Unschuld beteuerte, verlangten die Minister jedoch für seinen Verbleib in der Armee die Wiederherstellung seiner Ehre vor einem Kriegsgericht in Ceylon, woraufhin er die Rückreise antrat. Obwohl die Journalisten in Ceylon von dem unbestätigten Gerücht wussten, sahen sie von Berichten zunächst ab.

Erneut überführten erst eine parlamentarische Aussage und die Ankündigung eines Prozesses den Homosexualitätsvorwurf in die breite Medienöffentlichkeit. In die Zeitungen der gesamten westlichen Welt gelangten die Beschuldigungen, als Gouverneur Ridgeway im Legislative Council in Ceylon auf die Anfrage, wo

$219 \mathrm{Zu}$ seinem Lebensweg liegen entsprechend mehrere Biographien vor, die jedoch den Skandal und vor allem dessen öffentliche Thematisierung kaum berücksichtigten; vgl. bes. Trevor Royle, Death before Dishonour. The True Story of Fighting Mac, Edinburgh 1982; sowie: John Montgomery, Toll for the Brave. The Tragedy of Hector MacDonald, London 1963; Kenneth MacLeod, The Ranker, The Story of Sir Hector MacDonald's Death, Cortland 1976; knappe Hinweise in: Hyam, Empire and Sexuality, S.33-35.

220 Vgl. einführend zur öffentlichen Debatte hierüber: Paula M. Krebs, Gender, Race, and the Writing of Empire. Public Discourses on the Boer War, Cambridge 1999. S.32-54. Vgl. auch Kap. IV.3.

221 Ridgeway an Colonial Office 19.2.1903, in: TNA, CO 537.

222 Times 20.2.1903, S. 8. 
MacDonald sei, antwortete: „It is known to all here that grave, very grave charges have been made against Sir Hector Macdonald. "223 Nach einer Beratung in London wolle er diese vor einem Kriegsgericht klären. Und obwohl der Gouverneur sich nur vor lokalen Journalisten geäußert hatte, gelangte seine Antwort dank des Telegraphen- und Korrespondentennetzes von Reuters und Central News sofort in alle großen Redaktionen der westlichen Welt. Schon am nächsten Tag schrieben die großen englischen Qualitätszeitungen - wie die Times, die Daily News oder der Daily Chronicle - über die „very grave charges“.224 Die Daily News berichtete dabei auch unter der Überschrift „Opinion at the clubs“, dass sich die Offiziere schon am Vortag über den Fall unterhalten hätten. „Buller's affair was a mere fleabite to Macdonald's trouble. He was the idol of the army $[\ldots]$ “, wurde ein Offizier zitiert. Dennoch lobten ihn alle Offiziere und meinten, er komme aus der Sache raus, die ihm Feinde und „scandalmongers“ eingebrockt hätten. ${ }^{25}$ Auch eine deutsche Qualitätszeitung wie das Berliner Tageblatt schrieb unzweideutig über MacDonalds „Verbrechen, das nicht näher bezeichnet werden kann. "226 Abermals hielt sich dagegen das vermeintliche britische Sensationsblatt par excellence, die Boulevardzeitung Daily Mail, völlig mit Meldungen zurück. ${ }^{227}$ Hector MacDonald befand sich am gleichen Tag gerade im Frühstücksraum eines Pariser Hotels, als er in der europäischen Ausgabe des New York Herald einen entsprechenden Bericht über jenes transnationale Medienereignis entdeckte, in das sich der Vorwurf gegen ihn verwandelt hatte („Grave charges lie on Sir Hector MacDonald“). ${ }^{228}$ Daraufhin ging er in sein Zimmer und erschoss sich.

Sein Selbstmord lässt sich zunächst mit dem militärischen Ehrenkodex erklären. Er war aber auch eine Reaktion auf die vorhergehenden Skandale. Wie bereits zeitgenössische Studien zur Homosexualität ausmachten, waren Selbstmorde und Selbstmordgedanken unter Homosexuellen gerade wegen der Angst vor Skandalen weit verbreitet. ${ }^{229}$ Skandale wie die um Wilde, Cobain oder Somerset dürften MacDonald gezeigt haben, welche lang anhaltende öffentliche Demütigung ihm bevorgestanden hätte. Sein Entschluss stand ebenso in einem lockeren Zusammenhang mit dem deutschen Skandal um Friedrich Alfred Krupp, der nur wenige Monate zuvor nach Presseberichten über seinen homo-

223 Daily Chronicle 25.3.1903; Times 25.3.1903; Daily News 25.3.1903, S. 7.

224 Vgl. ebd.

225 Daily News 25.3.1903, S.7.

226 Berliner Tageblatt Nr.151, 25.3.1903.

227 Vgl. Daily MaIl 25.3.1903; auch am 26.3.1903 wird nichts Genaueres über die Vorwürfe gemeldet.

228 In der bisherigen Literatur wird betont, dass MacDonald sich wegen der Meldung in der amerikanischen Zeitung erschossen habe, die damit die Verantwortung hierfür erhält. Unerwähnt bleibt damit, dass auch englische Qualitätszeitungen am gleichen Tag hierüber geschrieben hatten und somit ebenfalls das Tabu brachen, das zu seinen Tod beitrug; vgl. dagegen etwa RoYle, Death, S. 130.

229 Vgl. zu diesen zeitgenössischen Studien und Schätzungen von Hirschfeld u. a.: STüмкE, Homosexualität, S. $29 \mathrm{f}$. 
sexuellen Verkehr mit italienischen Jungen schlagartig verstarb - vermutlich ebenfalls durch Selbstmord, um einem Skandal zu entgehen. Eine Emigration, wie sie im 19. Jahrhundert noch üblich war, war in einer medialen Welt für Prominente ohnehin keine echte Lösung mehr. Der Freitod machte nun den weiteren Verlauf des Skandals ungewiss, da er dem Fall eine komplexe Wendung gab: Einerseits erhöhte der Selbstmord die Publizität des Falles um ein Vielfaches und wirkte wie ein Schuldeingeständnis. Andererseits verhinderte er detaillierte Enthüllungen im Zuge eines Prozesses und legte der Öffentlichkeit Pietät gegenüber dem Toten nahe. Damit war offen, ob die Nachrufe seine militärischen Verdienste oder die Enthüllungen thematisierten.

Tatsächlich entschied sich die ganz überwiegende Mehrheit der Zeitungen dafür, Hector MacDonald trotz der Homosexualitätsvorwürfe in den höchsten Tönen zu loben. Lange Beschreibungen seines Lebensweges und seiner militärischen Einsätze standen neben allenfalls marginalen Andeutungen zu den Vorwürfen. Selbst die liberale Daily News, die sich im Burenkrieg besonders gegen koloniale Gewalt gerichtet hatte, berichtete unter der Überschrift „From Farm to Fame" lobend über seinen Aufstieg und seine Kämpfe. ${ }^{230}$ Die öffentliche Empörung richtete sich stattdessen gegen diejenigen, die für die Veröffentlichung der letztlich tödlichen Vorwürfe verantwortlich seien. Da die amerikanische Presse in Großbritannien generell als sensationsgierig galt, wurde ihr die Schuld an seinem Tod gegeben - obwohl die britischen Qualitätszeitungen zeitgleich ähnliche Berichte gedruckt hatten. Lieutenant Colonel Stuart Wortley schreibt gleich nach dem Tod einen entsprechend anklagenden Leserbrief an den New York Herald, den wiederum die englischen Zeitungen befriedigt abdruckten, da er sie von einer Mitschuld entlastete. ${ }^{231}$

Dieser liberal-konservative Konsens wurde freilich erneut durch die linke Reynolds's Newspaper durchbrochen, die den Fall in die Narrative der letzten Skandale und in die Klassenfrage einlas und nun zusätzlich mit einer Imperialismuskritik verband: „The charge because of which Lieutenant-General Hector Macdonald committed suicide is a common vice among the well-to-do classes in London, both sexes of whom luxury, idleness, and Imperialism have thoroughly corrupted. Needless to say that he was accused of a sexual offence. "232 Aus MacDonalds Fall leitete sie generelle Aussagen über große Soldaten ab, bei denen ein „exaggerated animalism“ typisch sei. Sie überführte die Vorwürfe zudem in eine direkte Kritik an der Regierung, die schon lange Bescheid gewusst habe und durch ihr Beharren auf ein Kriegsgericht den Tod verursachte. Ver-

230 Vgl. Daily News 26.3.1903, S.12; Times 26.3.1903, S. 8 und 27.3.1903, S.3; Westminster GAZETTE 26.3.1903.

231 „The publication you gave in your issue of yesterday and your manner of wording it, was sufficient to cause dismay to any men, whether guilty or not, of the crimes you have accused; but unfortunately all public men and their lives are public property nowadays as to certain sections of the press." Wieder abgedruckt etwa ihn: DAILY NEws 30.3.1903, S.12; REYNOLDs's NewSPAPER 5.4.1903, S. 4.

232 Reynolds's Newspaper 29.3.1903, S. 1. 
weise auf andere Skandale, wie auf den Cleveland Street-Fall und die KruppAffäre erhärteten ihre Anklage gegen die politische Führung; „even as the Krupp incident helped to show the German people the iniquity of their rulers." Die deutsche Presse blieb bei ihren Berichten über MacDonalds Tod zwar von ihren Wertungen her zurückhaltender, versuchte aber zumindest im Zuge der Ermittlungen die Ursachen des „Sittlichkeitsverbrechens“ auszumachen.233

Im weiteren Verlauf zeigte sich, dass die Öffentlichkeit MacDonald trotz der Homosexualitätsvorwürfe ehren wollte, die konservative Regierung ihm hingegen aus Angst vor einer Eskalation des Skandals jede öffentliche Anteilnahme verweigerte. Da das Kolonialministerium intern von ähnlichen Vorwürfen gegen MacDonald aus Südafrika und Indien erfahren hatte, ging es im hohen Maße von seiner Schuld aus. Die Regierung setzte sich erst für ein unauffälliges Begräbnis in Paris ein, dann auf Wunsch von MacDonalds Angehörigen für eine geheim gehaltene Beerdigung in Schottland - ohne jede militärische Ehre. Gerade dagegen wehrten sich jedoch weite Teile der Öffentlichkeit. Bereits gegen die heimliche Beerdigung erhoben sich vielfältige Proteste. Schon einen Tag, nachdem das Begräbnis bekannt wurde, kamen rund 30000 Menschen zu dem Friedhof, und zumindest nach den Medienberichten riss dieser Besucherstrom auch in den folgenden Wochen nicht ab. ${ }^{234}$ Gut eine Woche später kamen bereits verschiedene Kirchenvertreter, „clan societies“ und andere „Highland associations“ zusammen, um den Bau eines Denkmals für ihn zu planen. ${ }^{235}$ Zudem versuchte ein Komitee, MacDonalds Unschuld zu beweisen.236 Ebenso wurde im Unterhaus dem Kolonialminister Chamberlain vorgeworfen, die Bekanntgabe der Vorwürfe sei eine Vorverurteilung gewesen. Durch diese vielfältigen Sympathiebekundungen an MacDonald kam es zu einer Verlagerung der Empörung: Sie richtete sich nicht mehr gegen den vermeintlichen Homosexuellen, sondern gegen das Verhalten der Regierung.

In dieser öffentlichen Unterstützung MacDonalds zeigten sich unterschiedliche, sich überlagernde Umgangsweisen mit den Homosexualitätsvorwürfen. Indem die Öffentlichkeit sie ignorierte, stellte sie einerseits wieder eine moralische Ordnung her, in der Homosexualität nicht existent war. Andererseits bedeutete die Zurückstellung der öffentlichen Vorwürfe zugleich eine gewisse Akzeptanz möglicher Homosexualität oder zumindest das Zugeständnis, dass Verdienste für das Land diese Vermutung aufwiegen können. Dabei galt selbst der Freitod nicht als Schuldeingeständnis oder aus religiösen Deutungen heraus als problematisch. Vielmehr erschien MacDonald als ein Opfer der Medien und ihrer Skandalisierungen. Zugleich ist anzunehmen, dass die Zeitungen durch

233 Vgl. bes. die Berichte in Vossische Zeitung und Berliner Tageblatt ab 25.3.1903.

234 Reynolds's Newspaper 12.4.1903, S. 4; Royle, Death, S.137.

235 Times 10.4.1903, S. 8; Times 11.5.1903, S.6.

236 Da das Kolonialministerium sicherheitshalber die Akten über den Fall unmittelbar nach seinem Tod zerstörte, ist diese Schuldfrage auch für Historiker nicht zu beantworten; vgl. bereits Нуам, Empire, S. 34 
MacDonalds Tod selbst über die möglichen Folgen ihrer Berichterstattung so erschüttert waren, dass sie Homosexualität in den folgenden Jahren wieder stärker in der Sphäre des Geheimen beließen. Vergleichbare Skandale wie in den 1880 er und 1890er Jahren traten nun zumindest bis zum Ersten Weltkrieg nicht mehr auf. Vielmehr verlagerte sich die Welle der Homosexualitätsskandale ab 1900 nach Deutschland.

\section{Sozialdemokratische Kampagnen: Krupp auf Capri}

Vor allem die breite Berichterstattung über Oscar Wildes Skandal stieß in ganz Westeuropa öffentliche Diskussionen darüber an, was Homosexualität eigentlich ausmache und wie sie zu bewerten sei. Gerade in Frankreich, wo durch die liberalen Gesetze entsprechende Skandale ausblieben, verhalfen die zahlreichen Artikel über den Wilde-Prozess dazu, öffentliche Vorstellungen über Homosexualität zu konstruieren. ${ }^{237}$ In Deutschland kamen 1895/96 nicht nur zahlreiche Publikationen auf, die den Wilde-Prozess und Homosexualität generell thematisierten. In Reaktion auf den Prozess formierten sich auch die Homosexuellenbewegung und erste Homosexuellenzeitschriften, wie das Jabrbuch für sexuelle Zwischenstufen und die von Adolf Brand herausgegebene Zeitschrift Der Eige$n e .{ }^{238}$ Indem die Journalisten anderer Länder die britischen Fälle aufgriffen, bereiteten sie allerdings auch den Transfer entsprechender Skandale vor.

Ein deutscher Journalist, der aus London besonders ausführlich über die englischen Homosexuellenprozesse berichtete, war der Sozialdemokrat Eduard Bernstein. In dem eher programmatisch ausgerichteten SPD-Blatt Die Neue Zeit nahm er den Wilde-Skandal zum Anlass, um grundsätzlich den sozialdemokratischen Standpunkt zur Homosexualität zu reflektieren. Tatsächlich hatten sich die Sozialdemokraten bislang kaum mit ihr auseinandergesetzt. Bernstein kritisierte, in der SPD würde mehr „verurteilt statt beurteilt“. Er monierte gängige Zuschreibungen wie „widernatürlich“ und betonte, Homosexualität sei nicht nur in Verfallszeiten zu finden, sondern in allen Kultur- und Naturstufen. Zudem sei es eine Form der Doppelmoral, Verkehr mit Frauen zu tolerieren, der nicht der Kinderzeugung diene, sondern ein „reiner Genussakt“ sei, hingegen den zwischen Männern zu bestrafen. ${ }^{239}$ Mit seiner sowohl historischen als auch medizinischen Argumentation schloss Bernstein an englische und deutsche Reformdiskurse an. Bernstein wehrte sich zwar dagegen, dass sich der Staat

237 Nancy Erber, The French Trials of Oscar Wilde, in: Journal of the History of Sexuality 6 (1996), S. 549-588.

238 Vgl. zu den Blättern: Marita Keilson-Lauritz, Die Geschichte, S. 27 f.

239 Eduard Bernstein, Die Beurtheilung des widernormalen Geschlechtsverkehrs, in: Die NeUE ZeIt 13.2 (1895), S.228-233; wichtige Hinweise in: W.U. EIssler, Arbeiterparteien und Homosexuellenfrage. Zur Sexualpolitik von SPD und KPD in der Weimarer Republik, Hamburg 1980, S.39f. Bernsteins Diktum über die bislang tatsächlich wenig ausgearbeitete Position der Sozialdemokratie richtete sich gegen frühere Andeutungen von Bebel. 
die Rolle des Moralwächters anmaße. Auf der normativen Ebene formulierte Bernstein jedoch eine Position, die sich innerhalb der Sozialdemokratie bei allen späteren Skandalen als wirkungsmächtig erwies: „Es ist vielmehr in jedem einzelnen Fall zu unterscheiden, ob wüste Ausschweifungen oder eine unüberwindliche Liebe zum eigenen Geschlecht vorliegt, die nicht sittenrichterlich, sondern pathologisch zu beurteilen ist." 240 Diesem offenen Diktum folgend, verurteilte er auch Oscar Wildes Verhalten als „päderastisch“ und nicht akzeptierbar. In Folge der Wilde-Debatte und Bernsteins Überlegungen traten auch die Sozialdemokraten insgesamt für die Straffreiheit von Homosexualität ein, verurteilten aber fallweise „Ausschweifungen“, die sie besonders der Oberschicht zuschrieben. ${ }^{241}$

Die deutsche Rezeption des Wilde-Skandals hatte zudem eine weitere Auswirkung auf die Agitation der Sozialdemokratie, ihren Umgang mit Homosexualität und das Aufkommen von Skandalen. 1897 hatte der führende Berliner Sexualwissenschaftler, Magnus Hirschfeld, auch in Reaktion auf Wildes Verurteilung, eine Petition zur Abschaffung des $\$ 175$ organisiert, die August Bebel unterstützte und am 13. Januar 1898 im Reichstag begründete. ${ }^{242}$ Die englischen Skandale führten somit zumindest indirekt zu dem Versuch, die deutsche Gesetzgebung zu liberalisieren. Bestraft werden sollten Homosexuelle nur, wenn Gewalt angewendet würde, ein Beteiligter unter 16 sei oder sie ein öffentliches Ärgernis erregten. Gerade weil diese Forderung im Reichstag keine Chance auf eine Mehrheit hatte, setzte Bebel in der Debatte jedoch auf eine Strategie, die Bernsteins Zweiteilung in dekadente und zulässige Homosexualität aufgriff. Bebel forderte, um die Doppelmoral der bürgerlichen Abgeordneten und der Regierung vorzuführen, die „rosa Listen“ der Berliner Sittenpolizei zu öffnen, in der sich die Namen aus höchsten Kreisen finden würden. „Würde auf diesem Gebiet die Berliner Polizei - ich will zunächst nur einmal von dieser reden - ihre volle Pflicht und Schuldigkeit tun, dann gäbe es einen Skandal, gegen den der Panamaskandal, der Dreyfusskandal, der Lützow-Leckert- und der TauschNormann-Schumann-Skandal das reine Kinderspiel sind.“243 Dieser erpresserische Verweis, bei dem viele Zuhörer und Leser Namen assoziieren konnten, bildete gewissermaßen den Beginn späterer Kampagnen, mit denen die SPD die Doppelmoral der Eliten anprangerte. Der Sprengkraft eines derartigen Skandals um einen prominenten Homosexuellen, das unterstrich Bebels Rede, waren sich die Sozialdemokraten bewusst. Nicht zuletzt aus den englischen Skandalen kannten sie dessen Wirkung.

240 Bernstein, Die Beurtheilung, S. 231.

241 Diese normative Zweiteilung findet sich auch in der auflagenstärksten Schrift eines damaligen Sozialdemokraten: August Bebel, Die Frau und der Sozialismus, Stuttgart 1909, S. 148 (Erstaufl. 1878).

242 Lautmann und Taeger, Sittlichkeit, S. 243.

243 Verhandlungen des Reichstages 13.1.1898, Bd.159, 16. Sitz., S. 410. Die Existenz dieser Listen ist umstritten und ihre Bezeichnung variierte; in den Archiven ließen sich keine fundierten Spuren von ihnen finden. 
Die Probe aufs Exempel erfolgte am 15. November 1902 mit einem Artikel im Vorwärts, der dem Unternehmer Friedrich Alfred Krupp explizit homosexuellen Verkehr auf der italienischen Insel Capri vorwarf. ${ }^{244}$ Dass diese Enthüllung ausgerechnet Krupp traf, hatte vielfältige Gründe. Nicht allein die exzeptionelle Größe seines Unternehmens, das immerhin rund 50000 Menschen beschäftigte, war entscheidend, sondern vor allem Krupps herausragende öffentliche Stellung. Krupp war wie kaum eine andere Person eine Projektionsfläche für weltanschauliche Ressentiments. Dank seiner Rüstungsproduktion repräsentierte Krupp die militärische Expansion Deutschlands, und durch seine guten Kontakte zum Kaiser stand er für den Schulterschluss zwischen Monarchie und bürgerlichen Eliten. Das politische und soziale Engagement der Unternehmensführung machte Krupp zudem zum Sinnbild einer paternalistischen Bekämpfung der Sozialdemokratie. ${ }^{245}$ Die Sozialdemokraten hatten deshalb in den Jahren zuvor immer wieder versucht, Krupp durch verschiedene Kampagnen in Skandale zu verwickeln und ihn moralisch zu diskreditieren. So hatten sie im Reichstag - zusammen mit Teilen des Zentrums und der Liberalen - dem Unternehmen mehrfach Preisüberhöhungen bei Panzerplatten vorgeworfen, die er zudem den USA billiger liefere als dem Reich. ${ }^{246}$ Ebenso stellten viele Artikel und Karikaturen Krupp als jemanden dar, der auf unpatriotische Weise mit jedem Land Waffengeschäfte mache. ${ }^{247}$ Ernsthaft schaden konnten diese Vorwürfe Krupp nicht. Dennoch intensivierte Krupp daraufhin seine Öffentlichkeitsarbeit. ${ }^{248}$ Gegenüber dem Vorwurf der Homosexualität konnte dies jedoch ebenso wenig helfen wie seine Verbindungen zum Kaiser und zur Reichsleitung.

Die Enthüllung des Vorwärts war zwar spektakulär, sie erschien aber im Falle Krupps nicht abwegig genug, um sie einfach als abstruse Verleumdung zu übergehen. Dass Krupp seit 1898 jährlich oft mehrere Monate auf Capri verbrachte, war der Öffentlichkeit durch zahlreiche Illustriertenberichte bestens bekannt. Krupps Interesse an der Tiefseeforschung, gesundheitliche Probleme und eine gewisser Überdruss am Essener Unternehmens- und Familienalltag galten als wesentliche Gründe für diese langen Reisen, die er meist ohne seine Ehefrau machte. 1902 verbrachte er den Großteil des Jahres dort und kam bis zum Sommer lediglich kurz nach Essen. ${ }^{249}$ Bis Oktober 1902 schaffte er sich in Capri einige Besitzungen an, wie ein Hotel, eine Villa mit Weinhängen, die berühmte

244 VORWÄRTS 15.11.1902, S.2f.

245 Aus der umfangreichen Literatur zu dem Unternehmen und seinen Besitzern vgl. bes. LOTHAR Gall, Krupp. Der Aufstieg eines Industrieimperiums, Berlin 2000; kritisch, mit vielen Ungenauigkeiten: William Manchester, Krupp. Chronik einer Familie, München 1978.

$246 \mathrm{Vgl}$. generell zu den Kampagnen im 19. Jahrhundert und Krupps Reaktionen: BarbarA Wolbring, Krupp und die Öffentlichkeit im 19. Jahrhundert, München 2000, S.283f., 295 f.

247 Vgl. Kladderadatsch 17.3.1901; Wahre Jacob 6.5.1902; Ulk 15.7.1900 u. 7.9. 1902. Diese und weitere Ausschnitte in: HAK, FAH 3 D 19.

248 F.A. Krupp an Wilhelm II., 27.7.1897, in: GStA, BPH Rep. 53 J, Lit. K, Nr. 11-18.

$249 \mathrm{Zu}$ Krupps Reisen nach Capri vgl. die Unterlagen in: WA XVII 6. Vgl. zudem: Carlo Knight, Die Capri-Utopie von Krupp/L’Utopia Caprese di Krupp, Neapel 1989, bes. S. 50-62. 
Grotte Fra Felice und einige andere Grundstücke. ${ }^{250}$ Krupps Unterstützung der Inselbewohner, die die bürgerlichen Zeitungen bislang priesen, erhielt durch den Vorwärts eine Umdeutung. Dass die angeblichen Ausschweifungen auf einer fernen Insel stattgefunden haben sollten, war für den Vorwärts ebenfalls von Vorteil: Wie bei den Kolonialskandalen erhöhte dies die Imaginationsräume der Leser und erschwerte zugleich die Überprüfung der Vorwürfe.

Obgleich der Vorwärts keine echten Belege hatte, erschienen seine Beschuldigungen vielen Lesern, Journalisten und Politikern nicht ganz unbegründet. $\mathrm{Zu}$ mindest in gebildeten Kreisen und der Berliner Elite war Capri als Treffpunkt Homosexueller bekannt. Die Protagonisten der englischen Homosexualitätsskandale kamen ebenfalls hierher. So wohnten Alfred Douglas und Oscar Wilde unmittelbar nach Wildes Freilassung sogar im gleichen Hotel wie Krupp. ${ }^{251}$ Dass auch deutsche Homosexuelle hierher reisten, erfuhren die Zeitungsleser im Zuge des Krupp-Skandals etwa durch die zeitgleiche Verhaftung des homosexuellen Malers Wilhelm Allers, der in Capri neben Krupps Hotel wohnte und mit ihm befreundet war. ${ }^{252}$ In Berlin gab es anscheinend seit längerem Gerüchte über Krupp, wie die Vossische Zeitung betonte. ${ }^{253}$ Am Hof, so berichtet Graf Robert Zedlitz-Trützschler, sprach man öfters darüber, dass Krupp „ein merkwürdiges Interesse für männliche Künstler, Kellner und überhaupt junge Männer hatte", sie förderte und ihnen öffentlich den Kopf streichelte. ${ }^{254}$ Die professionellen Beobachter von Homosexualität teilten diese Einschätzung über Krupp. Magnus Hirschfeld meinte, aus „sicherer Quelle“ vor einiger Zeit gehört zu haben, Krupp habe sich wegen seiner Homosexualität von einem Berliner Arzt behandeln lassen. ${ }^{255}$ Der zuständige Berliner Kommissar für Sittendelikte, Hans von Tresckow, wusste angeblich, dass Krupp bei seinen Besuchen im Berliner Hotel Bristol nur private junge Diener hatte, die er extra aus Italien kommen ließ. ${ }^{256}$ Aus diesem Grunde hätte die Sittenpolizei Krupp auch in seinen „rosa Listen" geführt, auf die Bebel 1898 in seiner drohenden Reichstagsrede angespielt hatte. Auch wenn Krupps „wahres“ Privatleben hier nicht zur Debatte steht, prägten diese latenten Gerüchte zumindest das Aufkommen und den Verlauf des Skandals.

250 Vgl. die Aufstellungen nach seinem Tod in: Haux an Lo Bianco, 30.12.1902 und 20.1.1903, in: HAK, FAH III 67: 11 und $25 \mathrm{f}$.

251 Vgl. hierzu James Money, Capri. Island of Pleasure, London 1986, S.54f. Zu den englischen Capri-Reisenden 1895 zählten etwa William Somerset Maugham, Edward Frederick Benson und John Ellingham Brooks.

252 Berliner Lokal-Anzeiger, Nr. 558, 28.11.1902.

253 Vossische Zeitung Nr. 589, 17.12.1902.

254 Graf Robert Zedittz-Trützschler, Zwölf Jahre am Deutschen Kaiserhof, Stuttgart 1952 (Erstausgabe 1923); zugleich betont er, dass er nicht glaube, dass Krupp Homosexualität praktiziert habe.

255 Hirschfeld an Eisner 22.11.1902, in: Archiv der Sozialen Demokratie der Friedrich-Ebert Stiftung (AdsD), F 202: 43.

256 Hans von Tresckow, Von Fürsten und anderen Sterblichen. Erinnerungen eines Kriminalkommissars, Berlin 1922, S. 127. 
Die Enthüllungen des Vorwärts erschienen, im Unterschied zu früheren Kampagnen gegen Krupp, nicht als großer Aufmacher, sondern eher versteckt auf der zweiten Seite mit der unauffälligen Überschrift „Krupp auf Capri“. Die Sozialdemokraten waren sich offensichtlich bewusst, dass ein allzu sensationeller Artikel auf sie selbst hätte zurückfallen können. Dementsprechend begann der Artikel mit dem Verweis, die ausländische Presse sei seit Wochen „voll von ungeheuerlichen Einzelheiten über den ,Fall Krupp““, die sie jetzt erst nach langem Erwägen und gründlicher Prüfung der deutschen Öffentlichkeit übermittelte. Inhaltlich machte der Artikel einen ähnlichen Spagat wie Eduard Bernsteins Überlegungen zum Wilde-Skandal. Einerseits forderte der Vorwärts auf, anhand dieses prominenten Falles eine Diskussion über die Abschaffung des $\$ 175$ einzuleiten. Dementsprechend umschrieb er Homosexualität als „unglückliche Veranlagung“. Andererseits erhob der Artikel explizite moralische Anklagen gegen Krupp, die sich aus einer klassischen Kapitalismuskritik speisten, diese nun aber mit sensationellen sexuellen Enthüllungen verbanden. So hieß es äußerst anschaulich:

In seiner verschwenderisch ausgestatteten Villa - wir geben nur einige der notwendigsten Einzelheiten wieder, die unser italienischer Korrespondent uns berichtet - huldigte er mit den jungen Männern der Insel dem homosexuellen Verkehr. Die Korruption war bis zu einer solchen Höhe gediehen, dass man bei einem Photographen von Capri gewisse, nach der Natur aufgenommene Bilder sehen konnte.[...] das Mitleid, das das Opfer eines verhängnisvollen Natur-Irrtums verdient, muß versagen, wenn die Krankheit zu ihrer Befriedigung Millionen in ihre Dienste stellt. [...] Nachdem die Perversität zu einem öffentlichen Skandal geführt hat, wäre es die Pflicht der Staatsanwaltschaft, sofort einzugreifen. ${ }^{257}$

Ähnlich wie in England war es also vor allem das Narrativ des reichen Verführers und der bürgerlichen Doppelmoral, das die Angriffe legitimieren sollte. Unverkennbar wurde der sexuelle Normbruch enthüllt, um politische Ziele zu erreichen und das gegnerische politische Lager moralisch $\mathrm{zu}$ disqualifizieren. Insofern hatte der Skandal eine große Ähnlichkeit mit der Kampagne der Irischen Nationalisten im Dublin Castle-Skandal 1883/84, aber auch mit den Kampagnen der Radikalliberalen gegen Lord Somerset im Cleveland StreetSkandal.

Ein investigativ recherchierter Bericht war der Artikel nicht. Der Redakteur Kurt Eisner griff lediglich Meldungen auf, die bereits in ausländischen Zeitungen erschienen waren und bereits ähnlich Kapitalismus- und Homosexuellenkritik verknüpft hatten. ${ }^{258}$ Weitere Belege für die Anschuldigung, die über diese Artikel hinausgingen, hatte der Vorwärts vor der Veröffentlichung jedoch offensichtlich nicht recherchiert, und auch der erwähnte Korrespondent in Capri war eine Fiktion. Vor allem das neapolitanische sozialistische Blatt Propaganda hatte

257 VORWÄRTS 15.11.1902, S. 3 (H.i.O.).

258 Dass Kurt Eisner (der später 1919 ermordete bayrische Ministerpräsident) damals den Artikel aufbrachte, und Redaktionskollegen ihm abrieten, erinnert: FrIEDRICH STAMPfER, Erfahrungen und Erkenntnisse. Aufzeichnungen aus meinem Leben, Köln 1957, S. 67. 
im September und Oktober 1902 mehrfach derartige Berichte aufgebracht. Die Wiener Arbeiter-Zeitung hatte bereits am 27. Oktober hierüber geschrieben, und auch in Deutschland war in der katholischen BVP-nahen Augsburger Volkszeitung schon am 8. November ein entsprechender Artikel erschienen, der ohne Namensnennung unzweideutig erwähnte, dass „der Fall mit dem Namen eines Großindustriellen zu tun [hat], der mit dem kaiserlichen Hof eng verbunden ist. "259 Damit hatte die katholische Zeitung bereits einen wesentlichen Kern der Anschuldigung getroffen: Es ging darum, ob eine Person in der Umgebung des Kaisers, die zugleich das moderne Kaiserreich verkörperte, homosexuell sein könne.

Der Artikel im Vorwärts traf Friedrich Alfred Krupp somit keineswegs aus heiterem Himmel. Als er Mitte November erschien, hatte Krupp, wie seine Korrespondenz belegt, sich schon monatelang intensiv darum bemüht, einen entsprechenden Skandal zu verhindern. Bereits im März 1902 war er anonym gewarnt worden, sofort Capri zu verlassen, was er noch ausschlug. ${ }^{260}$ Im Juli/ August kursierten auf der Insel jedoch so penetrante Gerüchte, dass Krupp sich tatsächlich schweren Herzens von Capri zurückzog. ${ }^{261}$ Als im September die ersten Zeitungsartikel erschienen, versuchte Krupp weitere Enthüllungen durch seine politischen Kontakte zu verhindern: Er wandte sich brieflich an den „Kaiserlich Deutschen Generalkonsul in Neapel und beauftragte Freunde in Neapel, den Gerüchten nachzugehen. ${ }^{262}$ Krupps Vertrauter in Essen, Assessor Korn, machte Mitte Oktober 1902 bereits ein Treffen mit dem deutschen Botschafter in Italien aus, um „durch ihn eine Aufklärung der Kreise in Rom und ein endgültiges Ende der Publikationen zu erreichen." 263 Als die Artikel immer noch nicht aufhörten, bat er direkt den Außenstaatssekretär Oswald von Richthofen, ihm über sein Ministerium „die Mittel und Wege anzugeben, wie ich meine Ehre verteidigen kann und thunlichst selbst hierzu mir seinen Beistand leisten zu wollen.“264 Der Außenstaatssekretär, der Botschafter und seine Freunde in Italien rieten Krupp aber alle, die Artikel zu ignorieren. Ein gerichtliches Vorgehen, so Richthofen, würde nur die Wirkung „eines Kanonenschusses auf

259 Vgl. Propaganda 18.9.1902, 15. 10. und 20.10.1912.; La Tiempo 23.10.1902; Arbeiter-ZeiTUNG 27.10.1902; Ein Artikel des Matinos aus dem Sommer 1902 mit Andeutungen, der ebenfalls „Krupp auf Capri“ hieß, erschien später übersetzt in: BZ AM MitTAG 549, 23.11.1902. Zum Aufkommen und öffentlichen Ablauf des Skandals vgl. bereits knapp: Gall, Krupp, S.282; ohne Quellen und Belege: Manchester, Krupp, S. 226f; am ausführlichsten zur öffentlichen Wirkung: Wolbring, Krupp, S.307-333. Die Darstellungen von Wolbring kann hier jedoch, neben der anderen Fragestellung, um interne und öffentliche Quellen ergänzt werden.

260 HAK, FAH 3 B 3: 319; F.A. Krupp an A. Krupp, 20.5.1902, in: HAK, FAH III B 3: 323.

261 Vgl. hierzu auch Humbert Kesel, Capri. Biographie einer Insel, München 1971, S. $267 f$.

262 Krupp an Konsul Wantoch-Regowski 26. 9.1902, in: HAK, FAH 3 D 18: 17; Dohrn an Korn 27.9.1902, in: HAK, FAH 3 D 18: 33; Wedel an FA Krupp, 3.10.1902 in: HAK, FAH 3 D 18: 13.

263 Korn an Tuning, 10.10.1902, in. HAK, FAH 3 E 47: 10.

264 Krupp an Richthofen 27.10.1902, in: HAK, FAH 3 D 18: 1. 
Spatzen“ haben: Es mache viel Lärm und verhindere gerade dadurch den Erfolg. ${ }^{265}$ Anscheinend fanden einige seiner Berater die Vorwürfe der Presse jedoch nicht ganz abwegig, da sonst bei derartigen schweren Ehrverletzungen Verleumdungsklagen, neben dem Duell, die gängige Reaktion waren. Ebenso verzichtete Krupp nach dem Artikel in der Wiener Arbeiter-Zeitung auf eine Klage, obgleich seine österreichische Firmenleitung auf einen Prozess drängte. ${ }^{266}$ Gerade aus den entsprechenden Prozessen in Großbritannien dürfte Krupp gewusst haben, dass diese den Vorwürfen erst eine breite Öffentlichkeit gaben, unkalkulierbare Zeugenaussagen förderten und damit zum Ausbruch eines Skandals führten. Zugleich musste Krupp aber gegenüber den deutschen Eliten seine prinzipielle Bereitschaft zeigen, den Anschuldigungen durch Prozesse zu begegnen.

Um einen Skandal zu verhindern, ließ Krupp bereits einen Monat vor Erscheinen des Vorwärts-Artikels in Absprache mit dem Kaiser seine eigene Ehefrau in ein Sanatorium einliefern, weil sie ebenfalls das Gerücht über seine Homosexualität verbreitet hätte. In einem persönlichen Brief dankte Krupp dem Kaiser für diese Einweisung: „Im Einverständnis mit Eurer Majestät haben die Herren Hollmann Exc., Dr. Vogt und Assessor Korn es möglich gemacht, mir die schwerwiegenden Enthüllungen über manche Äußerung und Handlungen meiner Frau bis vor drei Tagen vorzuenthalten. Jetzt aber, da die Krankheitserscheinungen bei meiner Frau sich mehrten und die von ihr in Umlauf gesetzten Gerüchte in weitere Kreise drangen, entschlossen sich die drei Herren, mich nunmehr über den Zustand meiner Frau aufzuklären. “267 Diese Einbindung des Kaisers unterstrich damit einmal mehr, dass es sich bei dem Skandal schon vor dem Vorwärts-Artikel um eine Krise handelte, in die die Monarchie auf das Engste involviert war.

Erst auf die Veröffentlichung im Vorwärts reagierte Krupp sofort mit einer Verleumdungsklage, da jedes andere Verhalten ein Schuldeingeständnis gewesen wäre. Krupps privilegierte Stellung bei der Verhinderung des Skandals zeigte sich weiterhin. So erreichte er die sofortige Beschlagnahmung des Vorwärts und anderer sozialdemokratischer und linksliberaler Blätter, die den Vorwurf tagsdrauf nachgedruckt hatten. Das Gesetz sah dies bei persönlicher Beleidigung eigentlich nicht vor. Zudem erfolgte sofort eine Durchsuchung der Redaktionsräume des Vorwärts und der anderen Blätter und die Vernehmung des formell verantwortlichen Redakteurs Carl Leid, worüber sich der Justizminister selbst

265 Richthofen an F.A. Krupp 12.11.1902, in: HAK, FAH 3 D 18: 5.

266 Korn an Schmidt-Altherr 10.11.1902, in: HAK, FAH III D 60: 5-12; Telegramm Korn an Schmidt-Altherr, 14.11.1902 in: HAK, FAH III D 60: 19.

267 F.A. Krupp an Wilhelm II, 13.10.1902, in: GStA, BPH Rep. 53 J, Lit. K. Eine gedruckte Version auch in: Willi A. Boelcke (Hrsg.), Krupp und die Hohenzollern in Dokumenten. Krupp-Korrespondenz mit Kaisern, Kabinettschefs und Ministern 1850-1918, Frankfurt a. M. 1970, S. 161. Es ist unwahrscheinlich, dass die Einweisung seiner Frau tatsächlich ohne sein Wissen vorbereitet wurde. 
vom zuständigen Staatsanwalt informieren ließ.268 Krupp sah schließlich von neuen Strafanträgen gegen weitere sozialdemokratische Zeitungen ab, bat aber den Justizminister, bei jedem erneuten Abdruck strafrechtlich vorzugehen. ${ }^{269}$ Gerade im Vergleich zu Großbritannien machte der Fall damit die große, recht willkürliche Macht der staatlichen Zensurmittel in Deutschland deutlich, die nun auch liberale Zeitungen direkt kritisierten. ${ }^{270} \mathrm{Um}$ dennoch kursierenden Gerüchten zu begegnen, schickte Krupp eine Gegenerklärung an die Presse, die er auch in seinen Fabriken aufhängen ließ. Zudem übergab Krupps rechte Hand, Assessor Korn, der Kölnischen Zeitung eine längere Rechtfertigung über das Aufkommen der Gerüchte, die er bereits elf Tage vor dem Vorwärts Artikel prophylaktisch verfasst hatte. Demnach sei Krupp in Capri das Opfer eines Streites zwischen zwei im Kommunalwahlkampf verfeindeten Parteien geworden, wobei eine Seite ihn aus Neid auf seine Wohltaten verleumdet hätte. ${ }^{271} \mathrm{Zu}$ den starken Argumenten Krupps gegen den Vorwärts zählten aber vor allem, wie beim englischen Cleveland Street Scandal, Detailfehler in dem Artikel. So hatte Krupp nicht in einer „Villa“ gewohnt, sondern in einem Hotel. Dieses Detail schien den gesamten Vorwurf in Frage zu stellen.

Der kleine Artikel zeigte schnell die Gewalt einer medialen Skandalisierung. Trotz seiner zahllosen Bemühungen, den Gegenbelegen und seinen exzellenten Verbindungen zur Presse und Politik sah Friedrich Alfred Krupp die Situation anscheinend als völlig ausweglos an. Nur eine Woche nach den Enthüllungen verstarb der 49-jährige, aller Wahrscheinlichkeit nach durch Selbstmord. Ähnlich wie beim schottischen Kolonialhelden Hector MacDonald konnte der plötzliche Tod wie ein Schuldeingeständnis wirken, auch wenn die offizielle Diagnose Hirnschlag lautete. ${ }^{272}$ Durch die Todesmeldung ließ sich zwar, wie beim britischen Skandal um Hector MacDonald, der Vorwurf der Homosexualität überdecken, aber um der Sozialdemokratie die Schuld an Krupps Tod zu geben, musste die bürgerliche Öffentlichkeit wiederum deren Vorwurf thematisieren. Dieses Spannungsverhältnis prägte den folgenden Skandal.

$\mathrm{Da}$ in Deutschland bislang noch kaum Erfahrungen mit derartigen Homosexualitätsvorwürfen gegenüber Prominenten bestanden, war relativ offen, wie die Öffentlichkeit auf den Vorwärts-Artikel und Krupps Tod reagieren würde.

268 Vgl. Berichte Erster Staatsanwalt an Justizminister 17.11.1902 und 19.11.1902, in: GStA, HA I Rep. 84a Nr. 49713.

269 Eingabe des Direktoriums der Firma Friedr. Krupp an Justizminister 21.11.1902, in: GStA, HA I Rep. 84a Nr.49713-6.

270 Vgl. die Kritik in: Berliner Tageblatt Nr.607, 29.11.1902; Frankfurter Zeitung Nr.336, 4.12.1902; MÜnchner Neueste Nachrichten Nr.541, 21.11.1902; NZZ Nr.333, 1.12.1902.

271 HAK, FAH III D 60:1. KöLnische Zeitung 20.11.1902. Dies übernahmen alle Blätter.

272 Das Protokoll, das von vier Ärzten unterzeichnet ist, sagt, er sei um sechs Uhr mit Gehirnschlag gefunden worden und um drei Uhr nachmittags verstorben; in: HAK, FAH 3 D 20. Vogt hielt bis zu seinem Tode in persönlichen Gesprächen daran fest, dass Krupp sanft in seinen Armen entschlafen ist; vgl. etwa Aussage Cohn 18.1.1961 über Gespräch mit Vogt 1958, in: ebd. 
In den ersten drei Tagen griffen lediglich einige sozialdemokratische und ganz wenige linksliberale Zeitungen die Vorwürfe des Vorwärts auf. Da der Tabubruch politisch motiviert war, trugen ihn auch nur entsprechende politisch linksstehende Blätter. Die Mehrzahl der Zeitungen wartete dagegen, ähnlich wie bei den britischen Skandalen, zunächst das offizielle Dementi ab, das sie dann drei Tage später mit vorsichtigen Andeutungen zu den Vorwürfen abdruckten und die Thematisierung somit legitimierten. Selbst die Boulevard- und Massenblätter - wie der Berliner Lokal-Anzeiger, die BZ am Mittag oder die Berliner Illustrirte Zeitung - die bei Medienhistorikern als Sensationszeitungen gelten, berichteten zunächst nicht. Erst mit Krupps Tod erschienen in jeder Zeitschrift und Zeitung ausführliche tägliche Berichte über den Unternehmer und sein plötzliches Verscheiden.

Erst nach dem Tod versuchten die Zeitungen ausführlicher, die „Wahrheit“ über Krupp auf Capri zu ermitteln. Über eigene Korrespondenten in Italien, die die Vorwürfe auf Capri von journalistischer Seite hätten überprüfen können, verfügten die Zeitungen jedoch kaum. Lediglich der Vorwärts schickte sofort seinen Redakteur Georg Gradenauer zur Recherche nach Capri und Neapel, um den bevorstehenden Prozess vorzubereiten. Um Krupps Verteidiger einzuschüchtern, meldete er der Presse „Das aus Mailand, Florenz, Venedig, Rom, Neapel und von Capri herbeigeschaffte Material ist bergehoch“, ohne jedoch neue Anschuldigungen vorzubringen. ${ }^{273}$ Trotz fehlender Auslandskorrespondenten in Italien publizierten fast alle größeren Zeitungen Augenzeugenberichte aus Capri, indem sie Zuschriften von Reisenden und Augenzeugen druckten, die in den letzten Jahren auf Capri waren und die Rolle von Reportern übernahmen. Die meisten nahmen Krupp in Schutz. Die konservativen und katholischen Zeitungen erhielten etwa Berichte von dortigen Geistlichen, die Krupps Bescheidenheit, Wohltaten und Unschuld betonten. ${ }^{274}$ Eine Zuschrift an das liberale Berliner Tageblatt erwähnte einen Vizegeneral als „sein[en] ständigen Begleiter in jenen Tagen. “275 Dagegen erfuhren die Leser der linksliberalen Welt am Montag vom Reiseschriftsteller Karl Böttcher, der angeblich alljährlich mehrere Monate auf Capri weilte, das Gerücht sei auf der Insel schon seit Jahren bekannt. ${ }^{276}$ Alle diese unterschiedlichen Berichte zeigten die für Skandale typische Interaktion zwischen Zeitungen und Zeitungslesern, welche die kaum vorhandenen Korrenspondenten ersetzte.

Auch wenn die Capriberichte mehrheitlich Krupps Unschuld beschworen, überführten sie Krupps Privatleben weiter in die Öffentlichkeit. So erfuhren die Leser aus fast allen Artikeln Genaueres über Krupps Alltag: etwa über seine

273 Schleswig-Holsteinische Volks-Zeitung, Nr.279, 24.12.1902; Vossische Zeitung Nr.589, 17.12.1902; zu Gradenauers Besuch in Capri vgl. auch: La Propaganda 16.12.1902.

274 Reichsbote Nr.278, 27.11.1902; Rheinische Volksstimme Nr.279, 2.12.1902. Ähnlich: Neueste Nachrichten Nr. 275, 27.11.1902.

275 Berliner Tageblatt Nr. 608, 30.11.1902.

276 Welt am Montag, Nr. 50, 15.12.1902. 
Bruderschaft Fra Felice, die sich in einer von Krupp ausgebauten Grotte abgeschottet traf, über Krupps Musikleidenschaft und seinen Verkehr in Künstlerkreisen, seinen Umgang mit einfachen Menschen und seine schlechte gesundheitliche Konstitution. ${ }^{277}$ Auf diese Weise regten sie neue Imaginationsräume und alte Zuschreibungen an. Während diese Nachrufe Krupps Vater Alfred als zupackenden robusten Mann der Tat priesen, erschien sein Sohn Friedrich Alfred als das Gegenteil: als schwach, dekadent und weiblich. Und gerade diese Zuschreibungen formierten das Stereotyp des Homosexuellen.

Insgesamt führte der Skandal zu einer viel offeneren Debatte über die Bewertung und Bestrafung von Homosexualität als in Großbritannien. Vor allem die linksliberale Öffentlichkeit räsonierte hierüber, wobei ihre Position ähnlich uneinheitlich blieb wie bei den Sozialdemokraten. So hatte die Welt am Montag gleich nach dem Vorwärts-Artikel den Fall Krupp generell diskutiert und sich für die Beibehaltung des $\$ 175$ ausgesprochen. Homosexuelle würden „ihre ganze Umgebung verseuchen“ und verführten „Knaben und Jünglinge, die nichts weniger als homosexuell veranlagt sind“; wenn Mediziner sie als „krank“ bezeichnen würden, dann muss man sie in Krankenhäusern wegschließen. ${ }^{278}$ Das Narrativ des reichen Verführers legitimierte damit wie in Großbritannien auch bei Teilen der Linken die Bestrafung. Die großen liberalen Zeitungen hinterfragten dagegen erstaunlich offen die Kriminalisierung. So hoffte Ullsteins Boulevardblatt $B Z$ am Mittag, dass nach Krupps tragischem Tod die Strafbestimmungen des $\$ 175$ abgeschafft würden. ${ }^{279}$ Das liberale Berliner Tageblatt von Mosse äußerte die gleiche Erwartung mit Verweis auf den veränderten Forschungsstand: „Heute ist die Wissenschaft nahezu einig darüber, daß es sich hier um eine anormale körperliche Erscheinung handelt, welche einen strafbaren ,dolus' ausschließt. " 280 Die frühe Homosexuellen-Lobby unter Magnus Hirschfeld konnte damit durch den Skandal ihre Positionen zumindest in der liberalen Presse verbreiten.

Besonders Krupps tragischer Tod versprach somit eine öffentliche Neubewertung der Homosexuellenrechte und überführte medizinische Diskurse in die Medien. Auch einer der berühmtesten Publizisten der Zeit, Maximilian Harden, fand eine erstaunlich tolerante Einschätzung: „Angeborene oder erworbene Homosexualität hätte seinen Wert nicht gemindert," schrieb er in seinem Nachruf zu Krupp. Dennoch hätte der Vorwärts dies nicht veröffentlichen dürfen. Eine Woche später ergänzte er: „Krupps Ehre wäre dadurch nicht befleckt, denn der Urning ist nach moderner Auffassung nicht ein Ehrloser, sondern ein Kranker; wärs anders, dann müßten viele Diplomaten, Höflinge, gekrönte Herren

277 Vgl. etwa die Berichte aus Capri in: Essener Neueste Nachrichten Nr.288 15.12.1902; Der Tag, Nr.599, 25.10.1902 u. 30.11.1902; Allgemeine Zeitung München Nr.327, 27.11.1902.

278 Welt am Montag, 17.11.1902.

279 BZ am Mittag Nr. 549, 23.11.1902.

280 Berliner Tageblatt Nr.607, 29.11.1902. 
sogar ihre Häupter in Schande betten.“281 Da Harden nur einige Jahre später den nächsten großen politischen Homosexualitätsskandal anstieß, war diese zugleich liberale wie drohende Haltung umso bemerkenswerter. Denn zu den Diplomaten und Höflingen, auf die er bereits hier anspielte, gehörte zweifelsohne Eulenburg.

Magnus Hirschfeld und sein Wissenschaftlich-Humanitäres Komitee traten nun ebenfalls an die Medien, um den Fall Krupp als Beleg für die notwendige Abschaffung des $\$ 175 \mathrm{zu}$ deuten und ihr medizinisches Wissen an die Öffentlichkeit zu bringen. In einer Erklärung im Namen von 1500 Homosexuellen wandte es sich in einer Pressemitteilung dagegen, dass der Homosexualitätsvorwurf im Fall Krupp als Beleidigung gehandhabt würde, da Homosexuelle „in ihrem Charakter und sittlichen Verhalten genau so ehrenhaft sind, wie die normalsexuell Geborenen."282 Dies druckten allerdings nur die wenigsten Blätter. Hirschfeld wandte sich zudem als Experte mit zahlreichen Briefen direkt an den Vorwärts-Redakteur Eisner und versorgte ihn mit seinen wissenschaftlichen Einschätzungen, damit Eisner diese durch seine Artikel und den erwarteten Prozess in die breitere Öffentlichkeit überführen könne. So informierte Hirschfeld Eisner darüber, dass Homosexualität eine nicht behandelbare angeborene „Zwischenstufe zwischen Mann und Weib“ sei und Selbstmorde zu einem Drittel auf deren Diskriminierung zurückzuführen wären. Deshalb solle Eisner Krupp als ein Opfer des $\$ 175$ darstellen, „von dem Dr. Hirschfeld, einer der bekanntesten Forscher auf dem Gebiet der sexuellen Zwischenstufen sagt (in seiner Schrift \$175), daß an ihm mehr Leid, mehr Drangsal und zerschossene Gehirnmasse klebt, als an irgendeinem anderen \des StrG.B.“283 Ein paar Tage später riet er Eisner, der Vorwärts solle schreiben, dass er aus dem „über hervorragende Homosexuelle zur Verfügung stehenden authentischen Material nur den Fall Krupp herausgegriffen hatte“, und das Gesetz nun abgeschafft werden müsse. ${ }^{284}$ Neben Hirschfelds Eitelkeit lassen diese Briefe somit erkennen, dass er eine ähnliche Strategie wie die SPD verfolgte: Der drohende Hinweis auf prominente Homosexuelle sollte eine strafrechtliche Liberalisierung einleiten und zugleich ein neues öffentliches Wissen über die weite Verbreitung von Homosexualität schaffen.

Wie offen die deutsche Öffentlichkeit das Thema im Vergleich zu Großbritannien erörterte, zeigt auch ein Blick in die britische Berichterstattung zu dem Skandal. Während die internationale Presse insgesamt recht deutlich die Homosexualität thematisierte, nannten die meisten britischen Zeitungen nicht einmal

281 Zit. Harden, Die Zukunft 29.11.1902, S. 334 u. 6.12.1902, S. 378.

282 Trotz ihres Plädoyers für den $\$ 175$ auch abgedruckt in: Die Welt am Montag Nr.47, 24.11.1902.

283 Hirschfeld an Eisner 22.11.1902, in: AdsD, F 202: 43.

284 Hirschfeld an Eisner 26.11.1902, in: BAB/L, NY 4060:51. Kein direkter Beleg fand sich dagegen für die von den Zeitgenossen aufgebrachte Vermutung, Hirschfeld habe bereits vorher den Vorwärts mit Material über Krupp versorgt; so: Eugen JoHannes MaEcker, Harden-Hirschfeld. Eine Aufklärungsschrift, Berlin o. D. (1908), S. 18, in: GStA, HA I Rep. 84a Nr. 58203. 
den Vorwurf. Der Daily Telegraph, die Times und der Daily Express schrieben sachlich über Krupps Leben, erwähnten aber lediglich „Verleumdungen“, die zu seinem Tod mit beigetragen hätten. ${ }^{285}$ Allein die linksstehende Reynolds's Newspaper, die auch bei den britischen Homosexualitätsskandalen die deutlichsten Worte gefunden hatte, nannte den Fall ein herausragendes Ereignis, das in Deutschland die Gemüter mehr als alles seit Bismarcks Tod bewegt habe, und berichtete dann über Krupps Kontakte mit Jungen auf Capri, wobei neben dem Vorwärts französische Berichte als Quelle über die „mania homosexualis“ dienten. ${ }^{286}$ Verallgemeinernde Rückschlüsse auf die deutsche Moral zogen die nüchternen britischen Artikel jedoch nicht.

Die Mehrheit der britischen Presse wies damit gewisse Ähnlichkeiten zu den konservativen und nationalliberalen deutschen Zeitungen auf. Auch ihre Nachrufe sparten genauere Hinweise auf den Vorwurf der Homosexualität gegen Krupp aus und beteiligten sich somit auch nicht an der Debatte um den $\$ 175$. Selbst den Begriff „Homosexualität“ vermieden sie. Allein der umschreibende Verweis auf Vorwürfe, die den $\$ 175$ betreffen würden, diente ihnen als Synonym, um die Beschuldigungen des Vorwärts vorsichtig anzudeuten. Dennoch handelte es sich auch für diese Teilöffentlichkeit um einen Skandal. Ihre Empörung richtete sich jedoch weniger gegen Krupp als gegen den Vorwärts, der aus "Sensationssucht" und wegen der "Sensationslust seiner Leser" über Leichen gehe würde und direkt für den Tod von Krupp verantwortlich sei. ${ }^{287}$ Industrienahe Zeitungen wie die Leipziger Neuesten Nachrichten sprachen deshalb von „Meuchelmord." 288 Selbst in der Redaktion des Vorwärts, so erinnerte sich später der Redakteur Friedrich Stampfer, saß man nach der Todesmeldung schweigend am Redaktionstisch: „Uns war, als sähen wir das Blut über den Schreibtisch fließen. "289 Ebenso ging die sozialdemokratische Neue Zeit auf Distanz zu den Enthüllungen. ${ }^{290}$ Dass ein Presseartikel eine derartige Wirkung haben konnte, schockierte die Journalisten und die Zeitgenossen anscheinend ähnlich wie 1987 der Tod von Uwe Barschel, auch wenn die Ursachen verschieden waren.

Aus diesem Schock entwickelte sich eine weitere grundsätzliche Debatte, die sich um die Verantwortung und die Grenzen des Journalismus drehte. Sie kreiste zunächst um die Frage, ob das Privatleben in der politischen Öffentlichkeit eine Rolle spielen dürfe. Zahlreiche Zeitungen betonten ähnlich wie die Münchener Neueste Nachrichten, „daß unser ganzes öffentliches Leben erschüttert und vergiftet werden muß, wenn das Privatleben eines Einzelnen durchschnüffelt und in denunziatorischer Weise auf den Markt gezerrt wird, um mit dem Einzelnen - in törichter und böswilliger Verallgemeinerung - die Partei, die Ge-

285 Vgl. Times, Daily Telegraph und Daily Express am 24.11.1902.

286 Reynolds's NewsPaper 30.11.1902, S. 1.

287 Leipziger Tageblatt Nr.608, 29.11.1902; Kreuzzeitung Nr. 561, 30.11.1902; HannoverSCHER COURIER 24.11.1902.

288 Leipziger Neueste Nachrichten Nr. 326, 25.11.1902.

289 StAmpfer, Erfahrungen, S. 99.

290 Die Neue Zeit Nr. 9 (1902), S. 258. 
sellschaftsklasse zu treffen, der er angehört. “291 Die konservativen Medien leiteten daraus die Forderung ab, die Pressegesetze zu verschärfen, weil die Sozialdemokratie sonst „Skandalaffären ohne Ende“ produzieren würde, da sie zunehmend „geheime Aktenstücke veröffentlichen, vertrauliche Privatbriefe ans Licht zerren oder mit niedrigen Schmähungen und boshaften persönlichen Angriffen gegen Persönlichkeiten vorgehen [...].“292 Der Fall Krupp galt damit, nicht ganz zu unrecht, als Teil einer „Politik der Sensationen“, mit der die SPD seit den 1890er Jahren das Private in die Politik überführte, um das herrschende System zu diskreditieren.

Die meisten Zeitungen sprachen sich jedoch gegen schärfere Pressegesetze aus. Sie setzten vielmehr darauf, dass der Schock des Krupp-Skandals zur Etablierung neuer Normen bei den Journalisten und Lesern führe. So machten sie Vorschläge, wie in Zukunft ein jeder dazu beitragen könne, Derartiges zu verhindern. „Nicht nur durch Zeitungsnachrichten, nein auch durch mündlichen Klatsch und Tratsch werden Menschen in Verzweiflung gebracht, ja getödtet“, mahnte die katholische Westfälische Volkszeitung. ${ }^{293}$ Die Deutsche Tageszeitung empfahl deshalb, ein jeder solle am Stammtisch bei der Diskussion auf derartige Sensationsnachrichten antworten, „was wäre, wenn es Dich betreffen würde.“294 Auch der Berliner Lokalanzeiger empfahl, im Alltag die Neugier auf Sensationen zu unterdrücken. ${ }^{295}$ Die Leser sollten solche Zeitungen meiden und bereits in der Schule zum „richtigen“ Umgang mit derartigen Meldungen erzogen werden. Zugleich bedeutete der geforderte Schutz der Privatheit zumindest implizit, dass im privaten Raum auch ein homosexueller Verkehr legitim sein könne und nicht als Verbrechen gelte. Indem die Zeitungen Homosexualität als etwas „Privates“ bezeichneten, entkriminalisierten sie diese gewissermaßen.

Sowohl durch Krupps Tod als auch durch den Konsens, dass die private Sexualität und Gerüchte hierüber nicht in die Öffentlichkeit gehörten, richtete sich der Skandal per Bumerangeffekt gegen den Vorwärts. Dessen Rechtfertigung, er habe nicht über das Privatleben berichtet, da etwas Strafbares nicht privat sein könne, der Fall durch die Auslandsberichte öffentlich war und ein Zentrumsblatt zuerst darüber schrieb, drangen kaum durch. ${ }^{296}$ Dann erhielt der Skandal jedoch gerade durch die Gegenkampagnen gegen die SPD mehrere neue Wendungen und Dynamiken, welche die generelle Unberechenbarkeit von Skandalverläufen zeigten. Zunächst war das Auftreten des Kaisers hierfür verantwortlich. Obwohl Wilhelm II. im Oktober 1902 von den Gerüchten erfahren hatte, unterstützte er Krupp weiterhin persönlich. So schrieb er ihm Anfang November, er habe den Bau eines Linienschiffes in Krupps Germaniawerft angeordnet,

291 MNN, Nr. 588, 17. 12.1902.

292 Zit. Post Nr.557, 28.11.1902 und Nr.560, 29.11.1902; ähnlich etwa: Berliner Neueste NACHRichten Nr. 561, 30.11.1902.

293 Westrälische VolksZeitung Nr.276, 29.11.1902.

294 Deutsche Tageszeitung Nr. 566, 3.12.1902.

295 Berliner Lokal-Anzeiger Nr. 561, 30.11.1902; ähnlich: Bonner Zeitung 27.11.1902.

296 VORWÄRTS 26.11.1902. 
und berichtete ihm kurz darauf mit überschwänglichem Lob von seinem Werftbesuch. ${ }^{297}$ Auch wenn Krupp nur zur „Umgebung“ und nicht zum engen Freundeskreis des Kaisers zählte, machte Wilhelm II. selbst Krupps Begräbnis zu seiner persönlichen Angelegenheit. ${ }^{298}$ Philipp von Eulenburg, der den Kaiser an Krupps Todestag nach längerer Abwesenheit aufsuchte und mit ihm allein frühstückte, beriet ihn hierbei vermutlich. ${ }^{299} \mathrm{Da}$ Eulenburg selbst homosexuelle Neigungen besaß, dürfte er am Kampf gegen entsprechende Denunziationen kein geringes Interesse gehabt haben.

Die allgemeine Empörung über den Vorwärts wendete sich erst, als sich der Kaiser ihr mit drastischen Formulierungen beim Essener Begräbnis von Krupp anschloss. Ähnlich wie die konservativen Blätter zog er aus dem Skandal den Schluss, die Sozialdemokraten seien schärfer zu bekämpfen und auszugrenzen, da sie nicht länger das Recht hätten, als Deutsche zu gelten. Seine Worte waren nur noch drastischer: „Diese That mit ihren Folgen ist weiter nichts als Mord; denn es besteht kein Unterschied zwischen demjenigen, der den Gifttrank einem anderen mischt und kredenzt, und demjenigen, der aus dem sichern Versteck seines Redactionsbureaus mit vergifteten Pfeilen seiner Verleumdungen einen Mitmenschen um seinen ehrlichen Namen bringt und ihn durch die hierdurch hervorgerufenen Seelenqualen tödtet. [...] wer nicht das Tischtuch zwischen sich und diesen Leuten zerschneidet, legt moralisch gewissermaßen die Mitschuld auf sein Haupt. "300 Ähnliche Kaiserreden folgten in Breslau und Görlitz. ${ }^{301}$ Dass der Skandal das Bündnis zwischen Sozialdemokratie und den Arbeitern durchschnitten habe, sollte auch die anschließend überreichte „spontane“ Grußadresse an den Kaiser mit über 20000 Unterschriften von Krupp-Arbeitern symbolisieren, die sich auf Krupps Seite und gegen die Verleumdungen der SPD stellten. ${ }^{302}$

Tatsächlich löste beides in der Öffentlichkeit einen gegenteiligen Effekt aus. Einige Zeitungen sahen in dem Mordvorwurf des Kaisers die journalistische Berufsehre verletzt. ${ }^{303}$ Andere kritisierten, der Kaiser nehme mit seiner Unschuldsbeteuerung das noch ausstehende Gerichtsurteil vorweg und zeige unangemessenen Zorn. ${ }^{304}$ Der Mordvorwurf einte und mobilisierte vor allem die Sozial-

297 Wilhelm II. an Krupp 1.11.1902, in: HAK, FAH 3 C 227: 93; Wilhelm II. an Krupp 7.11.1902, in: HAK, FAH 3 C 227: 95.

298 Zur Unterscheidung zwischen „Umgebung“ und „Freundeskreis“: Isabel V. Hull, The Entourage of Kaiser Wilhelm II, 1888-1918, Cambridge 1982, S. 159.

299 Ein Bericht über das Treffen, aber ohne die Erwähnung Krupps in: Eulenburg an Bülow 23.11.1902, in: BAK, 1029-59.

300 Abgedruckt in: Boelcke, Krupp, S.167f.

301 Berliner Tageblatt Nr. 638, 16. 12.1902; Berliner Lokal-Anzeiger, Nr. 571, 6.12.1902.

302 Übergabe einer Kaiseradresse, Direktorium Krupp an Chef des Geheimen Zivilkabinetts, von Lucanus, 20.12.1902, abgedr. in: Boelcke, Krupp, S. 172

303 Demokratische Volks-Zeitung Nr.556, 27.11.1902; Danziger Zeitung Nr.559, 29.11.1902.

304 Frankfurter Zeitung Nr.329 27.11.1902; BZ am Mittag Nr.556, 27.11.1902; Berliner Tageblatt Nr.638, 16.12.1902; Münchener Zeitung, Nr. 284, 28.11.1902. 
demokraten. Bis hinein in die Ortsvereine empörte die Rede ihre Mitglieder. ${ }^{305}$ Für noch mehr Empörung sorgte die Meldung, dass zwei langjährige Arbeiter in Krupps Grusonwerk entlassen wurden, weil sie nicht die „freiwillige“ Treueadresse an den Kaiser unterzeichnet hatten. Dies führte zu Protestkundgebungen und auch zu Kritik in den bürgerlichen Zeitungen. ${ }^{306}$ Der Vorwärts versuchte dabei direkt an den Panama-Skandal und die Dreyfus-Affäre anzuknüpfen und trat mit einem „Wir klagen an!“ in der Pose Zolas auf. ${ }^{307}$ Im Direktorium von Krupp rechtfertigte man die Entlassung mit „Arbeitsmangel“ und erklärte, rund zehn Prozent der Arbeiter hätten nicht unterschrieben, aber immerhin führte die schlechte Presse zur Entlassung des verantwortlichen Geschäftsleiters des Grusonwerks. ${ }^{308}$ Die Kaiserrede und die erpressten Unterschriften verwandelten damit das kurzzeitige Mitleid mit Krupp wieder in die alten Ressentiments gegen ein patriarchalisch geführtes Unternehmen, das seine Macht aus der engen Verbindung zum Kaiser zog. Einen ähnlichen Effekt hatte das Redeverbot, dass der Reichstagspräsident Ballestrem dem SPD-Abgeordneten Vollmar erteilte, als der im Januar im Reichstag den Fall Krupp und die Kaiserrede dazu ansprach. Der dem Zentrum angehörende Reichstagspräsident untersagte jede Aussprache, da dies Privatangelegenheiten seien. ${ }^{309}$ Indem die Konservativen und die Zentrumspartei die parlamentarische Aussprache über den Skandal untersagten, trat er erneut in der Medienöffentlichkeit. Zudem wurde dies mit einer grundsätzlichen Debatte über die Redefreiheit im Reichstag verbunden.

Eine weitere neue Dynamik erfuhr der Skandal durch die Debatte, ob der Vorwärts auch nach Krupps Tod strafrechtlich zu verfolgen und Krupps „Schuld“ gerichtlich zu klären sei. Da nach Krupps Tod der Kläger entfiel, erwartete die gesamte Presse das Eingreifen des Staatsanwaltes im Namen des öffentlichen Interesses. Gerade die kaisertreuen Zeitungen forderten dies vehement ein, ${ }^{310}$ aber auch der Vorwärts blickte selbstbewusst dem Prozess entgegen, nahm nichts zurück und versprach Beweise für Krupps Homosexualität vorzulegen. ${ }^{311}$ Tatsächlich bereitete die Staatsanwaltschaft ein entsprechendes Verfahren vor, bis plötzlich Mitte Dezember dessen Einstellung auf

305 Vgl. Adelheid von Saldern, Auf dem Wege zum Arbeiter-Reformismus. Parteialltag in sozialdemokratischer Provinz. Göttingen (1870-1920), Frankfurt a. M. 1984, S.67.

306 So kritisierte die Germania (19.12.1902), dies „fälscht die öffentliche Meinung“. Schärfer in der SPD-Presse: Volksstimme Magdeburg Nr.290, 12.12.1902; Vorwärts Nr.293, 16.12.1902.

307 VORWÄRTS Nr.293, 16.12.1902: „Seit den Zwangskundgebungen und Nöthingungsadressen der Arbeiter ist der Fall Krupp zu einem Panama geworden, dessen Bloßlegung jetzt zu beginnen hat. [...] Wir klagen an!“

308 Friedrich Krupp/Direktorium an Direktor Teuffel, 17.12.1902, in: WA, 4/1286: 25; Direktor Sorge an Landrat 17.12.1902, in WA, 4/1286: 68.

309 Rede RT 20.1.1903, Sten. Ber., Bd. 8, S. 7419 f.

310 Vgl. etwa Post Nr.553, 26.11.1902; Kölnische Zeitung, Nr. 933, 27.11.1902; Deutsche Tages-Zeitung Nr. 558, 28.11.1902.

311 Vgl. zum Verhör: Denkschrift Oberstaatsanwalt Isenbiel an Justizminister 6.12.1902, in: GStA, HA I Rep. 84a Nr. 49713. 
Wunsch der Witwe bekannt wurde. ${ }^{312}$ In den Zeitungen stieß dies ganz überwiegend auf Unverständnis und Protest. Widersprüchlich erschien rechtlich, dass der Staatsanwalt erst ein öffentliches Interesse sah und dann auf Bitte der Witwe dies nicht mehr gegeben schien. Vor allem monierten die Blätter aber, dass dies ein verspäteter Sieg des Vorwärts sei und die Vorwürfe so ungeklärt blieben. Einerseits sahen sie sich also um jene gerichtliche verbürgte „Wahrheit" betrogen, die ein Prozess mit all seinen Enthüllungen versprach, andererseits um die ersehnte harte Bestrafung der sozialdemokratischen Journalisten, die weitere Skandale verhindern sollte. Während die SPD-Zeitungen triumphierten, zeigten sich gerade die konservativen Blätter äußerst befremdet über die Entscheidung und verlangten eine Rechtfertigung des Justizministers. ${ }^{313}$ Denn die Einstellung diskreditierte schließlich auch, wie viele Zeitungen bemerkten, den Kaiser. Der General-Anzeiger Hamburg sprach von einer „Desavouierung des deutschen Kaisers“ (H.i.O.), und die BZ am Mittag betonte, die kaiserlichen Anklagen gegen die SPD verlören dadurch ihre „Wirkungskraft." ${ }^{314}$ Damit richtete sich der Skandal von der SPD weg gegen den Justizminister und die Berater des Kaisers, die ebenfalls für die Einstellung verantwortlich gemacht wurden.

Wie kam es zu dieser umstrittenen Einstellung des Prozesses gegen den Willen des Kaisers und der bürgerlichen Öffentlichkeit, durch die der Skandal seine Dynamik verlor? Verantwortlich hierfür war zunächst die Witwe Margarethe Krupp. Nach Krupps Tod war die zwangsweise eingewiesene Ehefrau aus dem Sanatorium entlassen worden und zeigte keinerlei Anzeichen von geistiger Verwirrung, sondern trat recht überlegt das gewaltige Erbe an. Sie schickte dem Staatsanwalt und dem Oberhofmarschall August Graf von Eulenburg die Bitte, letzterer solle den Kaiser informieren, dass sie gegen einen Prozess sei, da dieser den Namen ihres Mannes nur weiter in den Schmutz ziehen würde und ihre Nerven dies nicht verkrafteten. Krupps Vertrauter, Assessor Korn, und das Direktorium unterstützten dies, da eine Verurteilung des Vorwärts schwierig sei, zumal Krupp nicht mehr per Eid seine Unschuld beweisen könne. ${ }^{315}$ Obwohl auch Eulenburg das ähnlich sah, lehnte Wilhelm II. die Einstellung brüsk ab: „Das Verfahren muß unter allen Umständen fortgesetzt werden. Coute que coute [...]. Ein Einstellen des Verfahrens würde bloß das Aufblühen unzähliger Verdachtsmomente herbeiführen.“316

312 Erklärung Erste Staatsanwalt an Vorwärts, 15.12.1902, abgedr. in: VoRwäRTs 15.12.1902.

313 Vgl. Vorwärts 15.12.1902, 17.12.1902; StaAtsbürger-Zeitung Nr.589, 17.12.1902 u. Nr.607, 30.12.1902; Germania 17.12.1902.

314 Zitate in: General-Anzeiger Hamburg, Nr.296, 18.12.1902, BZ am Mittag Nr.587, 16. 12.1902.

315 Margarethe Krupp an August von Eulenburg 5.12.1902 und August von Eulenburg an Wilhelm II. 6.12.1902, in: BAK N 1016-74-8f. (Abschrift Philipp von Eulenburg für Bülow 1.2.1903).

316 Antwortnotiz von Wilhelm II. 6.12.1902 auf Brief: August Eulenburg an Wilhelm II. 6.12.1902, in: BAK, N 1016-74-12 (Abschrift Philipp von Eulenburg für Bülow 1.2.1903). 
Dass es trotz dieses vehementen Protestes des Kaisers zu keinem Prozess kam, bleibt dennoch erklärungsbedürftig. Anzunehmen ist, dass sowohl die Witwe als auch die Unternehmensleitung zumindest gewisse Verdachtsmomente hatten und kein Risiko eingehen wollten, auch wenn die Einstellung wie ein Schuldbeweis wirkte. Wie viele Prozesse vorher zeigten, hätte jedoch selbst eine Verurteilung des Vorwärts unangenehme Details über ihr Privatleben verbreiten können. Eulenburg scheint den Kaiser in diesem Sinne beraten zu haben. Eine weitere sehr plausible Erklärung nannte Maximilan Harden gegenüber Kurt Eisner: „Die Einstellung ist Folge der Münchener Post. Tant mieux“.317 Denn diese hatte angedeutet, Krupp habe vor seinem Tode versucht, seine Frau zu entmündigen. Ein Prozess barg daher die Gefahr, dass die Umstände ihrer Einweisung an die Öffentlichkeit kamen, in die wiederum ja auch der Kaiser und einzelne Minister mit verwickelt waren. Deshalb beschränkte sich die Staatsführung darauf, auf der symbolischen Ebene an Krupps „Unschuld“ festzuhalten. Schon im Juni 1904 enthüllte der Kaiser ein Denkmal für ihn in Kiel, im Beisein des Reichskanzlers, von Staatssekretär Tirpitz und der gesamten Admiralität. ${ }^{318}$

Die vielschichtigen Stränge und Deutungen im Zuge des Skandals zeigten sich nicht nur in der Medienöffentlichkeit, sondern auch in der situativen Öffentlichkeit der Stammtische. Auffälliger Weise blieben in den meisten Hamburger Kneipenberichten zunächst Meldungen über den Skandal aus. Die Arbeiter empörten sich zwar wie so häufig über einen „Skandal“, meinten damit aber die Reichstagsdebatte über die Getreidezölle, in denen sich die „Junker“ gegen die Mehrheit durchgesetzt hätten. ${ }^{319}$ Entweder war die „Sensationssucht“ der Leser nicht so groß, wie die Eliten annahmen, oder die Polizisten scheuten sich bei diesem besonders prekären Fall zunächst, Aufzeichnungen über derartige Gespräche zu machen. Nach Krupps Tod, als die Zeitungsartikel zunahmen, verzeichneten sie insbesondere in den Kneipen im Hafenviertel intensivere Diskussionen über Krupp. Einige Gäste machten wie bei anderen Skandalen ihrer Empörung Luft: „Krupp habe sich frühzeitig aus dem Staub gemacht, fast hätte er sein letztes Stückchen Brot im Zuchthaus genießen können. Wenn von der Sittengeschichte nichts an dem sei, würde von der Presse wohl nicht einfach und so frei über K. schreiben. Außerdem würde in der Presse doch ausdrücklich bemerkt, daß man im Besitze von Photographien [sei] und dieses besage alles.“ Nun würde alles vertuscht, obwohl der Tod ein Beleg sei. ${ }^{320}$ Die Äußerung hinterfragte somit den Wahrheitsgehalt der Medien, sah aber in einem Zirkelschluss

317 Harden an Eisner 18.12.1902, in: BAB/L NY 4060-65 u. Eisner an Harden 19.12.1902, in: BAK, N 1062-33.

318 Dies vermerkte ohne jeden Kommentar auch: Monatsbericht DES Wissenschaftlich-HUMANITÄREN KOMITEES 1.7.1904.

319 So in den unterschiedlichen Bezirken: Polizeibericht, 4.12.1902, in: StAH, S 3930-26 Bd.1; Polizeibericht Sankt-Pauli-Süd 8.12.1902, in: StAH, S 3930-23 Bd.9; Polizeibericht 14.12.1902, in: StAH, S 3930-26 Bd.1.

320 Polizeibericht Sankt-Pauli-Süd 26.11.1902, in: StAH, S 3930-23 Bd. 9. 
den Druck der Nachricht als Beleg für ihre Wahrheit. Diese Authentizitätszuschreibung dokumentiert, welche Beweiskraft einem gedruckten Gerücht zugeschrieben wurde. Bemerkenswert ist zudem der Glaube an die Beweiskraft von Fotographien, deren Erwähnung - obgleich sie in diesem Fall nicht existierten - bereits als Beleg galt.

Die Kneipenbesucher nahmen die sensationelle Enthüllung und die wohlwollenden Nachrufe der Zeitungen zum Anlass, Krupps Unternehmensführung generell zu diskutieren. In einer Kneipe hieß es: „An den Leiden, woran dieser Kerl gestorben sei, wären noch viel zu gut für selbigen gewesen [sic] [...] Krupp wäre einer der größten Menschenschinder“. Er habe Millionen verdient, aber kaum Steuern bezahlt; „es wäre auch ein Skandal in dem soviel Zeitungen einen solchen Menschen vergöttert hätten, wo doch selbiger so unendlich schmutzige Sachen auf dem Kerbholz habe.“321 „Schmutzig“ bildete dabei generell, der in Deutschland beliebten Hygienemethaphorik entsprechend, eine zentrale alltagssprachliche Kategorie, um Homosexualität oder sonstige Missstände zu umschreiben. Krupp fand unter den Gästen aber auch einige Fürsprecher. Einer pries Krupps Wohltaten, die er durch seine frühere Tätigkeit in den Werken kannte. ${ }^{322}$ Andere Kneipenbesucher rechneten dagegen mit ihren Kenntnissen aus den sozialdemokratischen Medien vor, dass Krupp die drei Millionen Mark für seine Wohltätigkeit vorher seinen 45000 Arbeitern abgenommen habe. ${ }^{323}$ Die Medien hatten dementsprechend eine Agenda-Setting-Funktion: Durch den Skandal kam das Thema Krupp in die Gespräche und wurde dann durch Alltagserfahrungen, generelles Wissen und persönliche Einschätzungen abgewandelt.

Die Frage, ob eine Zeitung überhaupt derartige Enthüllungen veröffentlichen dürfe, löste ebenfalls kontroverse Debatten an den Stammtischen aus. Ein Gast lobte die Kaiserrede an Krupps Grab gegen die SPD-Presse, da letztere eben so „schmutzig“ sei wie die SPD selbst. ${ }^{324}$ Auch in anderen Kneipen hieß es, es sei gut, „wenn man einmal diesen schmutzigen Blättern etwas mehr auf die Finger setzen thäte. “325 Für Empörung sorgte wie in den Zeitungen die Einstellung des Verfahrens, da dies die Doppelmoral, die Klassenjustiz und die Schuld von Krupp zeige. Das Verfahren sei „eine ganz abgekaterte Sache gewesen, denn die obere Sippschaft wisse ja zu genau wie man am allerbesten schmutzige Sachen aus dem Wege kommen könnte. Dieser Fall zeige wieder einmal wie man das Volk für dumm verkaufen suchte, wenn man wirklich reine Seele hätte, so habe man das Verfahren nicht eingestellt, sondern das Verfahren vollständig zu Ende

321 Polizeibericht Sankt-Pauli-Süd 25.11.1902, in: StAH, S 3930-23 Bd. 9.

322 Polizeibericht Sankt-Pauli-Süd 27.11.1902 und 28.11.1902, in: StAH, S 3930-23 Bd. 9.

323 Polizeibericht, 2.12.1902, in: StAH, S 3930-26 Bd.1. Ob diese Angaben der Zeitungslektüre der Polizisten oder der Gäste entsprangen, ist, wie eingangs formuliert, natürlich nicht immer zu belegen.

324 Polizeibericht Sankt Pauli-Süd 27.11. 1902 und 28.11.1902, in: StAH, S 3930-23 Bd. 9.

325 Ebd. 1.12.1902. 
geführt. “326 Ebenso sorgte für massive Empörung, dass der sozialdemokratische Reichstagsabgeordnete Vollmar nicht zum Fall Krupp im Reichstag sprechen durfte. Allerdings betonten die Kneipenbesucher, dass auch dies letztlich nur der SPD nützen würde. ${ }^{327}$

Tatsächlich scheint die Empörung, die der Skandal auslöste, den Sozialdemokraten genützt zu haben. So erreichten sie bei der Wahl 1903 nicht nur reichsweit und besonders im Ruhrgebiet Zuwächse, sondern auch in Krupps Essener Wahlkreis einen haushohen Sieg. Da der Fall Krupp gerade hier das zentrale öffentliche Thema war, dürfte er die Wahlentscheidungen beeinflusst haben. Interne Untersuchungen von Krupp zeigten dabei, dass mindestens ein Viertel der eigenen Arbeiter die SPD wählten. ${ }^{328}$ Die Repressionsversuche des Staates bewirkten folglich das Gegenteil. Generell dürfte der Fall dazu beigetragen haben, die Gegenwartsdeutungen und Zukunftserwartungen der Sozialdemokraten zu prägen. Sie sahen den Fall Krupp in ihrem Jahresrückblick 1902 nur als einen von zahllosen Skandalen an, der die „innere Fäulnis“ des „Systems“ zeige. ${ }^{329}$ Die Skandale waren in dieser Lesart Symptome für den bald bevorstehenden Zusammenbruch des Kaiserreiches und die bevorstehende Herrschaft des Proletariats.

Der Skandal diskreditierte nicht nur den Kaiser und den Justizminister, deren angestrebte Verfolgung der SPD-Presse ins Leere lief. Er war vor allem ein Schlag für das moralische Selbstverständnis des Bürgertums. Während Homosexualität bis ins 19. Jahrhundert noch als ein moralischer Normverstoß galt, der sich abgrenzend dem Adel oder Unterschichten zuschreiben ließ, traf der Vorwurf nun einen der prominentesten Bürgerlichen. Bereits die Berichte über den Müßiggang des Unternehmers, die der Skandal vielfach aufbrachte, unterliefen wie bei entsprechenden Skandalen in Großbritannien das bürgerliche Selbstbild. Da es sich um den ersten großen deutschen Skandal im ausgehenden 19. Jahrhundert handelte, der offen Homosexualität anklagte und diskutierte, trug der Fall wesentlich dazu bei, das Bild des Homosexuellen zu konstruieren. Ähnlich wie in Großbritannien wurde es mit der Verführung Minderjähriger, weiblichem Verhalten und Schwäche verbunden. Eine verstärkte Verfolgung von Homosexuellen löste der Skandal jedoch nicht aus, ebenso keine Verschärfung der Gesetzgebung. ${ }^{30}$ Vielmehr machte der Fall deutlich, wie stark zumindest in liberalen und sozialdemokratischen Kreisen die Forderung nach einer Abkehr von der Bestrafung war.

Für die frühe Homosexuellenbewegung und Sexualforschung gab der Skandal den Anstoß für eine verstärkte Aktivität, da nun das Thema mit einem

\footnotetext{
326 Polizeibericht Schutzmann Struve, 17.12.1902, in: StAH, S 3930-23 Bd. 9.

327 Polizeibericht, 22.1.1903, in: StAH S 3930-22 Bd. 9.

328 Vgl. Anderson, Practicing Democracy, S. 274.

329 VORWÄRTS Nr.1, 1.1.1903.

330 Dabei sind die steigenden Zahlen der Verurteilungen pro Einwohner zu rechnen; vgl. die Daten bei: Hutter, Die gesellschaftliche Kontrolle, S. 77; Baumann, Paragraph 175, S. 58.
} 
prominenten Beispiel in der Öffentlichkeit war. Um ihre bisherigen Annahmen über die Verbreitung von Homosexualität auf eine empirische Basis zu stellen, schickte Hirschfelds Wissenschaftlich-humanitäres Komitee im Jahr 1903 an die 3000 Studenten der Technischen Hochschule Charlottenburg/Berlin Fragebögen, ebenso Anfang 1904 an die im Berliner Metallarbeiterverband organisierten Arbeiter. ${ }^{331}$ Immerhin ergab der große Rücklauf von 60 Prozent der Studierenden, dass 1,5 Prozent sich als homosexuell und 4,5 Prozent als teilweise homosexuell bezeichneten. Zusammen mit den Namens- oder Berufsnennungen von erpressten oder verurteilten Homosexuellen und den fortlaufenden Meldungen über deren Selbstmorde konnten sie so an Krupp anknüpfend belegen, dass auch im Bürgertum Homosexualität verbreiteter war als bisher angenommen und daher eine Bestrafung abzulehnen sei. Dass Hirschfeld auf Antrag eines Studenten wegen seiner Umfrage verurteilt wurde, erhöhte nur die Publizität seiner Studie. ${ }^{332}$ Bereits 1905 fanden sich in der neuen Ausgabe von Meyers Konversations-Lexikon diese Werte als statistische Schätzung. Ebenso setzte sich in dem Eintrag „Homosexualität“ die seit dem Oscar Wilde-Skandal popularisierte Vorstellung durch, Homosexuelle wären „oft fein entwickelte, hoch kultivierte Personen“, deren Geschlechtstrieb meist angeboren, selten „als Folge von Ausschweifungen“ zu verstehen sei. ${ }^{333}$

Die weitere Veröffentlichung der Homosexualität von Prominenten war jedoch auch bei den Lobbyisten für die Abschaffung des $\$ 175$ umstritten. Hirschfelds Komitee wehrte sich prinzipiell gegen Albert Molls Plädoyer in der Zukunft, durch die Enthüllung prominenter Homosexueller die Politiker zu der Einsicht zu bringen, dass auch ein ihnen vertrauter „braver, ausgezeichneter Mensch“ homosexuell sein könne, weil dies ein „Weg über Leichen“ sei. Vielmehr entgegnete Hirschfeld unter Andeutung seines Wissens:

Namentlich die Herren bei Hofe mögen sich keinen Beunruhigungen hingeben. [...] Wir wollen aber nicht unterlassen, diese Herren darauf aufmerksam zu machen, ein wie hohes Verdienst sie sich erwerben würden, wenn sie z.B. auf einer Nordlandreise Gelegenheit nehmen würden, den Kaiser über Wesen und Verbreitung der Homosexualität zu informieren. Mögen die Herren bedenken, in welche Unannehmlichkeiten sie nicht nur sich selbst, sondern auch den Kaiser durch einen betreffenden Skandal bringen, vor dem, wie leider die Fälle Hohenau und Krupp gezeigt haben, selbst die dem Thron zunächst stehenden nicht gesichert sind. 334

Damit richtete er jedoch bereits 1903 eine unverkennbare Drohung an Kaiserfreunde wie Philipp von Eulenburg, dass weitere Skandale im Umfeld des Kaisers folgen könnten, wenn der $\$ 175$ nicht geändert würde. Denn tatsächlich hatte der Krupp-Skandal vor allem eins gezeigt: Selbst jemand mit den größten

331 Vgl. Monatsbericht des Wissenschaftlich-Humanitären Komitees 1.4.1904.

332 Vgl. die Pressestimmen in: ebd. 1.6.1904.

333 Eintrag Homosexualität in: Meyers Konversations-Lexikon 1905.

334 So Albert Moll in: Die Zukunft 13.12.1902. Die zitierte Entgegnung dazu von Hirschfeld im Jahrbuch für sexuelle Zwischenstufen 1903; erneut abgedruckt in: MonATsBericht DEs WisSENSCHAFTLICH-HUMANITÄREN KoMITEES 1.7.1907, S. 126. 
finanziellen Ressourcen, besten politischen Kontakten und einer eigenen Presseabteilung war gegenüber einer Veröffentlichung wehrlos, die einen derartigen Normbruch in die Öffentlichkeit überführte.

\section{Im Umfeld des Kaisers: Kamarilla, Militär Und HOMOSEXUALITÄT}

Nach dem Krupp-Skandal spielte das Thema Homosexualität zunächst wieder nur eine untergeordnete Rolle in der deutschen Öffentlichkeit. Hirschfelds Wissenschaftlich-humanitäres Komitee versuchte zwar weiterhin, mit Petitionen eine Gesetzesänderung zu erreichen, aber vor allem die Zentrumspartei blockierte bereits die parlamentarische Debatte hierüber. Erst Ende März 1905 konnte der SPD-Abgeordnete Adolf Thiele die erhoffte Gesetzesänderung im Reichstag vorbringen. Seine Forderung nach einer Straffreiheit begründete er mit ausführlichen Hinweisen auf den naturwissenschaftlichen Forschungsstand, dem zufolge Homosexualität angeboren sei und über eine Millionen Deutsche homosexuell wären. Zudem argumentierte er unter Verweis auf Krupp mit der großen Toleranz gegenüber homosexuellen Eliten, die der Polizei bekannt seien, und leitete daraus die Forderung nach einer generellen Straffreiheit ab. ${ }^{335}$ Erwartungsgemäß wurde der Antrag jedoch abgelehnt und der Hinweis auf Krupp zurückgewiesen. Die Konservativen und Zentrumsabgeordneten begründeten dies mit der Unsittlichkeit von Homosexualität und der „Gefährdung der Staatsinteressen und der allgemeinen Wohlfahrt “. ${ }^{336}$ Immerhin führte dieser Vorstoß die naturwissenschaftliche Einschätzung zur Homosexualität und das Bild der homosexuellen Eliten erneut in die Öffentlichkeit. Und selbst die Zurückweisung bedeutete eine Auseinandersetzung mit diesen Deutungen.

Unmittelbar nach dem Krupp-Skandal lagen jedoch Nachfolgefälle in der Luft. Zumindest lassen sich zahlreiche Berichte über Erpressungen von prominenten Personen ausmachen, die mit ähnlichen Skandalen bedroht wurden. So wurde der Zentrumsabgeordnete Kaplan Georg Friedrich Dasbach 1904 mehrfach erpresst, konnte die Vorwürfe aber in Prozessen zurückweisen und Amt und Mandat trotz der virulenten Beschuldigungen behalten. Zudem erreichte der Abgeordnete ein gerichtliches Verbot einer Broschüre des Publizisten Adolf Brand, eines radikalen Aktivisten der Homosexuellen-Bewegung, der ihm Homosexualität vorwarf. Auch wenn es zu keinem Skandal kam, rückte der Vorwurf gegen den Politiker so in diverse Zeitungen. ${ }^{337}$ Drei Jahre später musste

335 Rede 31.3.1905, Sten. Ber. RT, Bd. 8, 177. Sitzung, S. 5826-5832.

336 Reden 31.3.1905, ebd., S. 5832-5842, zit. S. 5837.

337 Adolf Brand, Der Fall Dasbach und die Freundesliebe, München 1904; Hinweise darauf in: Eugen Johannes Maecker, Harden-Hirschfeld. Eine Aufklärungsschrift, Berlin o. D. (1908), S.19f., in: GStA, HA I Rep. 84a Nr. 58203. Zeitungsberichte über einen weiteren Prozess von Dasbach wegen Erpressung, die nur von „Gerüchten“ sprechen, abgedr. in: MonATsBericht Des Wissenschaftlich-Humanitären Komitees 1.4.1904. 
sich der Zentrumsabgeordnete Maximilian Josef Pfeiffer gegen ähnliche Gerüchte wehren. 338 Äußerst ausführlich berichteten Anfang 1905 auch zahlreiche Zeitungen darüber, dass ein Breslauer Landgerichtsdirektor seinen Erpressern Schrot ins Gesicht schoss, nachdem er rund 40000 Mark gezahlt hatte. Dies löste immerhin in den Medien eine Debatte darüber aus, ob der $\$ 175 \mathrm{zu}$ lockern sei, wobei die Positionen uneinheitlich blieben; selbst die liberale BZ am Mittag mahnte die Befürworter einer Entschärfung, vorsichtig vorzugehen, denn: „Der Ekel ist unter Umständen stärker als alle Vernunft.“339 Zumindest über ein schärferes Vorgehen gegen solche Erpresser bestand ein Konsens. Die zum Teil äußerst hohen Strafen für die Erpresser - im Fall des Landgerichtsdirektors neun Jahre Haft - unterstrichen, wie sehr gerade hier Nachahmungstäter abgeschreckt werden sollten, damit potentielle Homosexuelle zumindest einen gewissen Schutz zu erwarten hatten. 340 Dennoch blieben Selbstmorde nach Erpressungen an der Tagesordnung. So wählte im gleichen Jahr der Berliner Unternehmer Hermann Israel den Freitod, nachdem besonders antisemitische Blätter über seine Erpressung und einen bevorstehenden Prozess wegen der Homosexualitätsvorwürfe berichtet hatten. ${ }^{341}$ Ebenso mussten zahlreiche hohe Offiziere sich Erpressungen erwehren, bis sie sich schließlich der Polizei anvertrauten. ${ }^{342}$ Durch derartige Berichte bildeten nun Homosexualität, der $\mathbb{1 7 5}$ und Erpressung im Diskurs eine Einheit. Damit erschienen Homosexuelle unmittelbar nach dem Krupp-Skandal zunächst stärker als Opfer, weniger als Verführer.

Große Skandale entstanden aus diesen Berichten nicht. Selbst nach dem Selbstmord von Hermann Israel schwiegen viele große Blätter über die genauen Ursachen. ${ }^{343}$ Die Zeitungen beschränkten sich auf knappe Meldungen über Selbstmorde und die über Verurteilungen wegen Homosexualität oder Erpressung. Hier hieß es schlicht, wie etwa in der Frankfurter Zeitung: „Der Unteroffizier Naff vom Infanterie-Reg. Nr.28 erschoß sich mit seinem Dienstgewehr. Er hatte sich in geschlechtlicher Hinsicht an Untergebenen vergangen und sollte

338 Hinweise auf Zeitungsberichte über Pfeiffer in: Linsert, Kabale, S. $496 \mathrm{f}$.

339 BZ am Mittag 3.3.1905. Das Thema „männliche Prostitution“ kam so immerhin ins Preußische Abgeordnetenhaus: Rede Pallaske, Sten. Ber. über die Verhandlungen des Hauses der Abgeordneten 15.2.1905, XX. Leg. Per., I. Sess., 1904/05, 140. Sitzung, Bd.7, Sp.1001710021.

340 Vgl. BZ am Mittag 5.1.1905; Kleines Journal 18.1.1905, Breslauer Zeitung 5.1.1905; Hinweise im Reichstag hierauf auch Rede Thiele 31.3.1905, in: Stenographische Berichte über die Verhandlungen des Reichstages, Bd. 8, 177. Sitzung, S. 5826-5832.

$3413 \mathrm{mal} 5000$ Mark Schweigegeld waren anscheinend gefordert worden. Der erpresste Israel sagte laut Hirschfeld: „Die Presse habe ich nicht zu fürchten, die sind vom Jud abhängig." Hirschfeld an Harden 4.12.1905, in: BAK, N 1062: 51; zu den Zeitungen, die berichteten (wie die antisemitische Tägliche Rundschau) vgl. Die Zununft 2.12.1905, S.311-315.

342 Vgl. etwa zur Erpressung von Hohenau und Wedel: Tresckow, Von Fürsten, S.118f. u. 140.

343 Maximilian Harden führte dies in einem anklagenden, antisemitisch akzentuierten Artikel auf den starken Einfluss des jüdischen Anzeigengeschäfts zurück; DiE Zukunft 2.12.1905, S. 311-315 u. 16.12.1905, S. 410-412. 
in Untersuchung gezogen werden."344 Obwohl viele dieser Fälle so sensible Bereiche wie das Militär betrafen, führten sie zu keiner breiten Empörung. Die geringe Prominenz der Beschuldigten und der Ausschluss der Öffentlichkeit bei den Verhandlungen blockierte offensichtlich zusammen mit der Selbstbeschränkung der Medien eine breite Berichterstattung.

Dies änderte sich 1907/08. In diesen Jahren kam es zu einer Häufung von miteinander verbundenen Skandalen, die das Tabuthema Homosexualität in die breite Öffentlichkeit rückten. Im Zentrum stand dabei der Eulenburg-Skandal, der sich zum größten und heute noch bekanntesten deutschen Skandal des ausgehenden 19. Jahrhunderts entwickelte. Der Eulenburg-Skandal bildete allerdings nur den Nukleus von mehreren miteinander verbundenen Homosexualitätsprozessen, die sich etwa um den Generalmajor und Kommandanten von Berlin, Kuno Graf von Moltke, und eine Reihe weiterer hoher Adliger drehten. Selbst Reichskanzler Bülow musste sich in einem Verleumdungsprozess gegen den Vorwurf der Homosexualität erwehren. Da die Beschuldigten überwiegend aus dem Umfeld des Kaisers stammten, entwickelten sich aus diesen Fällen politische Skandale, die neben der Homosexualität auch die Monarchie insgesamt attackierten.

Die große Bedeutung des Eulenburg/Moltke-Skandals betonten bereits zahlreiche übergreifende Darstellungen. Schon Ernst-Rudolf Huber urteilte in seiner Verfassungsgeschichte, so wie die Skandalaffären des Hauses Bourbon zur Geschichte der französischen Revolution gehören, so zähle der Moltke-Eulenburg-Skandal zum Zusammenbruch der Monarchie, da er ihr Ansehen schädigte und ihren Sturz beschleunigte. ${ }^{345}$ Der Fall Eulenburg ist dementsprechend mit Sicherheit der am besten erforschte Skandal der deutschen Geschichte. So liegen populär verfasste Darstellungen zum Ereignisablauf vor ${ }^{346}$, zur juristischen Urteilsbildung ${ }^{347}$, zu Eulenburgs Beziehung zu Wilhelm II. ${ }^{348}$ und zur öffentlichen Deutung der Monarchie im Zuge des Skandals. ${ }^{349}$ Ebenso sind zahlreiche Briefe der Beteiligten in umfangreichen Editionen publiziert. ${ }^{350} \mathrm{Im}$ Unterschied zu den meisten genannten Studien stehen hier einerseits die Interaktion von Presse, Politik und Öffentlichkeit im Vordergrund, andererseits die ausgehandelten Normen - insbesondere beim Umgang mit Homosexualität.

344 Frankfurter Zeitung 4. 9.1904. Zahlreiche ähnliche Artikel aus Tageszeitungen in den folgenden Ausgaben des: Monatsbericht des Wissenschaftlich-Humanitären Komitees.

345 Ernst Rudolf Huber, Deutsche Verfassungsgeschichte seit 1789, Bd. 4: Struktur und Krisen des Kaiserreiches, Stuttgart 1969, S. 301.

346 Allerdings ohne Aktenkenntnis: Jungblut, Famose Kerle; ebenfalls ereignisorientiert und wissenschaftlich nur bedingt brauchbar: Leuchtmann, Der Fall Eulenburg. Eine umfassende Analyse des Eulenburg-Skandals wird 2009 von Norman Domeier (EUI Florenz) als Dissertation abgeschlossen.

347 Неснт, Die Harden-Prozesse.

348 Hull, The Entourage.

349 Kohlrausch, Der Monarch, S. 186-242.

350 John C. G. RöHL (Hrsg.), Philipp Eulenburgs politische Korrespondenz, 3 Bde., Boppard 1976-1983; Helmuth Rogge, Holstein und Harden. Politisch-publizistisches Zusammenspiel zweier Außenseiter des wilhelminischen Reichs, München 1959. 
Dass der Skandal eine derartig starke öffentliche Rezeption aufwies, lag nicht nur an den verhandelten Themen, sondern bereits an seinen beiden Protagonisten. Beide waren ebenso prominent wie öffentlich umstritten. Auf der einen Seite stand Maximilian Harden, der bereits um die Jahrhundertwende zu den wichtigsten deutschen Journalisten zählte. So rückte die Berliner Illustrirte Zeitung 1904 in einem Portraitbericht über „Führende Geister auf dem Gebiet der politischen Publizistik“ sein Bild groß in die Mitte. ${ }^{351}$ Der 1861 geborene Harden, der diesen Künstlernamen erst später wählte, stammte aus einem jüdischen Elternhaus, war aber früh zum Protestantismus konvertiert. Nach einigen Erfahrungen als Schauspieler und freier Journalist gab er seit 1892 die mit intellektuellen Essays bestückte Wochenzeitschrift Die Zukunft heraus, deren wichtigster Autor er zugleich selbst war. Diese zeichnete sich vor allem durch eine Bismarck-treue Ausrichtung aus, die sich gegen den „neuen Kurs“ von Wilhelm II. und dessen Umfeld richtete. Hardens Essays glänzten durch einen feinsinnig verspielten Stil, durch Hintergrundinformationen aus politischen Kreisen und durch ungewöhnlich eigenständige Urteile, die keiner politischen Linie dauerhaft entsprachen. Dementsprechend reichte seine umfangreiche Korrespondenz von der politischen Linken bis zur Rechten. ${ }^{352}$ Harden war ein Anhänger der Monarchie, zugleich aber einer der schärfsten Kritiker von Wilhelm II., was dem Journalisten Haftstrafen einbrachte. ${ }^{353}$ Er war prinzipiell konservativ, aber wie sich im Fall Krupp zeigte, gegenüber Homosexualität durchaus liberal eingestellt, weshalb er auch mit Magnus Hirschfeld korrespondierte. ${ }^{354}$ Im Unterschied zu vielen anderen Journalisten, die Skandale in Deutschland und Großbritannien anstießen, war Harden jedoch nie als Politiker aktiv gewesen. Er war vielmehr ein Journalist, der durch seine Artikel, Briefe und Kontakte Politik gestalten wollte. Damit glich er in vieler Hinsicht dem führenden englischen Journalisten W.T. Stead, auch wenn Harden weniger durch investigative Recherche auf der Straße agierte, sondern eher als intellektueller Einsiedler aus dem Berliner Grunewald. 355

Auf der anderen Seite stand mit dem 1847 geborenen Philipp von EulenburgHertefeld der lange Zeit engste Freund und Berater des Kaisers. Eulenburg stammte aus altem Adel, hatte ein großes Vermögen geerbt und einflussreiche

351 BIZ Nr. 37, 11. 9. 1904. Zu Hardens Vita vgl. BJörn Uwe Weller, Maximilian Harden und die „Zukunft“, Bremen 1970; H.F. Young, Maximilian Harden. Censor Germaniae, Ein Publizist im Widerstreit 1892 bis 1927, Münster 1971; knapp und wenig hilfreich: Helga Neumann und Manfred Neumann, Maximilian Harden (1861-1927). Ein unerschrockener deutsch-jüdischer Kritiker und Publizist, Würzburg 2003.

352 Vgl. seine Briefe in: BAK, N 1062.

353 Weller, Maximilian Harden, S. 114.

354 Vgl. etwa die Briefe Hirschfelds an Harden im Jahr 1905 in: BAK, N 1062: 51.

355 Als ein Vergleich zwischen Harden und Stead vgl. Frank Bösch, Volkstribune und Intellektuelle. W.T. Stead, Harden und die Transformation des politischen Journalismus in Großbritannien und Deutschland, in: Clemens Zimmermann (Hrsg.), Politischer Journalismus, Öffentlichkeiten, Medien im 19. und 20. Jahrhundert, Ostfildern 2006, S. 99-120. 
Politiker in seiner Familie. Besonders in den 1890er Jahren war er durch seine freundschaftliche Beziehung zu Wilhelm II. einer der einflussreichsten Politiker, obgleich er nur einen Posten als Gesandter in München und dann als Botschafter in Wien einnahm. Seine Briefwechsel bersten von Vorschlägen zu Personalrochaden, von Intrigen(berichten) und Überlegungen zu politischen Schachzügen, bei denen er immer gleich die öffentliche Wirkung mit einkalkulierte. ${ }^{356}$ Viele seiner vertraulichen Briefe, insbesondere an Bülow und Moltke, waren zugleich von einer homoerotischen Freundschaftseuphorie durchzogen, die die Grenzen der zeitgenössischen romantischen Rhetorik leicht überschritten. ${ }^{357} \mathrm{Er}$ selbst ließ sich „Phili“ und „Philine“ nennen, den Kaiser nannten er und seine Freunde „das Liebchen.“ Ebenso wurde der „Liebenberger Kreis“, also jene hohen Adligen aus dem Umfeld des Kaisers, die sich regelmäßig auf Eulenburgs Schloss trafen, im hohen Maße durch homoerotische Neigungen zusammen gehalten. ${ }^{358}$ Im Adel und bei der Berliner Sittenpolizei kursierten dementsprechend bereits vor dem Skandal Gerüchte über Eulenburgs Homosexualität, und in Wien musste er sich Erpressungen erwehren. ${ }^{359}$ Letzteres dürfte auch mit erklären, dass er sich 1902, im Jahr des Krupp-Skandals, von seinem Posten als Botschafter zurückzog, zumal sich sein Verhältnis zu Wilhelm II. schon vorher abgekühlt hatte.

Eulenburg hatte durch seine anfängliche Schlüsselstellung im „persönlichen Regiment“ von Wilhelm II. von Beginn an zu den Politikern gezählt, die Harden kontinuierlich kritisierte. Spott über Eulenburgs Privatleben, insbesondere seine Liebe zu romantischen Liedern und Gedichten, gehörte zu Hardens festem Arsenal. ${ }^{360}$ Das essayartige Format seiner Artikel erleichterte derartige flüchtige Andeutungen. Da Eulenburg im hohen Maße der Figur des schlechten Beraters zu entsprechen schien, stieß Hardens Kritik auf breite Resonanz. ${ }^{361}$ Dass Harden ausgerechnet 1906 seine folgenreichste Kampagne startete und auf Eulenburgs Homosexualität anspielte, lässt sich aus der politischen Konstellation erklären. Harden reagierte auf den seiner Meinung nach schlechten Einfluss der Kaiserberater bei der ersten Marokkokrise, auf das Gerücht, eine Kamarilla um

$356 \mathrm{Vgl}$. aus den zahlreichen gedruckten Briefen etwa exemplarisch: Eulenburg an Bülow 24.4.1897, abgedr. in: RöHL (Hrsg.), Eulenburgs Politische Korrespondenz Bd.3, S. 1820.

357 Auch Bülow schrieb ihm in diesem Stil; vgl. etwa: „Meine zärtlichsten Gedanken sind immer bei Dir. Innigsten Dank für Dein Bild. Es steht auf meinem Schreibtisch. Ich werde es oft betrachten. [...] In Liebe und Treue umarmt Dich Dein.“ Bülow an Eulenburg 31.3.1894, abgedruckt in: RöHL (Hrsg.), Eulenburgs politische Korrespondenz, Bd. 2, S. 1277.

358 Hull, The Entourage, S. $61 \mathrm{f}$.

359 Vgl. Rogge, Holstein, S. 59; Bericht Berckheims Nr.24, 8. 11.1906, in: RöHL (Hrsg.), Eulenburgs politische Korrespondenz, Bd.2, S.2138; Anton von Monts, Erinnerungen und Gedanken des Botschafters Graf Monts, hrsg. von Karl Friedrich NowaK und Friedrich Thimme, Berlin 1932, S. 183-185.

360 Vgl. etwa Die ZuKunft 28.9.1895 über Eulenburg: „ein unerfahrener und in diplomatischen Prüfungen nicht bewährter Herr, der Skaldengesänge und Märchenlieder von der Freiheit dichtet und komponiert und zur Sommerzeit Schiffsdienst hat."

361 So auch: KoHLrausch, Monarch, S. 189. 
Eulenburg würde den Sturz des erkrankten Kanzlers Bülows vorbereiten, auf die Verleihung des schwarzen Adlerordens an Eulenburg und auf die Entlassung der grauen Eminenz des Auswärtigen Amtes, Friedrich von Holstein, zu dem Harden nach dessen Sturz einen intensiven Kontakt aufbaute. ${ }^{362}$ Zudem brachten die Memoiren des ebenfalls durch Eulenburg gestürzten Kanzlers Hohenlohe das Bild von einer unverantwortlichen Kamarilla erneut in die Öffentlichkeit, obgleich Hohenlohes posthume „Denkwürdigkeiten“ Eulenburg fast gar nicht erwähnten. ${ }^{363}$ Ähnlich wie bei den Kampagnen der Iren, der englischen Radicals und der Sozialdemokraten war es somit weniger der Hass auf Homosexuelle als die Verbitterung über eine spezifische politische Konstellation, die Harden zu den Enthüllungen trieb.

Der Skandal begann ähnlich wie bei den britischen Homosexualitätsskandalen nicht durch eine auffällig angekündigte Enthüllung in einer Boulevardzeitung, sondern durch verschlüsselte Andeutungen in einer kleinen politischen Zeitschrift. Zwischen Oktober 1906 und Mai 1907 streute Harden in seine politischen Essays in der Der Zukunft verspielte Formulierungen ein, die Eulenburg und Moltke in die assoziative Nähe von Homosexualität setzten. So fanden sich etwa ganz nebenbei Begriffe wie „warmes Eckchen“, „verschiedener Sinnesrichtung“, „Der Süße“ und schließlich der deutliche Hinweis auf eine nicht gesunde „vita sexualis“. ${ }^{364}$ Harden betonte dabei, dass ihr Privatleben eigentlich nicht an die Öffentlichkeit gehörte, wenn Eulenburg nicht dem Reich durch seine Personalpolitik und Intrigen schaden würde. ${ }^{365}$ Ähnlich wie bei den skandalauslösenden Artikeln von O’Brien oder Labouchere in Großbritannien waren die Andeutungen gezielte Erpressungsversuche, die politische Ziele und Reaktionen erreichen sollten. So hieß es direkt in einem fiktiven Dialog, mit dem Harden ohne Namensnennung auf Eulenburg und Moltke anspielte: „Der Harfner: ,Meinst Du, daß noch mehr kommt?‘ Der Süße: ,Wir müssen mit der Möglichkeit rechnen; er scheint orientiert, und wenn er Briefe kennt, in denen vom Liebchen die Rede ist...' Der Harfner: ,Undenkbar! Aber sie lassen alles

362 Vgl. auch Hull, The Entourage, S. 121-127; Hull betont zwar den de facto geringen Einfluss von Eulenburg, allerdings waren gerade die Gerüchte und öffentlichen Wahrnehmungen für das Aufkommen des Skandals entscheidender. Zur suggestiven Kraft des Kamarilla-Diskurs vgl. auch KoHlrausch, Monarch, S. 176-185.

363 Lediglich drei beiläufige Einträge beziehen sich auf ihn; Friedrich Curtius (Hrsg.), Denkwürdigkeiten des Fürsten Chlodwig zu Hohenlohe-Schillingsfürst, 2 Bde., Stuttgart und Leipzig 1906.

364 Vgl. bes. Die Zununft 27.10.1906, S.135; 17.11.1906, S.264f.; 24.11.1906, S. 291; 8.12.1906; 27.4.1907, S. 118.

365 Vgl. Die Zukunft 17.11.1906, S.265f. „Jahre war kein wichtiger Posten ohne seine Mitwirkung besetzt worden. [...] Er hat für all seine Freunde gesorgt. Ein Moltke ist Generalstabschef, ein anderer, der ihm noch näher steht, Kommandant von Berlin, Herr von Tschirschky Staatsekretär im Auswärtigen Amt; und für Herrn Varnbüler hofft man auch noch ein warmes Eckchen zu finden. [...] Das alles wäre ihre Privatwirtschaft, wenn sie nicht zur engsten Tafelrunde des Kaisers gehörten und (ich habe noch lange nicht alle Affiliierten aufgezählt) von sichtbaren und unsichtbaren Stellen aus Fädchen spönnen, die dem deutschen Reich die Athmung erschweren." 
abdrucken. Sie wollen uns mit Gewalt an den Hals.' Der Süße: ,Eine Hexenzunft. Vorbei! Vorbei!‘ Der Harfner: ,Wenn Er nur nichts davon erfährt! ‘“366 Die eigentliche medial vermittelte Erpressung war damit, dass alle und selbst der Kaiser von ihren homoerotischen Neigungen erfahren würden, falls sich die „Kamarilla“ nicht zurückzöge. Zudem bedrohten die angekündigten Briefe den Kaiser selbst: Wenn heraus käme, dass Wilhelm II. homosexuelle Freunde hatte, die ihn auch noch „Liebchen“ nannten, war sein Autoritätsverlust abzusehen, zumal er selbst in den Verdacht der Homosexualität geraten könnte.

Zumindest die Betroffenen und die politische Elite verstanden diese verschlüsselte politische Erpressung des Journalisten deutlich. Entsprechend setzten nun informelle Verhandlungen mit dem Journalisten ein. Über einen Mittelsmann, den Hamburger Schauspielhausdirektor Alfred von Berger, begannen die Beschuldigten mit Harden zu verhandeln, um die drohende weitere Veröffentlichung der Vorwürfe und einen Skandalprozess zu verhindern. ${ }^{367} \mathrm{Be}-$ reits die kurzfristigen Erfolge Hardens waren nicht gering: Eulenburg verließ tatsächlich das Land, und Harden stellte die erpresserischen Artikel ein. Als Eulenburg dann nach drei Monaten wieder zurückkehrte, sich in die Frankreichpolitik einzumischen schien und sich dabei mit dem von Harden ebenfalls als homosexuell eingeschätzten Botschaftsrat Lecomte traf, begann Harden seine Angriffe erneut. Diesmal allerdings umso deutlicher, wenn auch weiterhin ohne explizite Namensnennung, die sofort einen Verleumdungsprozess erfordert hätte. Stattdessen begannen im April und Mai 1907 erneute Verhandlungen mit dem Journalisten. Als Unterhändler traten neben Berger nun auch Moltkes Vetter und Walter Rathenau auf, wobei letzteren Reichskanzler Bülow sandte. ${ }^{368}$ Ähnlich wie bei den englischen Skandalen versuchte die Regierung damit ebenfalls, mit allen Mitteln einen Prozess zu verhindern. Harden ließ jedoch über Rathenau drohend übermitteln, dass er genug Material habe, um „einen Skandal [zu] machen, von dem die Welt widerhallt. "369 Schließlich forderte Moltke Harden sogar zum Duell auf, was Harden ablehnte. ${ }^{370}$ Obwohl Duelle bereits

366 Die Zukunft 24.11.1906, S.291.

367 Dass Berger nicht eigenständig auftrat, wie er und Eulenburg zunächst betonten, zeigt ein späterer Brief von ihm an Harden über die Gespräche „in dem Novembertagen 1906 (die mit dem Gfn. Moltke, mit Ihnen, mit dem Fstn. E., mit Ihnen und dann wieder mit dem Gfn. M.)“; Berger an Harden 21.12.1907, in: BAK, N 1062-13. Vgl. auch Berger an Harden 4.12.1906 und 6.12.1906, in: ebd. Diese Verhandlung sind zudem bekannt, da Harden sie später publik machte: Vgl. ZuKunFT 22.6.1907; Schreiben Harden an: BZ Nr. 139 17.6.1907; Vossische Zeitung Nr.605, 28.12.1907.

368 Vgl. Berger an Harden 10.5.1906, in: BAK, N 1062-13; Harden an Holstein 12.5.1907 u. 1.6.1907, abgedr. in: Rich und Fisher (Hrsg.), Die geheimen Papiere Friedrich von Holsteins, Bd. 4, S. 428f. u. 434f. Zu Rathenau Vermittlung vgl. die Briefe in: Hans Dieter HeLLIGE nimmt an, dass Harden auf diese Weise Einfluss auf die Pressepolitik nehmen wollte; DERs. (Hrsg.), Walther Rathenau - Maximilian Harden, Briefwechsel 1897-1920, München 1983, S. 522-529.

369 Harden an Rathenau 20.6.1907, abgedr. in: Hellige (Hrsg.), Harden - Rathenau, S. 529.

370 Vgl. Hardens spätere Rechtfertigung für seine Ablehnung in: Harden an BZ am Mittag Nr. 139 17.6.1907. 
gesetzlich verboten waren, erforderte der militärische Ehrenkodex eine entsprechende Reaktion des Generals. Zudem erlaubte das Duell, im Unterschied zum modernen Verleumdungsprozess, auf eine Klärung der Vorwürfe zu verzichten, während ein Prozess ihre Veröffentlichung sorgen würde.

Die ersten Andeutungen Hardens hatten die Vorwürfe in die mündliche Öffentlichkeit der Eliten überführt, kaum jedoch in die Medienöffentlichkeit. Die großen Zeitungen reagierten auf die erpresserischen Andeutungen zunächst ähnlich zurückhaltend wie bei den britischen Fällen und ignorierten sie weitgehend. Immerhin griff die BZ am Mittag die versteckten Hinweise auf, blieb auf der spielerischen Ebene von Harden und thematisierte den unterschiedlichen Sagbarkeitsgrad in den jeweiligen Öffentlichkeiten: „Sie fragen, wer der Süße und wer der Harfner ist? Ich darf's Ihnen nicht sagen; aber in jedem Salon unserer tugendsamen Stadt wird ihnen eine Freundin hinter dem Fächer die Namen der beiden Herren zuflüstern. “371 Wie bei den Zuschauern bei den Gerichtsprozessen galten damit Frauen wiederum als die eigentlichen Adressaten von skandalösen Gerüchten. Und wie bei den britischen Skandalen kamen die Vorwürfe erst in die breite Medienöffentlichkeit, als eine offizielle Reaktion einsetzte. Von einer reaktionsschnellen „Sensationslust“ der Boulevardmedien kann man also auch bei diesem Skandal nicht sprechen.

Da der Skandal durch eine eigenständige Veröffentlichung eines Journalisten ausgelöst wurde, ähnelte er typologisch dem politischen Kampagnenstil, wie er bereits im britischen Dublin Castle-Skandal erkennbar wurde. Auch Hardens erste öffentliche Anspielungen beruhten nur auf Gerüchten, einigen informell übermittelten Informationen und Briefen mit Andeutungen. Vor allem die geschiedene Frau von Moltke, Lilly von Elbe, war Hardens wichtigste Informantin. Die eigentliche Recherche, die die schlagenden Beweise gegen Eulenburg hervorbrachte, setzte jedoch auch in diesem Skandal erst im Zuge der Prozesse ein. Wie bei den englischen Skandalen beschäftigte auch Harden einen Detektiv hierfür, der vor allem am Starnberger See Zeugen und frühere Liebhaber von Eulenburg aufstöberte. Der Gerichtsprozess erwies sich damit erneut als Katalysator für die Ausbildung des recherchierenden Journalismus.

Dass der Skandal schließlich ausbrach, lag nicht zuletzt erneut an der impulsiven Reaktion des Kaisers. Nachdem der Kronprinz ihm Anfang Mai 1907 von den Gerüchten erzählt hatte, verlangte er sofort den Rücktritt von Moltke und Eulenburg und eine Klärung per Duell oder Prozess. Damit war die breite Veröffentlichung der Vorwürfe unvermeidlich. Während Moltke nach den gescheiterten Vermittlungsversuchen eine Verleumdungsklage einreichte, versuchte Eulenburg diese dennoch mit allen Mitteln zu umgehen. Eulenburg warnte Wilhelm II. mit etwas drohendem Unterton, Harden wolle nur einen „politischen Skandal-Presseprocess“, den er selbst aber gerade mit Rücksicht auf den Kaiser

371 BZ am MitTag 3.12.1906. 
vermeiden wollte. ${ }^{372}$ Ähnliches schrieb er Bülow. ${ }^{373}$ Der Generalstaatsanwalt, mit dem Eulenburg sich austauschte, empfahl ihm ebenfalls von einem Prozess abzusehen. ${ }^{374}$ Um den Kaiser zu beruhigen, forderte Eulenburg stattdessen ein Disziplinarverfahren und leitete schließlich eine Selbstanzeige wegen Verstoßes gegen den $\ 175$ an, was eine kleine kontrollierbare Untersuchung mit wenig Aufmerksamkeit versprach. Dieses Zurückweichen vor einem Prozess gegen den Journalisten zeigte, dass eine derartige Skandalisierung nicht mehr mit herkömmlicher Pressezensur auffangbar erschien. Ein Verleumdungsprozess, das wussten die Beteiligten aus früheren Fällen, war bei einem derartigen Vorwurf ein unkalkulierbares Risiko.

Erst mit den Suspendierungen und den angekündigten Prozessen setzte ab Ende Mai 1907 eine breite Presseberichterstattung und Empörung in allen Zeitungen ein und damit auch der Skandal. Die Zeitungen druckten Hardens Artikel ab und gaben eigene Einschätzungen zum „Liebenberger Kreis“. Im Unterschied zum Fall Krupp beklagten sie sich bereits in dieser Phase über die Homosexualität der Liebenberger Runde, aber ebenso auch deren „Mystizismus“ und „Spiritismus“. ${ }^{375}$ Dies war jedoch nur der Anfang eines nahezu zweijährigen Skandals mit zahlreichen Prozessen, der alle anderen Fälle von seinem Ausmaß und seinen vielfältigen Wendungen übertrat. Deshalb scheint, auch wenn dies nicht immer zu trennen ist, zunächst ein analytischer Blick auf seine dynamischen Verlaufsformen hilfreich, um dann in einem zweiten Schritt die ausgehandelten Normen und Deutungsmuster zu untersuchen, die vor allem Zuschreibungen über Homosexuelle konstruierten.

\section{VERLAUFSFORMEN}

Der Eulenburg-Skandal war ein Paradebeispiel dafür, mit welcher Macht die Medialisierung den Obrigkeitsstaat herausforderte. Auch die Karikaturen der Zeit sahen den Skandal als einen Kampf zwischen den Journalisten und der Politik, die im „Sensationszirkus“ ihre Muskeln spielen ließen (vgl. Abb. 2). ${ }^{376}$ Wie offen der Ausgang dieses Ringens war, zeigten die zahlreichen überraschenden Wendungen des Skandals, die vor allem den staatlichen Kontrollverlust markierten. Wie im folgenden Abschnitt gezeigt wird, ging dies mit einem äußerst wechselhaften Verhalten aller Beteiligten einher. Sowohl die politischen Akteure als auch die Presse reagierten immer wieder mit äußerst unterschiedlichen, teil-

372 Eulenburg an Wilhelm II., 5.5.1907, in: GStA, BPH Rep 53 J Lit. E Nr.1.

373 Eulenburg an Bülow 12.5.1907, in: Aufzeichnungen des Fürsten Eulenburgs 1910, in: BAK, 1029: 75, 105.

374 General-Staats-Anwalt Wachler an Eulenburg 13.5.1907 in: GStA, BPH Rep 53 J Lit. E Nr.1.

375 Vgl. die Pressesammlung in: BAB/L, R 8034II: 7836; etwa: Deutsche Zeitung Nr.120; 4.6.1907.

376 LuSTIGE BLÄTTER I9. I I. I907. 


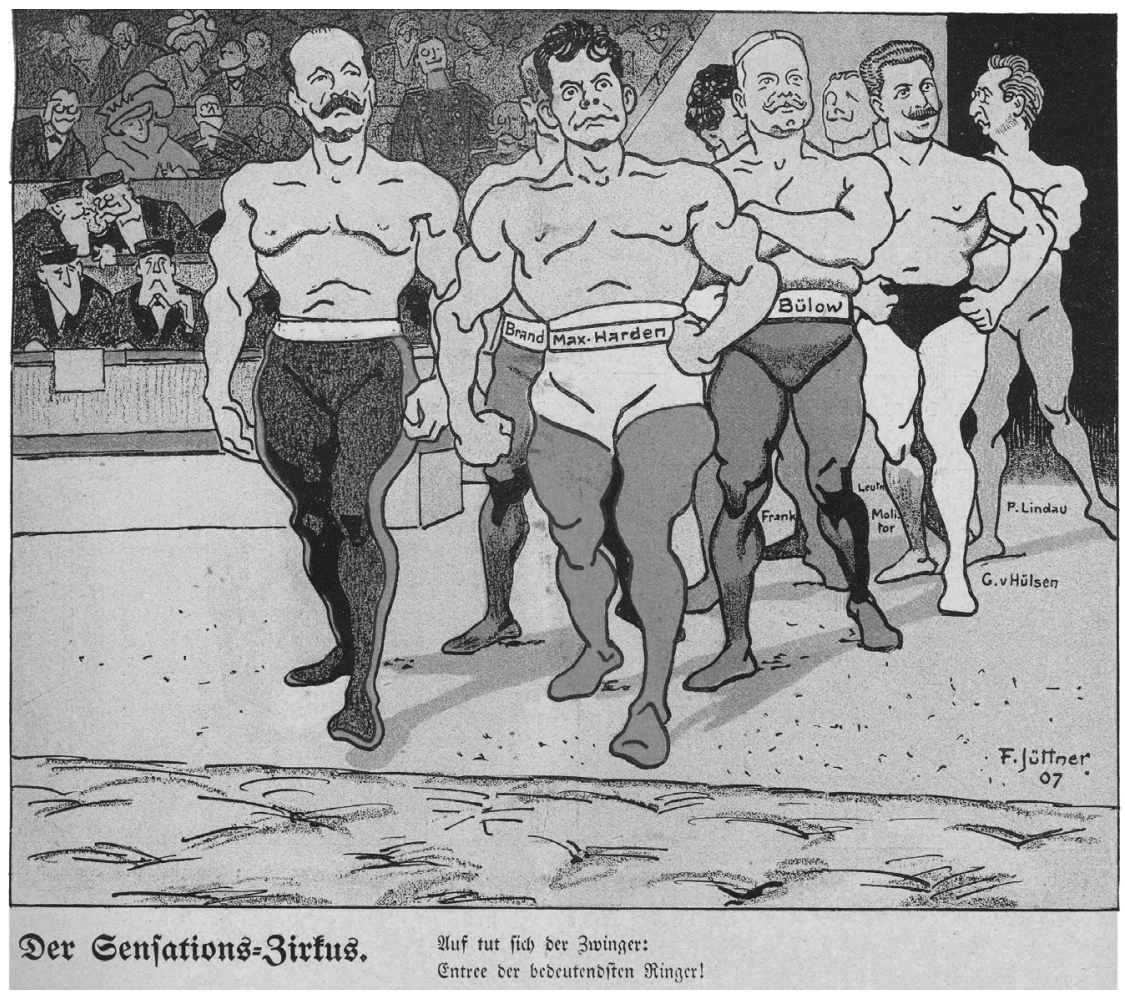

Abb. 2: Der Skandal als Schaukampf zwischen Medien und Politik; Quelle: Lustige Blätter 19.11.1907.

weise diametral entgegen gesetzten Strategien und Bewertungen. Das lag nicht nur an den typischen, unberechenbaren Dynamiken, die der Skandal im öffentlichen Aushandlungsprozess entwickelte. Auch die allgemeine Unsicherheit, wie mit den tabuisierten Vorwürfen umzugehen sei, verstärkte das sprunghafte Verhalten. Beides führte zu trial and error-Reaktionen und zu öffentlichen Empörungen, die sich abwechselnd auf den anklagenden Journalisten, die beschuldigten Adligen und auf die Justiz richteten.

Wie schnell der Skandal seine Ausrichtung verändern konnte, zeigte sich bereits in den ersten Monaten. Während im Krupp-Skandal der Vorwärts für seine Enthüllungen mehrheitlich verdammt worden war, galten Hardens Enthüllungen nach Ausbruch des Eulenburg-Skandals in fast allen Kommentaren als richtiger Schritt, da er Kaiser und Staat vor schlechten Beratern beschützt habe. Damit galt weniger die Homosexualität als die politische Kompetenz als der eigentliche Malus. Diese Einschätzung veränderte sich jedoch bereits am 15. Juni 1907 schlagartig, als Harden eine eidesstaatliche Aussage gegen Eulenburg ver- 
weigerte, der ihn als einzigen Zeugen für seine Selbstanzeige berufen hatte. ${ }^{377}$ Harden rechtfertigte seine plötzliche Zurückhaltung damit, er spare sein Material für einen richtigen Prozess auf. Dennoch richtete sich die öffentliche Empörung nun gegen ihn, weil eine detaillierte Offenlegung des Geheimnisses erwartet wurde. Damit war gleich zu Beginn des Skandals erneut deutlich, wie schnell sich Enthüllungen über sexuelle Normbrüche gegen den anklagenden Journalisten selbst wenden konnten.

Ähnlich wechselhaft waren die Reaktionen der Staatsführung. So fällt im Unterschied zum Krupp-Skandal und den englischen Skandalen auf, dass der Monarch und der Regierungschef die Beschuldigten zunächst nicht unterstützten. Das hatte persönlich politische Gründe, da Harden jene Kamarilla bekämpfte, der Bülow zwar seinen Aufstieg zum Außenstaatssekretär und dann zum Kanzler mit verdankte, die ihn aber zugleich angeblich im letzten Herbst hatten stürzen wollen. Zudem ahnte Bülow vermutlich durch seine frühere enge Freundschaft zu Eulenburg die mögliche Stichhaltigkeit der Gerüchte, so dass er kein Risiko eingehen wollte. Den „Freundesschutz“, den Eulenburg von ihm persönlich erbat und den die vorherigen bei vielen anderen Skandalen gewährten, lehnte Bülow daher wie der Kaiser ab. ${ }^{378}$ Vielmehr teilte Bülow Eulenburg auch im Namen des Kaisers brieflich mit, dass Eulenburg in Liebenberg Gäste mit „anrüchigem Renommee“ empfangen habe, dass er heimlich mit Harden verhandelt hätte, obwohl er angeblich die Artikel nicht kannte, und dass dem Kaiser Teile der belastenden Briefe von Harden bekannt seien. Eulenburg solle deshalb sofort seine Pensionierung einreichen und mit klarer Erklärung gegen Harden vorgehen oder „unter Rückgabe des Schwarzen Adler-Ordens unter Vermeidung jeden Aufsehens sich in das Ausland begeben. “379 Ähnlich wie bei den englischen Fällen galt damit die Emigration, und nicht das Gefängnis, als die eigentliche Lösung und Strafe für die mutmaßliche Homosexualität.

Zurückhaltung zeigten Regierung und Justiz auch beim ersten Prozess, den Moltke gegen Harden im Oktober 1907 führte. Das Gericht hatte recht freie Hand, verhandelte öffentlich und versuchte vergleichsweise unvoreingenommen gegenüber Harden die Stichhaltigkeit der Vorwürfe zu ermitteln. Im Vorfeld hatte Bülow seine Mitarbeiter schon angewiesen, Angriffe auf die Zukunft zu unterlassen. ${ }^{380}$ Bülow bemühte sich vor allem um Distanz zu Eulenburg. Als er für den Prozess als Zeuge bestellt wurde, sicherte er sich daher mit zahlreichen Briefen ab, dass er verhindert sei und blieb im heimischen Klein Flott-

377 Vgl. die Presseausschnittssammlung in: BAB/L, W 8034 III 114.

378 Bülow an Eulenburg 17.5.1907, Eulenburg an Bülow 5.6.1907, in: ebd. Zur Protektion der Eliten durch die politische Führung, die hier vor allem Moltke erfuhr, weitere Beispiele in den folgenden Kapiteln.

379 Bülow an Eul. 31.5.1907, in: Aufzeichnungen des Fürsten Eulenburgs 1910, in: BAK, 1029: 75, S. 114.

380 Bülow an Löbell 27.9.1907, in: BAB/L, N 2106/13: $22 \mathrm{f}$. 
bek. ${ }^{381}$ Ebenso erschienen nicht die adligen Zeugen aus der Hofgesellschaft, die wegen ihrer homosexuellen Neigungen ebenfalls kein Risiko eingehen wollten - wie Eulenburg und der Major Graf Lynar. Das Gericht überführte Moltke zwar nicht des homosexuellen Verkehrs, wohl aber einer homosexuellen Veranlagung. Zudem sah es homosexuelle Orgien von hohen Offizieren mit Soldaten in einer benachbarten Villa von Moltke als belegt an. Der freigesprochene Harden galt deshalb Ende September öffentlich als klarer Sieger. Zahlreiche Zeitungen lobten unmittelbar nach dem Prozess seine Enthüllungen und die Beseitigung einer Kamarilla als sein Verdienst. Damit hatte ein Journalist über die alten Eliten triumphiert, und die Empörung richtete sich erneut gegen die besiegte Kamarilla.

Gerade dieser Triumph eines Journalisten leitete jedoch eine weitere öffentliche Neubewertung des Skandals ein. Sie richtete sich gegen den Journalisten und die Homosexuellenbewegung. Der Antisemitismus der Konservativen war dabei ein entscheidendes Movens, um die scheinbar unbegrenzte Macht von Harden anzugreifen. In den konservativen Zeitungen sorgte schon kurz nach dem Prozess für Empörung, dass ein „jüdischer Advokat“ einen preußischen General der Unmoral überführte, weshalb etwa die Deutsche Zeitung aus „arischem Empfinden“ Moltke Mitleid aussprach. 382 Auf das "Judentum“ von Hardens Verteidiger Bernstein, und dann auch auf Harden selbst, führten die rechten Zeitungen auch die öffentliche Verbreitung unsittlicher Äußerungen zurück. Moltke sei zudem ein Opfer ihrer „jüdischen Rabulistik“, der er sich nicht erwehren konnte. ${ }^{383}$ Auch die beschuldigten Adligen deuteten den Fall ähnlich. Eulenburg stilisierte sich selbst gegenüber dem Staatsanwalt und Freunden als Opfer des "Juden Harden“ und des „Judenthums“, das die öffentliche Meinung beherrsche, und Graf von Wedel rief angeblich aus: „regiert denn dieser Jude heute in Preußen und setzt Generäle und Botschafter ab?"384 Um die rassistischen Vorurteile gegen den längst konvertierten Harden zu schüren, begannen die konservativen Zeitungen ab Anfang November 1907 Harden mit seinem früheren Namen „Wittkowski“ zu bezeichnen. ${ }^{385}$ Obgleich er mit dem Vornamen Felix Ernst geboren wurde, nannte die Konservative ihn nun häufig „Isodor Wittkowski“, um ihn als polnischen Juden zu diskreditieren. Diese antisemitische Stoßrichtung verband die konservative Presse mit Schuldzuweisungen an die Justiz. „Wo war die preußische Justizverwaltung im Prozeß Molkte-Harden?" fragte etwa die Tägliche Rundschau und sprach vom Versagen des Justizministers, der die „sittliche und politische Bedeutung“ des Prozesses

381 Vgl. Loebell an Bülow, 19.10.1906; Loebell an Amtsgericht 19.10.1906; AA an Loebell 23.10.1906, Bülow an Loebell 24.10. u. 26.10.1906, in: BAB/L, R 43/ 798b: 6.

382 Deutsche Zeitung Nr. 300; 30.10.1907.

383 Post Nr.510, 30.10.1907; Conservative Correspondenz Nr.77, 28. 10.1907.

384 Vgl. Eulenburg an Staatsanwalt Isenbiel 11.5.1908 u. Eulenburg an Horst von FarenheidBeyruhnen 31.12.1908 (Abschrift 1918), in: BAK, N 1029-78; Wedel laut: Tresckow, Von Fürsten, S. 183.

385 Dies setzt ein etwa in: PosT Nr.525 8.11.1907. 
nicht erkannt habe - entweder aus „Unfähigkeit“ oder aus „Furcht vor der vom jüdischen Liberalismus zersetzten Presse. "386 Die konservative Presse trat damit als Akteur gegen Harden auf und förderte einen Kurswechsel in der Regierung, den zugleich auch der Kaiser mit seinen erbosten Kommentaren an den Zeitungsausschnitten verlangte. ${ }^{387}$ Zumindest in ihrem Lager gelang es dadurch, mit der Beschwörung der jüdischen Bedrohung die angebliche Bedrohung durch Homosexualität zu überdecken.

Ein nur zwei Wochen später folgender Prozess, der erneut einen Homosexualitätsvorwurf verhandelte, verstärkte diese Wende in der öffentlichen Meinung und führte endgültig zu einer harten staatlichen Reaktion gegen den Journalisten. Hardens Erfolg hatte Trittbrettfahrer ermutigt. Im September 1907 hatte der Publizist Adolf Brand in einer Broschüre einen Artikel über „Fürst Bülow und die Auffassung vom $\$ 175$ “ publiziert, der dem Kanzler ein homoerotisches Verhältnis mit seinem Sekretär Max Scheefer nachsagte. Dieser würde ihn auf seinen Urlauben nach Norderney zu „Scheeferstunden“ begleiten, gelte als des Kanzlers „bessere Hälfte“ und Bülow selbst habe bereits einen Erpressungsversuch wegen des $\$ 175$ hinter sich. Zudem sei der Neffe des Kanzlers, Bernhard von Bülow, der Privatsekretär von Eulenburg, „ebenso wie sein Onkel selber homosexuell veranlagt. “388 Brand stand der Homosexuellenorganisation „Gemeinschaft der Eigenen“ vor und publizierte seit längerem über Homosexualität, was bereits zu Gefängnisstrafen geführt hatte. ${ }^{389}$ Durch diese „Enthüllung“ über einen weiteren Politiker hoffte er anscheinend, die Akzeptanz der Homosexualität zu erhöhen und sie zu „normalisieren“. Sein Heftchen verschickte er an verschiedene Zeitungen, die aber ganz überwiegend nicht darüber berichteten, was Bülows Pressebeauftragter, Otto Hammann, auch direkt mit den Journalisten aushandelte. ${ }^{390}$ Dennoch kursierte Brands Beschuldigung schnell, und auch Harden wusste bereits wenige Tage später davon. ${ }^{391}$ Bülow, der Eulenburg hinter den Vorwürfen vermutete, entschied sich nach einigem Abwägen für eine Klage, obwohl er sonst stets von Beleidigungsprozessen gegen Journalisten absah. Da die Vorwürfe völlig haltlos waren, griff das Gericht nun mit voller Härte durch und verurteilte Brand zur Höchststrafe von 11/2 Jahren Haft. ${ }^{392}$ Die

\footnotetext{
386 TäGliche Rundschau Nr. 509, 30.10.1906.

387 Vgl. auch die abgedruckten Kommentare von Wilhelm II. in RogGe, Holstein, S. 234.

388 Exemplar der Schrift vom 10.9.1907 in: Landesarchiv Berlin (LB), A Rep. 358-01 Nr. 8.

389 Hinweis auf eine Verurteilung 1903 in: Monatsbericht des Wissenschaftlich-humanitäREN Komitees, November 1903.

390 Loebell an Bülow und Hammann an Bülow, beide 26.9.1907, in: BAB/L, N 2106/13; Vgl. rückblickend auch: Deutsche Tageszeitung, 12.10.1907.

391 Holstein an Harden 16.9.1907, abgedr. in: Rogge, Holstein, S. 212.

392 Urteil in: LB A Rep. 358-01. Vgl. auch: Marita KeILson-Lauritz, Wilhelmshagen gegen das Deutsche Reich. Adolf Brands Flugschrift gegen den Reichskanzler von Bülow, in: CAPRI, 17 (1994), S.2-16. Einzelne Hinweise zu Brand in: Ulfried Geuter, Homosexualität in der deutschen Jugendbewegung: Jugendfreundschaft und Sexualität im Diskurs von Jugendbewegung, Psychoanalyse und Jugendpsychologie des 20. Jahrhunderts, Frankfurt a. M. 1994, S. 46.
} 
Justiz unterstrich damit nach der Kritik an ihren zu milden Urteilen, dass sie für Verleumder harte Strafen erließ.

Entscheidend für die Wende in der öffentlichen Meinung war zudem, dass der bei diesem Prozess eigentlich unbeteiligte Eulenburg unter Eid aussagte, nie gegen den $\$ 175$ verstoßen zu haben. Da hier keine Zeugen und Fragen von Harden drohten, war dies ein taktisch kluger Zug, durch den nun in der Öffentlichkeit auch Hardens Vorwürfe haltlos erschienen. Erstaunlicherweise führte dies zu einem völligen Umschwung in der öffentlichen Meinung. Die bürgerliche Presse richtete sich jetzt überwiegend gegen Harden, und die konservativen Zeitungen forderten seine Verurteilung und die seines „jüdischen“ Anwaltes Bernstein. Auch Magnus Hirschfeld, der sich im Moltke-Prozess noch als Experte profilieren konnte und im Brand-Prozess erneut als Sachverständiger auftrat, stieß nun selbst in den liberalen Zeitungen auf harte Kritik. Selbst sie bezeichneten ihn, der eben noch als Experte galt, als „gemeingefährlich“, sprachen von „Volksvergiftung“ und „schmutziger Scheußlichkeit“.393 Hirschfeld und sein Komitee stürzten durch den Vorwurf, die Homosexuellen-Lobbyisten würden selbst den Kanzler als homosexuell denunzieren, um ihre Ziele durchzusetzen, in die schwerste Krise seit ihrer Gründung. ${ }^{394}$

Wie lässt sich dieser rasante Umschwung der öffentlichen Meinung und Empörung erklären? Erstens löste der Prozess von Bülow die Angst aus, Politiker könnten zukünftig laufend derartigen Beschuldigungen ausgesetzt sein. Um weitere Nachahmer abzuschrecken, erschien auch Hardens Bestrafung nötig. Zweitens führte Eulenburgs Eid zu der Hoffnung, mit einer Beschuldigung Hardens die gesamten Enthüllungen revidieren zu können, die der Moltke-Prozess über hohe Militärs gemacht hatte, und so das Ansehen des Staates, des Militärs und damit die soziale Ordnung wieder herzustellen. Drittens hatte Hirschfeld bei seiner Expertise, die ausführlich auf die (oft angebliche) Homosexualität von prominenten historischen Persönlichkeiten hinwies, offensichtlich eine Grenze überschritten. Die historische Argumentation der Homosexuellenbewegung erwies sich damit als deutlich weniger akzeptabel als die zuvor aufgebrachte medizinische Umdeutung. Hirschfelds Ausführungen lösten zudem die Angst aus, dass nun nicht nur die gegenwärtigen Politiker, sondern auch die vergangenen als homosexuell bezeichnet würden. ${ }^{395}$ Vor seinem Haus wurden antisemitische Flugblätter verteilt mit Überschriften wie „Dr. Hirschfeld eine

393 Vgl. Deutsche Zeitung 7.11.1907; Berliner Tageblatt 7.11.1907; Vossische Zeitung 7.11.1907; Frankfurter Zeitung 7.11.1907. Bes. drastisch etwa der Artikel „Das Trio Wittkowski-Bernstein-Hirschfeld“, in: Post Nr.525, 8.11.1907. Vgl. auch: ERwin J. Haebele, Justitias zweischneidiges Schwert - Magnus Hirschfeld als Gutachter in der Eulenburg-Affäre, in: Klaus M. BeIER (Hrsg.), Sexualität zwischen Medizin und Recht, Stuttgart/Jena 1991, S. 5-20.

394 So sah es auch Hirschfeld selbst; vgl. Monatsbericht Des WissenschaftLich-HUManitären Komitees 1.12.1907, S. 229.

395 Neue Preussische Zeitung 7.11.1907; Deutsche Zeitung 7.11.1907; Münchner NeueSTE NACHRICHTEN 8.11.1907. 
öffentliche Gefahr - Die Juden sind unser Unglück“.396 Das Ziel der öffentlichen Empörung hatte sich damit in kurzer Zeit gewandelt: Statt gegen die homosexuelle Kamarilla richtete sie sich jetzt wieder gegen diejenigen, die Vorwürfe aufbrachten.

Ebenso veränderten die Staatsführung, die Justiz und die Beschuldigten ihren Umgang mit dem Skandal. Sie gingen jetzt offensiv gegen Harden und die Vorwürfe vor und leiteten seine Verurteilung ein. Am hartnäckigsten sprach sich der Kaiser gegen einen heimlichen Vergleich von Moltke-Harden aus und verlangte einen erneuten Prozess. ${ }^{397}$ Sowohl der Justizminister als auch Eulenburg ließen den Staatsanwalt wissen, dass ein „öffentliches Interesse“ an einer Verfolgung der Vorwürfe bestehe, woraufhin dieser Anklage erhob. Die Reichskanzlei hoffte zwar weiter auf eine Verhinderung eines erneuten Prozesses, ließ Harden dann wissen, er solle sich im Interesse des Landes beim Prozess mäßigen und würde dann im schlimmsten Falle eine Geldstrafe erhalten. ${ }^{398}$ Um Harden keinerlei Forum zu geben, wurde bei dem Prozess „im Interesse der öffentlichen Sittlichkeit“ die gesamte Öffentlichkeit, auch die Presse, ausgeschlossen. ${ }^{399}$ Wichtige Zeugen von Harden hörte das Gericht nicht an. Die Pressemeldungen und das rigide Auftreten der Justiz schüchterten offensichtlich ein: Harden selbst blieb erstaunlich zurückhaltend, Experten wie Hirschfeld und Kommissar Tresckow sahen plötzlich Moltkes Unschuld, und die wichtigste Zeugin, die Ex-Frau von Moltke wurde für „hysterisch“ erklärt. Ohnehin hatte der Staatsanwalt dem Justizminister schon vor dem Prozess seinen Befund vorgelegt, bei Moltke und Eulenburg seien keinerlei Anzeichen von Homosexualität festzustellen, was er in seinem Plädoyer wiederholte („Nicht eine Spur von Homosexualität ist an dem Grafen nachgewiesen, nicht ein Atom femininer Eigenschaften“). .00 Angesichts dieser Absprachen überraschte es wenig, dass Harden zu vier Monaten Haft verurteilt wurde.

Das vernichtende Urteil, dass das Gericht über Hardens journalistische Sorgfalt sprach, drückten die Zeitungen noch deutlicher aus. Auch die liberale und katholische Presse sprach jetzt von dem völligen Ende der Karriere des Journalisten, den sie vor wenigen Monaten noch vielfach als ihren herausragenden Repräsentanten gefeiert hatten. ${ }^{401}$ Das strenge Urteil sei eine Warnung, dass das Privatleben privat bleiben müsse; „wir wollen in dieser Beziehung den Engländern nicht nacheifern“, hieß es im Berliner Tageblatt mit Verweis auf den dor-

\footnotetext{
396 Vgl. Monatsbericht des Wissenschaftlich-Humanitären Komitees 1.12.1907.

397 Bülow an Hammann o. D. (wohl Ende Nov.) 1907, in: BAB/L, N 2106/13: 22 f.

398 So etwas später, aber recht glaubhaft: Harden an Ballin 3.4.1909, in: BAB/L, N 2106/2: 6. Zu den Vermittlungsversuchen in der Reichskanzlei: Loebell an Podbielski 7.12.1907, Podbielski an Loebell 14.12.1907, in: BAB/L, R 43/798b: 53 und 65, 67.

399 Vgl. bis dahin das Protokoll in: Berliner Tageblatt Nr. 646, 20.12.1907.

400 Isenbiel an Justizminister Beseler 21.12.1907, in: GStA, I HA Rep. 84a Nr. 49838-88. Plädoyer nach: Vossische ZeItung Nr.610, 31.12.1907.

401 Vgl. etwa Freisinnige Zeitung Nr.306, 29.12.1907 („Hardens Ende“); Germania Nr. 249, 29.12.1907 („der Herausgeber der Zukunft hat keine Zukunft mehr.“).
} 
tigen Skandal um Charles Stewart Parnell. ${ }^{402}$ Die Rechte triumphierte, dass der Homosexualitätsvorwurf sich als ebenso haltlos erwiesen habe wie der einer Kamarilla, und sowohl Harden als auch Hirschfeld ihre Rolle ausgespielt hätten. ${ }^{403}$ Der Skandalverlauf bewies damit ein weiteres Mal, wie unberechenbar sich Empörungen in der Öffentlichkeit entwickelten und dass man nicht einfach pauschal von einer Dominanz der Medien ausgehen konnte. Weite Teile der Presse folgten vielmehr den Einschätzungen, die von den Gerichten und der politischen Führung angestoßen wurden.

Die Verschiebung der Empörung zeigte sich auch auf der Ebene der situativen Öffentlichkeit. In den Hamburger Kneipen hieß es nun mit Blick auf Hardens einstigen Hochmut: „Harden kann sich nun mit dem Gefängnis bekannt machen. Dort wird er nachher Zeit haben und über seine große Liebe zum Lande nachdenken können. “ 404 Andere Stammtische empörten sich über Hardens $\mathrm{Zu}$ rückhaltung: „Der Mensch hat vorher geprahlt, daß er noch soviel Beweismaterial auf Lager habe und jetzt? Wo es drauf ankommt Beweise zu bringen, da hat er nichts, er streitet alles ab und seine Krankheit?" 405 In anderen Kneipen blieben die Gäste dagegen skeptisch. Sie nahmen weitere Prozesse an ${ }^{406}$ oder vermuteten, Harden sei „bloß pro forma bestraft“ wegen irgendwelcher Absprachen. Moltke sei bestimmt homosexuell, denn dies komme in diesen Kreisen „am meisten vor und das wird bei diesem Herrn auch der Fall gewesen sein, sonst hätte es Harden nicht in die Öffentlichkeit gebracht. “407 Die Äußerungen deuten an, dass sich die Stammtische dem Medientenor zwar weitgehend anschlossen, ihm aber nicht ganz folgten.

Nach diesem harten Durchgreifen der Justiz nahm der Skandalverlauf jedoch erneut eine radikale Kehrtwendung. Dies machte deutlich, dass im wilhelminischen Deutschland ein Journalist nicht mehr mit Verurteilungen zu unterdrücken war. Aus seiner Verbitterung bereitete Harden seinen berühmten Prozess gegen Eulenburg vor, der erst den Höhepunkt des Skandals bildete. Über die Presse kündigte er an, er würde demnächst sein Material ausbreiten und informierte den Staatsanwalt unter Zusendung von einigen Unterlagen. ${ }^{408}$ Nachdem die preußische Justiz den letzten Berliner Prozess vorab arrangiert hatte, inszenierte nun Harden einen Prozess vor einem Münchner Gericht, da er sich vor der bayrischen Justiz mehr Freiheiten versprach. Ein befreundeter Journalist schrieb nach Absprache in einem Münchener Blatt, Harden hätte gerüchteweise eine Millionen Mark für sein Schweigen bekommen. Dagegen klagte Harden

402 Berliner Tageblatt Nr. 5, 4.1.1908.

403 Deutsche Zeitung 28.12.1907; Tägliche Rundschau Nr. 5 4.1.1908.

404 Polizeibericht Schutzmann Szymanski, 23. 12. 1907, in: StAH, S 3930-40 Bd.1.

405 Ebd.

406 Polizeibericht Schutzmann Szymanski, 27.12. 1907, in: StAH, S 3930-40 Bd. 1.

407 Polizeibericht Schutzmann Zerulli, 6.1.1908, in: StAH, S 3930-38 Bd.2.

408 Harden an Isenbiel 13.3.1908, in: BAK, KLE 690; Isenbiel an Justizminister 20.3.1907, in: GStA, HA I. Rep. 84a Nr. 49830. Neben Hardens nahezu wöchentlichen Beiträgen in der Zukunft vgl. etwa: Das Reich Nr.17, 21.1.1908; Leipziger Neueste Nachrichten 18.3.1908. 
und bekam so die Möglichkeit, vor einem nicht-preußischen Gericht Zeugen unter Eid aussagen zu lassen. ${ }^{409} \mathrm{Da}$ beim Münchner Prozess Journalisten zugelassen waren, konnten sie ungehindert und ausführlich über Hardens Beweisführung berichten.

Diese Zeugenaussagen zeigten erneut, wie Skandale Menschen aus der Unterschicht ein öffentliches Forum und eine Machtstellung gewährten. Gleich als erster Zeuge trat ein Fischer vom Starnberger See auf, der detailliert erzählte, Eulenburg habe ihn regelmäßig zum gemeinsamen Onanieren bei Bootsfahrten ermuntert. Dafür habe er ihm hohe „Trinkgelder“ von bis zu 200 Mark gegeben, ihn in sein Liebenberger Schloss eingeladen, auf Reisen mitgenommen und ihm ein Darlehen von 12000 Mark gewährt. ${ }^{410}$ Ein Milchhändler und früherer Fischer berichtete von ähnlichen Bootspartien. Eulenburg habe ihn zudem zu Freunden gebracht, die ihm Geschlechtsverkehr gegen eine Entlohnung anboten. Durch diese eidesstattlichen Aussagen schien Eulenburg des Meineides überführt. Ebenso kam heraus, dass Eulenburg den Fischer mit Briefen ersucht hatte, eine Falschaussage zu machen. Das Prozessergebnis diskreditierte damit nicht nur Eulenburg, sondern auch Staatsanwalt Isenbiel, der Eulenburg im letzten Prozess als völlig schuldlos gepriesen hatte, obwohl entsprechende Beweise vorlagen. Die Presse vollzog daraufhin in ihren ausführlichen Berichten über diese Enthüllungen einen erneuten Kurswechsel: Ihre Empörung richtete sich jetzt gegen Eulenburg, aber auch gegen den Staatsanwalt. ${ }^{411}$

Den jetzt bevorstehenden Meineidsprozess gegen Eulenburg bereiteten alle Beteiligten mit einer intensiven Öffentlichkeitsarbeit vor. Harden, der außerhalb der konservativen Presse wieder positiv gesehen wurde, gab vielen Zeitungen Interviews, die sein Vorgehen erläuterten und drohend von weiterem Material sprachen, auch gegen andere Persönlichkeiten als Eulenburg. ${ }^{412}$ Eulenburg führte ebenfalls Interviews und öffnete sein Schloss gegenüber einem Journalisten des Boulevardblattes BZ am Mittag. Diese demonstrative Offenheit reichte soweit, dass der erkrankte Fürst den Journalisten am Bett empfing und von seinem Diener durch die Räume führen ließ. ${ }^{413}$ Vielleicht noch bemerkenswerter war, dass sich selbst der Staatsanwalt Isenbiel per Interview äußerte, um sein Vorgehen zu rechtfertigen. Angesichts der öffentlichen Kritik kündigte er wie selbstverständlich an, „sobald mir gültiges Material gegen den Fürsten Eulenburg vorliegt, werde ich mit aller Rigorosität ohne Ansehen der Person gegen

409 Zu dem Prozess vgl. bereits: Weller, Harden, S. 194; Leuchtmann, Fall Eulenburg, S.217221; Hecht, Harden-Prozesse.

410 Aussagen in: Protokoll der Sitzung 21.4.1908, S.22, in: BAK, N 1062-123; zudem auch in: Anklageschrift 5.6.1908, in: GStA, HA I Rep. 84a, Nr. 49830.

411 Vgl. selbst: Tägliche Rundschau Nr.187, 22.4.1908; Hamburger Nachrichten Nr.312, 4.5.1908; Berliner Tageblatt Nr. 204, 22.4.1908.

412 Vgl. BZ am Mittag Nr. 97 25.4.1908; Fränkischer Courier Nr. 209, 24.4.1908; Berliner LoKal-Anzeiger Nr.232, 7.5.1908. Auch einzelne nationalliberale Zeitungen sahen Harden nun positiver.

413 BZ am MitTag Nr. 95, 23.4.1908. 
ihn einschreiten. " 414 Das bislang in Deutschland noch wenig verbreitete Format des Interviews etablierte sich somit durch den unberechenbaren Skandalverlauf zu einem Mittel, mit dem selbst Beamte den nun in Berlin anstehenden Meineidsprozess gegen Eulenburg vorbereiteten.

Begleitet wurde diese Stimmungsbildung durch Gerüchte. Über Eulenburg hieß es nun etwa, er habe auch mit seinem rumänisch-jüdischen Sekretär ein Verhältnis gehabt, weshalb seine Tochter diesen nur gegen seinen Willen heiraten konnte. ${ }^{415}$ Ebenso hieß es, Eulenburg sei wegen homosexuellen Verhaltens in einer Wiener Badeanstalt erpresst worden und habe 60000 Mark für Schweigegelder gezahlt. ${ }^{416}$ Die Zeitungen druckten zudem Briefe von Eulenburg, die seine früheren Intrigen zeigten. ${ }^{417}$ Die Reichskanzlei blieb ebenfalls nicht verschont. Reichskanzler Bülow erfuhr, dass sein Bruder gerüchteweise der Homosexualität verdächtigt werde. 418 Ebenso ging Bülow dem Gerücht nach, er habe Hardens Vorgehen gegen Eulenburg abgesegnet und damit unterstützt. ${ }^{419}$ Auch wenn Harden sicherlich nicht immer der Urheber der Gerüchte war, streute er „Neuigkeiten“ über befreundete Journalisten und politische Kreise, wobei der vom Auswärtigen Amt entlassene Holstein ein wichtiger Verbindungsmann war. ${ }^{420}$ Derartige Meldungen trugen dazu bei, im Vorfeld des Prozesses Verunsicherungen beim Angeklagten Eulenburg, der Justiz und der Staatsführung auszulösen.

Die Dynamik, die der Skandal durch die Gerüchtebildung erhielt, ging auch von „unten“ aus. Durch die umfangreiche Berichterstattung über Eulenburg und vor allem durch seine fotographische Abbildung meldeten sich zahlreiche Zeitungsleser bei den Redaktionen oder den Ermittlungsbehörden, die Eulenburg in kompromittierenden Situationen gesehen haben wollten. So war der Hauptzeuge, der Fischer vom Starnberger See, auf die Zeitungsberichte hin mit Harden in Kontakt getreten, nachdem er sich beim Zeitungslesen an seinem Stammtisch mit seinem Wissen gebrüstet hatte. Nach dem Münchner Prozess häuften sich diese denunziatorischen Meldungen von Personen, die sich als Zeugen anboten. Sie stammten vor allem aus dem Umfeld der Bediensteten, die durch ihre Arbeit mit dem Privatleben des Fürsten zu tun hatten. Zu ihnen zählten etwa ein Hausmeister, der angeblich unsittlich angefasst worden sei, ein

414 BZ am MitTag Nr. 94 22.4.1908. Zur Kritik, dass der Staatsanwalt sich in Interviews ausfragen ließ: Deutsche Tageszeitung Nr.98 24.4.1908.

415 Vossische Zeitung Nr. 288, 22.6. 1908; Notiz den Fürsten Max Fürstenberger-Donaueschingen betreffend o.D. (Abschrift 1918), in: BAK, N 1029-78.

416 Aufzeichnung Eulenburg, Abschnitt „Die Ehre vergiftet“ (1910). In: BAK, 1029:76, S.6-10. Tatsächlich erhielt Eulenburg auf Weisung des Kaisers „die Summe von 60000 Mark aus dem geheimen Fond“, was auf interne Denunziationen hinweist; Eulenburg an Hohenlohe 31.7.1900, in: RöHL (Hrsg.), Eulenburgs politische Korrespondenz, Bd.3, S. 1986.

417 Berliner Tageblatt Nr.338, 6.7.1908; BZ am Mittag Nr.143, 20.6.1908.

418 Zimmermann an Bülow 11.7.1908, in: BAK, N 1016-131-1ff.

419 Notiz Bülow 12.3.1908, Antwort 14.3. in: BAK, 1016-32-45.

420 Vgl. etwa Harden an Holstein 30.5.1908, in: Rich und Fisher (Hrsg.), Die Geheimen Papiere, Bd. 4, S. 4. 
Diener, der kündigte, weil er mit Eulenburg in einem Bett hätte schlafen sollen, ein Klavierspieler, der Eulenburg angeblich durch das Schlüsselloch eines Hotelzimmer beim homosexuellen Verkehr beobachtet hatte, ein Tischler, der in den 1880ern Eulenburg nur mit einem Hemd bekleidet neben dessen Leibjäger gesehen hatte, ein Münchner Dienstmädchen, und ein Matrose der kaiserlichen Yacht, dem Eulenburg homosexuelle Anträge gemacht haben soll. ${ }^{421}$ Ebenso meldete eine geschiedene Frau eines Kommissars, ihr Mann sei nach Besuchen auf Eulenburgs Schloss immer mit „Afterbluten“ zurückgekehrt. ${ }^{422}$ Einfache Männer und Frauen erhielten so einen weiteren Zugang zur Öffentlichkeit und konnten den Verlauf des Skandals, den sie in den Zeitungen verfolgten, aktiv mitgestalten.

Vor allem der Wunsch nach öffentlicher Aufmerksamkeit dürfte diese mitunter unhaltbaren Aussagen angespornt haben. Durch die täglichen Zeitungsberichte erschien Eulenburg den Lesern wie ein vertrauter Verbrecher, dessen Überführung zu einer kollektiven Aufgabe wurde. Auf diese Weise trugen insbesondere einfache Bedienstete mit dazu bei, einen der einflussreichsten Adligen des Landes zu stürzen und damit die bestehenden Machtverhältnisse zu verkehren. ${ }^{423}$ Die Journalisten förderten das Aufkommen dieser Gerüchte, indem sie die „Tatorte“ aufsuchten. So kamen Reporter zahlreicher Blätter zu Eulenburgs Schloss und zum Starnberger See, um mit Eulenburgs Hausverwalter, dem Bürgermeister und möglichen Zeugen zu sprechen. ${ }^{424}$ Auch wenn Journalisten nur selten Skandale durch investigative Recherchen anstießen, verstärkten zumindest ihre Nachforschungen in der zweiten Phase des Skandals seine Dynamik.

Die Regierung und die Justiz versuchten durch enge Absprachen, beim im Juni 1908 bevorstehenden Eulenburg-Prozess dennoch die Kontrolle zu behalten. Bülow hielt laufend Rücksprache mit dem Justizminister und traf sich vorher mit dem Staatsanwalt, dem er eine Konzentration auf die Anklagepunkte abverlangte, um eine generelle Debatte über Homosexualität in Militär und Politik zu vermeiden. ${ }^{425}$ Nicht nur das Ansehen der Monarchie dürfte den Reichskanzler dabei interessiert haben. Da bei Eulenburg jetzt polizeiliche Durchsuchungen stattfanden, fürchtete Bülow zweifelsohne, seine leicht homoerotisch gefärbte Korrespondenz mit dem Angeklagten könne gefunden werden und durch Indiskretionen an die Öffentlichkeit gelangen. Dehalb verlangte der Kanzler von Eulenburg seine Chiffriermaschine zurück und wies an, alle aufge-

421 Vgl. Anklageschrift 5.6.1908, in: GStA, HA I Rep. 84a, Nr. 49830; in der Presse etwa: BerLINer Tageblatt Nr.314, 23.6.1908 u. 4.7.1908.

422 Staatsanwalt Isenbiel an Beseler 13.5.1908, in: GStA, HA I Rep. 84a, Nr. 49830.

423 Zur breiten Denunziation bei Verbrechen vgl. Philipp Müller, Auf der Suche, S. 150-172.

424 Vgl. die Berichte über die Journalisten dort in: Berliner Tageblatt Nr. 225, 4.5.1908, Münchner Post Nr.103 6.8.1908.

425 Vgl. Loebell an Beseler 1.5.1908, in: BAB/L R43/798b: 150; Beseler an Bülow 2.5.1908, in: BAB/L, R43/798b: 144; Notizen in: GStA, HA I Rep. 84a, Notiz Willisch 20.5.1908, in: BAK, 1016-32-69; Rogge, Holstein, S. 299. 
spürten Briefe von „hochstehenden Persönlichkeiten“ wie dem Kaiser und ihm selbst sofort zu verschließen und ihn zu informieren. ${ }^{426}$ Auch der Kaiser selbst wurde kontinuierlich und explizit durch Justizminister Beseler über die Ermittlungen informiert. ${ }^{427}$ Offensichtlich sollte dies verhindern, dass Wilhelm II. für Eulenburg Partei ergriff. Tatsächlich trat genau das Gegenteil ein: Gerade der Kaiser war es, der nach dem Abbruch des quälenden Prozesses besonders vehement seine Fortführung verlangte. ${ }^{428}$ Die so forcierten Ermittlungen diskreditierten jedoch vor allem seinen eigenen Hof. So überführten sie schon vor dem Eulenburgprozess auch noch Graf Edgar von Wedel der Homosexualität, der Zeremonienmeister und königlicher Kammerherr war und im Prinzessinnenpalais wohnte. Selbst die konservative Tägliche Rundschan empörte sich nun, „daß er im Prinzessinnenpalais oftmals Teegesellschaften veranstaltet habe, bei denen fast ausschließlich abnorm veranlagte Herren aus den höchsten Gesellschaftskreisen teilgenommen haben." ${ }^{2} 29$ Ältere Fälle, wie der bereits 1901 stillschweigend erfolgte Hof-Ausschluss der homosexuellen Brüder von Eulenburg und Hohenau, kamen nun ebenfalls an die Öffentlichkeit. Der Prestigeverlust des Adels und der Monarchie schritt damit voran.

Der Prozess schmälerte zudem die Reputation der Justiz, da die Gerichte bei Hardens Bestrafung die Makellosigkeit von Eulenburg betont hatten. Um Harden und die Öffentlichkeit zu beruhigen, ohne einen Fehlurteil einzugestehen, hob die Staatsanwaltschaft nun Hardens Haftstrafe wegen eines Formfehlers im letzten Prozess auf und wies den Fall an die erste Instanz zur nochmaligen Verhandlung zurück. ${ }^{430}$ Zugleich musste sie dem öffentlichen Vorwurf der Klassenjustiz begegnen. Deshalb erschien ihr jetzt, ähnlich wie in Großbritannien nach dem Cleveland Street-Skandal, ein hartes Vorgehen gegen Eulenburg erforderlich. Da die Durchsuchungen bei Eulenburg weitere Belege gebracht hatten und seine Rechtfertigungen gegenüber dem Staatsanwalt wenig plausibel waren, erfolgte jetzt sogar Eulenburgs Verhaftung. Trotzdem beklagten die Medien die Sonderbehandlung des prominenten Gefangenen. Berichte über seine Verlegung in ein großes Krankenhauszimmer mit Diener oder über seine Spazierfahrten während der Prozesspausen illustrierten den Vorwurf der Ungleichbehandlung von Arm und Reich vor dem Gesetz. ${ }^{431}$ Gleiches galt für den Umgang mit Eulenburgs Gesundheitsproblemen, da das Gericht ihn erst von einer Bahre aussagen ließ, dann die gesamte Gerichtverhandlung in die Charite verlegte und

426 Handschriftliche Aufzeichnung Bülows auf Schriftstück vom 18.5.1908 u. Aufzeichnung Chef des Chiffrierbüros 20.5.1908, abgedr. in: RogGe, Holstein, S. 290.

427 Beseler an Wilhelm II 21.3.1908, 25.4., 1.5., 8.5., 9.5., 13.5., 27.5., 2.6., 8.6., 15.8., 8.7. 1908 in: BAB/L, R 43/798b: 152ff.; Beseler an Wilhelm II. 28.5.1908, in: GStA, HA I Rep. 84a, Nr. 49830.

428 Kaiserliche Gesandte an AA 17.7.1908, in: GStA, HA I Rep. 84a, Nr. 49830.

429 Tägliche Rundschau Nr. 261, 5.6.1908.

430 Beseler an Wilhelm II. 27.5.1908, in: BAB/L, R43/798b: 177; 22. 6. 1907, in : GStA, I HA Rep. 84a Nr. 49838-142ff.

431 Vgl. etwa den Fotobericht in: BIZ, Nr. 28, 12.7.1908. 
schließlich wegen Eulenburgs Krankheit den Prozess abbrach und vertagte. Die Medien kritisierten Eulenburgs Gebrechen hingegen als Simulation, die das Gericht leichtfertig tolerierte. ${ }^{432}$ Wie bei den anderen Skandalen stand damit nicht mehr die Homosexualität im Vordergrund, sondern die Gerechtigkeit vor Gericht.

Der Konflikt zwischen Justiz und Presse war zudem dadurch vorprogrammiert, dass beim Berliner Eulenburg-Prozess im Juni 1908 die gesamte Öffentlichkeit ausgeschlossen wurde. Während die katholischen und konservativen Blätter dies wegen der Gefährdung der Moral begrüßten, protestierten die restlichen Zeitungen mit grundsätzlichen Bedenken. Dennoch gelang es der Justiz und Regierung nicht, eine kritische Berichterstattung einzudämmen. Die Journalisten des Berliner Tageblattes und Berliner Lokal-Anzeigers verschafften sich etwa als Zeugen Zutritt zum Gerichtssaal, andere zehrten von Berichten, die sie an der Tür erhielten. 433 Daraufhin ließ das Gericht zumindest den „besonders zuverlässigen Gerichtsberichterstatter" Adolf Thiele von der Vossischen Zeitung $\mathrm{zu}$, der nun für die Öffentlichkeit stenographierte. ${ }^{434}$ Alle Blätter berichteten nun so explizit wie nie zuvor über den Fall. Viele Blätter nutzten typographische Hervorhebungen, um spektakuläre Meldungen hervorzuheben. ${ }^{435}$ Während die Massenpresse in der Anfangsphase des Skandals noch recht unbeteiligt war, sorgte sie nun im Zuge der gerichtlichen Publikation von Beweisen und Narrativen für seine rasante und emotionalisierende Verbreitung.

Bezeichnend für die mediale Eigendynamik war, dass auch die konservativen und katholischen Zeitungen nicht minder ausführlich über die Prozesse berichteten, obwohl sie gegen eine öffentliche Gerichtsverhandlung protestierten. Ähnlich wie die „Kreuzzeitung“ drückten sie lediglich regelmäßig ihren Widerwillen aus: „Die Redaktionen ernster Blätter besitzen nun gewiß ebenso viel Einsicht in den Ernst der Sache wie die Richter; aber leider werden sie durch die Leser gezwungen, die Berichte zu veröffentlichen." 436 Ebenso forderte die katholische Kölnische Volkszeitung das Verbot der Wiedergabe der Gerichtsverhandlungen, die eine Gefahr für die Moral und Jugend seien. Denn ohne ein Verbot seien die Zeitungen gezwungen, derartiges abzudrucken, weil sie sonst als „langweilig“ gelten würden. ${ }^{437}$ Damit sahen sich die konservativen und katholischen Blätter als Opfer ihrer Leser und der Zeitungskonkurrenz, die sie zu einer ausführlichen Skandalberichterstattung zwingen würden.

Die Zeitungsleser in den Hamburger Kneipen griffen tatsächlich die Berichte über den Skandal ausführlich mit eigensinnigem Spott auf. Nach Eulenburgs

\footnotetext{
432 Vgl. etwa BZ am MitTag Nr. 94 22.4.1908; vgl. auch Karikaturen wie im: KLAdderadatsch 10.5. 1908 .

433 Vgl. Berliner LokAL-Anzeiger Nr.352, 13.7.1908.

434 Protokoll 15. Verhandlungstag 16.7.1908, in: BLHA, Rep 37: 564.

435 Vgl. Sätze wie „die sexuellen spiritistischen Neigungen des Fürsten Eulenburgs“(H.i.O), in: Berliner Lokal-Anzeiger Nr.347, 10.7.1908.

436 Neue Preussische Zeitung, 13.7.1908, abends.

437 Kölnische Volkszeitung, Nr. 571, 4.7.1908.
} 
Überführung gingen sie jetzt auch von Moltkes Schuld aus.. ${ }^{438}$ Vor allem monierten sie die ungleiche Behandlung zwischen Arm und Reich: „Graf Honenau [sic] sowie Graf Linar [sic] hätten beide ohne Pension entlassen werden müssen, da jeder andere Beamte ohne Pension entlassen wäre. Ebenso ist es mit dem Fürsten Eulenburg, dem steckt man alles zu, was er im Gefängnis wünscht.“439 Zugleich sorgte der Prozess für eine spöttisch-spielerisch und humoreske Aneignung in den Kneipen. So beobachtete ein Polizist „Bauhandwerker“, die sich beim Frühstück „unsittliche Bilder“ zeigten, „worauf dann einer von diesen Kollegen sagte: ,das müßte Eulenburg sehen. ““440 Andere Kneipengäste erzählten sich Witze, die sich um den Skandal drehten. So griff ein Kohlenarbeiter die Zeitungsberichte gegenüber seinen Kollegen mit dem Hinweis auf, in Berlin müssten die Kohlenhändler „jetzt mit den Kohlenpreisen herunter gehen, sonst werden die überhaupt nichts mehr los. Hierauf fragte der dritte, warum denn'? ,Das ist doch ganz einfach zu erraten, weil es dort viel zu warm ist. ““441 Der Witz deutet zugleich an, dass durch den Skandal die neue Metropole Berlin als Ort der Homosexualität erschien.

Der Prozess gegen Eulenburg bildete zweifelsohne den Höhepunkt eines Skandals, der einen denkbar langen Vorlauf hatte. Als die Ärzte mitten im Prozess Eulenburg aus gesundheitlichen Gründen für verhandlungsunfähig erklärten, war die Unzufriedenheit groß. Obgleich die Beweise ganz überwältigend gegen Eulenburg sprachen und das lang diskutierte Geheimnis aufgedeckt war, fehlte das erwartete offizielle Urteil gegen ihn. Im September 1908 wurde Eulenburg aus der Charité gegen eine hohe Kaution nach Hause entlassen. Obgleich der Kaiser und verschiedene Politiker immer wieder regelmäßig auf die Fortführung des Prozesses drängten, blieb Eulenburgs Gesundheitszustand angeblich so schlecht, dass er nicht verhandlungsfähig war. ${ }^{442}$ Dass er 1909 trotzdem nach Bad Gastein reisen konnte, wurde von der Presse allgemein als Niederlage der deutschen Rechtsprechung gesehen. ${ }^{443}$ Reichskanzlei und Justizministerium hofften dagegen 1909, dass es nicht zu einem erneuten Prozess kommen würde, um den Skandal endlich zu beenden. ${ }^{44}$ Tatsächlich wurde im Sommer 1909 ein erneuter Prozess wegen eines „Herzkrampfes“ von Eulenburg am ersten Tag abgesetzt. ${ }^{445}$ Dass der Prozess nie beendet wurde, erschien öffentlich immer wieder als neuer Beleg für eine Zweiklassenjustiz.

\footnotetext{
438 Polizeibericht Schutzmann Zerulli, 11.5.1908, in: StAH, S 3930-38 Bd. 2.

439 Polizeibericht Schulz 24.6.1908, in: StAH, S 3930-42.

440 Polizeibericht Schulz 9.7.1908, in: StAH, S 3930-42.

441 Polizeibericht Zerulli 31.10.1908 (über Kneipenbesuch 30.10.1907), in: StAH, S 3930-38 Bd.1.

${ }^{442}$ Vgl. zu Wilhelms Drängen: Beseler an Wilhelm II. 4.9.1909 und 13.6.1909, in: BAB/L, R43/ 798b: $293 \mathrm{ff}$.

443 Vgl. die Pressesammlung in LHB, ReP. 37: 554/1.

444 Loebell an Ballin 18.6.1909, in: BAK, N 1062-4.

445 Bericht Staatsanwalt und Protokoll 8.7.1909, in: GStA, HA I Rep. 84a Nr. 49831.
} 
Eine Fortsetzung des Skandals drohte jedoch durch eine Revision des MoltkeProzesses. Dabei zeigen die überlieferten Quellen detailliert, wie sehr von politischer Seite in die Justiz eingegriffen wurde, um eine Beendigung der Prozesse und einen Ausgleich mit dem Journalisten zu erreichen. Vor allem Reichskanzler Bülow versuchte mit allen Mittel, einen weiteren Prozess zu verhindern. $\mathrm{Zu}$ nächst setzte er sich dafür ein, ihn bis nach dem Abschluss des Eulenburg-Prozess zu vertagen; der preußische Justizminister Max von Beseler sollte beim Staatsanwalt darauf hinwirken. ${ }^{446}$ Der Justizminister sprach mit dem Staatsanwalt Isenbiel ab, Harden solle im Falle eines Prozesses mit einer Geldstrafe davon kommen, die Zeugen Riedel und Ernst seien nicht einzuberufen und er brauche sich nur auf den Fall Moltke zu konzentrieren. ${ }^{447}$ Um direkt auf Harden einzuwirken und indirekt seine Forderungen zu erfahren, bediente sich Bülow des Journalisten Eugen Zimmermann, der bei der Reichskanzlei in Sold stand und als Bülows Vertrauter arbeitete. ${ }^{448}$ Wie ernst Bülow den Skandal weiterhin nahm, unterstrichen seine handschriftlichen Notizen, in denen er seine Standpunkte reflektiert („Meine Beziehung zu Ha[rden]“). ${ }^{449}$ Zugleich schützte Bülow Harden, als ihm im November 1908 wegen seiner Artikel im Rahmen der Daily-Telegraph-Affäre ein Prozess drohte. Das Verbot der Zukunft wurde auf Bülows Geheiß abgemildert und ein Majestätsbeleidigungsprozess blieb aus, wofür sich Harden indirekt über Zimmermann bei Bülow bedankte. ${ }^{450}$

Tatsächlich konnte der Reichskanzler Harden mit materiellen und symbolischen Zugeständnissen beruhigen. Bülow ließ über den offiziösen Journalisten Zimmermann einen geheimen Vergleich zwischen Moltke und Harden aushandeln. Harden wiederholt darin, „daß er in seiner Wochenschrift Seine Excellenz, den Herren Grafen Kuno von Moltke nicht der Homosexualität beschuldigt hat. [...] Beide Herren sind er Überzeugung, daß sich nach dieser Erklärung jede Beweisaufnahme erübrigt."451 Obwohl Moltke und Harden durch diese Vermittlung gemeinsam den Staatsanwalt um die Einstellung des Verfahrens baten und letzterer dies unterstützte, kam es durch das Drängen des Justizministeriums schließlich dennoch zu einem Prozess. ${ }^{452}$ Über den Justizminister wies Bülow den Staatsanwalt an, aufgrund des Vergleichs der Parteien auf jede Beweisaufnahme zu verzichten und keine Strafe zu beantragen. ${ }^{453}$ Auch die

446 In zwei Briefen am selben Tag: Bülow an Reichskanzlei u. an Loebell 8.10.1908, in: BAB/L, R43/798b: 231 u. 234.

447 Notiz Reichskanzlei 7.10.1908, in: BAK, 1016-32-73ff.

448 Vgl. Zimmermann an Loebell 12.10.1908 und 17.10., in: BAB/L, R43/798b: 246 u. 248 ; vgl. auch Zimmermann an Bülow 13.12. u. 31.12.1908, 15.1., 9.3. u. 8.4.1909 in: BAB/L, R43/ 798b: $257 \mathrm{ff}$.

449 Handschriftliche Aufzeichnung Bülow, o. D. (wohl 1908) in: BAK, 1016-32-33.

450 Guenther an Loebell 8.11.1908, in: BAB/L, R43/798b: 252; Zimmermann an Loebell 3.12.1908, in: BAB/L, R43/798b: 256.

451 19.3.1909, in: BAB/L, R43/798b: 272.

452 Erklärung Moltke/Harden 22.3.1909, in: BAB/L, R43/798b: 273.

453 Bericht 23.4.1909, in: BAB/L, N2106/2: 17ff; Bülow an Loebell 15.4.1909, in: BAB/L, R43/ 798b: 277 
Aussagen der Kontrahenten wurden abgesprochen. Moltke sollte die Frage nach der Homosexualität nicht direkt beantworten und sich nur auf frühere Aussagen berufen. Ein weiterer Unterhändler, der Reeder Albert Ballin, erreichte eine briefliche Versicherung Hardens, sich vor Gericht nicht belastend zu äußern und selbst eine Verurteilung durch das Gericht hinzunehmen." ${ }^{454}$ Tatsächlich hielt sich Harden an diese Absprachen, womit Bülow die Bezähmung des unberechenbaren Journalisten gelungen war. Im Unterschied $\mathrm{zu}$ allen vorherigen Prozessen war dieser damit nur noch eine abgesprochene Farce.

Trotz dieser scheinbar perfekten Planung des Prozesses durch die Reichsleitung war allerdings auch hier der Prozess und damit der Skandalverlauf nicht steuerbar. Da das Gericht zumindest eine Absprache unterlief und Harden wegen „übler Nachrede“ zu 600 Mark Geldstrafe und zur Zahlung der Prozesskosten verurteilte, schien ein weiterer Prozess bevorzustehen. Harden beschuldigte nun zu unrecht Bülow, nicht für den vereinbarten Freispruch beim Justizminister gesorgt zu haben. ${ }^{45}$ In einer Zuschrift an den Hannoverschen Courier kündigte er sofort seine Revision an und verdammte seine „einseitige Rücksichtnahme". ${ }^{456}$ Daraufhin startete der Reichskanzler weitere Versuche, den Journalisten zu beruhigen. Bülow verhandelte mit Harden wieder über den Unterhändler Ballin, die zahlreiche Briefe austauschten und Gespräche führten. ${ }^{457}$ Schließlich gelang über zwei Gesten eine Einigung: Erstens akzeptierte Harden, um seine Ehre wieder herzustellen, nach einigen Debatten über einzelne Formulierungen einen eigenhändigen Brief Bülows, der Harden von seiner Schuld freisprach und damit seine Ehre wieder herstellte. Hier hieß es: „Ich glaube mit vollem Recht, daß Herr Harden nicht aus Sensationslust, sondern aus patriotischen Erwägungen gehandelt hat und nicht leichtfertig dabei zu Werke gegangen ist. “458 Zweitens wurde Harden mit 40000 Mark aus geheimen Mitteln der Reichskanzlei versöhnt, die ihm seine Unkosten bei den Prozessen unter der Bedingung ersetzten, dass er den Revisionsantrag zurückziehe. ${ }^{459}$ Damit akzeptierte einer der großen unabhängigen Journalisten letztlich ein Schweigegeld, um den Skandal zu beenden. Akzeptabel war es für Harden aber ohnehin nur deshalb, weil er selbst völlig erschöpft von den Prozessen war und voller patriotischer Selbstzweifel, ob sein Verhalten dem Land mehr schade oder nütze.

Insofern gingen schließlich alle Beteiligten als Verlierer aus dem Skandal. Harden hatte an Ansehen verloren, weil er durch den Abbruch des EulenburgProzesses und den geheimen Ausgleich mit Moltke nicht per Gerichtsurteil seine Vorwürfe rechtskräftig belegen konnte. Zudem wurde er für die Diskreditie-

454 Loebell an Bülow 14.4.1909, in: BAB/L, R43/798b: 276.

455 Vgl. Hardens Korrespondenz im April 1909, in: BAB/L, N2106/2.

456 Hannoversche Courier 25.4.1909.

457 Loebell an Bülow 9.5.1909 und Loebell an Ballin, in: BAB/L, R43/798b: $282 \mathrm{ff}$. Ballin an Harden April bis Juni 1909 in: BAK, N 1062-4.

458 Bülow an Ballin 29.5.1909, in: BAK, N 1062-123.

459 Ballin war wieder der Mittelsmann: Betragsbestätigungen Loebell und Ballin 12.6.1909 in: BAK, 1016-32-162 und 164. 
rung der Monarchie und die Verbreitung von „unmoralischen“ Berichten verantwortlich gemacht. Eulenburgs und Moltkes Reputation war hingegen auch ohne Urteil zerstört. Auch Bülows Stellung litt unter dem Skandal, da er wegen seines wechselhaften und zurückhaltenden Durchgreifens sowohl beim Kaiser als auch in der Öffentlichkeit an Ansehen verloren hatte. ${ }^{460}$ In gewisser Weise war dieses Ergebnis symptomatisch für den Verlauf des Skandals, der zeigte, dass sich in der medialisierten Öffentlichkeit weder anklagende Journalisten noch machtvolle Politiker eindeutig durchsetzen konnten. Der Ausgang ihrer Auseinandersetzungen hing vielmehr von sich schnell wechselnden öffentlichen Stimmungen $\mathrm{ab}$, die für beide Seiten nicht kontrollierbar waren. Die zahlreichen Versuche, die öffentliche Meinung oder Prozessverläufe zu beeinflussen, scheiterten zumindest immer wieder.

\section{Deutungen und Normen}

Der Skandal war jedoch mehr als ein Machtkampf zwischen Teilen der Presse und der Politik. Er verhandelte zugleich verschiedene Normen und Deutungsmuster. Besonders Homosexualität wurde im Zuge des Skandals so offen und ausführlich thematisiert, wie es bislang in der deutschen Öffentlichkeit sicherlich noch nie der Fall war. Sowohl die bürgerliche Abgrenzung gegenüber der adligen „Kamarilla“ als auch die große Zahl an gerichtlich dokumentierten Aussagen zu Homosexualitätsfällen erleichterten dabei den Umgang mit dem Tabuthema.

In den Artikeln vieler liberaler Zeitungen erfuhr die Homosexualität zunächst eine erstaunlich tolerante Bewertung, wie sie in Großbritannien undenkbar gewesen wäre. Sie reichte noch über die verständnisvollen Zuschreibungen im Krupp-Skandal hinaus. So urteilte die National-Zeitung im Zuge des MoltkeHarden-Prozesses, es sei für die Politik unerheblich, ob ein Beamter sich homosexuell betätige oder nicht. Sie betonte vielmehr, „daß ein Mensch homosexuell empfinden und doch eine Natur von hoher sittlicher Kraft sein kann." Wenn Berater Interna verrieten oder einen Ring um den Kaiser bildeten, sei dies verwerflich, nicht aber ihre Homosexualität. ${ }^{461}$ Ebenso empfahl sie den Richtern vor dem Prozess, die Formulierung „widernatürlich“ des $\$ 175$ in Anlehnung an die „Wissenschaft über jene Zwischenstufen“ neu auszulegen. ${ }^{462}$ Ähnlich tolerant äußerte sich die freisinnige Frankfurter Zeitung: Prinzipiell könne ein Homosexueller selbst zu einer hohen Stellung und als Ratgeber des Kaisers taugen. Auch wenn sie sich gegen die Abschaffung des $\$ 175$ aussprach, seien Homosexuelle nicht zu verachten: „Moralisch deshalb nicht, weil es mindestens sehr

460 Diese Einschätzung zu Bülow auch bei: Wolfgang J. Mommsen, Bürgerstolz und Weltmachtstreben. Deutschland unter Wilhelm II. 1890-1918, Frankfurt a. M. 1995, S. 257.

461 National-Zeitung Nr.504, 26.10.1907.

462 National-Zeitung 16.10.1907. 
wahrscheinlich ist, daß in vielen Fällen eine natürlich-unnatürliche Veranlagung vorliegt, und im übrigen, weil es in der Tat bedeutende Homosexuelle gegeben hat."463 Damit überführten die Blätter sowohl die medizinischen als auch die historischen Argumente der Expertendiskurse in die breite Öffentlichkeit.

Bereits vor den Prozessen erhielt Magnus Hirschfeld in der Zukunft Gelegenheit, seinen Standpunkt zur Homosexualität darzulegen. ${ }^{464}$ Der erste MoltkeHarden Prozess im Oktober 1907 förderte diese Popularisierung toleranter Expertendeutungen, indem Magnus Hirschfeld als Gutachter auftrat. Das Fazit, das Hirschfeld hier über Moltkes Sexualität zog, drang durch die recht wörtliche Prozessberichterstattung selbst in konservative Blätter wie die „Kreuzzeitung“. Hirschfeld sprach nach ihrem Bericht davon, es liege „objektiv eine Abweichung von der Norm“ vor, „und zwar eine unverschuldete, angeborene und nach meiner Überzeugung ihm selbst nicht bewußte Anlage, die man als homosexuell zu bezeichnen pflegt. “ Zugleich vermittelte er die Deutung, „daß die Homosexualität keine Krankheit ist, sondern im Plane der Natur“, weshalb der $\$ 175 \mathrm{abzu-}$ schaffen sei. ${ }^{465}$ Während die konservativen und katholischen Zeitungen noch im Sommer 1907 eine offene Debatte über Homosexualität vermieden hatten, führte der Prozess im Herbst somit zumindest zu Berichten über unterschiedliche Positionen, auch wenn ihre Kommentare sie erwartungsgemäß nicht teilten. Die Konservativen stellten die medizinischen Erkenntnisse vielmehr hinter das „gesunde Volksempfinden“, das Homosexualität als „widernatürlich und ekelhaft [...] abnorm und krankhaft" ansehe, weshalb Homosexuelle nicht in führende Positionen kommen dürften. ${ }^{466}$ Gerade das aufkeimende Verständnis für gleichgeschlechtliche Beziehungen förderte somit entsprechende Gegenreaktionen.

Ähnlich ambivalent wie im Fall Krupp urteilten die sozialdemokratischen Medien. Auf der einen Seite betonten sie erneut, Homosexualität sei eine Krankheit und daher eine Bestrafung oder Entrüstung unangebracht. Auf der anderen Seite sahen sie das Verhalten der Adligen als amoralisch und strafbar an, indem sie argumentierten, „daß es außer der angebornen Homosexualität noch eine erworbene, oder sagen wir, künstliche gibt, die ein Produkt des Verfalls ist. “467 Dementsprechend bezeichneten sie Eulenburg als einen „Päderasten“, der durch sein Geld andere verführt habe, und benutzten die Homosexualität zur Anklage gegen die Regierung. ${ }^{468}$ Ihre weltanschauliche Umdeutung der Homosexualität in der politischen Auseinandersetzung trug somit erneut dazu bei, Homosexuelle als korrumpierende Gefahr zu brandmarken.

463 Frankfurter Zeitung Nr. 300, 27.10.1907.

464 Die Zukunft 29.6.1907.

465 Neue Preussische Zeitung, 26.10.1907, morgens. Vgl. auch das Urteil, ausgefertigt 7.11.1907, in: GStA, I HA Rep. 84a Nr.49838-36, S. 23.

466 Kölnische ZeITUng Nr.1121, 28.10.1907.

467 VORWÄRTS 24.10.1907.

468 Vgl. Formulierung wie: „Die Pädasterie scheint es also gewesen zu sein, die diesen Nebenregierungszirkel zusammenhielt“. Zit. LeIPZiger Volkszeitung. Nr.127, 5.6.1907; ähnlich: VORWÄRTS 24.10.1907, 3.7.1908, 18.7.1908. 
3.1.

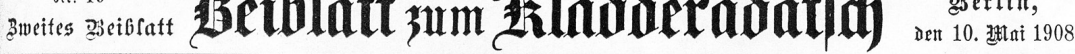

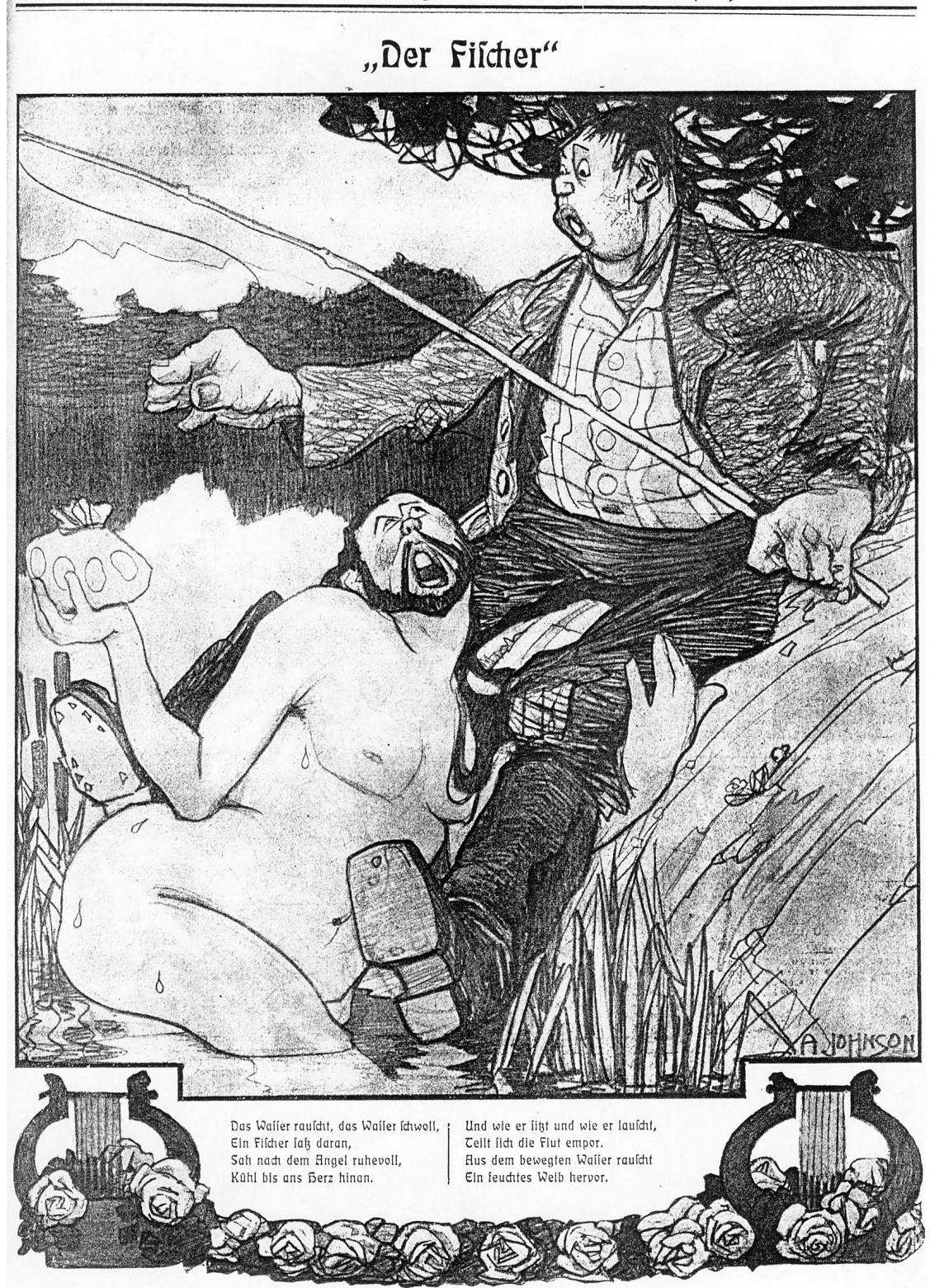

Abb. 3: Auch in Deutschland brachten die Skandale mit erstaunlich expliziten Darstellungen das Bild des reichen Homosexuellen auf, der durch sein Geld verfübrt; Quelle: Kladderadatsch 10.5.1908 (Zweites Beiblatt). 
Aber auch einige bürgerliche Blätter schlossen sich dieser Deutung an und sahen Homosexualität als ein Phänomen der Oberschicht, das durch erbliche Anlagen und dekadenten Lebenswandel verursacht würde. So beschrieb der konservative Der Tag aus dem Scherl-Verlag Homosexualität als eine „gefährliche Krankheit just in den Gesellschaftsregionen, die berufen sind, uns einen großen Theil unserer Führer zu geben. [...] Allzuleicht erworbener Besitz, angezüchtigter Eisenmangel im Blut und intellektuelle Schwäche halten sie einerseits von der Arbeit fern, peitschen sie andererseits zu immer neuen sogenannten Lebensgenüssen." Dies sei privat legitim, wenn sie nicht an die Spitze des Landes drängten. ${ }^{469}$ Ebenso gingen der konservative Reichsbote und die katholische Germania davon aus, dass die aufgedeckte Homosexualität keine Ausnahme, sondern in höchsten Schichten verbreitet sei. ${ }^{470}$ Der Reichsbote zog daraus sogar den Schluss, die Innere Mission sollte sich in Zukunft verstärkt um die Moral der Oberschicht bemühen. Damit verbreitete der Skandal ähnlich wie im spätviktorianischen England von der linken bis zur rechten Öffentlichkeit die Vorstellung, ein normaler bürgerlicher Lebenswandel mit entsprechendem Arbeitsethos würde Homosexualität ausschließen. Nachdem sich zunehmend die Deutung etablierte, Homosexualität sei eine Art Krankheit, standen nun die Behandlungsmöglichkeiten im Vordergrund.

Eine zentrale Frage war, welche Bedeutung Homosexualität innerhalb des Militärs hatte. Immerhin stand im ersten Prozess mit Moltke ein General im Mittelpunkt des Skandals. Obgleich der erste Prozess Moltke nur homosexueller Neigungen, nicht homosexueller Praktiken überführt hatte, thematisierten die Prozessberichte homosexuelle „Orgien“ von hohen Militärs. Ein früherer Gardekürassier erzählte im Prozess etwa von unsittlichen Anträgen, die ihm Major Graf Lynar, Generalleutnant Wilhelm Graf von Hohenau und andere Offiziere gemacht hätten. In der Villa hätten diese, so die Vossische Zeitung, „mit ihm Handlungen vorgenommen, die von ihm genau geschildert werden, deren Wiedergabe sich aber verbietet." 471 Dieser Zeuge glaubte auch Eulenburg und Moltke wieder zu erkennen, die dabei zugeschaut hätten. Teile der Presse generalisierten diese Befunde. So nannte es die Freisinnige Zeitung „unbestreitbar“, dass Homosexualität im Militär häufiger vorkomme. ${ }^{472}$ Dass der Skandal selbst innerhalb der Militärführung diese Annahme etablierte, deutete rückblickend der für Sittenfragen zuständige Berliner Kommissar von Tresckow an: „Fast täglich kommen Kommandeure der Berliner und Potsdamer Garderegimenter zu mir und bitten um Rat, wie sie die in den Regimentern eingerissene Päderastie der Soldaten bekämpfen könnten. “473 Die kurz vorher verübten Selbstmorde

469 Der TAg Nr. 259, 19.7.1908.

470 Reichsbote Nr.251, 29.10.1907; Germania zit. in: Die Post Nr.249, 27.10.1907. Nicht „krankhafte Anlage“, aber auch „Übersättigung“ als Ursache: Deutsche TAgeszeitung 12.10.1907.

471 Vossische Zeitung Nr. 500, 24.10.1907.

472 Freisinnige Zeitung Nr. 257, 30.10.1907.

473 Von Tresckow, Von Fürsten, S. 185. 

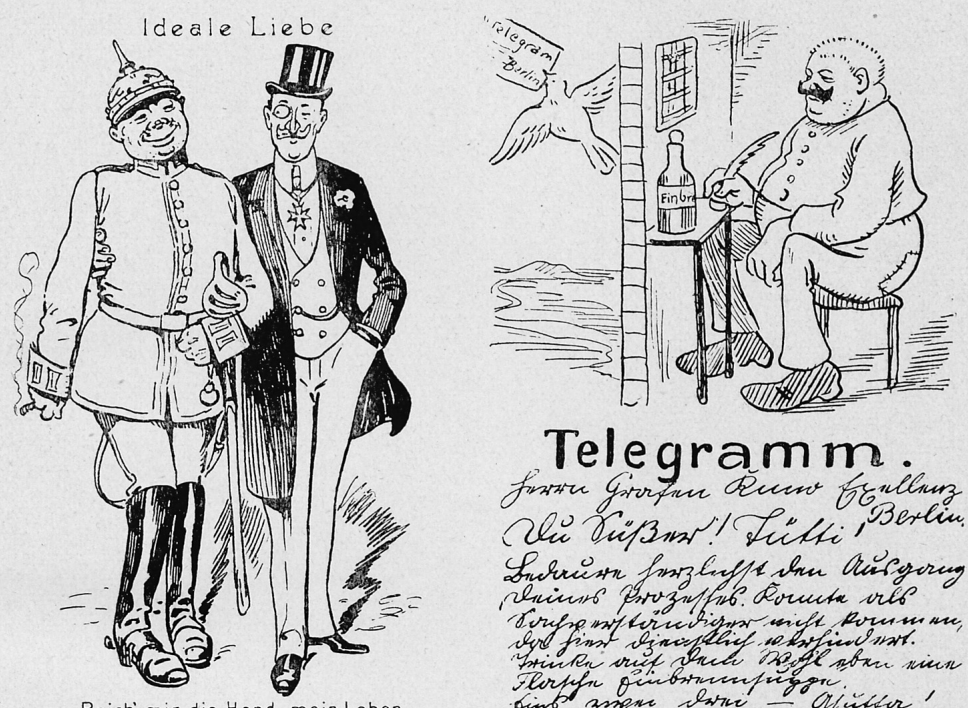

\section{Telegramm}

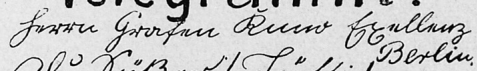

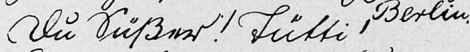
Lharcien finzheffe thu Oinsyong

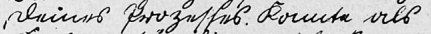

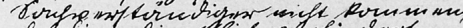

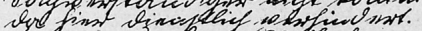

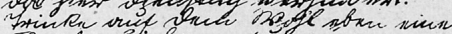

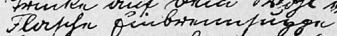

Reich mir die Hand mein Leben. Komm auf mein Schloss mit mir!

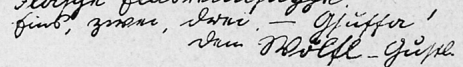

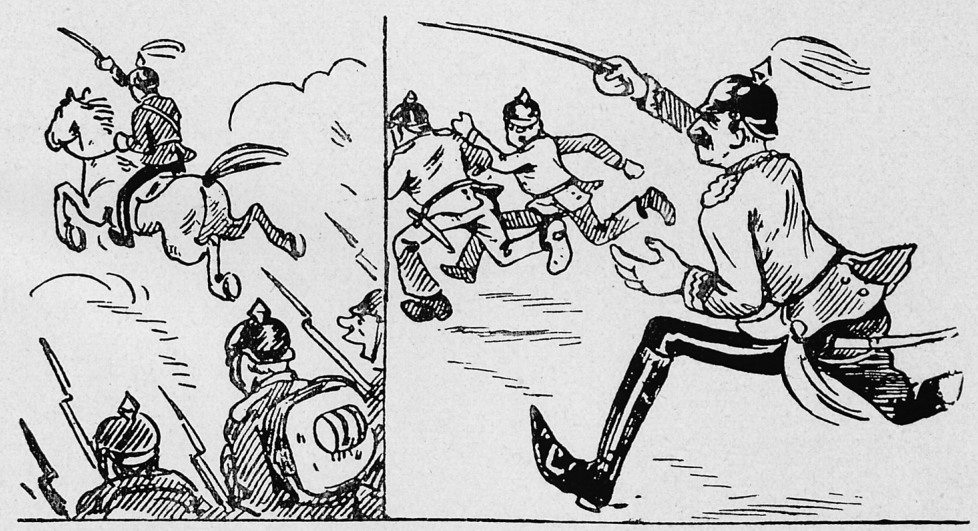

1870: Da lebf noch der Mittke, ein tapferer Mann, 1907: Der heufige Molthe, man hat es gehört, Der griff die Soldaten von vorne an. Der machte den Angriff immer - "verkehri"!

Abb. 4: Spott und Empörung über die Homosexualität im Militär zeigten sich auch in Postkarten, die im Zuge der Skandale vertrieben wurden; Quelle: LINSERT, Kabale, S. 474. 
von Offizieren wegen derartiger Vorwürfe (wie vom Hauptmann von Tschirschky und Leutnant von Uetritz) verstärkten diesen Eindruck. ${ }^{474}$ Immerhin waren zwischen 1905 und 1907 rund 20 Offiziere wegen Homosexualität verurteilt worden und sechs Selbstmorde von erpressten Offizieren zu verzeichnen. ${ }^{475}$

Die durch den Skandal diskutierte Verbindung von Homosexualität und Militär vereinte dreierlei Ängste: die Furcht vor einer Minderung der Kampfeskraft durch „verweiblichte“ Soldaten; die Angst vor einem Autoritäts- und Reputationsverlust des Militärs, auch mit Blick auf das Ansehen im Ausland; und eine Krise der Männlichkeit, die gerade in Preußen durch das Militär verkörpert und durch militärische Werte definiert wurde. Dementsprechend forderten insbesondere die konservativen, katholischen und nationalliberalen Blätter eine „eiserne Reinigung" des Militärs. ${ }^{476}$ Männer wie Moltke bezeichneten sie wegen ihres „süßlichen Wesens“ und „abnormer Empfindungen“ als eine Gefahr für das Militär, was die Norm militärischer Männlichkeit wieder restituierte. ${ }^{477}$ Die liberalen Zeitungen sahen sie zumindest als ungeeignet für militärische Führungsposten an. ${ }^{478}$ Die zugeschriebene feminine Schwäche des Homosexuellen bedrohte demnach die Kraft des Staates, wie Harden bereits an dem angeblich durch Eulenburg verursachten Zurückweichen in der Marokkokrise 1906 auszumachen geglaubt hatte. ${ }^{479}$

Der Reputationsverlust für das Militär war nicht leicht aufzufangen. Vor allem die satirischen Zeitschriften und Zeitungsbeilagen verbreiteten Karikaturen über die homoerotische Neigung von Offizieren, die sich an ihren Soldaten ergötzten. ${ }^{480}$ Den weit verbreiteten öffentlichen Spott drückten auch Postkarten aus, die in Kneipen vertrieben wurden und entsprechende Vorstellungen über den Missbrauch von Untergebenen verfestigten (vgl. Abb. 4). Besonders die Musterung durch den Vorgesetzten erhielt vielfältige homoerotische Umdeutungen in den Bildern. Zudem kursierten provokative Broschüren mit Titeln wie „Armee und Homosexualität“, die behaupteten, die Homosexualität würde überhaupt erst den inneren Zusammenhalt im Militär herstellen. ${ }^{481}$ Nicht nur die Grenzen des Sagbaren, sondern auch die Grenzen des Zeigbaren erwiesen sich somit in Deutschland als deutlich weiter als in Großbritannien, wo derartig

474 Vgl. zu weiteren Fällen im Militär, die damit in Verbindung standen: Monatsbericht DES Wissenschaftlich-humanitären Komitees 1.7.1907, in: Staatsbibliothek Berlin.

475 Diese Zahlen, allerdings nur nach Angaben des dubiosen Publizisten Adolf Brand: James D. STEAKLEY, Iconography of a Scandal. Political Cartoons in the Eulenburg-Affair, in: WAYNe R. Dynes (Hrsg.), History of Homosexuality in Europe and America, New York 1992, S.323385, S. 334.

476 Zit. Köln. Volkszeitung Nr. 934, 28.10.1907.

477 Vgl. Die Post Nr. 505, 27.10.1907; KöLnische Zeitung Nr.1121, 28.10.1907.

478 Frankfurter Zeitung 30.10.1907.

479 Diesen Aspekt betont auch: BRUns, Skandale, S. 62.

480 Vgl. bes. Simplicissimus 11.11.1907, S. 517, 519 u. 532 u. 10.12.1907. Zu den Karikaturen vgl. James StEakley, Die Freunde des Kaisers. Die Eulenburg-Affäre im Spiegel ihrer zeitgenössischen Karikaturen, Hamburg 2004.

481 Karl Franz von Leexow, Armee und Homosexualität, Leipzig 1908. 
satirische Bilder kaum aufgetreten waren, geschweige denn ernst gemeinte Darstellungen.

Wie sehr gerade die Homosexualität beim Militär die Öffentlichkeit bewegte, zeigte sich auch in den Kneipengesprächen. Aus den Zeitungsberichten entwickelten sich recht persönliche Unterhaltungen über individuelle Erlebnisse. So berichtete ein Gast über seine Erfahrungen mit homosexuellen Offerten beim Militär. ${ }^{482}$ In einer anderen Kneipe meinte ein Gast laut Polizeibericht, der Skandal „hat wohl einige Übelstände bei unserem so herrlichen Kriegsheer aufgedeckt aber noch lange nicht genügend, denn in ihm passiert noch viel mehr [...].“483 Wie „alltäglich“ dies beim Militär sei, belegte der Gast mit dem Hinweis auf die benachbarte Wandsbeker Garnison, wo bei einem Begräbnis viele als homosexuell bekannte Männer erschienen seien. Unabhängig von dem Wahrheitsgehalt derartiger persönlicher Aussagen führten die Medienberichte somit dazu, dass ein derartig tabuisiertes Thema äußerst offen diskutiert wurde.

Auch in der Versammlungsöffentlichkeit des Reichstages regte der Skandal entsprechende Debatten über die Homosexualität beim Militär an. Wie stark die Empörung hierüber war, zeigte sich Ende November 1907 bei den Reichstagsdebatten zum Moltke-Skandal. Der Zentrumspolitiker Spahn sprach etwa von einem „Mißbrauch der Dienstgewalt“ von Offizieren, der Eltern besorgen müsse. Ebenso explizit beschwerte sich der Nationalliberale Bassermann darüber, „daß deutsche Offiziere sich vergingen mit Untergebenen“. Und der Sozialdemokrat Bebel berichtete von Selbstmorden von erpressten Offizieren, weshalb er erneut die Abschaffung des $\$ 175$ forderte. ${ }^{484}$ Der Reichskanzler entgegnete diesen Vorwürfen mit dem Versprechen, besonders hart gegen Homosexualität im Militär vorzugehen. Auch Kriegsminister von Einem versprach Maßnahmen. Die Angst vor der homosexuellen Überwältigung des Militärs zeigte sein Verweis auf das schon länger bestehende Verbot für Kürassiere, bei Dunkelheit in ihrer Uniform auszugehen, um sie „vor den Angriffen der pervers veranlagten Teile des Zivilpublikums zu schützen. “485 Abschließend zog der Kriegsminister die Grenze zwischen Homosexuellen und Militär mit aller Deutlichkeit: „mir sind diese Leute ekelhaft (Bravo! rechts) und ich verachte sie! Aber, meine Herren, eins steht unbedingt fest: mag dem sein, wie ihm wolle, ein solcher Mann darf nie und nimmer Offizier sein. (Lebhaftes Bravo rechts) [...] ein solcher Mann zwingt seine Mannschaften, den Vorgesetzten zu verachten. "486 Homosexualität galt folglich erneut als Gefahr für die Autorität und die Hierarchien. Entsprechende Prozesse gegen die bislang nur verabschiedeten Offiziere folgten. Major Lynar wurde wegen Missbrauchs der Dienstgewalt in sechs

\footnotetext{
482 Polizeibericht Stoike 26.10.1907, in: StAH, S 3930-39.

483 Polizeibericht Hinz 5.11.1907, in: StAH, S 3930-26, Bd. 6.

484 Zit. 28.11.1907, Sten. Ber. RT, 60. Sitz., S.1875 u. 1889; 29.11.1907, Sten. Ber. RT 61. Sitz., S. 1910.

485 29.11.1907, Sten. Ber. RT 61. Sitz., S. 1913.

486 29.11.1907, Sten. Ber. RT 61. Sitz., S. 1916.
} 
Fällen, davon vier sittlichen Vergehen, zu einem Jahr und drei Monaten Gefängnis verurteilt, und der Generalleutnant Wilhelm Graf von Hohenau wurde zwar wegen mangelnder Beweise freigesprochen, musste aber seinen Dienst wegen nicht erwiesener Unschuld quittieren. ${ }^{487}$ Die anfänglichen toleranten Deutungen der liberalen Öffentlichkeit wurden somit durch die Angst vor einer militärischen Schwäche wieder überschrieben.

Durch derartige Debatten trug der Skandal maßgeblich dazu bei, generelle Eigenschaften und Erkennungsmerkmale von Homosexuellen zu konstruieren. Da Eulenburg und Moltke schlagartig die bekanntesten Personen im Land waren, denen man Homosexualität zuschrieb, folgten aus ihren angeblichen Charaktereigenschaften pauschale Verallgemeinerungen. Wie beim Krupp-Skandal zählten dazu künstlerische Neigungen, Arbeitsscheu, ein „weicher“ Charakter sowie der inadäquate Kontakt mit jungen Männern aus der untersten Gesellschaftsschicht, die durch Geld korrumpiert würden. Hinzu kamen Intrigantentum, die Patronage von Männern mit ähnlichen Neigungen und eine begrenzte Ehrlichkeit, die der Zwang zur Verstellung auslöse. Den „femininen Einschlag“ von Homosexuellen verifizierte auch der Experte Hirschfeld, indem er ihnen irrationale weibliche Charaktereigenschaften zuschrieb wie „ein Vorherrschen des Gefühlslebens“ oder „ein Hang zum Mystizismus“. 488 Auch das Urteil des Gerichtes, das alle Zeitungen verbreiteten, machte in Anlehnung an Hirschfelds Expertise Homosexualität vor allem an drei Eigenschaften aus: „er [Moltke] ist dem weiblichen Geschlecht abgeneigt, hat eine Zuneigung zu dem männlichen Geschlecht und hat gewisse feminine Eigenschaften - alles Merkmale der Homosexualität. “489 Diese Erkennungsmerkmale wurden anhand seiner Verhaltensweisen belegt und spezifiziert. Dass Moltke im Theater gerne Süßigkeiten esse, von seiner Frau verspottet und geschlagen werde, den ehelichen Sexualverkehr zwei Tage nach der Hochzeit aufgab und am Taschentuch seines angebeteten Freundes roch, waren zentrale Indizien. Das Urteil des zweiten MoltkeProzesses, das ihn entlastete, begründete seine „Normalität“ genau umgekehrt, indem es ihm alle femininen Eigenschaften absprach. ${ }^{490}$ In diesem Sinne erschienen Homosexuelle tatsächlich wie ein „drittes Geschlecht“ zwischen Mann und Frau, das äußerlich erkennbar war.

Allein die zugeschriebenen weiblichen Eigenschaften disqualifizierten Homosexuelle bereits für einige Berufe. Das galt nicht nur für das Militär, sondern mit Blick auf Eulenburg auch für die Politik und die diplomatische Laufbahn. Zeitgenossen am Hof, wie Graf Robert Zedlitz-Trützschler, gingen zwar während des Prozesses davon aus, dass Moltke und Eulenburg keine Homosexualität praktiziert hätten, sie aber deshalb nicht für die Umgebung des Kaisers

\footnotetext{
487 Vossische Zeitung 24.1.1908.

488 Rede Hirschfelds in: Monatsbericht des Wissenschaftlich-Humanitären Komitees 1.11.1907, S. 214.

489 Urteil zit. Neue Preussische Zeitung, 29. 10.1907, abends.

490 Vossische Zeitung Nr. 610, 31.12.1907.
} 
geeignet wären, weil ,ihre weibische Auffassung, ihr weichliches und phantastisches Wesen in politischer Beziehung und insbesondere in der Umgebung Wilhelms II. gefährlich sein konnten."491 Da Homosexuelle schwatzhaft wie Frauen seien, so auch Kommissar Tresckow, besäßen sie nicht die nötige Diskretion für solche Posten. Und weil sie sich nur untereinander förderten, hätten sie nicht den nötigen Patriotismus. ${ }^{492}$ Der weltweit beachtete österreichische Skandal um den homosexuellen Generalstabschef Alfred Redl, der Militärgeheimnisse an Russland verkauft hatte, verfestigte 1913 dieses Klischee des geschwätzigen und daher unzuverlässigen Homosexuellen erneut. Zudem brachte dieser Fall auch in Österreich die Angst auf, im Militär sei Homosexualität verbreitet. ${ }^{493}$

Zumindest andeutungsweise schuf der Skandal auch ein öffentliches Wissen über die Praktiken des homosexuellen Liebeslebens. Aus den Zeugen- und Expertenaussagen erfuhren die Zeitungsleser, wie homosexuelle Männer Kontakte anbahnten. Der von Eulenburg mehrfach benutzte Eingangssatz „Hast Du denn ein Mädchen?“ wurde als charakteristisch erachtet. Zwar übernahm keine Zeitung in ihren scheinbar wörtlichen Berichten die äußerst expliziten Aussagen über den homosexuellen Geschlechtsverkehr, die besonders im Moltke-Prozess und in den beiden Eulenburg-Prozessen 1908 fielen. Allerdings berichteten zumindest die linken Zeitungen erstaunlich offen etwa über das gemeinsame Onanieren, das Eulenburg mit einem Fischer praktizierte. ${ }^{494}$ Wie explizit hierüber geschrieben werden durfte, wurde ebenfalls ausführlich diskutiert. Während die konservativen und katholischen Zeitungen die Berichte als eine Gefahr für Frauen und Kinder sahen und somit das Wissen um Homosexualität als ein männliches Geheimnis verstanden, argumentierten liberale Zeitungen wie die $B Z$ eher aufklärerisch, die Zeitungen seien eben nicht für Kindern geschrieben: „Erwachsene aber dürfen und müssen eine Gruppenerkrankung kennenlernen, von deren leider schon endemischer Verbreitung die neueren Ereignisse jedem wohl eine Vorstellung gegeben haben. “495 Die Wissenskonstruktion sollte damit der aufklärenden Warnung dienen, während die katholische und konservative Öffentlichkeit vor allem Nachahmungseffekte befürchtete.

Da die Homosexualität somit als eine äußerlich erkennbare Eigenschaft galt, traf der Skandal auch den Kaiser. Dabei verhandelte der Skandal Zuschreibungen über den Monarchen, die über sein homoerotisch orientiertes Umfeld seine Kompetenz hinterfragten. Wie bereits Martin Kohlrausch unterstrich, bedrohte

\footnotetext{
491 Eintrag 26.11.1907 in: Graf Robert Zedlitz-Trützschler, Zwölf Jahre, S. $171 \mathrm{f}$.

492 Tresckow, Von Fürsten, S. $112 \mathrm{f}$.

493 Vgl. die populärwissenschaftliche Darstellung: Georg Markus, Der Fall Redl. Mit unveröffentlichten Geheimdokumenten zur folgenschwersten Spionage-Affäre des Jahrhunderts, Berlin 1986.

494 Vorwärts 22.4.1908. Vgl. die Aussagen in Anklageschrift 5.6.1908, in: GStA, HA I Rep. 84a, Nr. 49830; Protokoll der Sitzung 21.4.1908, in: BAK, N 1062-123.

495 BZ Nr.153, 2.7.1908. Einen Verzicht auf Berichte zum Schutz von Frauen und Kindern forderte etwa: Der TAg Nr.221, 4.6.1908.
} 
der Skandal seine Autorität. ${ }^{496}$ Dass Wilhelm II. die Homosexualität in seinem engsten Umfeld nicht bemerkt hatte, stellte seine Menschenkenntnis nachhaltig in Frage. So schrieb die damals auflagenstärkste Tageszeitung, die liberale Berliner Morgenpost: „Ewig rätselhaft aber wird es bleiben, daß der Kaiser nicht, unabhängig von allen Zuträgern, aus eigener Beobachtung einen Verdacht gegen die Wesensart der Männer schöpfte, die zu seinem intimsten Freundeskreise gehören. " ${ }^{497}$ Ähnlich spotteten auch die Arbeiter in den Hamburger Kneipen: „Ob das Wilhelm nicht gewußt hat, der doch so einen scharfen Blick hat für alles, was meinst du? “498, hieß es etwa in einem Vigilianzbericht. Andere Gäste spotteten: „der Kaiser hat ja eine gute Umgebung gehabt, seine besten Freunde, sogar sein Duzfreund Eulenburg sind warm, in dem Prozeß wird wohl noch viel mehr zum Vorschein kommen, ist doch gut, daß so etwas in die Öffentlichkeit kommt und nicht bei Ausschluß der Öffentlichkeit verhandelt wird."499 Allerdings verzeichneten die Kneipenprotokolle der Hamburger Geheimpolizei auch Gespräche, die den Kaiser wegen seines Durchgreifens in dem Fall lobten. ${ }^{500}$ Der Kaiser erschien damit zugleich als Unwissender und als Aufdecker.

Die nun überall veröffentlichten Details über das Privatleben der Kaiserfreunde und -vertrauten, die sich „Tütü“ und „Philine“ nannten und über den Kaiser als das „Liebchen“ sprachen, diskreditierten den Monarchen ebenso. Hinzu kam, dass der Skandal die Unwissenheit des Kaisers über öffentliche Debatten publik machte. Während die gesamte politische Elite bereits ein halbes Jahr über die Kampagne Hardens sprach, erfuhr der Kaiser erst Anfang Mai 1907 durch seinen Sohn davon. Dies lag daran, wie die Zeitungsleser lernten, dass der Kaiser nur die von seinen Beratern ausgewählten Zeitungsausschnitte lese und allenfalls den Berliner Lokal-Anzeiger im Ganzen zur Hand nehme. Deshalb monierten nun auch bürgerliche Zeitungen die Unwissenheit des Kaisers. ${ }^{501}$ „Erfährt der Kaiser die Wahrheit?“, fragte etwa die Kölnische Volkszeitung. ${ }^{502}$ Da fast alle Vorwürfe gegen Eulenburg und den Liebenberger Kreis sich zugleich gegen den Kaiser richteten, war klar, dass Wilhelm II. ebenso eine Zielscheibe des Skandals war. Weil die Zensurpraktiken und Normen der politischen Kommunikation eine direkte Kritik am Kaiser nur bedingt zuließen, richtete sie sich stattdessen aber vornehmlich gegen die Berater. Herabsetzend für den Kaiser war bereits die Annahme, dass eine Kamarilla um ihn herum bestehen würde, da sie die beanspruchte monarchische Souveränität un-

\footnotetext{
496 Vgl. Kohlrausch, Monarch, S.233f.

497 Berliner Morgenpost Nr. 255, 30.10.1907.

498 Polizeibericht Zerulli 26.10.1907, in: StAH, S 3930-38 Bd.1.

499 Ebd.

500 „Das muß man den von Gottes Gnaden lassen, in solchen Sachen wienert er immer selbst gleich tüchtig aus. Er hat doch seinen eigenen Kopf, denn so leicht läßt er sich die Ohren nicht voll tuten." Polizeibericht Schutzmann Ramming 29.10.1907, in: StAH, S 3930-29 Bd. 4.

501 Germania Nr. 128, 7.6.1907; BZ am Mittag Nr.320, 8.7.1907.

502 Kölnische Volkszeitung Nr. 609, 16.7.1908.
} 
terlief. ${ }^{503}$ Dass es ausgerechnet der Presse bedurfte, um ihn von dieser Kamarilla zu befreien, unterminierte ebenfalls seine Souveränität.

Entsprechend stand die Frage, ob oder in welchem Maße es eine Kamarilla gegeben habe, von vorneherein im Mittelpunkt des Skandals. Von einer Kamarilla um Wilhelms Thron war zweifelsohne schon länger die Rede. Auch Harden hatte bereits in den 1890er Jahren Artikel über die Kaiserfreude so betitelt. $^{504}$ Als Harden im November 1906 seine erpresserischen Andeutungen publizierte, brachte Bülow zeitgleich im Reichstag den Begriff in die Debatte: „Kamarilla, das bedeutet eine häßliche fremde Giftpflanze, und man hat nie versucht, sie in Deutschland einzupflanzen ohne großen Schaden für das Volk." 505 Durch diesen Ausspruch wies er auf eine Bedrohung für Volk und Kaiser hin, die eigentlich vor allem ihn selbst bedrohte. Als der Skandal und die Empörung Ende Mai 1907 losbrachen, erinnerten sich viele Zeitungen an diese Formulierung und lobten nun Harden dafür, dass er den Kaiser von dieser Pflanze befreit habe. In Anlehnung an Bülow bediente sich die Presse dabei Metapher und Visualisierungen, die die Kamarilla als giftiges oder überwucherndes Gewächs darstellten, das nun „auszumerzen“ sei. Besonders das Titelblatt des Simplicissimus verband diese Metaphorik mit Pflanzenformen, die an die homoerotischen Züge des Liebenberger Kreises erinnerten. ${ }^{506}$ Durch solche Assoziationen entstand vor allem das Bild, der Kaiser sei durch die homoerotische Kamarilla von allem abgeschirmt und würde durch ihre Beseitigung wieder frei sehen können.

Einige eher konservative Blätter wie der kaiserfreundliche Berliner LokalAnzeiger betonten zwar, dass der Kaiser selbständig urteile und durch „Charakterstärke und Herrscherqualifikation jeglicher Beeinflussung unzugänglich ist." 507 Aber mehrheitsfähig war diese Deutung selbst bei den konservativen und nationalliberalen Zeitungen nicht. Entweder sie sahen die Kamarilla und Intrigen als normale Erscheinung an einem Königshof an, ${ }^{508}$ oder sie formulierten sogar direkt ihre Kritik. So kommentierten etwa die Leipziger Neuesten Nachrichten: „Denn seit Jahr und Tag hat nichts so vergiftend gewirkt, wie die Existenz eines kleinen, abermächtigen Häufleins, das den Kaiser umgab und nicht nur sein Ohr besaß, sondern auch durch eine eigentümliche Art von anbetender Huldigung in dem Monarchen hyperromantische Anschauungen vom Königsrecht und von einem mystischen Gottesgnadentum zu erwecken und zu

503 Relativierbar scheint mir die These, die Annahme einer adligen Kamarilla „erregte kein großes Aufsehen“; so Bruns, Skandale, S.71. Die Figur der Kamarilla steht im Mittelpunkt bei: Kohlrausch, Monarch, S. 196.

504 Vgl. zur frühen Zukunft auch: Rogge, Holstein, S. 55; Weller, Harden, S. 111.

505 Reichstag 14.11.1906, Bd.5, 117. Sitz., S. 3660. In dieser Rede warnte Bülow bereits vor einem „übertriebenen Hervortreten des Regenten“ und einem „zu weit getriebenen monarchischen Subjektivismus.“

506 Simplicissimus Nr. 12, 17.6.1907.

507 Berliner Lokal-Anzeiger Nr. 278, 4.6.1907.

508 Hamburger Nachrichten Nr. 391, 7.6.1907; Deutsche Tageszeitung Nr. 263, 8.6.1907. 
erhalten suchte. " ${ }^{509}$ Solche Artikel sprachen den Kaiser auf den ersten Blick von aller Schuld frei, indem sie diese den schlechten Beratern zuwiesen. Zugleich richtete sich ihre Kritik im Kern unübersehbar gegen den Monarchen und dessen Kurs. Die katholischen Zeitungen erhofften dagegen, dass mit dem Kreis um Eulenburg der antikatholische Einfluss auf den Kaiser abnehmen würde. Da Eulenburg sich im Sommer 1908 als Opfer einer katholischen Verschwörung stilisierte, weil er in München das „protestantische Kaisertum“ vertreten habe, nahm diese konfessionelle Deutung des Skandals zu. So gaben sie Eulenburg die Schuld daran, dass der Kaiser nie einen Zentrumsabgeordneten empfangen habe. ${ }^{510}$ Auch dieser Vorwurf an Eulenburg galt natürlich eigentlich dem Kaiser selbst.

Der Begriff Kamarilla und die Zuschreibungen über sie verstärkten die Vorstellung, bei Wilhelm II. würde es sich um eine unzeitgemäße absolutistische Herrschaftsweise handeln. Dass diese Kamarilla zudem noch durch homosexuelle Neigungen zusammenhielt, schien dieses Bild zusätzlich zu bestätigen. Nicht minder häufig griffen die Journalisten Hardens Vorwurf auf, in der Hofgesellschaft sei Spiritismus verbreitet. Je nach politischer Richtung leiteten die Teilöffentlichkeiten unterschiedliche Konsequenzen aus der Aufdeckung der Kamarilla ab. Während die Konservativen das Ideal des autonomen Monarchen beschworen, empfahl die freisinnige Presse von England zu lernen, wo der Premierminister die politische Verantwortlichkeit trage, die Beamten selbst ernenne und entlasse und ein enges Vertrauensverhältnis zur Krone bestehe. ${ }^{511}$ Ebenso sah das liberale Berliner Tageblatt die Kamarilla als Ergebnis des monarchischen Systems und des „Kryptoabsolutismus“, weshalb Parlament und Öffentlichkeit zu stärken seien. 512

Noch direktere Demokratisierungsforderungen leiteten die Sozialdemokraten aus dem Skandal ab. Sie argumentierten, „nur die Demokratie wird dem mittelalterlichen Spuk der Kamarillen- und Höflingswirtschaft ein Ende bereiten! “513 Nachdem Bebel dieses Argument im Reichstag wiederholte, widersprach Bülow, in parlamentarisch regierten Ländern seien die „Intrigen und Hintertreppeneinflüsse“ viel größer; zudem gäbe es „nicht nur eine höfische Kamarilla, es gibt auch eine rote Kamarilla. (sehr wahr! Und große Heiterkeit)“; diese umschmeichle die Massen und rede ihr über die Presse Ideen ein. ${ }^{514}$ Alle diese unterschiedlichen Positionen hatten aber zumindest eine gemeinsame Perspektive: Sie formulierten das Ideal eines frei und transparent entscheidenden Politikers und Monarchen. Dabei richteten sie sich vor allem gegen den informellen Einfluss des hohen Adels und gegen das kaiserliche Konzept eines „persönlichen

\footnotetext{
509 LeipZiger Neueste Nachrichten Nr. 155, 6.6.1907.

510 Kölnische Volkszeitung Nr. 605, 13.7.1908; vgl. auch ebd. 16.7. u. 18.7.1908.

511 Vossische Zeitung Nr. 517, 3.11.1907.

512 Berliner Tageblatt Nr. 547, 27.10.1907.

513 VORWÄRTS Nr. 253, 29.10.1907.

514 Sten. RT 29.11.1907, 61. Sitz., S. 1923.
} 
Regiments“. Hier lag eine Konfliktlinie, durch die der Skandal seine Wirkung entfachte. Und hierin lag auch ein gewisses Potential für Demokratisierungsforderungen.

Diese Deutungen zeigen, welche Konsequenzen der Skandal jenseits der Entlassungen hatte. Zweifelsohne schuf er einen schweren Ansehensverlust für die Monarchie, den die dann folgende Daily-Telegraph-Affäre noch verstärkte. Die öffentliche Zurückhaltung des Kaisers nach 1908 hing somit sicherlich auch mit dem Eulenburg-Skandal zusammen. Ob man den Sturz des Liebenberger Kreises als Demokratisierungstendenz sehen muss, ist zumindest für das Umfeld des Kaisers eher fraglich. Denn wie John Röhl frühzeitig betonte, verstärkte Eulenburgs Sturz den Einfluss des Militärs auf den Kaiser. ${ }^{515}$

Folgen hatte der Skandal auch für die Homosexuellen. Während es in der Anfangsphase so schien, als könnte er durchaus Vorstellungen über Homosexualität liberalisieren, führte die ab November 1907 einsetzende Umdeutung zu einer Verfestigung und Erweiterung von Vorurteilen. Dementsprechend reagierte die Regierung mit einem Gesetzesentwurf, der den $\$ 175$ verschärfen sollte, indem er bis zu fünf Jahren Haft vorsah. Auch wenn die Novelle nach langer Diskussion an liberalen Gutachtern scheiterte, zeigte ihre Begründung den engen $\mathrm{Zu}$ sammenhang zwischen Gesetzesreform und Skandalen: Homosexualität wurde nun als „Gefahr für den Staat“ definiert, und auch die geplante Strafverschärfung gegenüber männlicher Prostitution und dem Verkehr mit Abhängigen verwies direkt auf die vorherigen Skandale. ${ }^{516}$ Selbst die SPD, die bislang als einzige Partei klar für eine Straffreiheit homosexuellen Verkehrs unter Erwachsenen eingetreten war, vertrat nun ihre Forderungen verhaltener. ${ }^{517}$

Auch die Verfolgung und Bestrafung von zahlreichen weiteren Homosexuellen spricht dafür, dass der Skandal die Grenzen des Tolerierbaren eher verengte. Die Zahl der Verurteilungen stieg statistisch gesehen in den Jahren nach 1908 deutlich an. ${ }^{518}$ Auch die symbolischen Anklagen gegen prominente Adlige wie die Grafen Wedel, Lynar und Hohenau unterstrichen, dass die Skandale eher eine Norm verfestigten statt sie zu liberalisieren. Entsprechende Vorwürfe, die nun in der Jugendbewegung aufkamen, mögen ein weiterer Beleg für die zunehmende Angst vor Homosexualität sein. ${ }^{519}$ Ebenso erreichte Hirschfelds Bewegung zwar durch den Skandal eine große Bekanntheit, verlor aber an Ansehen und Fördermitgliedern. ${ }^{520}$

515 RöHL, Einleitung, in: Ders. (Hrsg.), Philipp Eulenburgs politische Korrespondenz, Bd.1, S. 59 .

516 Vgl. zu der geplanten Reform: Sommer, Strafbarkeit, S.146f. Vgl. auch den Überblick in: Susanne zur Nieden, Homophobie und Staatsräson, in: Dies. (Hrsg.), Homosexualität, S. 1751.

517 Zur weiteren Haltung der SPD nach 1908 vgl. EissLer, Arbeiterparteien, S. 124.

518 Vgl. die Statistik in: Sommer, Strafbarkeit, S. 377.

519 Geuter, Homosexualität in der deutschen Jugendbewegung, S. 38. Erst nach Abschluss des Manuskriptes erschien Bruns, Politik des Eros.

520 Einen Rückgang der „Fondszeichner“ verzeichnet: KeIlson-Lauritz, Die Geschichte, S.34. 
Zugleich dürfte der Skandal mit dazu beigetragen haben, den schwärmerischen Umgang unter befreundeten Männern zu verändern. Romantisierende Briefe, die freundschaftliche Liebeserklärungen machten, erschienen angesichts des Homosexualitätsverdachts problematisch. Insofern stand Hardens Kampagne tatsächlich im Zeichen einer kühlen, intellektuellen und zynischen Härte. ${ }^{521}$ Am Kaiserhof selbst nahm man allerdings nicht sogleich Abstand vom homoerotisch geprägten Umgang. Zumindest tanzte nur wenige Monate nach den Enthüllungen im Eulenburg-Prozess der Chef des Militärkabinetts, General Dietrich Graf von Hülsen-Haeseler, bei einer heiteren Gesellschaft im Ballettröckchen vor Wilhelm II. Allein der plötzliche Tod des Generals bei diesem Tanz machte diese Szene bis heute bekannt. ${ }^{522}$

Konsequenzen hatte der Skandal auch für die Öffentlichkeit von Prozessen. Die offene Berichterstattung über den ersten Prozess führte zur Forderung nach dem Ausschluss der Öffentlichkeit und gesetzlichen Gegenmaßnahmen der Regierung. So verhandelte das Staatsministerium schon 1908 Entwürfe über die Reform der Strafprozessordnung, die sich direkt auf den Moltke-Harden-Prozess bezogen. Sie zielten auf eine Verschärfung der Strafen bei Beleidigung sowie eine Einschränkung des Wahrheitsbeweises und der Öffentlichkeit bei Beleidigungsprozessen in „Folge der bei dem Moltke-Hardenprozeß hervorgetretenen Mißstände. “523 Auch Fragen an die Zeugen sollten abgeschnitten werden können. ${ }^{524}$ Insofern nannte die politische Rechte es als einen positiven Effekt des Skandals, dass er den Ausschluss der Öffentlichkeit bei derartigen Prozessen gefördert habe und die Bewegung für die Abschaffung des $\$ 175$ lächerlich gemacht habe. ${ }^{525}$

Als eine einfache politische Intrige, bei der etwa der entlassene Friedrich von Holstein den Journalisten Harden als Instrument für seine Rache benutzte, lässt sich der Skandal somit sicherlich nicht verstehen. Selbst wenn Holstein Harden Informationen verschaffte oder mitunter bestärkte, nahm der Skandal so viele unkontrollierbare Wendungen, dass er sich nicht auf die Entscheidungen weniger politischer Akteure beschränken lässt. Vielmehr zeigte sich das vielfältige Scheitern aller Akteure an den wechselnden öffentlichen Zuschreibungen. Vergleichbar große Skandale um Homosexualität kamen in Deutschland danach nicht mehr auf. Natürlich versuchten verschiedene Zeitungen weiterhin entsprechende Enthüllungen zu lancieren. Aber vermutlich löste der EulenburgMoltke-Skandal verbunden mit dem Krupp-Skandal auch bei den Journalisten eine derartige Schockwirkung aus, dass sie, ganz ähnlich wie in Großbritannien, bei diesem Thema zurückhaltender blieben.

521 Vgl. hierzu auch: RadKaU, Das Zeitalter der Nervosität, S. $325 \mathrm{f}$.

522 Den Fall schildert: Tagebuch Zedlitz-Trützschler, Eintrag 8.2.1909, in: DERs., Zwölf Jahre, S. 216.

523 Protokoll Staatsministerium 29.2.1908 u. 2.5.1908, in: GStA, HA I, Rep. 90A, Nr. 3613

524 Protokoll Staatsministerium 26.6.1908 in: GStA, HA I, Rep. 90A, Nr.3613.

525 Deutsche Volkscorrespondenz Nr. 91, 21.4.1909. 


\section{ZWISCHENFAZIT}

Sowohl in Großbritannien als auch in Deutschland traten im ausgehenden 19. Jahrhundert verstärkt Skandale auf, bei denen gezielt die Homosexualität von gesellschaftlichen Eliten offen gelegt wurde. Diese Enthüllungen dienten jedoch nicht primär der Bekämpfung gleichgeschlechtlicher Beziehungen, sondern waren vor allem ein Druckmittel, um bestimmte politische Veränderungen zu erreichen. Dennoch trugen die Skandale in beiden Ländern maßgeblich dazu bei, ein recht ähnliches Bild über Homosexualität zu verbreiten. Sie verstärkten erstens in beiden Ländern die Auffassung, die Zahl der Homosexuellen sei Ende des 19. Jahrhunderts schlagartig angestiegen und würde eine Bedrohung für die Gesellschaft bilden, gegen die man sich schützen müsse. Zweitens prägten sie die Vorstellung, Homosexualität sei weniger ein Laster von moralisch ungefestigten Unterschichten, sondern besonders in Kreisen des hohen Adels und im vermögenden Bürgertum verbreitet. Damit hinterfragten die Skandale insbesondere den bürgerlichen Selbstentwurf, ein tugendhaftes Vorbild zu sein. Drittens verfestigten die Skandale das Narrativ, dass vornehmlich reiche Homosexuelle gegen Bezahlung arme Menschen zur Homosexualität verführten und aufgrund der Klassenjustiz nicht dafür bestraft würden. Dies ging mitunter sogar mit einer Umdeutung männlicher Prostituierten einher, die als Opfer gesehen wurden. Viertens verbreiteten die Skandale die Vorstellung, Homosexuelle würden feminine Charaktereigenschaften aufweisen. Die in den Skandalen beschuldigten Männer wurden als emotional, schwärmerisch, künstlerisch veranlagt, wenig durchsetzungsstark und kaum belastbar beschrieben, was die Gerichte, Parlamente und Medien generalisierten. Dass die skandalisierten Männer zumeist keiner geregelten Arbeit nachgingen, grenzte sie ebenfalls von der so konstruierten „normalen“ Form der Männlichkeit ab. Fünftens popularisierten die Skandale zumindest in Deutschland die als wissenschaftlich deklarierte Vorstellung, Homosexualität sei eine Art angeborene Krankheit. Umdeutungen von Medizinern und die zeitgenössische Annahmen über eine „Heilung“ verbanden sich hierbei. Alle diese in den Skandalen konstituierten Deutungen ließen Homosexualität als Bedrohung der Gesellschaftsordnung erscheinen: Der klassenübergreifende Verkehr drohte in dieser Sichtweise soziale Grenzen aufzuweichen, die korrumpierende Kraft des Geldes die Jugend zu verderben und der angeblich feminine Charakter die Wehrkraft und den Staat zu zersetzen sowie politische Geheimnisse zu gefährden.

In beiden Länder bildeten eine restriktive Gesetzgebung und starke Tabuisierung wichtige Vorraussetzungen für das Aufkommen der Skandale. Der Vergleich zwischen den Ländern zeigte jedoch durchaus Unterschiede. Generell waren die öffentlichen Sagbarkeitsgrenzen beim Thema Homosexualität in Deutschland weiter gespannt. Auch im Zuge der Skandale blieben die Tabugrenzen in Großbritannien deutlich enger. Hier rangen sich lediglich linksliberale Zeitungen zu einer direkteren Auseinandersetzung mit Homosexualität durch. Wie sehr die Grenzen zwischen den beiden Ländern differierten, zeigte sich 
nicht zuletzt in den britischen Medienberichten über deutsche Homosexualitätsskandale, die häufig nur mit vorsichtigen Andeutungen arbeiteten, Übersetzungsprobleme thematisierten oder den Vorwurf ganz aussparten. Entsprechend räsonierte 1907 der Berliner Korrespondent der Times in seinem Bericht über Bülows Prozess gegen Adolf Brand, der ihm Homosexualität vorwarf: „It is really difficult to know how to report a case of this kind in The Times. It is impossible to transmit the evidence verbatim [...]." ${ }^{\text {"26 }}$ Durch diesen Bericht über den deutschen Skandal-Prozess wurde überhaupt erstmalig das Wort „homosexual" in den Sprachgebrauch der Times überführt. In den aktiven Wortschatz des Blattes rückte es allerdings erst seit den 1950er Jahren langsam.

Die Skandale förderten nicht nur in den Medien, Parlamenten und Gerichtssälen ein Sprechen über Homosexualität, sondern auch in den alltäglichen Gesprächen. In beiden Ländern erleichterten spöttische, humoreske Kommentare die Auseinandersetzung mit dem Tabu. Wie die Auswertung der Polizeiprotokolle deutscher Kneipengespräche zeigte, führten die Skandale aber durchaus auch zu ernsthaften Diskussionen, die persönliche Erfahrungen mit dem Thema Homosexualität austauschten, etwa über die Homosexualität im Militär. Zudem bildeten die Homosexualitätsfälle auch für die Zeitungsleser nur einen Anstoß, um aus ihnen heraus jene grundsätzlichen politischen Fragen zu diskutieren, mit denen die Kampagnen und Skandale verbunden waren.

Denn in beiden Ländern zielten die Skandalisierungen auf weiterreichende politische Fragen - wie die irische Unabhängigkeit, den Sturz der Tory-Regierung, den Kampf gegen die Klassenjustiz, gegen den Kapitalismus oder gegen das "persönliche Regiment" von Wilhelm II. Der als besonders ehrverletzend empfundene Vorwurf der Homosexualität richtete sich dementsprechend auch nicht primär an Politiker, sondern an Repräsentanten der jeweils bekämpften gesellschaftlichen Ordnung, wie die englische Administration in Irland, den Adel im Umfeld des Königshofes oder reiche Unternehmer. Politisch waren die Skandale allein schon deshalb, weil sie jeweils die Regierungen herausforderten. Dabei benutzten sie Anklagen, die aufgrund ihres prekären Tabucharakters und ihrer kommunikativen Dynamik kaum zu bekämpfen waren.

Dass der Vorwurf der Homosexualität in die politische und mediale Arena trat, war zweifelsohne das Ergebnis zunehmend polarisierter politischer Konfliktlinien. Sie führten dazu, dass neue Akteure auftraten, die gerade durch ihren Außenseiterstatus mit den bisherigen Regeln der politischen Kommunikation brachen. In Großbritannien waren dies vornehmlich die Iren und Radicals, in Deutschland die Sozialdemokraten und bürgerlichen Gegner des „persönlichen Regiments“. Angestoßen wurden die Homosexualitätsskandale in beiden Ländern fast ausschließlich von Journalisten, die zugleich politisch aktiv waren und für kleine Blätter schrieben, mit denen sie Politik gestalten wollten. Die Beschuldigungen dieser Journalisten beruhten auf Gerüchten, die sie erst im Zuge der folgenden Beleidigungsprozesse mithilfe von Detektiven genauer verifi-

526 Times 7.11.1907, S. 3. 
zierten. In dieser Phase ermittelten sie jene Zeugen, die in den Prozessen und über die Medien freizügig über homosexuelle Praktiken berichteten. Gerade die Homosexualitätsskandale zeigten dabei besonders karnevaleske Elemente, da mehrfach Zeugen aus unteren sozialen Schichten zum Sturz und zur Ausgrenzung mächtiger Eliten beitragen konnten. Die großen Boulevard- und Massenblätter hielten sich dagegen beim Aufbringen der Vorwürfe zurück, und verstärkten erst durch ihre ausführlichen Berichte im Zuge der Prozesse die Dynamik der Skandale.

Fast alle Homosexualitätsskandale wiesen kontingente Verlaufsformen auf und erstaunliche Schwankungen in der öffentlichen Beurteilung. In allen Fällen wurden die verantwortlichen Journalisten nicht nur wegen Verleumdung vor Gericht gestellt, sondern auch von der Öffentlichkeit wegen ihrer Enthüllungen verurteilt. Dadurch war jeweils offen, ob der Skandal sich nicht vornehmlich wie ein Bummerang gegen die Enthüllungsjournalisten richtete. Auch die Stammtische folgten den wechselnden Bewertungen der Medien und sahen die Journalisten mal als heldenhafte Aufdecker, mal als sensationslüsternde „Schmutzfinken.“

Zudem brachten die Regierungen in beiden Ländern einen großen Aktionismus auf, um das weitere Aufkommen dieser Vorwürfe zu verhindern und das Thema von der Medienöffentlichkeit fern zu halten. So beeinflussten die Regierungschefs die Ermittlungen der Justiz und die Prozessverläufe, blockierten weiterführende Untersuchungen und unterbanden parlamentarische Aussprachen. Den betroffenen Eliten ermöglichten sie großzügige Gelegenheiten zur Flucht ins Ausland, um so einen Skandal zu vermeiden. Besonders für das parlamentarische Großbritannien mag diese starke Einflussnahme der Exekutive auf die Justiz erstaunen. Nicht die Haft, sondern die tolerierte Emigration war hier die eigentliche Strafpraxis. Das große Risiko, das die Staatsführungen dabei eingingen, zeigte, wie gefährlich ihnen die Homosexualitätsvorwürfe für die Gesellschaftsordnung erschienen. Tatsächlich war es gerade diese Skandalbekämpfung der Regierung, die den Skandalen immer wieder ihre Dynamik gab. Denn gerade weil die Kampagnen eigentlich die Regierung und weniger die einzelnen Homosexuellen treffen sollten, bildete die Vertuschung der Homosexualität jenen Normbruch, der in einer zweiten Phase den Skandalen eine zusätzliche Dynamik verlieh.

Neben unverkennbaren Parallelen ließen sich auch kulturelle Transferprozesse zwischen den britischen und den deutschen Skandalen ausmachen. Vor allem Großbritannien gab dabei Anstöße für Deutschland, weil hier die entsprechenden Skandale ein bis zwei Jahrzehnte früher auftraten. Insbesondere die großen britischen Homosexualitätsskandale in den ersten Hälfte der 1890er Jahre sorgten dafür, dass das Thema in der zweiten Hälfte der 1890er Jahre auch in Deutschland öffentlich präsenter wurde, wie am Beispiel der sozialdemokratischen Presse und dem Engagement Magnus Hirschfelds gezeigt wurde. Dies bildete eine zentrale Voraussetzung für den ersten großen deutschen Homosexualitätsskandal um Friedrich Alfred Krupp. Der Krupp-Skandal zeigte erneut 
die ambivalente Haltung, die selbst die politische Linke zur Homosexualität hatte: Während sie aus der Annahme heraus, dass Homosexualität krankhaft angeboren sei, eine Abschaffung des $\$ 175$ forderte, hielt sie zugleich an dem in Großbritannien bereits etablierten Bild des dekadenten reichen Homosexuellen fest, der arme Jungen gegen Geld missbrauche und daher bestraft und öffentlich gebrandmarkt werden müsse.

Die Medien und die Medialisierung der Gesellschaft spielten bei diesen Skandalen eine komplexe, oft widersprüchliche Rolle. Indem sie die Skandale zumeist eigenständig anstießen und ihnen eine Dynamik gaben, die die Regierungen herausforderte, nahmen sie durchaus die Rolle einer „vierten Gewalt“ ein. Ihre Kampagnen richteten sich gegen überkommene, vordemokratische $\mathrm{Zu}$ stände, und in der offiziellen Logik des damaligen Rechtes halfen sie bei der Verbrechensbekämpfung. Zugleich wird man aber die Enthüllung der Homosexualität kaum als einen Akt der Demokratisierung bezeichnen können. Sie war vielmehr eine Politik der Sensationen, die über spektakuläre Neuigkeiten mediale Aufmerksamkeit auf bestimmte grundsätzliche Missstände zu lenken versuchte. Zudem zeigte die enge Verbindung zwischen den Enthüllungsjournalisten und der Politik, dass die entsprechenden Zeitungen eben nicht als ein autonomes System agierten. Gerade bei den englischen Homosexualitätsskandalen saßen die journalistischen Enthüller sogar zugleich im Parlament.

Mit der Thematisierung der Homosexualität brachen die Medien zwar ein Tabu, sie verstärkten es aber auch wieder. Kurz nach ihrem Ausbruch brachten die Skandale zumindest in der liberalen und sozialdemokratischen Öffentlichkeit noch erstaunlich tolerante Diskurse über Homosexualität auf. Längerfristig führten sie jedoch in den Jahren nach den Skandalwellen dazu, dass in beiden Ländern die Toleranz gegenüber Homosexualität sank, sie stärker tabuisiert wurde und die Verfolgungen zunahmen. Die bürgerliche Öffentlichkeit markierte im Laufe der Skandale eine explizite Grenze, die Homosexuelle von einflussreicheren Posten ausschloss. Die drohende Strafe war dabei weniger die Gefängnishaft als der Skandal, der öffentliche Geständnisse erzwang. Bereits die Angst vor ihm erwies sich dabei als ein Disziplinierungsinstrument. Wie groß sie war, zeigte die vielfache Flucht in den Selbstmord oder die lebenslange Emigration nach Frankreich oder Italien. 